Aprendizado de máquina em redes complexas

Fabricio Aparecido Breve 
Data de Depósito:

Assinatura:

\title{
Aprendizado de máquina em redes complexas
}

\author{
Fabricio Aparecido Breve
}

Orientador: Prof. Dr. Zhao Liang

Tese apresentada ao Instituto de Ciências Matemáticas e de Computação - ICMC-USP, como parte dos requisitos para obtenção do título de Doutor em Ciências - Ciências de Computação e Matemática Computacional.

\section{USP - São Carlos}

Julho de 2010 



\section{Agradecimentos}

A Deus, pela vida e todas as bençãos que nela recebi, e pela força para superar todas as dificuldades e atingir meus objetivos;

Aos meus pais, Dirceu e Beatriz, pelo amor, carinho, incentivo, confiança e dedicação durante todos esses anos, compartilhando cada sonho e cada conquista, sem eles não teria chegado até aqui, serei sempre grato;

À minha namorada Claudia, pelo carinho, dedicação e compreensão, compartilhando comigo todos os bons e maus momentos vividos durante o desenvolvimento deste trabalho;

Ao Prof. Dr. Zhao Liang, meu orientador, por todos os conhecimentos que com ele adquiri, pela confiança e atenção que dedicou a mim durante estes anos;

Ao Prof. Dr. Witold Pedrycz, que me aceitou em seu grupo de pesquisa e me orientou durante minha visita acadêmica ao Department of Electrical and Computer Engineering da University of Alberta;

Ao colega de doutorado, Prof. Dr. Marcos Quiles, pelas sugestões, dúvidas esclarecidas, e parceria em vários trabalhos e artigos publicados;

Aos professores Dr ${ }^{\mathrm{a}}$. Roseli Aparecida Francelin Romero, Dr. Nei Yoshihiro Soma e Dra . Vilma Alves de Oliveira, pelas valiosas correções, sugestões e observações feitas no Exame de Qualificação;

A todos os professores e funcionários do ICMC-USP;

À FAPESP e ao CNPq pelo apoio financeiro durante os três últimos anos de desenvolvimento deste trabalho;

Ao IEEE CIS e ao INNS pelos IEEE CIS Outstanding Student Paper Travel Grant e INNS Travel Grant, concedidos a mim nos anos de 2009 e 2010, que me permitiram participar da International Joint Conference on Neural Networks (IJCNN 2009) e do IEEE World Congress on Computational Intelligence (WCCI 2010);

A todos que diretamente ou indiretamente colaboraram durante o desenvolvimento deste trabalho. 



\section{Resumo}

Redes complexas é um campo de pesquisa científica recente e bastante ativo que estuda redes de larga escala com estruturas topológicas não triviais, tais como redes de computadores, redes de telecomunicações, redes de transporte, redes sociais e redes biológicas. Muitas destas redes são naturalmente divididas em comunidades ou módulos e, portanto, descobrir a estrutura dessas comunidades é um dos principais problemas abordados no estudo de redes complexas. Tal problema está relacionado com o campo de aprendizado de máquina, que tem como interesse projetar e desenvolver algoritmos e técnicas que permitem aos computadores "aprender", ou melhorar seu desempenho através da experiência. Alguns dos problemas identificados nas técnicas tradicionais de aprendizado incluem: dificuldades em identificar formas irregulares no espaço de atributos; descobrir estruturas sobrepostas de grupos ou classes, que ocorre quando elementos pertencem a mais de um grupo ou classe; e a alta complexidade computacional de alguns modelos, que impedem sua aplicação em bases de dados maiores. Neste trabalho tratamos tais problemas através do desenvolvimento de novos modelos de aprendizado de máquina utilizando redes complexas e dinâmica espaço-temporal, com capacidade para tratar grupos e classes sobrepostas, além de fornecer graus de pertinência para cada elemento da rede com relação a cada cluster ou classe. Os modelos desenvolvidos tem desempenho similar ao de algoritmos do estado da arte, ao mesmo tempo em que apresentam ordem de complexidade computacional menor do que a maioria deles. 



\section{Abstract}

Complex networks is a recent and active scientific research field, which concerns large scale networks with non-trivial topological structure, such as computer networks, telecommunication networks, transport networks, social networks and biological networks. Many of these networks are naturally divided into communities or modules and, therefore, uncovering their structure is one of the main problems related to complex networks study. This problem is related with the machine learning field, which is concerned with the design and development of algorithms and techniques which allow computers to "learn", or increase their performance based on experience. Some of the problems identified in traditional learning techniques include: difficulties in identifying irregular forms in the attributes space; uncovering overlap structures of groups or classes, which occurs when elements belong to more than one group or class; and the high computational complexity of some models, which prevents their application in larger data bases. In this work, we deal with these problems through the development of new machine learning models using complex networks and space-temporal dynamics. The developed models have performance similar to those from some state-of-the-art algorithms, at the same time that they present lower computational complexity order than most of them. 



\section{Sumário}

Resumo

$\mathbf{v}$

$\begin{array}{lll}\text { Abstract } & \text { vii }\end{array}$

Sumário $\quad \mathbf{x}$

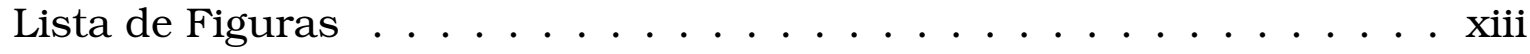

Lista de Tabelas . . . . . . . . . . . . . . . . . xv

Lista de Algoritmos . . . . . . . . . . . . . . . . xvii

1 Introdução 1

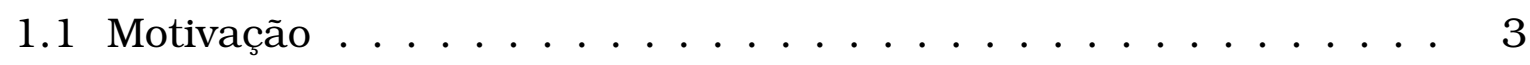

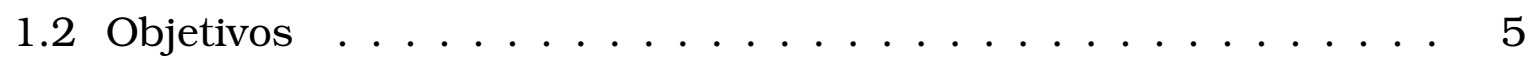

1.3 Organização do Documento . . . . . . . . . . . . . . 6

2 Revisão Bibliográfica $\quad 7$

2.1 Redes Complexas . . . . . . . . . . . . . . . . 7

2.1.1 Representação de Redes Complexas . . . . . . . . . . . . . . 9

2.1.2 Detecção de Comunidades em Redes . . . . . . . . . . . . 10

2.2 Aprendizado de Máquina . . . . . . . . . . . . . . 11

2.2.1 Principais Categorias de Aprendizado de Máquina . . . . . . 13

2.3 Aprendizado Não Supervisionado . . . . . . . . . . . . . . . . 13

2.3.1 Métodos Baseados em Otimização . . . . . . . . . . . . . 14

2.3.2 Métodos Hierárquicos . . . . . . . . . . . . . 18

2.3.3 Métodos Baseados em Densidade . . . . . . . . . . . . 20

2.3.4 Modelo Dinâmico de Agrupamento de Dados . . . . . . . . . 22

2.3.5 Métodos Baseados em Grafos . . . . . . . . . . . . . . 24

2.4 Aprendizado Semi-Supervisionado . . . . . . . . . . . . 35

2.4.1 Auto Treinamento . . . . . . . . . . . . . . . 38

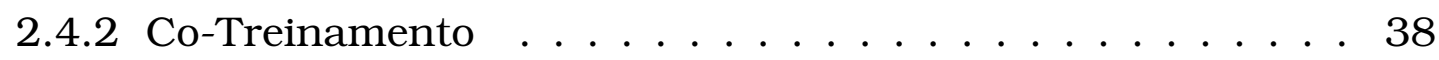


2.4 .3 Modelos Generativos . . . . . . . . . . . . . . . . . 39

2.4 .4 Agrupar e Rotular . . . . . . . . . . . . . . . . 41

2.4.5 Separação de Baixa Densidade . . . . . . . . . . . . 41

2.4.6 Métodos Baseados em Grafos . . . . . . . . . . . . . . 42

2.5 Sistemas Dinâmicos . . . . . . . . . . . . . . . . 47

2.5.1 Comportamento Assintótico . . . . . . . . . . . . . 49

2.5.2 Sincronização em Sistemas Caóticos . . . . . . . . . 56

3 Modelos baseados em Redes de Osciladores Acoplados 69

3.1 Aplicação dos Modelos em Atenção Visual . . . . . . . . . . . . 69

3.2 Atenção Visual com Sincronização por Fase em Redes de Osciladores . . . . . . . . . . . . . . . . . 74

3.2.1 Descrição do Modelo . . . . . . . . . . . . . . . . . . 74

3.2.2 Simulações Computacionais . . . . . . . . . . . 78

3.3 Atenção Visual com Sincronização e Dessincronização por Fase em Redes de Osciladores . . . . . . . . . . . . . . . . . 82

3.3.1 Descrição do Modelo . . . . . . . . . . . . . . . . . 82

3.3.2 Simulações Computacionais . . . . . . . . . . . 85

4 Modelos baseados em Movimentação de Partículas em Redes Complexas $\quad 95$

4.1 Detecção de Comunidades Sobrepostas em Redes Complexas com Competição de Partículas . . . . . . . . . . . . . . . . 96

4.1 .1 Descrição do Modelo . . . . . . . . . . . . . . . . . . 97

4.1.2 Simulações Computacionais . . . . . . . . . . . . 100

4.2 Aprendizado Semi-Supervisionado em Redes Complexas com Competição e Cooperação entre Partículas . . . . . . . . . . . . 103

4.2.1 Descrição do Modelo . . . . . . . . . . . . . . . . . 108

4.2.2 Complexidade Computacional . . . . . . . . . . . 115

4.2.3 Simulações Computacionais . . . . . . . . . . . . . 120

4.2.4 Saída Nebulosa e Detecção de Outliers . . . . . . . . . . . 132

4.2 .5 Aplicação em Dados Biológicos . . . . . . . . . . . . . . 139

5 Conclusões $\quad 143$

5.1 Principais Contribuições . . . . . . . . . . . . . . . . . 148

5.2 Trabalhos Futuros . . . . . . . . . . . . . . . . . . . . . 149

$\begin{array}{ll}\text { Referências Bibliográficas } & 165\end{array}$ 


\section{Lista de Figuras}

2.1 Espaços de atributos com elementos de 4 classes diferentes. . . 15

2.2 Exemplo de dendograma (Jain et al., 1999). . . . . . . . . . . 18

2.3 Probabilidades de Movimento em Caminhada Aleatória. . . . . . 30

2.4 Processo de detecção de comunidades pelo método de competição de partículas . . . . . . . . . . . . . . . . 36

2.5 Um problema de classificação binário em aprendizado semisupervisionado . . . . . . . . . . . . . . 40

2.6 Classificação de um problema com duas classes em forma de banana por métodos tradicionais . . . . . . . . . 45

2.7 Classificação de um problema com duas classes em forma de banana pelo Método de Consistência Global e Local . . . . . . . 46

2.8 Diagrama de bifurcação para o mapa logístico. . . . . . . . . . 50

2.9 Dinâmica de Ponto Fixo no mapa logístico com coeficiente de bifurcação $a=2,8 \ldots \ldots \ldots \ldots \ldots \ldots \ldots \ldots \ldots \ldots \ldots \ldots \ldots$

2.10 Dinâmica de Ciclo Limite no mapa logístico com coeficiente de bifurcação $a=3,4$ e 2 pontos periódicos. . . . . . . . . . . 52

2.11 Dinâmica de Ciclo Limite no mapa logístico com coeficiente de bifurcação $a=3,5$ e 4 pontos periódicos. . . . . . . . . . 52

2.12 Dinâmica Quase-Periódica no mapa logístico com coeficiente de bifurcação $a=3,82 \ldots \ldots \ldots \ldots \ldots \ldots \ldots$

2.13 Dinâmica Caótica com coeficiente de bifurcação $a=4,0 \ldots \ldots$. . 54

2.14 Duas trajetórias caóticas de mapas logísticos com diferentes condições iniciais. . . . . . . . . . . . . . . . . . 54

2.15 Expoentes de Lyapunov para o mapa logístico da Equação (2.41). 56

2.16 Dois mapas logísticos acoplados com $\varepsilon=0,45 \ldots \ldots$. . . . 58

2.17 Dois mapas logísticos acoplados com $\varepsilon=0,23 . \ldots \ldots$. . . . . . 59

2.18 Série Temporal das unidades $x$ e $y$ de um Oscilador WilsonCowan. . . . . . . . . . . . . . . 6 60

2.19 Trajetória de fase de um Oscilador Wilson-Cowan. . . . . . . . 61 
2.20 Dois osciladores Wilson-Cowan acoplados com $k=0,5$. . . . . . 62

2.21 Dois osciladores Wilson-Cowan acoplados com $\theta_{x 1}=0,2$ e $\theta_{x 2}=$

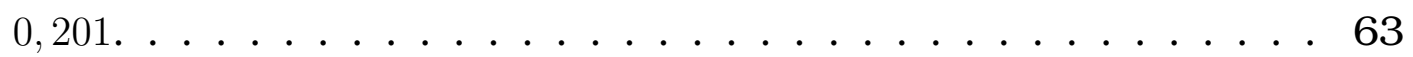

2.22 Dois osciladores Wilson-Cowan acoplados com $\theta_{x 1}=0,2$ e $\theta_{x 2}=$

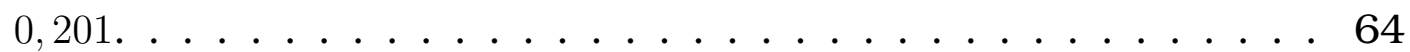

2.23 Série Temporal das unidades $x, y$ e $z$ de um Oscilador de Rössler. 65

2.24 Trajetória de fase de um Oscilador de Rössler. . . . . . . . . . . . 65

2.25 Fase acumulada do Oscilador de Rössler das Figuras 2.23 e 2.24. 66

2.26 Diferença de fase entre dois Osciladores de Rössler acoplados ao longo do tempo . . . . . . . . . . . . . . . . . 67

2.27 Diferença entre as variáveis $x, y$ e $z$ de dois Osciladores de Rössler acoplados . . . . . . . . . . . . . . . 67

3.1 Diagrama de bifurcação de um oscilador Rössler variando o pa-

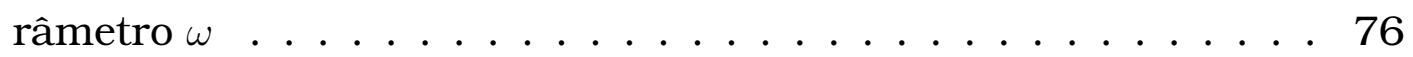

3.2 Atividades temporais de osciladores Rössler com $\omega=0,8, \omega=$ $0,9, \omega=1,0, \omega=2,0, \omega=3,0$ e $\omega=4,5 \ldots \ldots 77$

3.3 Atenção visual em imagem artificial com 5 objetos linearmente não separáveis (incluindo o fundo). . . . . . . . . . . . 79

3.4 Atividades temporais de blocos de osciladores Rössler em atividade de atenção visual. . . . . . . . . . . . . . . . . . 80

3.5 Atenção visual em imagem artificial com 7 segmentos. . . . . . . 81

3.6 Atenção visual em imagens artificiais com 15 objetos cada, e diferentes níveis de contraste . . . . . . . . . . . . 86

3.7 Resultados observados com a imagem artificial de alto contraste. 87

3.8 Resultados observados com a imagem artificial de médio contraste. . . . . . . . . . . . . . . . 89

3.9 Resultados observados com a imagem artificial de baixo contraste. 90

3.10 Atenção visual com imagem real - "Flor Gloxínia". . . . . . . . . . 91

3.11 Atenção visual em imagem artificial - "Espirais". . . . . . . . . . 92

3.12 Atenção visual em imagem real - "Cachorro". . . . . . . . . . . . 94

4.1 Problema de classificação com 1000 elementos divididos em quatro comunidades com sobreposição. . . . . . . . . . . . . . . . 104

4.2 Classificação da Rede do Clube de Caratê de Zachary (Zachary, 1977) com detecção dos índices de sobreposição de cada nó. 104

4.3 Ilustrações das dinâmicas de partículas e nós. . . . . . . . . 111

4.4 Análise de complexidade do método proposto em rede com média mistura. . . . . . . . . . . . . . . . . 118

4.5 Análise de complexidade do método proposto em rede com alta mistura. . . . . . . . . . . . . . . . 119 
4.6 Taxa de classificação correta $\phi$ vs. $p_{\text {grd }}$ vs. $\Delta_{v}$ para redes com diferentes misturas. . . . . . . . . . . . . . . . . 122

4.7 Taxa de classificação correta $\phi$ vs. $p_{\text {grd }}$ vs. $\Delta_{v}$ para redes com diferentes tamanhos. . . . . . . . . . . . . . . . . . . . . 123

4.8 Taxa de classificação correta $\phi$ vs. $p_{\text {grd }}$ vs. $\Delta_{v}$ para diferentes valores de grau médio dos nós. . . . . . . . . . . . . . . . . 124

4.9 Séries temporais para diferentes valores de $p_{\text {grd }} \ldots \ldots \ldots$. . . . . 126

4.10 Classificação de bases de dados artificiais com diferentes distribuições. . . . . . . . . . . . . . . . . 128

4.11 Classificação nebulosa de duas classes em forma de banana. . . 135

4.12 Classificação de classes com distribuição normal (distribuição Gaussiana). . . . . . . . . . . . . . . . 136

4.13 Comparativo entre o modelo padrão e o modelo modificado. . . . 138

4.14 Índices de sobreposição na Rede do Clube de Caratê de Zachary (Zachary, 1977) detectados pelo método proposto. . . . . . . . 139 


\section{Lista de Tabelas}

4.1 Classificação nebulosa de um nó conectado em uma rede com 4 comunidades geradas com $z_{\text {out }} / k=0,125$. . . . . . . . . 101

4.2 Classificação nebulosa de um nó conectado em uma rede com 4 comunidades geradas com $z_{\text {out }} / k=0,250$. . . . . . . . . . 102

4.3 Classificação nebulosa de um nó conectado em uma rede com 4 comunidades geradas com $z_{\text {out }} / k=0,375$. . . . . . . . . . 102

4.4 Classificação nebulosa da rede do clube de caratê de Zachary obtida pelo método proposto. . . . . . . . . . . . . 105

4.5 Informações básicas das base de dados de teste . . . . . . . . . 127

4.6 Métodos de aprendizado semi-supervisionado usados para comparação de desempenho . . . . . . . . . . . . . . . . . . . . 129

4.7 Erros de teste (\%) com 10 pontos de dados rotulados. . . . . . . 130

4.8 Erros de teste (\%) com 100 pontos de dados rotulados. . . . . . . 130

4.9 Classificação de métodos de aprendizado semi-supervisionado com 10 pontos de dados rotulados . . . . . . . . . . . 131

4.10 Classificação de métodos de aprendizado semi-supervisionado com 100 pontos de dados rotulados . . . . . . . . . . . . 131

4.11 Taxa de classificação correta dos algoritmos de aprendizado semisupervisionado aplicados a base de dados Yeast (Asuncion \& Newman, 2007). . . . . . . . . . . . . . . . . 141 


\section{Lista de Algoritmos}

2.1 K-Médias nebuloso . . . . . . . . . . . . . . . . 18

2.2 Método hierárquico aglomerativo . . . . . . . . . . . . . 19

2.3 Método betweeness . . . . . . . . . . . . . . . . . . . . . . . 29

2.4 Método de caminhadas aleatórias . . . . . . . . . . . . . 32

2.5 Método de otimização de modularidade . . . . . . . . . . . 33

2.6 Propagação de rótulos (Zhu \& Ghahramani, 2002) . . . . . . . . . . 43

2.7 Propagação de rótulos inspirada no algoritmo de iteração de Jacobi (Bengio et al., 2006) . . . . . . . . . . . . . . . . 43

2.8 Método de Consistência Local e Global (Zhou et al., 2004) . . . . 44

4.1 Detecção de comunidades sobrepostas com competição de partículas . . . . . . . . . . . . . . . . . 100

4.2 Aprendizado semi-supervisionado com cooperação e competição entre partículas . . . . . . . . . . . . . . . . . 115 


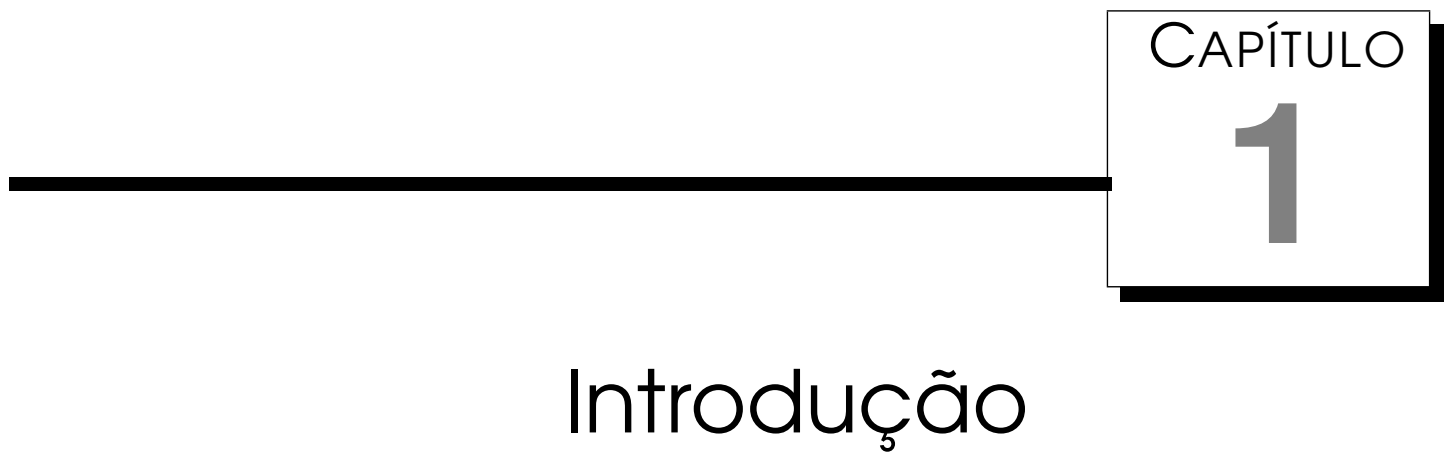

Redes complexas é um campo de pesquisa científica recente e bastante ativo, que estuda redes de larga escala com estruturas topológicas não triviais, tais como redes de computadores, redes de telecomunicações, redes de transporte, redes sociais e redes biológicas (Newman, 2003; Dorogovtsev \& Mendes, 2003; Bornholdt \& Schuster, 2006). Muitas destas redes são naturalmente divididas em comunidades ou módulos, portanto descobrir a estrutura dessas comunidades é um dos principais problemas abordados no estudo de redes complexas (Newman \& Girvan, 2004; Newman, 2006; Duch \& Arenas, 2006; Reichardt \& Bornholdt, 2004; Danon et al., 2005).

O problema de detecção de comunidades também está relacionado com o campo de aprendizado de máquina, o qual tem como interesse projetar e desenvolver algoritmos e técnicas que permitem aos computadores "aprender", ou melhorar seu desempenho através da experiência (Mitchell, 1997). Algoritmos de aprendizado de máquina normalmente estão em uma destas duas categorias: aprendizado supervisionado e aprendizado não supervisionado. No aprendizado supervisionado, o algoritmo aprende uma função a partir dos dados de entrada, os quais consistem de pares de amostras (elementos, observações, itens de dados ou vetores de atributos) e seus respectivos rótulos, de forma que após ver uma quantidade de exemplos de treinamento o algoritmo pode predizer os rótulos de dados ainda não vistos. Por outro lado, no aprendizado não supervisionado as amostras não são rotuladas e o objetivo é determinar como as amostras estão organizadas.

Uma forma de aprendizado não supervisionado é o agrupamento de dados, que divide padrões de entrada em grupos (clusters, comunidades) baseados em sua similaridade, ou seja, padrões pertencentes ao mesmo grupo são mais 
similares do que padrões que pertencem a grupos diferentes. Métodos de agrupamento de dados vêm sendo utilizados em aplicações de tomada de decisão, mineração de dados, recuperação de documentos, segmentação de imagens e reconhecimento de padrões (Jain et al., 1999; Schaeffer, 2007; Duda et al., 2000; Kaufman \& Rousseeuw, 1990; Jain \& Dubes, 1988).

Devido ao estudo de redes complexas e ao constante aumento do poder computacional, as bases de dados sendo processadas têm se tornado cada vez maiores. Em muitas situações apenas um pequeno subconjunto dos itens de dados dessas bases podem ser efetivamente rotulados. Isto acontece porque o processo de rotular dados costuma ser caro e demorado, por requerer o trabalho de especialistas humanos. Nestes casos, o aprendizado supervisionado nem sempre obtém bons resultados, pois os métodos dessa categoria utilizam apenas os poucos dados rotulados no treinamento. Os métodos de aprendizado não supervisionado também terão problemas, pois não aproveitam as informações de rótulo que estão disponíveis. Com o objetivo de resolver estes problemas, surgiu uma nova categoria de algoritmos de aprendizado de máquina, chamada de aprendizado semi-supervisionado. Tais métodos combinam uma pequena quantidade de itens de dados rotulados com uma grande quantidade de dados não rotulados, com o objetivo de construir melhores classificadores requerendo menor esforço humano ( $\mathrm{hhu}, 2005$; Chapelle et al., 2006b; Abney, 2008).

Um dos principais problemas observados, tanto em métodos de aprendizado não supervisionado quanto em métodos de aprendizado semi-supervisionado, é que as técnicas geralmente são desenvolvidas para identificar formas específicas no espaço de atributos, pois o cálculo de similaridade freqüentemente envolve medidas de distância física entre os elementos, dificultando sua utilização em problemas em que os grupos ou classes apresentam formas mais irregulares. No caso do aprendizado semi-supervisionado, algumas abordagens criam grafos baseados na similaridade entre pares de elementos, e a partir daí lidam apenas com os grafos, sem considerar os valores dos atributos originais. Tais técnicas minimizam o problema de encontrar classes de formas mais irregulares, porém a maioria dos métodos baseados em grafos têm um custo computacional alto (Zhu, 2005), impedindo sua utilização em bases de dados maiores, que é justamente o caso onde o aprendizado semisupervisionado se torna mais interessante.

Outro problema também encontrado, tanto no aprendizado não supervisionado quanto no aprendizado semi-supervisionado, é que nem sempre os elementos pertencem a um único grupo. Por exemplo, em uma rede social de amizades, as pessoas freqüentemente pertencem a várias comunidades: suas famílias, seus colegas de classe, seus colegas de trabalho, etc.; de forma que 
há sobreposição entre os clusters, e muitos dos algoritmos tradicionais não podem detectar tais estruturas. Conseqüentemente, descobrir a estrutura de sobreposição destes clusters ou classes é um tópico importante no aprendizado de máquina (Zhang et al., 2007a; Palla et al., 2005; Zhang et al., 2007b).

Neste trabalho tratamos tais problemas através da construção de novos modelos de aprendizado de máquina utilizando redes complexas e dinâmica espaço-temporal, com capacidade para tratar grupos e classes sobrepostas, além de fornecer graus de pertinência para cada elemento da rede com relação a cada cluster ou classe.

\subsection{Motivação}

A maioria dos algoritmos de aprendizado de máquina tem como base modelos estáticos, que embora eficientes em alguns casos, podem não se adequar a dados cujos grupos ou classes apresentem diferentes formas, densidades e tamanhos. Por exemplo, o conhecido algoritmo K-Médias assume que os grupos têm forma de hiper-elipses e tamanhos similares, não funcionando adequadamente para grupos com diferentes tamanhos e formas. No aprendizado semi-supervisionado, alguns modelos baseados em grafos minimizam este problema através da transformação do conjunto de atributos originais em um grafo onde cada vértice representa um elemento e cada aresta representa a similaridade entre os pares de elementos, porém a maioria dos métodos utiliza uma abordagem semelhante de propagação de rótulos em que, a cada iteração, todo elemento propaga seu rótulo para todos os outros elementos vizinhos, o que resulta em algoritmos com alta ordem de complexidade computacional.

Zhao et al. (2004, 2005) propuseram um modelo dinâmico para agrupamento de dados que tem como base a teoria dos sistemas dinâmicos e suas características de sincronização e dessincronização. Nesse modelo, cada elemento da rede é representado por um mapa caótico, que por sua vez corresponde a um elemento no espaço de atributos. Assim, quando uma base de dados é fornecida para a rede, os elementos se auto-organizam de acordo com um critério de similaridade pré-definido, de modo que o acoplamento entre elementos que representam um mesmo grupo é mantido, enquanto que elementos que representam diferentes grupos têm seus respectivos acoplamentos eliminados. Dessa forma, todos os elementos pertencentes a um mesmo grupo serão sincronizados, ou seja, após um período transiente cada elemento será representado por uma trajetória caótica sincronizada com a dos demais elementos do mesmo grupo. Ao mesmo tempo, elementos de grupos diferentes terão diferentes trajetórias caóticas. Quaisquer números de tais trajetórias caóticas já se distinguem uma das outras seguindo a alta sensibilidade às 
condições inicias e propriedades densas do caos, de modo que é possível fazer a separação.

A sincronização completa entre dois sistemas dinâmicos, utilizada no modelo dinâmico, ocorre quando ambos geram trajetórias idênticas, incluindo fase e amplitude. E a sincronização de fase entre dois sistemas dinâmicos ocorre quando a diferença de fase entre ambos é limitada enquanto a amplitude permanece não correlacionada. Geralmente a sincronização pode ser realizada através de um valor adequado de peso de acoplamento entre os elementos da rede. Através das definições acima é fácil perceber que o estado de sincronização por fase exige um valor de peso de acoplamento bem menor do que a realização de sincronização completa, evitando a divergência para o infinito causada pelo forte acoplamento e, portanto, a sincronização por fase é mais segura. Outra vantagem é que a sincronização por fase pode ser realizada mesmo com diferença entre os parâmetros, isso implica que ela é mais robusta que a sincronização completa. A sincronização por fase é uma característica saliente de atividades dos neurônios biológicos em processamento de informações (Fries et al., 2001). Portanto a investigação de sincronização por fase em uma rede de osciladores acoplados tem importância teórica e prática. Neste trabalho é investigada a sincronização por fase em osciladores caóticos acoplados em rede, especificamente no oscilador proposto por Rössler (1976), no qual já foi demonstrado que o fenômeno de sincronização por fase pode ser observado mesmo quando os sistemas tem comportamento caótico (Rosenblum et al., 1996).

Quiles et al. (2008) propuseram um modelo de detecção de comunidades baseado em competição de partículas que caminham em uma rede. As partículas competem umas com as outras pela posse de vértices da rede, ao mesmo tempo em que rejeitam partículas intrusas. Após um número de iterações, cada partícula estará confinada em uma comunidade da rede, de forma que as comunidades podem ser definidas examinando-se a qual partícula cada vértice pertence. Este modelo apresentou bons resultados em detecção de comunidades em redes aleatórias, comparáveis aos de vários algoritmos do estado da arte, ao mesmo tempo em que tem uma ordem de complexidade computacional inferior à de vários desses algoritmos, permitindo sua utilização em redes de larga escala. Neste trabalho, esta abordagem foi estudada com o objetivo de aperfeiçoá-la e estendê-la para outros domínios do aprendizado.

Dentre os problemas mais desafiadores na área de aprendizado de máquina se encontram os problemas modelados através de redes complexas, cujo interesse vem aumentando, principalmente pela disponibilidade de computadores e redes de comunicação que permitem analisar dados em uma escala muito 
maior do que era possivel anteriormente. Exemplos dessas aplicações incluem a Internet, a World Wide Web (WWW), sistemas de telecomunicações, redes de energia elétrica, redes sociais, redes de tráfego, e redes biológicas, como redes neurais e redes de interação entre proteínas (Clauset, 2005; Boccaletti et al., 2007; Newman \& Girvan, 2004). O aprendizado de máquina em redes complexas é uma das metas desse trabalho.

\subsection{Objetivos}

O objetivo principal deste trabalho é construir técnicas de aprendizado de máquina com dinâmica espaço-temporal que sejam capazes de identificar formas arbitrárias de classes e também de revelar a estrutura de sobreposição existente entre elas, tanto no âmbito do aprendizado não supervisionado quanto no âmbito do aprendizado semi-supervisionado, utilizando dados organizados em redes complexas. Além disso, é desejável que os modelos desenvolvidos tenham complexidade computacional baixa e que possam ser aplicados em outras aplicações de aprendizado, como segmentação de imagens e atenção visual, que são partes essenciais de sistemas de visão computacional.

Para tanto, inicialmente foram estudados e adaptados modelos físicos teóricos e foram aprimorados modelos computacionais já existentes. Mais especificamente, o modelo dinâmico de Zhao et al. (2004) foi estudado e novos modelos baseados em sincronização entre osciladores caóticos foram propostos. A sincronização completa utilizada no modelo dinâmico foi substituída pela sincronização por fase, que é uma forma mais robusta de sincronização, com o objetivo de facilitar a aplicação do modelo em outras tarefas de aprendizado devido à menor força de acoplamento necessária para manter a coerência entre os osciladores. Especificamente, os modelos desenvolvidos foram aplicados inicialmente em tarefas de segmentação de imagens e posteriormente em tarefas de atenção visual, tornando-se os primeiros modelos a utilizar sincronização por fase entre osciladores caóticos para essa tarefa.

Durante o desenvolvimento deste trabalho, Quiles et al. (2008) propuseram um modelo de movimentação e competição entre partículas para detectar comunidades em redes. Tal abordagem também foi extensivamente estudada, de forma que novos modelos baseados em partículas foram propostos. Especificamente, foi proposto um modelo de competição de partículas que não apenas identifica os grupos, mas que também é capaz de identificar elementos que participam de mais de um grupo, fornecendo os respectivos graus de pertinência de cada elemento à cada grupo. Tal objetivo é alcançado através de informações obtidas a partir da dinâmica temporal do modelo. Este modelo foi então estendido para tratar problemas de aprendizado semi-supervisionado. 
Para tanto, foi implementada a cooperação entre partículas que representam uma mesma classe, ao mesmo tempo em que existe uma competição entre partículas representando classes diferentes. Tal modelo apresentou desempenho compatível com o de vários algoritmos do estado da arte em aprendizado semi-supervisionado, além de apresentar uma ordem de complexidade computacional menor que a de vários outros modelos baseados em grafos. Assim como na versão não supervisionada, este algoritmo também é capaz de detectar classes sobrepostas, além de fornecer uma medida de sobreposição para cada elemento da rede.

\subsection{Organização do Documento}

Este trabalho está organizado da seguinte maneira. No Capítulo 2 é apresentada uma revisão bibliográfica sobre redes complexas, aprendizado de máquina, com foco em aprendizado não supervisionado e semi-supervisionado, apresentando um resumo sobre as principais categorias de cada classe, bem como a descrição de algumas técnicas tradicionais encontradas na literatura. Além disso, são incluídos alguns conceitos de sistemas dinâmicos e sincronização (completa e por fase), que foram aplicados em alguns modelos desenvolvidos. No Capítulo 3, são apresentados as descrições e os resultados obtidos por modelos desenvolvidos baseados em sincronização entre osciladores caóticos em reticulado e aplicados em tarefas de segmentação de imagens e atenção visual. No Capítulo 4 são apresentados alguns modelos desenvolvidos baseados em movimentação de partículas e os resultados de sua aplicação em redes utilizando aprendizado não supervisionado e semi-supervisionado. Finalmente, no Capítulo 5 são apresentadas algumas conclusões. 


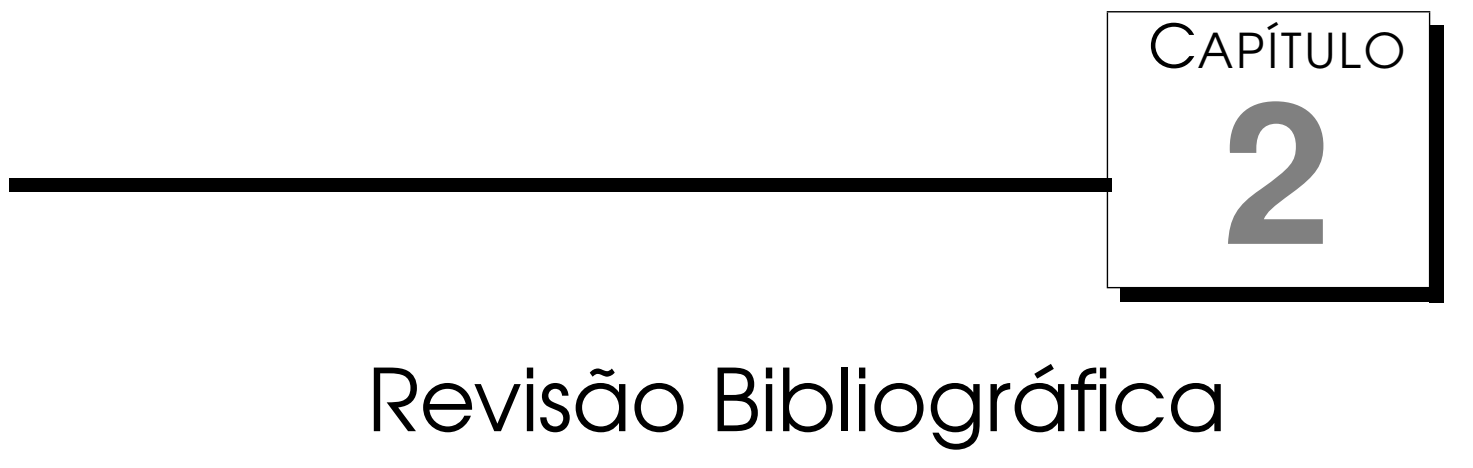

Neste capítulo é apresentada uma revisão bibliográfica de redes complexas (Seção 2.1) e aprendizado de máquina (Seção 2.2), com ênfase nas categorias de aprendizado não supervisionado (Seção 2.3) e aprendizado semisupervisionado (Seção 2.4), áreas do aprendizado de máquina em que estão inseridos os métodos desenvolvidos, que serão apresentados nos capítulos subseqüentes. Além disso, na Seção 2.5 é apresentado um resumo sobre sistemas dinâmicos e sincronização de osciladores, fundamentos que embasam alguns dos modelos desenvolvidos.

\subsection{Redes Complexas}

Recentemente, tem sido testemunhada uma nova direção na pesquisa em redes, com o foco passando da análise de grafos pequenos para o estudo de propriedades estatísticas de grafos de larga escala. Essa nova abordagem tem sido levada em consideração principalmente pela disponibilidade de computadores e redes de comunicação que permitem analisar dados em uma escala muito maior do que era possível anteriormente. Estudos anteriores costumavam focar redes de dezenas de milhares ou em casos extremos centenas de milhares de vértices, mas não é incomum encontrar na prática redes com milhões ou até bilhões de vértices. Exemplos incluem a Internet, a World Wide Web (WWW), sistemas de telecomunicações, redes de energia elétrica, redes sociais, redes de tráfego, redes biológicas, como redes neurais, redes de interação entre proteínas, etc. (Newman, 2003).

Muitas redes sociais, biológicas e tecnológicas apresentam características topológicas não triviais entre seus elementos que não são totalmente regu- 
lares nem totalmente aleatórias. Tais características têm forte relação com a distribuição do grau, alto coeficiente de agrupamento, assortatividade e desassortatividade entre vértices (preferência de nós da rede de se conectarem com nós que tenham uma determinada similaridade ou diferença), estrutura de comunidade, e estrutura hierárquica. No caso de redes direcionadas, também estão incluídos atributos como reciprocidade, dentre outros. Em contraste, muitos modelos matemáticos de redes estudados no passado, como matrizes e grafos aleatórios, não mostram estas características.

A primeira tentativa séria de construção de um modelo para redes grandes e (aparentemente) aleatórias, denominadas Redes Aleatórias, foi realizada por Erdõs \& Rényi (1961), que pesquisaram exaustivamente e rigorosamente o assunto. Em 1998, Watts \& Strogatz (1998) descobriram que o diâmetro (a média dos menores caminhos) de uma rede regular pode ser drasticamente reduzido preservando sua estrutura local, medida pelo coeficiente de agrupamento. Esta redução do diâmetro da rede pode ser realizada por alterações aleatórias de uma pequena percentagem das arestas. As redes resultantes são chamadas de Redes de Pequeno-Mundo ${ }^{1}$, que representam algumas redes reais, como redes sociais e lingüísticas.

Em 1999, Barabasi \& Albert (1999) descobriram que a distribuição do grau de muitas redes complexas obedece a lei da potência ${ }^{2}: P(k) \sim k^{-\gamma}$, onde $k$ é o número de ligações de um nó aleatório e $\gamma$ é o expoente de escala. Essa distribuição heterogênea significa que a probabilidade de que um conjunto de nós tenha um grande número de ligações não é pequena. Esse tipo de rede é chamado de Redes Livre de Escala $^{3}$, o oposto de redes aleatórias, que possuem distribuição de graus de vértices homogênea, resultando na ausência de vértices dominantes.

Depois de tais descobertas, muitas pesquisas têm sido realizadas em redes complexas, que conseqüentemente tornou-se uma sólida área de pesquisa. Os principais resultados apresentados à comunidade científica são: o crescimento de redes e auto-organização, distribuição do grau e de betweenness, resistência de redes complexas contra falha ou ataque, navegação em redes, estrutura de comunidades, otimização de redes complexas, estabilidade e sincronização de redes, etc. (Albert \& Barabasi, 2002; Newman, 2003).

O campo de redes complexas continua a se desenvolver rapidamente, e reuniu pesquisadores de muitas áreas, incluindo matemática, física, biologia, ciência da computação, sociologia, epidemiologia, e outros. Idéias oriundas do estudo de redes complexas foram aplicadas à análise de redes de regulação metabólica e genética, projeto de redes de comunicação robustas e escaláveis

\footnotetext{
1 do inglês: Small-World Networks

2 do inglês: power law

3 do inglês: Scale-Free Networks
} 
com e sem fio, desenvolvimento de estratégias de vacinação para controle de doenças, e várias outras abordagens úteis.

\subsubsection{Representação de Redes Complexas}

A teoria dos grafos é a maneira mais natural de representar e tratar matematicamente as redes complexas, e estas podem ser formalmente representadas como grafos (Boccaletti et al., 2006). Grafos podem ser definidos como estruturas compostas por conjunto de vértices (nós) e por um conjunto de pares destes vértices (arestas). As arestas freqüentemente são usadas para indicar alguma espécie de relação entre os nós que ligados por ela, de acordo com o problema modelado.

Matematicamente, um grafo é um par de conjuntos $G=(V, E)$, onde $V$ é o conjunto de vértices e $E$ é o conjunto de arestas do grafo. O número de vértices $n=|V|$ é a ordem do grafo. Em um grafo não direcionado, cada aresta é um par não ordenado $\{v, w\}$, enquanto em grafos direcionados (digrafos) os pares são ordenados. O tamanho do grafo é dado pelo número de arestas $m=|E|$. Em um grafo com pesos é definida uma função $\omega: E \rightarrow \mathbb{R}$ para designar um peso para cada aresta.

A densidade de um grafo é definida como a proporção de arestas presentes e o número total de arestas possíveis. Em um grafo não direcionado a proporção é dada por:

$$
\delta(G)=\frac{2 m}{n(n-1)},
$$

com $\delta(G)=0$ quando $n=\{0,1\}$, de modo que a densidade mínima será 0 e a máxima será 1 (grafo completo).

Se dois vértices $\{u, v\} \in E$, dizemos que $v$ e $u$ são vizinhos (ou adjacentes). O conjunto de vizinhos de $v$ é chamado vizinhança de $v$ e pode ser denotado por $\Gamma(v)$. A matriz de adjacência $\mathbf{A}_{G}$ de um grafo $G$ de ordem $n$ tem tamanho $n \times n, \mathbf{A}_{G}=\left(a_{u, v}^{G}\right)$ onde:

$$
a_{u, v}^{G}= \begin{cases}1, & \text { se }\{u, v\} \in E, \\ 0, & \text { caso contrário. }\end{cases}
$$

O número de arestas que incidem sobre um dado vértice $v$ é chamado grau de $v$ e é denotado como $\operatorname{deg}(v)$. Um grafo é regular se todos os vértices têm o mesmo grau. Denotamos por:

$$
\operatorname{deg}(S)=\sum_{v \in S} \operatorname{deg}(v)
$$

a soma dos graus em um sub-grafo $S$.

Quando modelamos redes complexas através de grafos, os elementos da 
rede são representados por vértices e a similaridade entre pares é representada pelas conexões (ou pelo peso das conexões no caso de conexões com peso).

A similaridade entre um par de vértices pode ser representada através da distância entre eles dado um ou mais atributos numéricos dos elementos da rede. Muitas medidas de distância já foram propostas na literatura, mas basicamente toda medida de distância deve seguir os seguintes critérios:

1. A distância de um vértice para ele mesmo é zero: $\operatorname{dist}\left(d_{i}, d_{i}\right)=0$;

2. Distâncias são simétricas: $\operatorname{dist}\left(d_{i}, d_{j}\right)=\operatorname{dist}\left(d_{j}, d_{i}\right)$;

3. A desigualdade triangular é válida: $\operatorname{dist}\left(d_{i}, d_{j}\right) \leq \operatorname{dist}\left(d_{i}, d_{k}\right)+\operatorname{dist}\left(d_{k}, d_{j}\right)$.

Em algumas aplicações os vértices sozinhos não têm informações suficientes para o cálculo de uma matriz de similaridades. Neste caso as arestas que incidem nos vértices podem ser utilizadas para derivar medidas similares. Uma das maneiras mais diretas de se calcular a similaridade entre dois vértices usando apenas a informação de adjacência é verificar a sobreposição de suas respectivas vizinhanças. Outras medidas mais complexas também podem ser derivadas da matriz de adjacência.

\subsubsection{Detecção de Comunidades em Redes}

Muitas redes complexas apresentam uma estrutura de comunidade, onde existem muitas conexões entre os elementos de um mesmo grupo e poucas associações entre elementos de grupos distintos, isto inclui a World Wide Web, redes de citação, redes de transporte, redes de e-mail e redes sociais. Muitos algoritmos de aprendizado de máquina tem sido propostos para este tipo de estrutura, incluindo os algoritmos de Newman \& Girvan (2004) e Newman (2004) para agrupamento em grafos.

Por exemplo, em redes de telefonia com voz sobre IP e serviços como batepapo ou mensageiros instantâneos como Microsoft Live Messenger, Yahoo Messenger, Google Talk e Skype, estatísticas de uso podem ser utilizadas para otimizar as configurações de software e hardware relacionadas. Cada usuário poderia ser representado como um vértice em um grafo, e as arestas teriam peso proporcional a quantidade de vezes que os usuários se comunicam utilizando o sistema em questão. Assim em um ambiente multi-servidor seria vantajoso colocar grupos densos de usuários no mesmo servidor, de modo a reduzir o tráfico interservidores (Schaeffer, 2007).

Uma análise similar se aplica a telefonia tradicional, as operadoras de telefonia podem identificar grupos de usuários que fazem chamadas entre si 
freqüentemente, como famílias, grupo de trabalhos e grupos de amigos, e assim direcionar suas ofertas de taxas especiais para chamadas a um número limitado de telefones pré-cadastrados. Através do aprendizado de máquina podemos identificar uma mudança no padrão de chamadas de um determinado cliente, por exemplo: repentinamente repetidas chamadas de longa distância começam a ser feitas para telefones fora do grupo que o cliente costuma chamar, isto pode indicar que o telefone foi clonado ou roubado, ou que o cliente simplesmente decidiu não pagar mais a conta.

A característica de grandes redes como a World Wide Web torna a detecção de comunidades um grande desafio, pois a maioria dos algoritmos tradicionais são computacionalmente inviáveis para um número tão grande de nós e arestas, tornando necessário o desenvolvimento de novos algoritmos, o que faz esta área de pesquisa ser bastante relevante e promissora.

Na próxima sessão (Seção 2.2), é apresentada uma visão geral do aprendizado de máquina, e posteriormente são detalhadas duas das principais categorias: a de aprendizado não supervisionado (Seção 2.3) e a de aprendizado semi-supervisionado (Seção 2.4), que são as categorias onde estão inseridos os algoritmos desenvolvidos durante este projeto. Ao tratar com dados organizados em redes complexas, uma vez que a rede esteja representada como um grafo, os métodos baseados em grafos (Seções 2.3.5 e 2.4.6) podem ser diretamente aplicados.

\subsection{Aprendizado de Máquina}

O aprendizado de máquina é uma disciplina científica que trata do projeto e desenvolvimento de algoritmos que melhoram automaticamente com a experiência, imitando o comportamento de aprendizado de humanos. Tal comportamento pode ser obtido através do ajustes de parâmetros com base nos dados de entrada que são apresentados e, em alguns casos, nas informações de saída desejadas. Um dos principais focos da pesquisa em aprendizado de máquinas é aprender automaticamente a reconhecer padrões complexos e tomar decisões inteligentes com base em dados; a dificuldade está no fato de que o conjunto de todos os possiveis comportamentos, dadas todas as possíveis entradas, é muito complexo para ser descrito em forma de linguagens de programação. Muitas aplicações de aprendizado de máquina já foram desenvolvidas, variando de programas de mineração de dados que detectam transações fraudulentas em cartões de crédito a sistemas de filtragem de informações que aprendem os hábitos de leitura do usuário. Dentre os diversos campos relacionados podemos citar: inteligência artificial, teoria de probabilidade, mineração de dados, reconhecimento de padrões, controle adaptativo e 
teoria da computação (Mitchell, 1997; Alpaydin, 2004; Natarajan, 1991).

Alguns algoritmos de aprendizado de máquina tentam eliminar a necessidade de especialistas humanos na análise de dados, enquanto outros adotam uma estratégia de colaboração entre humanos e máquinas. A intuição humana não pode ser inteiramente eliminada, pois o projetista do sistema precisa especificar como os dados serão representados e quais mecanismos serão usados para caracterizar os dados. O aprendizado de máquina também é utilizado em casos onde o conhecimento humano não existe ou onde os especialistas não conseguem explicar seu raciocínio. Por exemplo, considere a conversão de gravações de áudio de fala em texto escrito. Humanos podem cumprir esta tarefa sem dificuldade, mas não conseguem explicar como fazem isso. Pessoas diferentes pronunciam as mesmas palavras de maneiras diferentes devido à diferenças de idade, gênero, sotaque, etc. Um algoritmo de aprendizado de máquina precisa analisar uma grande coleção de amostras de sotaques de diferentes pessoas e aprender a mapeá-las para palavras. Alguns problemas de aprendizado também mudam ao longo do tempo, ou dependem de um ambiente em particular. O objetivo é construir sistemas que possam se adaptar a circunstâncias específicas, sem que seja preciso escrever um novo programa para cada situação nova (Alpaydin, 2004).

Com os avanços na tecnologia dos computadores, podemos guardar e processar uma quantidade bastante grande de dados. Por exemplo, uma rede de supermercados pode armazenar os dados de vendas de todas as suas lojas, tendo informações dos hábitos de compras de milhares de consumidores. Para cada venda são registrados dados como: data, código do cliente, produtos comprados, quantidades, valores, etc. É uma quantidade muito grande de dados que só serão úteis se puderem ser analisados e transformados em informações que possam ser utilizadas. Por exemplo, podemos criar um sistema de indicação de livros, CDs ou filmes baseado no histórico de compras do cliente e nas listas de itens comprados por outros clientes com gostos similares. Se essas relações fossem todas conhecidas bastaria escrever o código, mas como não são, resta coletar os dados e tentar extrair essas informações. Apesar de não termos total conhecimento de como funciona o comportamento de consumo, sabemos que o comportamento dos consumidores não é totalmente aleatório, as pessoas compram mais sorvete no verão do que no inverno, quando compram salgadinhos compram também refrigerantes, e assim por diante. Existem certos padrões nos dados que podem ser extraídos, e este é o papel do aprendizado de máquina. 


\subsection{Principais Categorias de Aprendizado de Máquina}

Dentre as principais categorias de aprendizado de máquina, podemos destacar:

Aprendizado Supervisionado : Os algoritmos desta categoria deduzem uma função a partir dos dados de treinamento. Os dados de treinamento consistem de pares de exemplos de entradas e saídas desejadas. A saída pode ser um valor contínuo (regressão), ou pode predizer um rótulo de classe para o objeto de entrada (classificação). O objetivo é obter uma função que seja capaz de predizer a saída para qualquer entrada válida, após ter visto um número suficiente de exemplos de treinamento. Para atingir este objetivo, o algoritmo deve ter capacidade de generalização para que possa prever, de maneira aceitável, a saída para dados ainda não vistos .

Aprendizado Não Supervisionado : Os algoritmos desta categoria buscam determinar como os dados estão organizados. Os dados de treinamento consistem apenas de exemplos de entrada, sem rótulos ou valores de saída. O objetivo é encontrar padrões no espaço de entradas. Uma das formas de atingir este objetivo é observar quais são as regiões com maior e menor densidade de dados.

Aprendizado Semi-Supervisionado : Os algoritmos desta categoria fazem uso tanto de dados rotulados quanto de dados não rotulados para o treinamento, normalmente poucos dados rotulados e bastante dados não rotulados. Esta categoria está localizada entre o aprendizado supervisionado e o não supervisionado. Em muitos casos, o uso de alguns dados rotulados em meio aos dados não rotulados melhora consideravelmente a precisão do aprendizado.

Nas seções a seguir, apresentaremos em maiores detalhes as categorias de aprendizado não supervisionado (Seção 2.3) e de aprendizado semi-supervisionado (Seção 2.4), que são as categorias onde estão inseridos os algoritmos desenvolvidos durante este projeto.

\subsection{Aprendizado Não Supervisionado}

No aprendizado supervisionado, o objetivo é aprender um mapeamento dos dados de entrada para dados de saída cujos valores são fornecidos por um supervisor (também chamado professor ou especialista). No aprendizado não supervisionado (ou auto-organizado), não há supervisor e deve-se aprender apenas a partir dos dados de entrada. O objetivo é descobrir como os dados 
estão organizados. O aprendizado não supervisionado está bastante relacionado com problemas de estimativa de densidade em estatística. Porém, engloba também muitas outras técnicas que buscam resumir e explicar atributos chaves dos dados (Alpaydin, 2004; Duda et al., 2000).

Uma das formas mais comuns de aprendizado não supervisionado é o agrupamento de dados (também chamado clusterização de dados), um processo de classificação não supervisionada de padrões (também chamados de observações, itens de dados, vetores de atributos, etc.) em grupos (clusters) baseados em sua similaridade (Jain et al., 1999). Dessa forma, padrões dentro de um grupo são mais similares entre si do que a padrões pertencentes a outros grupos. O problema de agrupamento já foi abordado de muitas maneiras, por diversos pesquisadores de diferentes áreas, o que demonstra sua ampla utilização na análise de dados. A variedade de técnicas para representar e agrupar elementos de dados, medindo a proximidade (similaridade) entre eles, produziu uma grande variedade de métodos de agrupamento. Estes métodos vêm sendo utilizados em aplicações de tomada de decisão, aprendizado de máquina, mineração de dados, recuperação de documentos, segmentação de imagens e reconhecimento de padrões (Jain et al., 1999; Schaeffer, 2007; Duda et al., 2000; Kaufman \& Rousseeuw, 1990; Jain \& Dubes, 1988).

Os grupos são obtidos mediante a apresentação de um conjunto de dados $S=\left\{\mathbf{x}_{1}, \mathbf{x}_{2}, \ldots, \mathbf{x}_{n}\right\}$, onde $N$ é o número total de elementos, $\mathbf{x}_{i}=\left\{x_{i 1}, x_{i 2}, \ldots, x_{i D}\right\}$ é o vetor de atributos do i-ésimo elemento de $S$ e $D$ é o número de atributos dos elementos.

Um dos principais problemas da maioria dos métodos de agrupamento tradicionais é que as técnicas geralmente são desenvolvidas para identificar formas específicas no espaço de atributos, pois o cálculo de similaridade freqüentemente envolve medidas de distância entre os elementos. Na Figura 2.1 podem ser observados dois espaços de atributos contendo elementos de 4 classes diferentes, o da esquerda é relativamente fácil de ser resolvido empregando técnicas tradicionais de agrupamento que utilizam a distância entre os dados, mas o problema da direita dificilmente poderia ser resolvido com as mesmas técnicas, pois as distribuições apresentam formas mais irregulares.

Neste capítulo descreveremos algumas das várias classes de algoritmos de agrupamento existentes.

\subsection{Métodos Baseados em Otimização}

Os métodos baseados em Otimização também são conhecidos como métodos de partição. Nestes métodos são maximizadas as medidas de similaridade entre os elementos de um grupo e/ou são minimizadas as medidas de similaridade entre os diferentes grupos. Também podem ser aplicadas restrições, 

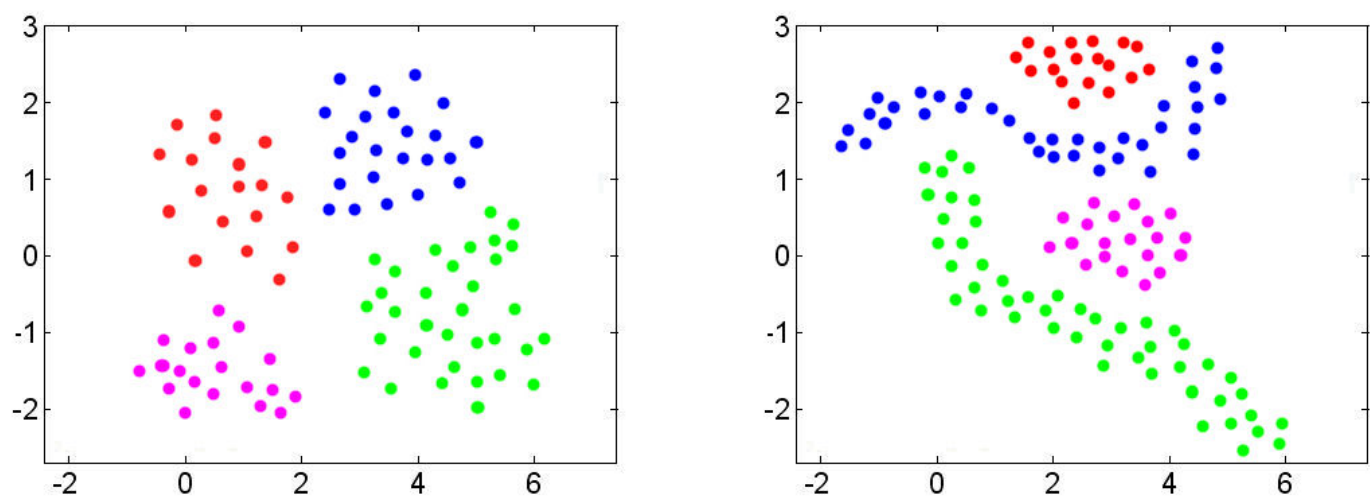

Figura 2.1: Espaços de atributos com elementos de 4 classes diferentes.

como o número de grupos ou a separação mínima entre grupos (Hansen \& Jaumard, 1997).

\section{K-Médias}

Um dos mais conhecidos algoritmos dessa categoria é o algoritmo de $\mathrm{K}$ médias (MacQueen, 1967; Duda et al., 2000), que particiona o conjunto de dados em $K$ grupos com base em uma medida de similaridade. O algoritmo inicia com um conjunto de $K$ centróides, um para cada grupo. Cada elemento pertencente ao conjunto de dados é representado por um ponto em um espaço $d$-dimensional, onde $d$ é o tamanho do vetor de entrada, ou seja, a quantidade de atributos de cada padrão. A cada iteração, um vetor média é computado para cada grupo e os pontos são realocados para o vetor média mais próximo, de acordo com a medida de similaridade utilizada. Esse processo é repetido até a convergência (até que o vetor média para cada grupo não mude mais), ou até atingir um número máximo de iterações. Estes passos estão descritos detalhadamente a seguir:

\section{Passo 1: Definir o número $(K)$ de grupos a serem formados.}

As técnicas baseadas em partição necessitam que o número de grupos seja definido a priori, o que costuma ser uma das principais dificuldades, pois nem sempre o conjunto de dados é conhecido. Algumas heurísticas foram propostas para auxiliar na definição de $K$ (Everitt et al., 2001).

\section{Passo 2: Determinar os centróides iniciais para os $K$ grupos.}

Esse algoritmo também é bastante dependente dos centróides iniciais $\left.\mathbf{m}_{1}(1), \mathbf{m}_{2}(1), \ldots, \mathbf{m}_{K}(1)\right)$ que devem ser fornecidos ao algoritmo. Em geral isso é feito de maneira aleatória, mas algumas heurísticas também podem ser utilizadas visando a escolha dos valores mais adequados. 


\section{Passo 3: Atribuir cada um dos elementos a um dos $K$ grupos.}

Atribuir cada um dos $n$ elementos em $S$ para um dos $K$ grupos utilizando:

$$
\mathbf{x} \in S_{j}(t) \text { se }\left\|\mathbf{x}-\mathbf{m}_{j}(t)\right\| \leq\left\|\mathbf{x}-\mathbf{m}_{i}(t)\right\|, \quad i, j=1,2, \ldots, K, \quad i \neq j
$$

onde $S_{j}(t)$ denota o conjunto de objetos que pertencem ao grupo $j$ na interação $t$ e $\mathbf{m}_{j}(t)$ é o centróide do grupo $j$. Assim os $n$ objetos do conjunto de dados $S=\left\{\mathbf{x}_{1}, \mathbf{x}_{2}, \ldots, \mathbf{x}_{n}\right\}$ são divididos em $K$ grupos.

\section{Passo 4: Determinar os novos centróides dos $K$ grupos}

Após os elementos serem distribuídos entre os grupos, os centróides devem ser recalculados usando:

$$
\mathbf{m}_{j}(t+1)=\frac{1}{N_{j}(t)} \sum_{\mathbf{x} \in S_{j}(t)} \mathbf{x}, \quad j=1,2, \ldots, K
$$

onde $N_{j}(t)$ é a quantidade de objetos no grupo $j$ na iteração $t$. O objetivo é minimizar a distância entre os elementos e o seu respectivo centróide, ou seja, minimizar a seguinte função objetivo:

$$
J=\sum_{j=1}^{K} \sum_{\mathbf{x} \in S_{j}}\|\mathbf{x}-\mathbf{m}\|^{2} .
$$

\section{Passo 5: Verificar a convergência do algoritmo}

O algoritmo converge quando $\mathbf{m}_{j}(t+1)=\mathbf{m}_{j}(t)$ para $j=1,2, \ldots, K$. Se essa condição for satisfeita o procedimento termina. Caso contrário retorna-se ao passo 3 .

K-Medóides (PAM)

Outro algoritmo baseado em otimização bastante usado é o $k$-medóides ${ }^{4}$, também conhecido como PAM $^{5}$ (Kaufman \& Rousseeuw, 1990), mais robusto a ruídos e a outliers comparado ao K-médias. Um medóide pode ser definido como o elemento do grupo, cuja distância média com relação a todos os outros elementos do grupo é mínima, ou seja, o elemento mais central do grupo. O algoritmo inicia com uma seleção arbitrária de elementos como sendo os $K$ medóides. Cada elemento é então associado ao medóide mais similar. A cada iteração é selecionado aleatoriamente qualquer elemento $i$ que não seja

5 sigla de Partition Around Medoids 
medóide, e computa-se a distância média entre os elementos do grupo e o elemento selecionado. Se essa distância for menor que a distância do medóide, $i$ passa a ser o novo medóide. O processo é repetido até a convergência (quando não houver mais nenhuma troca), ou até atingir um número máximo de iterações.

O algoritmo K-médias e seus derivados nem sempre encontram a melhor solução, muitas vezes a solução encontrada é apenas um mínimo local. O resultado depende do número de grupos definido inicialmente e da posição inicial dos centróides (ou medóides), portanto é comum que ele seja executado diversas vezes com parâmetros diferentes buscando um melhor resultado.

\section{K-Médias Nebuloso}

Em cada iteração do K-médias clássico, cada ponto está em exatamente um grupo. Essa condição pode ser relaxada e assumir que cada elemento $\mathbf{x}_{i}$ pertence a um ou mais grupos $c_{j}$ com um determinado grau de pertinência $c_{j}\left(\mathbf{x}_{i}\right)$, onde $0 \leq c_{j}\left(\mathbf{x}_{i}\right) \leq 1$. Esses graus de pertinência equivalem a probabilidade $P\left(c_{j} \mid \mathbf{x}_{i}\right)$ do elemento pertencer a cada um dos grupos (Duda et al., 2000). Assim a função a ser minimizada é:

$$
J=\sum_{j=1}^{K} \sum_{i=1}^{n}\left[P\left(c_{j} \mid \mathbf{x}_{i}\right)\right]^{b}|| \mathbf{x}_{i}-\mathbf{m}_{j} \|^{2}
$$

onde $b>1$ é um parâmetro livre escolhido para ajustar a mistura entre os grupos. Se $b=0$ não há mistura e o algoritmo é um K-médias convencional. As probabilidades são normalizadas para atender a seguinte condição:

$$
\sum_{j=1}^{K} P\left(c_{j}, \mathbf{x}_{i}\right)=1 \quad i=1, \ldots, n .
$$

Assim os centróides são definidos por:

$$
\mathbf{m}_{j}=\frac{\sum_{i=1}^{n}\left[P\left(c_{j} \mid \mathbf{x}_{i}\right)\right]^{b} \mathbf{x}_{i}}{\sum_{i=1}^{n}\left[P\left(c_{j} \mid \mathbf{x}_{i}\right)\right]^{b}}
$$

$\mathrm{e}$

$$
P\left(c_{j} \mid \mathbf{x}_{i}\right)=\frac{\left(1 / d_{i j}\right)^{1 /(b-1)}}{\sum_{r=1}^{K}\left(1 / d_{i r}\right)^{1 /(b-1)}}, \quad d_{i j}=\left\|\mathbf{x}_{i}-\mathbf{m}_{j}\right\|^{2} .
$$

Em geral, a função critério é minimizada quando os centróides $\mathbf{m}_{j}$ estão próximos dos pontos que têm maior probabilidade de estar no grupo $j$. Como as Equações (2.9) e (2.10) raramente tem soluções analíticas, os centróides e probabilidades são estimados iterativamente de acordo com o Algoritmo 2.1.

Apesar de o K-médias nebuloso ser melhor que o K-médias em evitar míni- 


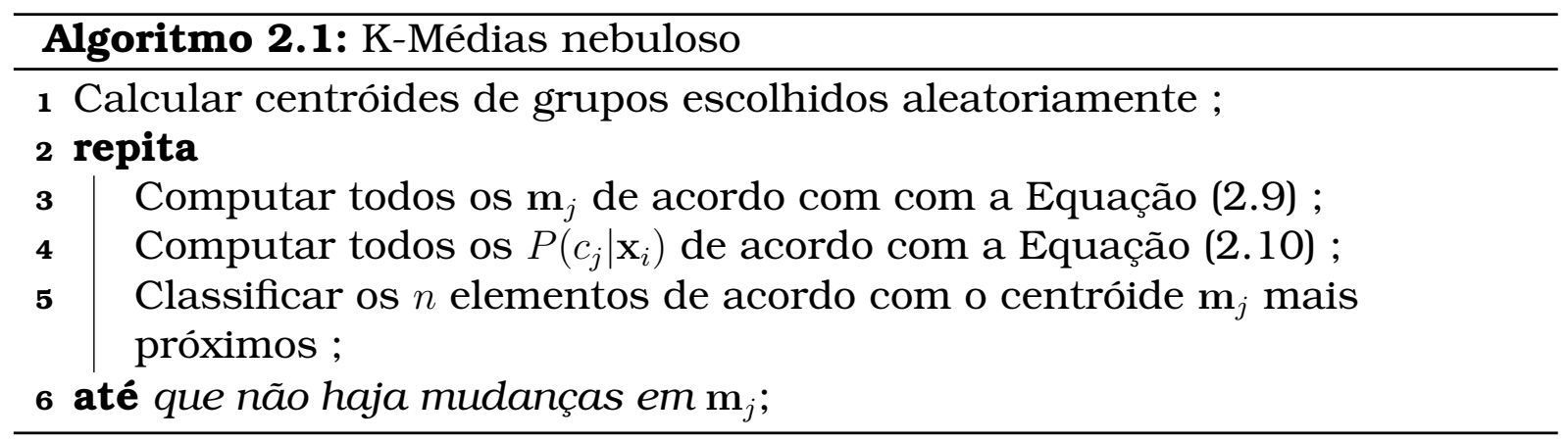

mos locais, eventualmente ele também pode convergir para um mínimo local (Jain et al., 1999).

\subsubsection{Métodos Hierárquicos}

Os métodos hierárquicos tem como alvo produzir uma árvore hierárquica (dendograma) através de sucessivas junções (métodos aglomerativos) ou sucessivas separações (métodos divisivos) de grupos (Duda et al., 2000; Kaufman \& Rousseeuw, 1990; Jain et al., 1999). A abordagem aglomerativa começa com $n$ grupos com um único elemento em cada, a seqüência de partições é formada com os grupos sendo aglomerados a cada nível. A abordagem divisiva começa com um grupo com todos os elementos e forma a seqüência de partições dividindo os grupos a cada iteração.

Um dendograma consiste de camadas de nós onde cada nó representa um grupo. A Figura 2.2 ilustra um dendograma. As linhas conectam os nós, representando grupos aninhados. O corte de um dendograma na horizontal (representado pela linha tracejada) significa uma partição ou agrupamento em um número específico de grupos.

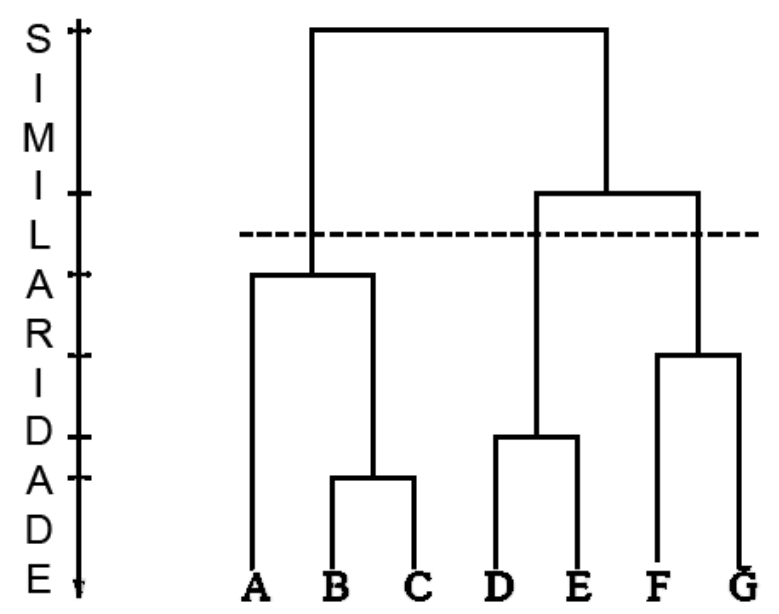

Figura 2.2: Exemplo de dendograma (Jain et al., 1999).

Alguns exemplos de métodos hierárquicos são: Single-Link, Complete-Link, 
Average-Link, Centróides, DIANA ${ }^{6}$, e o método de Ward (Kaufman \& Rousseeuw, 1990). Destes, os algoritmos Single-Link e Complete-Link são os mais populares (Jain et al., 1999). Eles se diferem na maneira pela qual a similaridade entre dois grupos é atualizada (Yip et al., 2006). No método Single-Link, a distância entre dois grupos é o mínimo das distâncias entre todos os pares de padrões tirados dos dois grupos (um padrão para o primeiro grupo e o outro para o segundo). No método Complete-Link, a distância entre dois grupos é o máximo de todas as distâncias entre pares de padrões nos dois grupos. Em ambos os casos, dois grupos são mesclados para formar um grupo maior baseado em um critério de mínima distância.

Algoritmos hierárquicos costumam ser mais versáteis que os baseados em otimização. Por exemplo, o método Single-Link pode encontrar grupos bastante separados, grupos em cadeia, grupos concêntricos e outras formas de grupos que um algoritmo como o K-médias não consegue. Por outro lado, a complexidade e o tempo de execução dos algoritmos hierárquicos é tipicamente maior que a dos algoritmos baseados em otimização (Jain et al., 1999).

Um algoritmo hierárquico aglomerativo pode ser implementado como mostrado no Algoritmo 2.2. A saída desse algoritmo é uma hierarquia aninhada de grafos que pode ser cortada em qualquer nível formando uma partição (grupo) apenas com componentes conectados no grafo correspondente. A distância entre dois grupos é definida de acordo com o método selecionado. A seguir são descritos os principais deles.

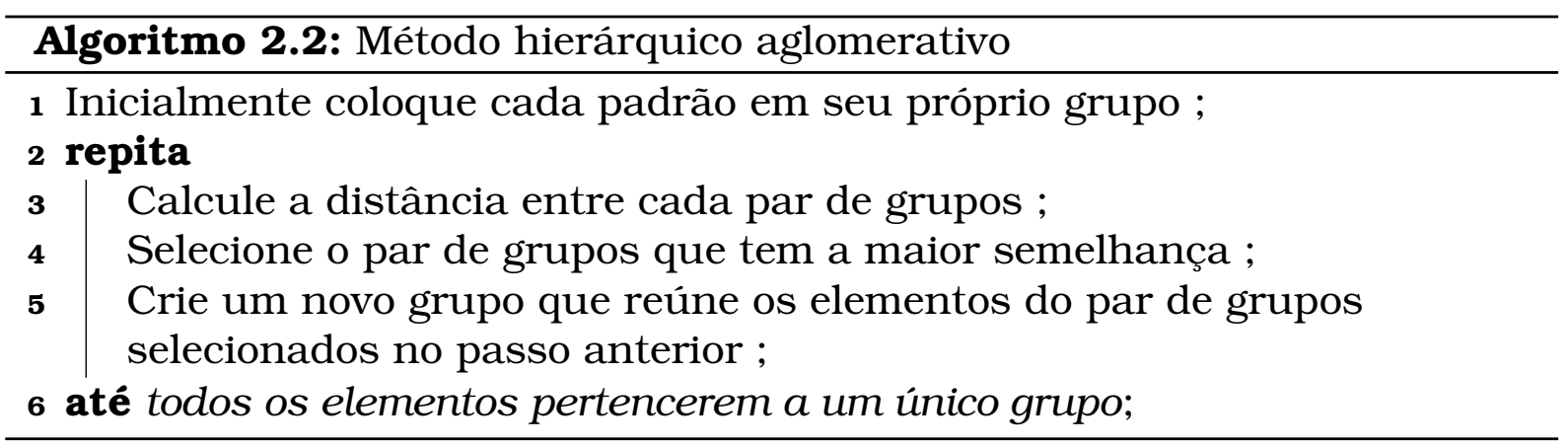

Método Single-Link

O método Single-Link (Sneath \& Sokal, 1973) também é conhecido como critério do vizinho mais próximo. A medida de similaridade entre dois grupos é a menor distância entre seus elementos, e pode ser definida por:

$$
D\left(S_{x}, S_{y}\right)=\min \left(d\left(\mathbf{x}_{i}, \mathbf{x}_{j}\right)\right)
$$

onde $\mathbf{x}_{i} \in S_{x}, \mathbf{x}_{j} \in S_{y}$ e $d\left(\mathbf{x}_{i}, \mathbf{y}_{j}\right)$ é a medida de similaridade.

6 sigla de DIvisive ANAlysis 
Este algoritmo apresenta um problema, conhecido como efeito de cadeia, que acontece quando existem elementos entre grupos distintos formando uma ponte, forçando uma conexão indevida entre esses dois grupos.

\section{Método Complete-Link}

No método Complete-Link (King, 1967) a medida de similaridade entre dois grupos é a maior distância entre seus elementos, e pode ser definida por:

$$
D\left(S_{x}, S_{y}\right)=\max \left(d\left(\mathbf{x}_{i}, \mathbf{x}_{j}\right)\right)
$$

onde $\mathbf{x}_{i} \in S_{x}, \mathbf{x}_{j} \in S_{y}$ e $d\left(\mathbf{x}_{i}, \mathbf{y}_{j}\right)$ é a medida de similaridade.

Por utilizar a maior distância entre os grupos, este algoritmo tem uma maior propensão a encontrar grupos mais curtos. Ele costuma produzir melhores resultados que o Single-Link na maioria das aplicações (Jain \& Dubes, 1988).

\section{Método Average-Link}

As medidas utilizadas por Single-Link e Complete-Link, mínima e máxima respectivamente, representam os extremos em termos de distância entre grupos e dessa forma são bastante sensiveis a ruídos. O uso de uma abordagem intermediária entre ambos é uma maneira de amenizar este problema (Duda et al., 2000).

No algoritmo Average-Link a medida de distância entre dois grupos é definida pela média das distâncias entre todos os pares de exemplos em cada grupo (cada par formado por um elemento de cada grupo):

$$
D\left(S_{x}, S_{y}\right)=\frac{1}{\left|S_{x}\right| \times\left|S_{y}\right|} \sum\left(d\left(\mathbf{x}_{i}, \mathbf{x}_{j}\right)\right),
$$

onde $\mathbf{x}_{i} \in S_{x}, \mathbf{x}_{j} \in S_{y}$ e $d\left(\mathbf{x}_{i}, \mathbf{y}_{j}\right)$ é a medida de similaridade.

\subsubsection{Métodos Baseados em Densidade}

Os métodos baseados em densidade são baseados na idéia de que grupos são regiões de alta densidade separadas por regiōes de baixa densidade (Yip et al., 2006). Uma abordagem comum é encontrar os picos de densidade e então expandir as fronteiras do grupo para fora, até que elas se encontrem em algum lugar, que se supõe serem as regiões de vale (mínimos locais) dos contornos de densidade. O algoritmo CLIGUE ${ }^{7}$ (Agrawal et al., 1998) utiliza esta

7 sigla de CLustering In QUEst 
metodologia, uma de suas principais vantagens é encontrar grupos em espaços de alta dimensionalidade, sem assumir nenhum tipo de distribuição dos elementos e sendo insensivel à ordem em que os elementos são apresentados.

Outra abordagem é começar das regiões de vale e gradualmente conectar os pontos das regiões de baixa densidade aos grupos definidos pelos picos de densidade. Esta estratégia tem sido usada por algoritmos como o Valley Seeking (Fukunaga, 1990) e o DENCLUE ${ }^{8}$ (Hinneburg \& Keim, 1998). No Valley Seeking a idéia é conectar cada ponto a outro ponto próximo tendo uma alta densidade. Desta forma, obtemos uma floresta onde cada árvore é um grupo. Presume-se que o nó raiz de cada árvore está localizado em um pico de densidade, enquanto os nós folhas estejam em regiões de vale. No DENCLUE a idéia é modelar analiticamente a densidade de todos os pontos como a soma de funções de influência dos elementos. Assim os grupos podem ser identificados determinando atratores de densidade.

Uma terceira abordagem é utilizada pelo DBSCAN $^{9}$ (Ester et al., 1996), e consiste em computar a alcançabilidade de um ponto a partir de alguma semente, e então conectar os pontos alcançáveis com suas respectivas sementes. Uma variante do DBSCAN é o OPTICS ${ }^{10}$ (Ankerst et al., 1999), o qual ordena os dados de forma que grupos em diferentes parâmetros de densidade são obtidos eficientemente.

Os métodos baseados em densidade têm bom desempenho quando os grupos são bem separados, onde os picos e regiões de vale são bem definidos e fáceis de detectar. Quando os grupos estão próximos uns dos outros, o que freqüentemente é o caso em situações reais, ambos o centro do grupo e as fronteiras se tornam vagos e difíceis de determinar (Yip et al., 2006). Para melhor compreensão do funcionamento dos métodos dessa categoria, a seguir será apresentado o algoritmo DBSCAN.

O algoritmo DBSCAN (Ester et al., 1996) tem como objetivo encontrar um número arbitrário de grupos de forma automática para um dado limiar de densidade. Este limiar é representado pelo raio de vizinhança $(\epsilon)$, que é determinado pela função de distância utilizada e pelo número mínimo de pontos (MinPts) que uma determinada $\epsilon$-vizinhança precisa ter para ser considerada densa. O algoritmo classifica os pontos do agrupamento como pontos centrais, que possuem MinPts ou mais vizinhos similares; e pontos de borda, que possuem pelo menos um vizinho classificado como ponto central. Dados dois pontos quaisquer, x e y, a relação entre eles pode ser:

- Um elemento $\mathrm{x}$ é diretamente conectado a um elemento $\mathrm{y}$ se $\mathrm{x}$ faz parte da $\epsilon$-vizinhança de $\mathbf{y}(N \epsilon(\mathbf{y}))$, ou seja $\operatorname{dist}(\mathbf{x}, \mathbf{y}) \leq \epsilon$.

\footnotetext{
8 sigla de DENsity-based CLUstEring

9 sigla de Density Based Spatial Clustering of Applications with Noise

${ }^{10}$ sigla de Ordering Points To Identify the Clustering Structure
} 
- Um elemento x é diretamente alcançável por densidade a partir de um ponto y se $\mathbf{x} \in(N \epsilon(\mathbf{y}))$ e $(N \epsilon(\mathbf{y})) \geq$ MinPts.

- Um elemento x é alcançável por densidade a partir de um ponto y se existe uma cadeia de elementos $\mathbf{z}_{1}, \mathbf{z}_{2}, \ldots, \mathbf{z}_{n}$, com $\mathbf{z}_{1}=\mathbf{y}, \mathbf{z}_{n}=\mathbf{x}$, tal que $\mathbf{z}_{i+1}$ é diretamente alcançável por densidade a partir de $\mathbf{z}$.

- Um elemento x é conectado por densidade a um elemento y se existe um ponto $\mathrm{z}$ tal que ambos os pontos $\mathrm{x}$ e $\mathrm{y}$ são alcançáveis por densidade a partir de $\mathbf{z}_{i}$.

$\mathrm{O}$ algoritmo inicia o processo de agrupamento selecionando um elemento $\mathrm{x}$ qualquer e recupera todos os pontos alcançáveis por densidade a partir de $\mathbf{x}$. Se $\mathrm{x}$ é um ponto central inicia-se a construção de um grupo, adicionando todos os pontos alcançáveis em uma lista para processamento da mesma forma que foi feito com x. Se x é um ponto de borda, nenhum ponto será alcançável a partir de x e o algoritmo passa para o próximo elemento da base. Este procedimento é repetido até que todos os elementos da base sejam processados.

A forma da vizinhança é definida pela distância utilizada, por exemplo: se for usada a distância Manhattan em um espaço 2D, a forma da vizinhança será retangular. $\mathrm{O}$ algoritmo funciona com qualquer medida de distância, porém esta deverá ser definida a priori de acordo com o problema a ser tratado. O algoritmo DBSCAN funciona bem quando os agrupamentos possuem formatos e tamanhos arbitrários. Além disso, este algoritmo é regular, e resiste muito bem a ruídos e exceções. Por outro lado, ele não funciona bem se os agrupamentos possuem densidade variada, ou quando o problema possui alta dimensionalidade, pois isto faz com que seja difícil determinar densidades. Outra dificuldade consiste em encontrar os valores ideais para MinPts e $\epsilon$ para determinado problema.

\subsubsection{Modelo Dinâmico de Agrupamento de Dados}

Zhao et al. (2005, 2004) propuseram um modelo dinâmico para agrupamento de dados, baseado na teoria da Correlação Oscilatória Caótica (Zhao et al., 2000; Zhao \& Macau, 2001). O esquema geral pode ser descrito da seguinte maneira: Cada elemento de dados é representado por um mapa caótico. Quando uma base de dados é fornecida para a rede, os elementos se auto-organizam de acordo com um critério de similaridade pré-definido, de modo que elementos que pertencem ao mesmo grupo serão mantidos juntos, enquanto que elementos de grupos diferentes serão eliminados. Conseqüentemente, todos os elementos pertencentes ao mesmo grupo serão sincronizados, cada grupo será representado por uma trajetória caótica sincronizada. Quaisquer números de tais trajetórias caóticas já se distinguem uma das outras 
seguindo a alta sensibilidade às condições iniciais e propriedades densas do caos.

O modelo proposto pode ser utilizado para agrupamento de pixels, conforme mostrado por Zhao et al. (2004), onde o modelo é um vetor unidimensional composto de $N$ mapas caóticos, cada um correspondendo a um pixel em uma dada imagem. Por exemplo, a imagem de entrada bidimensional é primeiramente organizada em um vetor unidimensional. Mais especificamente, o modelo é governado pelas seguintes equações:

$$
\begin{aligned}
& x_{i}(t+1)=(1-\varepsilon) f\left(x_{i}(t)\right)+\frac{\varepsilon}{M_{i}(t)} \sum_{j=1}^{N} z_{i} j(t) f\left(x_{j}(t)\right), \\
& z_{i j}(t+1)=\beta z_{i j}(t)+(1-\beta) H\left(e^{-\alpha\left\|\mathbf{c}_{j}(t)-\mathbf{c}_{i}(t)\right\|}-\theta\right), \\
& c_{i k}(t+1)=\left\{\begin{array}{cl}
0, & \text { se } c_{i k}(t)+\eta F_{i k}(t) \leq 0, \\
c+i k(t)+\eta F_{i k}(t), & \text { se } 0<c_{i k}(t)+\eta F_{i k}(t)<1, \\
1, & \text { se } c_{i k}(t)+\eta F_{i k}(t) \geq 1,
\end{array}\right. \\
& \mathbf{F}_{i}(t)=\frac{\sum_{j \in \Delta_{i}(t)} \frac{\mathbf{c}_{j}(t)-\mathbf{c}_{i}(t)}{\left\|\mathbf{c}_{j}(t)-\mathbf{c}_{i}(t)\right\|} e^{-\alpha\left\|\mathbf{c}_{j}(t)-\mathbf{c}_{i}(t)\right\|}}{M_{i}(t)}, \\
& j \in \Delta_{i}(t) \operatorname{se} H\left(e^{-\alpha\left\|c_{j}(t)-c_{i}(t)\right\|}-\theta\right)=1, \\
& H(v)= \begin{cases}1, & \text { se } v \geq 0 \\
0, & \text { se } v<0\end{cases}
\end{aligned}
$$

onde $i, j$ são os índices dos elementos $i, j=1,2, \ldots, N . f(x)=A x(1-x)$ define um mapa logístico com $A$ sendo o parâmetro de bifurcação. $\mathbf{c}_{i}(t)=$ $\left(c_{i 1}(t), c_{i 2}(t), \ldots, c_{i K}(t)\right)$ representa o vetor de atributos do $i$ ésimo pixel na iteração $t$, com $K$ sendo o número de atributos. Especificamente, para uma imagem em tons de cinza, $K=1$ e $c_{i}$ é um valor escalar representando a intensidade do $i$ ésimo pixel; para uma imagem colorida $K=3$ e $\mathbf{c}_{i}(t)$ é um vetor representando as três componentes de cores do $i$ ésimo pixel. $\mathbf{c}_{i}(0)$ é o valor original do iésimo pixel. $H(v)$ é uma função Heaviside. O termo $e^{-\alpha\left\|\mathbf{c}_{j}(t)-\mathbf{c}_{i}(t)\right\|}$ é uma função Gaussiana, a qual resulta em um valor entre 0 e 1, e tem sua rigidez controlada pelo parâmetro $\alpha$. $\|\bullet\|$ é a norma Euclideana. O parâmetro $\theta$ é um limiar, o qual desloca a função Heaviside. Conforme $\theta$ aumenta, a possibilidade da função Heaviside retornar 1 é reduzida. O parâmetro $\beta$ controla a taxa de integração, com $0 \leq \beta \leq 1$. Um valor baixo para $\beta$ resulta em um rápido ajuste para o valor retornado pela função Heaviside; um $\beta$ alto leva a um ajuste suave. $\Delta_{i}(t)$ é um conjunto de pixels locais em torno do pixel $i$. $\mathbf{F}_{i}(t)=\left(F_{i 1}(t), F_{i 2}(t), \ldots, F_{i K}(t)\right)$ representa a força total imposta sobre o pixel $i$ vindo de todos os pixels $\Delta_{i}(t)$ na iteração $t$. $M_{i}(t)$ é o número de pixels em $\Delta_{i}(t)$. O vetor $\frac{\mathbf{c}_{j}(t)-\mathbf{c}_{i}(t)}{\left\|\mathbf{c}_{j}(t)-\mathbf{c}_{i}(t)\right\|}$ define a direção da força imposta ao pixel $i$ pelo pixel 
$j$. Finalmente $\eta$ controla a taxa de ajuste de $\mathbf{c}_{i}(t)$.

O processo de agrupamento do pixel pode ser descrito da seguinte maneira: Inicialmente, a força de agrupamento $\varepsilon$ é ajustada para um valor maior que 0,5, tal que todos os elementos agrupados estejam sincronizados. Em seguida, um vetor de imagem $\mathbf{c}_{i}(0), i=1,2, \ldots, N$, é colocado como entrada do sistema (Zhao et al., 2004). Conforme o sistema executa, a variável $z_{i j}(t)$ se aproxima do valor de retorno da função Heaviside na Equação (2.19). A função Heaviside retorna o valor 1 se a similaridade entre $\mathbf{c}_{i}(t)$ e $\mathbf{c}_{j}(t)$ está além de um limiar, o qual pode ser ajustado pelos parâmetros $\alpha$ e $\theta$; caso contrário, ele retorna o valor 0 . Na verdade, o termo $H\left(e^{-\alpha\left\|c_{j}(t)-c_{i}(t)\right\|}-\theta\right)$ define uma região $\Delta_{i}(t)$ de pixels, dos quais todos os pixels $j$ são considerados similares ao pixel $i$. Conseqüentemente, o agrupamento entre os elementos $i$ e $j$ é mantido quando $z_{i j}(t)$ se aproxima de 1 , enquanto a conexão é removida quando $z_{i j}(t)$ se aproxima de 0 . Conforme o sistema evolui, os elementos com características similares irão se juntar e, então formar uma trajetória caótica sincronizada devido a poderosa força de agrupamento. Ao mesmo tempo, elementos com características muito diferentes serão distribuídos em diferentes grupos sincronizados, pois não há conexão entre eles. Devido a todas essas trajetórias serem geradas localmente (dentro de um grupo de elementos agrupados), elas terão atividades temporais distintas das demais. Isto ocorre porque quaisquer duas trajetórias caóticas se afastam exponencialmente, mesmo que elas tenham apenas uma pequena diferença em um instante qualquer. Desta forma, o modelo tem uma capacidade de agrupamento ilimitada.

Deve ser observado que, freqüentemente, alguns pixels são agrupados em mais de um grupo. Este problema de ambigüidade pode ser resolvido por um processo adaptativo definido nas Equações (2.17), (2.18) e (2.19). De forma geral, elementos no centro do grupo de dados se moverão lentamente, pois a maioria das forças impostas a eles são canceladas, enquanto que elementos fora do centro irão se mover rapidamente em direção aos seus respectivos centros. Elementos ambíguos (que recebem força de mais de um grupo) irão deixar os outros grupos e se fixar em apenas um grupo, o qual tiver atração mais forte por ele. Portanto, sucessivas iterações irão diminuir a distância entre pixels similares (diminuir a distância intra-classe) e aumentar a diferença entre pixels muito diferentes (aumentar a distância inter-classe). Se a taxa de movimento $\eta$ for suficientemente pequena $(\eta \rightarrow 0)$, cada grupo de $\mathbf{c}_{i}(t)$ irá se aproximar e se confinar em uma pequena região.

\subsubsection{Métodos Baseados em Grafos}

Nos métodos baseados em grafos, os elementos são representados por vértices e a similaridade entre pares é representada pelas conexões (ou pelo peso 
das conexões no caso de conexões com peso). Após a construção do grafo, que contém toda a informação necessária para o processo de agrupamento, é possivel obter os grupos utilizando métodos de particionamento de grafos.

Existem duas abordagens principais para identificar um bom grupo: computar alguns valores para os vértices, e classificá-los em grupos baseado nos valores obtidos; ou computar uma medida de aptidão sobre o conjunto de possíveis grupos e então escolher, entre o conjunto de grupos candidatos, aqueles que otimizam a medida usada (Schaeffer, 2007).

Muitos algoritmos são baseados na similaridade entre vértices. Podemos estabelecer alguma medida de similaridade entre todos os pares de vértices e usar esses valores como base para o processo de agrupamento. Quanto mais similares forem os vértices, maior será a necessidade de classificá-los no mesmo grupo. Calcular tais similaridades não é simples, muitas vezes é mais complexo que classificar os vértices uma vez que as similaridades já sejam conhecidas. Se uma medida de similaridade for definida para os vértices, o grupo deve conter vértices com valores próximos. Se em vez de similaridade for usada alguma medida de distância, a fronteira do cluster deverá estar localizada em uma área em que incluir mais vértices externos aumentaria drasticamente a distância intragrupo. Portanto é desejável alocar no mesmo grupo os vértices que têm menores distâncias entre eles (Schaeffer, 2007).

Grupos em grafos também podem ser definidos através de sua conectividade, calculando o número de caminhos que existem entre um par de vértices. Nesse caso dois vértices devem ser altamente conectados para pertencerem ao mesmo grupo. Se dois vértices não estão ligados diretamente um ao outro é possivel calcular uma medida de distância entre eles, dessa forma também é possivel estabelecer um limiar de distância e tratar dois vértices como similares se a distância entre eles estiver abaixo desse limiar.

Também são bastante utilizadas medidas de aptidão de grupo, que são funções que medem a qualidade de um dado grupo ou de uma dada classificação. Tais funções podem ser utilizadas para: identificação de grupos (através da otimização da medida de aptidão), escolher entre classificações alternativas (comparando os valores de uma ou mais medidas de aptidão), e comparar diferentes algoritmos de agrupamento (estudando os valores de aptidão das classificações fornecidas por cada algoritmo).

No uso dessas medidas para agrupamento, a idéia é tentar identificar diretamente os grupos que contém alguma propriedade desejável. Diversos critérios incluem variáveis de densidade, ou seja, medidas que levam em consideração a quantidade de arestas presentes no sub-grafo dos vértices contidos no grupo encontrado. Muitos algoritmos utilizam um limiar para a medida de densidade, considerando bons grupos aqueles que obtiverem uma medida de 
densidade acima desse limiar.

Além das medidas de densidade diretas também podem ser usadas medidas de conectividade de um sub-grafo com o restante do grafo, ou seja, medidas que calculam a "independência" do sub-grafo. Assim é possivel encontrar o conjunto de vértices que minimizam essa independência (com um alto custo computacional) e avaliar sub-grafos conhecidos.

Nas subseções a seguir são mostrados alguns dos principais métodos de agrupamento baseados em grafos.

\section{Cortes}

Um corte em um grafo é definido como a partição do conjunto de vértices $V$ de um grafo $(G, V)$ em dois conjuntos não vazios $S$ e $V \backslash S$. Qualquer subconjunto de $V$ pode ser um corte, identificado por $S$. Normalmente se define $S$ como o menor conjunto, portanto $|S| \leq\left\lfloor\frac{n}{2}\right\rfloor$, onde $n$ é o número de vértices. O tamanho de um corte é dado pelo número de arestas que conectam vértices de $S$ a vértices de $V \backslash S$ :

$$
c(S, V \backslash S)=|\{\{v, u\} \in E \mid u \in S, v \in V \backslash S\}| .
$$

Assim o corte mínimo para um determinado grafo pode ser definido eficientemente com algoritmos de máximo fluxo (Elias et al., 1956). Um corte bem escolhido deve separar dois ou mais grupos, em vez de quebrar em dois subconjuntos os vértices de um único grupo. O problema dessa abordagem é que a ordem dos sub-grafos deve ser considerada, pois a remoção de vértices únicos resultaria em grupos de um único elemento, mas ao adicionar restrições a ordem dos sub-grafos resultantes, também é aumentada a complexidade computacional do problema. O problema de dividir um grafo de $2 n$ vértices em dois sub-grafos de $n$ vértices cujo tamanho de corte é minimizado é chamado de mínima bisseção e é um problema NP-difícil (Garey et al., 1974).

Outra complicação dessa abordagem, que também ocorre com a maioria dos métodos hierárquicos, é que é preciso saber qual o momento certo de parar de dividir os sub-grafos, o que requer algum conhecimento a priori de como os grupos devem ser. Hartuv \& Shamir (2000) propõem um critério de parada baseado em densidade, onde a idéia é que vértices do mesmo grupo tenham alta conectividade, enquanto vértices de grupos distintos tenham baixa conectividade. A cada iteração são removidos os vértices dos cortes mínimos atuais e cada subconjunto é avaliado com relação a sua conectividade, se esta for alta o subconjunto não será mais dividido.

Outro critério popular para particionamento é o de baixa condutância (Carrasco et al., 2003; Shi \& Malik, 2000), que em geral é superior ao corte mínimo simples quando usado em agrupamento de grafos. (Flake et al., 2004; Kannan 
et al., 2000). A condutância é definida para qualquer subconjunto $S \in V$ de um grafo $G=(V, E)$ da seguinte forma:

$$
\Phi(S)=\frac{c(S, V \backslash S)}{\min \{\operatorname{deg}(S), \operatorname{deg}(V \backslash S)\}} .
$$

Uma das vantagens de usar a condutância é que esta é uma medida que leva em consideração a ordem dos conjuntos sendo separados, o que em geral leva a separações mais significativas. A condutância e outras medidas similares tendem a achar valores ótimos na fronteira dos grupos, visto que cada grupo deve ser internamente denso e esparsamente conectado com o restante do grafo. Porém ainda é necessário tomar cuidado com o critério de parada para que um único grupo não seja dividido em dois subconjuntos. Normalmente a condutância mínima de um grupo com apenas um grafo é muito maior que a de um grupo com vários grafos, porém a magnitude da diferença depende da estrutura do grafo. Não há um limiar ou porcentagem do incremento relativo que sirva para parar o agrupamento no momento ideal para todos os grafos.

\section{Fluxo Máximo}

Existe uma conexão entre problemas de mínimo corte e problemas de máximo fluxo, como pode ser visto em Cormen et al. (2001), portanto é natural que existam algoritmos de agrupamento baseados em cálculos de fluxos (Brandes et al., 2003; Carrasco et al., 2003; Flake et al., 2002). O fluxo máximo pode ser computado eficientemente por algoritmos como o de Goldberg \& Tarjan (1986), tais algoritmos podem ser implementados como sub-rotinas de um algoritmo de agrupamento.

Flake et al. (2004) identifica grupos inserindo um coletor artificial e calculando os fluxos para este coletor. Os cortes mínimos que correspondem aos fluxos máximos são usados para construir uma árvore de cortes mínimos, que por sua vez é usada para definir qual é o grupo de um dado vértice $v$ usando sua relação com o vértice coletor. O algoritmo foi projetado para grafos não direcionados e com peso, e o peso associado as arestas do vértice coletor é o parâmetro do método, o que requer alguma intuição para ser adequadamente selecionado.

\section{Betweenness}

Este método foi proposto por Newman \& Girvan (2004) para descobrir comunidades em redes formadas por grafos sem peso. Eles adicionam pesos às arestas utilizando uma medida chamada betweenness (Freeman, 1977), que é baseada na estrutura do grafo e favorece arestas que estão entre comuni- 
dades, enquanto desfavorece aquelas que estão dentro das comunidades. Em geral existem poucas arestas interligando comunidades quando comparado ao número de arestas dentro de uma comunidade, dessa forma qualquer caminho entre vértices de comunidades diferentes terão de passar por alguma dessas poucas arestas entre diferentes comunidades. Dada uma quantidade apropriada de caminhos, é possível contar quantos deles passam por cada aresta do grafo, e este número tende a ser maior nas arestas que conectam duas comunidades, e assim é possivel identificá-las.

Essa idéia pode ser implementada de várias formas. Newman \& Girvan (2004) apresentam três delas, mas afirmam que muitas outras poderiam ser utilizadas. A mais simples é baseada nos menores caminhos entre dois vértices: encontra-se o menor caminho entre todos os pares de vértices do grafo e conta-se quantos passam por cada aresta. Eventualmente podem haver dois ou mais menores caminhos de igual tamanho, assim cada um deve ser incrementado proporcionalmente, ou seja, se houverem $k$ menores caminhos conectando $v$ e $u$, cada um deles terá um peso $\frac{1}{k}$ no cálculo das arestas.

Uma segunda forma de calcular betweenness é colocar um sinal viajando aleatoriamente nos caminhos do grafo, saindo de um vértice de origem até chegar a um vértice de destino. Assim é possivel estimar a quantidade de vezes que o sinal passa por uma determinada aresta ao fazer o caminho aleatório entre dois vértices. Esse "passeio aleatório" é conhecido como random-walk.

Newman \& Girvan (2004) apresentam ainda uma terceira forma de calcular betweenness, motivada por idéias da teoria elementar de circuitos. O circuito é criado colocando-se um resistor em cada aresta da rede, e uma corrente com fonte e coletor colocados em um determinado par de vértices. O fluxo de corrente resultante percorrerá a rede da fonte ao coletor por muitos caminhos, sendo que aqueles com menor resistência carregarão a maior fração da corrente. Assim a medida de betweenness de uma aresta é definida como sendo o valor absoluto da soma da corrente que passa pela aresta com todos os pares de fonte/coletor.

É importante ressaltar que para funcionar corretamente, este método precisa recalcular todas as medidas a cada aresta removida, pois a cada aresta removida os valores de betweenness do passo anterior não refletem mais a atual configuração da rede. Por exemplo, se duas comunidades estão unidas por duas arestas, mas por algum motivo a maioria dos caminhos passam por apenas uma delas, então uma aresta terá um valor de betweenness alto e a outra não. Ao eliminar a primeira aresta, se não recalcularmos as medidas, a segunda aresta não será removida tão cedo, e assim a óbvia divisão entre as duas comunidades não será detectada pelo algoritmo.

O método de betweenness pode ser definido como mostrado no Algoritmo 


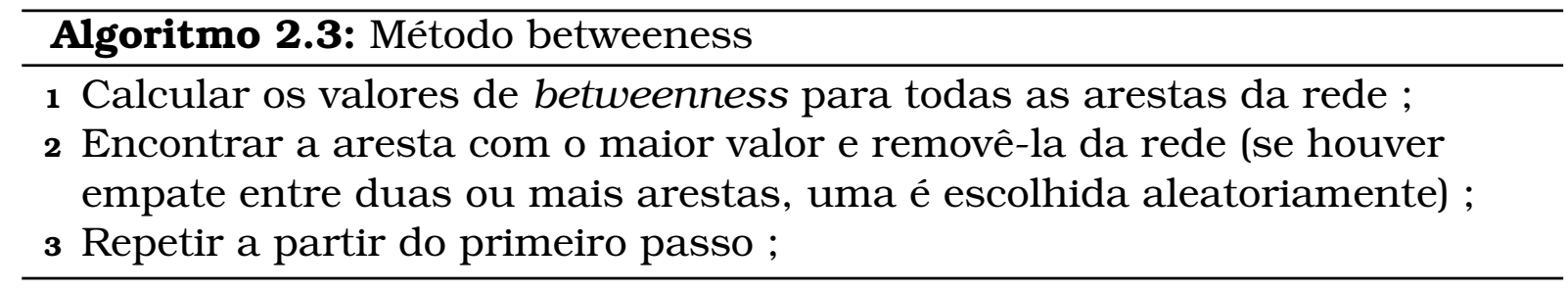

Outro método hierárquico semelhante ao betweenness foi proposto por Fortunato et al. (2004), porém em vez de valores de betweenness eles utilizam informações de centralidade que são definidas para cada aresta como o declíneo na eficiência média do grafo após a remoção desta mesma aresta. Latora \& Marchiori (2001) definem a eficiência de um par de vértices $v$ e $u$ como o inverso da distância entre eles no grafo: $\frac{1}{\operatorname{dist}(v, u)}$, e a eficiência média é a média da medida de eficiência de todos os pares distintos de vértices.

Assim como nos métodos baseados em cortes, os algoritmos dessa categoria também precisam saber quando parar de particionar. Newman \& Girvan (2004) propõem uma medida de qualidade chamada modularidade, que é definida para todo o grafo a cada iteração. É definida uma matriz e simétrica de tamanho $k \times k$, onde $k$ é a quantidade de comunidades separadas na atual divisão. $\mathrm{O}$ elemento $e_{i, j}$ é a fração de todas as arestas na rede que ligam vértices na comunidade $i$ a vértices na comunidade $j$ (aqui são consideradas todas as arestas da rede original, inclusive as arestas removidas durante a execução do algoritmo). A medida de modularidade é definida por:

$$
Q=\sum_{i}\left(e_{i, j}-a_{i}^{2}\right)=\operatorname{Tr} \quad \mathbf{e}-\left\|\mathbf{e}^{2}\right\|
$$

onde $\|\mathbf{x}\|$ indica a soma dos elementos da matriz x, e $a_{i}=\sum_{j} e_{i, j}$ que representa a fração de arestas que se conectam aos vértices da comunidade $i$. $Q$ mede a fração de arestas na rede que conectam vértices do mesmo tipo (arestas dentro de uma comunidade) menos o valor esperado da mesma divisão, mas com conexões aleatórias entre os vértices. Se as conexões não forem melhores que o aleatório, $Q=0$. Com valores próximos ao máximo $Q=1$ temos uma rede com uma forte estrutura de comunidade. Valores típicos se encontram entre 0,3 e 0,7 (Newman \& Girvan, 2004). Calculando $Q$, a cada divisão da rede, podemos encontrar os picos locais que correspondem às divisões mais satisfatórias. 


\section{Caminhadas Aleatórias}

$\mathrm{Na}$ categoria de Caminhadas Aleatórias ${ }^{11}$ se encontram os métodos baseados nos conceitos de movimento browniano em uma rede. Zhou (2003b) sugere que se uma partícula passeia em uma rede por um determinado período, ela teria sua própria perspectiva do panorama da rede. A distância entre nós medida por essa partícula pode ser usada para construir a estrutura da comunidade e identificar o nó central de cada comunidade. Dois vértices no mesmo grupo devem ser rapidamente alcançáveis de um ao outro. Além disso, quando a partícula visita um vértice de um grupo é provável que ela visite vários outros vértices desse mesmo grupo antes de deixá-lo (van Dongen, 2000), como ilustra o exemplo da Figura 2.3. Zhou (2003a) define uma quantidade chamada índice de dissimilaridade entre vizinhos mais próximos, que indica a probabilidade de dois vértices estarem na mesma comunidade. Um algoritmo hierárquico faz uso desses índices para decompor a rede em uma seqüência hierárquica de grupos.

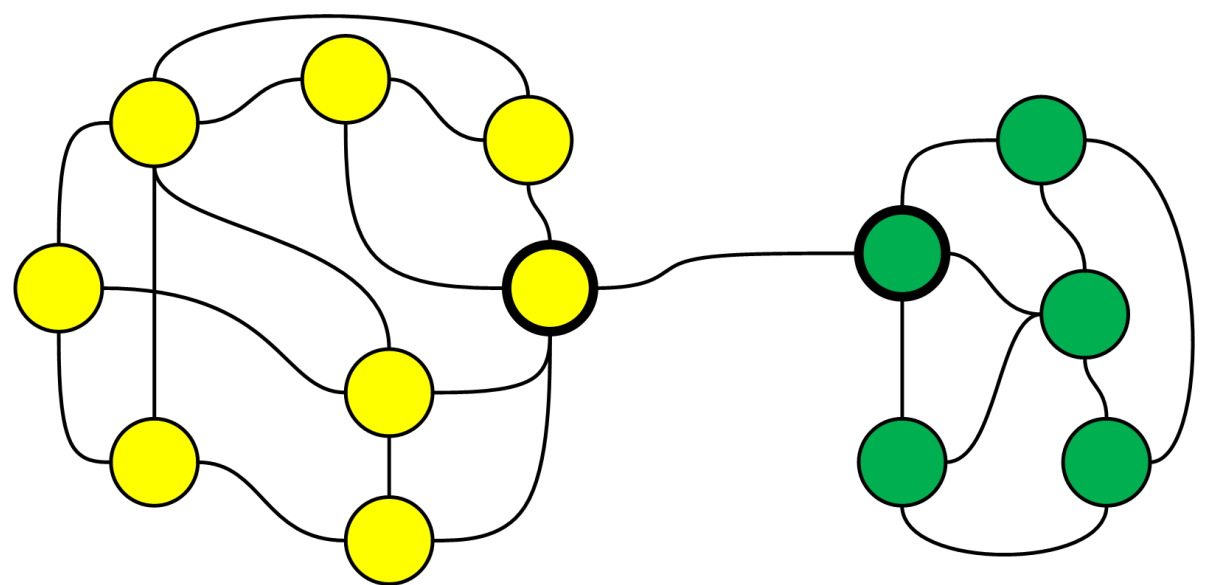

Figura 2.3: Probabilidades de Movimento em Caminhada Aleatória. Um grafo com dois grupos (verde e amarelo). Se uma partícula está atualmente no vértice amarelo com borda mais grossa, ele irá permanecer no grupo amarelo com probabilidade $\frac{4}{5}$ e mudar para o grupo verde com probabilidade $\frac{1}{5}$. Estando em qualquer outro vértice amarelo, a partícula necessariamente continuará no grupo amarelo. Da mesma forma, se a partícula estiver no vértice verde com borda mais grossa, a probabilidade de permanecer no grupo verde será $\frac{3}{4}$ e a probabilidade de mudar para o grupo amarelo será $\frac{1}{4}$.

Zhou (2003a) considera que um vértice deve ter maior interação com outros vértices de sua própria comunidade do que com vértices de qualquer outra comunidade do grafo. Considerando uma rede conectada de $N$ vértices e $M$ arestas, com as conexões representadas pela matriz de adjacência $A$, a distância $d_{i j}$ do vértice $i$ ao vértice $j$ é definida como a média do número de passos necessários para que a partícula Browniana se locomova do vértice $i$

${ }^{11}$ do inglês: Random Walks 
para o vértice $j$. Em cada vértice (por exemplo, $k$ ), a partícula Browniana irá saltar no próximo passo para um vizinho mais próximo (por exemplo, $l$ ) com uma probabilidade dada por:

$$
P_{k l}=\frac{A_{k l}}{\sum_{m=1}^{N} A_{k m}} .
$$

A matriz de distância portanto é assimétrica (em geral $d_{i j} \neq d_{j i}$ ). Tomando qualquer vértice $i$ como origem da rede, então o conjunto $\left\{d_{i, 1}, \ldots, d_{i, i-1}, d_{i, i+1}, \ldots, d_{i, N}\right\}$ mede a distância de todos os outros vértices com relação a origem, ou seja, é uma visão de toda a rede do ponto de vista de $i$. Dado dois vértices $i$ e $j$ que são vizinhos mais próximos $\left(A_{i, j}\right)$, a diferença entre seus pontos de vista pode ser medida quantitativamente através do índice de dissimilaridade, calculado por:

$$
\Lambda(i, j)=\frac{\sqrt{\sum_{k \neq i, j}^{N}\left[d_{i k}-d_{j k}\right]^{2}}}{N-2} .
$$

Se dois vértices $i$ e $j$ são vizinhos mais próximos que pertencem à mesma comunidade, então as distâncias $d_{i k}$ e $d_{j k}$, onde $k$ é qualquer outro ponto do grafo (com $k \neq i, j$ ), serão bastante similares, assim a perspectiva da rede do ponto de vista de $i$ e $j$ também serão bastante similares. Conseqüentemente, $\Lambda(i, j)$ será pequeno se $i$ e $j$ pertencerem a mesma comunidade, e grande se pertencerem a comunidades diferentes.

Após o cálculo da matriz de distância e dos índices de dissimilaridade para todos os pares de vértices vizinhos mais próximos, o Algoritmo 2.4 deve ser executado.

\section{Métodos Aglomerativos Globais}

Além das abordagens top-down (de cima para baixo) em que a cada iteração dividi-se um grafo em sucessivos grupos de menor nível, também existem abordagens bottom-up, onde inicia-se com singletons (grupos contendo um único vértice) e através de sucessivas combinações são formados os grupos de maior nivel. Tais métodos são chamados algoritmos aglomerativos de agrupamento. Tipicamente uma medida de similaridade é utilizada para verificar quais vértices devem ser unidos em um grupo, um exemplo de medida poderia ser baseado na quantidade relativa de vizinhos que dois vértices têm em comum.

Uma dessas abordagens é proposta por Newman (2004), baseada no cálculo de modularidade apresentado na Equação (2.23), proposto por Newman \& Girvan (2004). A idéia é que, considerando que o valor de $Q$ indica quão boa é uma divisão de comunidades, poderíamos simplesmente otimizar $Q$ para encontrar logo a melhor configuração possivel. O problema é que esta otimi- 


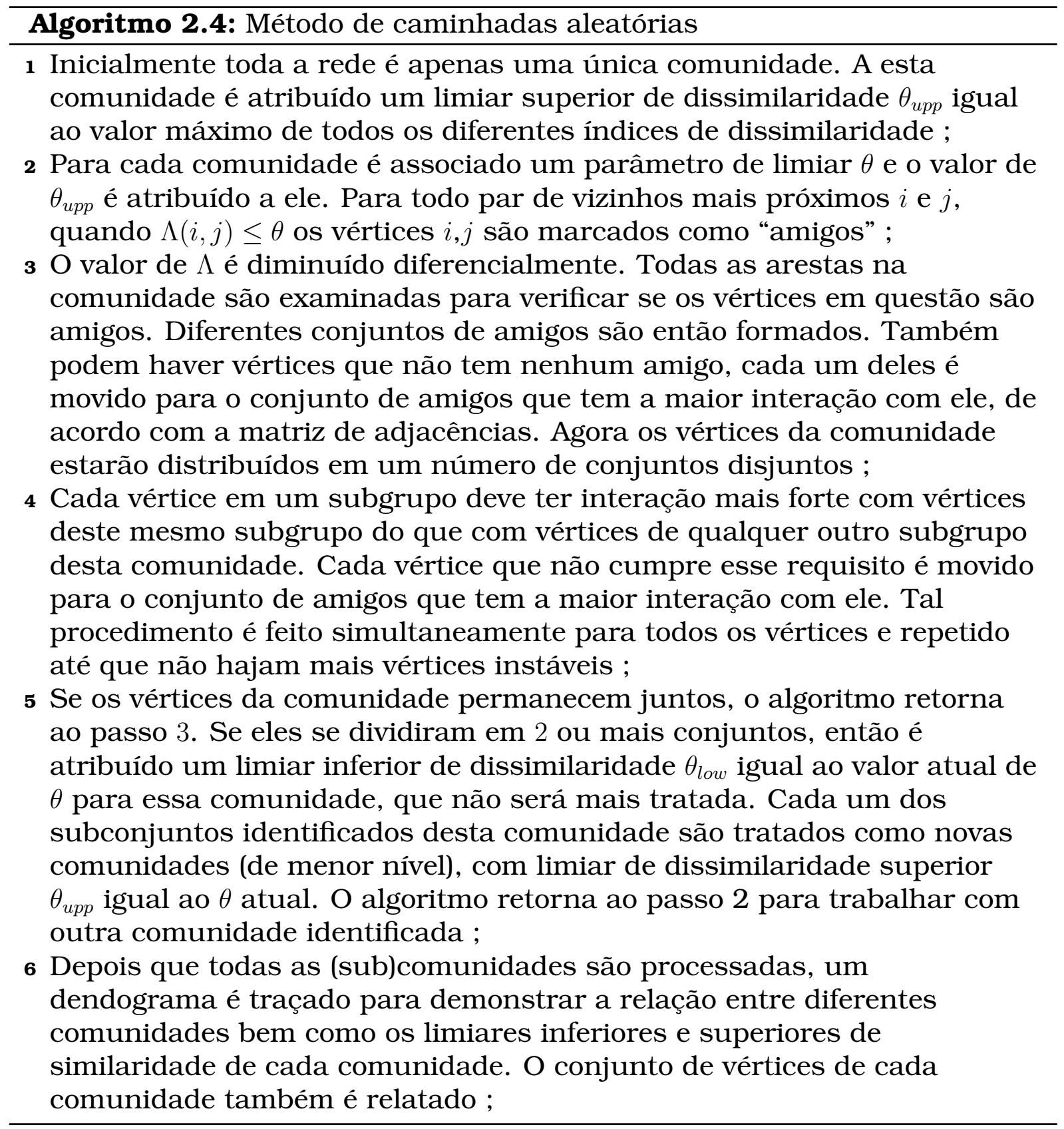

zação seria muito custosa e inviável na prática para grafos com mais de 20 ou 30 vértices. O autor propõe então um esquema baseado em um algoritmo de otimização "guloso" 12 padrão que funciona como descrito no Algoritmo 2.5

O resultado pode ser representado como um dendograma (como o do exemplo na Figura 2.2), cortes em diferentes níveis do dendograma darão divisões em mais ou menos comunidades, podemos selecionar o melhor corte através do maior valor de $Q$. Ao calcular os valores $\Delta Q$, pares de comunidades entre os quais não há nenhuma aresta nunca resultariam em um $\Delta Q$ positivo, assim só é necessário considerar os pares entre os quais existem arestas, diminuindo o tempo de execução do algoritmo.

Newman (2004) destaca que a vantagem dessa otimização com relação ao

12 do inglês greedy 


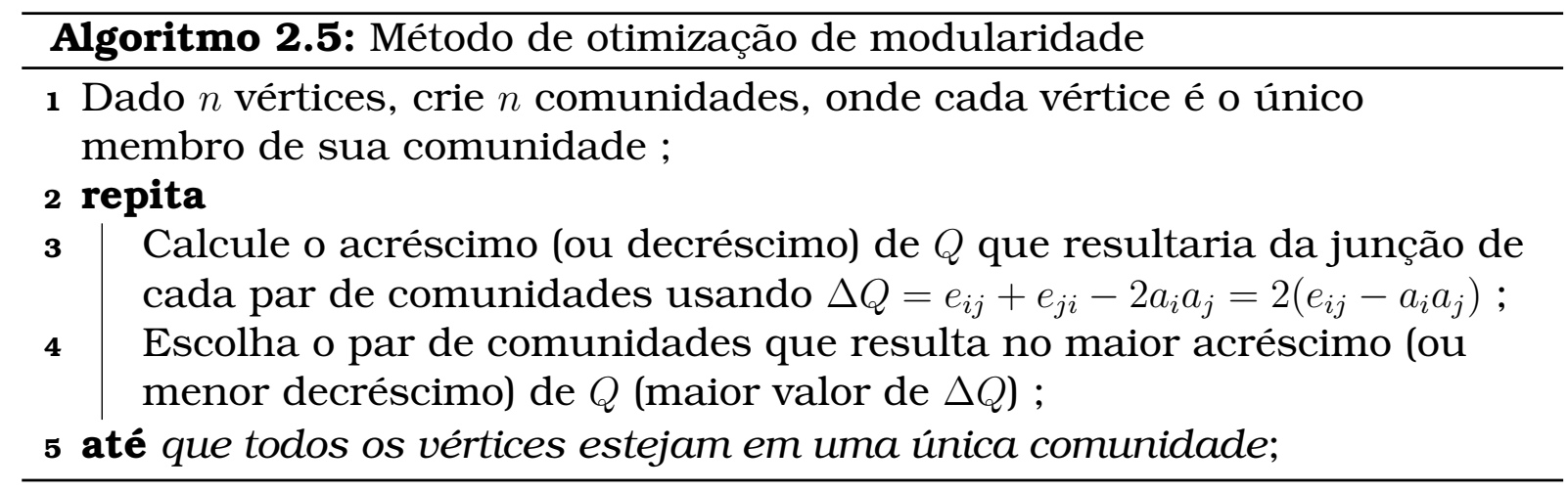

algoritmo Betweenness (também proposto por ele), é que essa otimização é muito mais rápida para problemas com grande número de vértices. Porém o Betweenness produz resultados melhores, sendo preferível nos problemas em que é computacionalmente tratável (problemas com menor número de vértices).

\section{Competição de Partículas}

O método de detecção de comunidades baseado em competição de partículas foi proposto por Quiles et al. (2008). Neste modelo, algumas partículas caminham em uma rede, competindo com as outras pela posse de nós, ao mesmo tempo em que rejeitam partículas intrusas. Após um número de iterações, cada partícula estará confinada em uma comunidade da rede, portanto as comunidades podem ser divididas examinando a qual partícula cada nó pertence.

O modelo de competição de partículas envolve conceitos de sistemas dinâmicos, processos estocásticos e mecanismos de competição. O modelo considera dois tipos de dinâmica, a dinâmica das partículas e a dinâmica dos vértices. Cada partícula $\rho_{j}$ é descrita por duas variáveis, $\rho_{j}^{v}(t)$ e $\rho_{j}^{\omega}(t)$, a primeira indica o vértice $v_{i}$ que a partícula está visitando no instante $t$, e a segunda, $\rho_{j}^{\omega} \in\left[\omega_{\min }, \omega_{\max }\right]$, representa o potencial da partícula, que caracteriza a sua habilidade de exploração no instante $t$. Os valores de $\omega_{\min }$ e $\omega_{\max }$ são os valores mínimo e máximo permitidos para o potencial dos vértices e das partículas e são pré-definidos. A dinâmica das partículas é expressa pelas seguintes equações:

$$
\begin{gathered}
\rho_{j}^{\omega}(t+1)=v_{i}, \\
\rho_{j}^{\omega}(t+1)=\left\{\begin{array}{lll}
\rho_{j}^{\omega}(t) & \text { se } v_{i}^{\rho}(t)=0 \\
\rho_{j}^{\omega}(t)+\left(\omega_{\max }-\rho_{j}^{\omega}(t)\right) \Delta_{\rho} & \text { se } & v_{i}^{\rho}(t)=\rho_{j} \neq 0 \\
\rho_{j}^{\omega}(t)-\left(\rho_{j}^{\omega}(t)-\omega_{\min }\right) \Delta_{\rho} & \text { se } & v_{i}^{\rho}(t) \neq \rho_{j} \neq 0
\end{array}\right.
\end{gathered}
$$


onde $\Delta_{\rho}$ é um parâmetro que controla a velocidade de incremento ou decremento do potencial de uma partícula.

De forma simétrica, cada vértice $v_{i}$ possui duas variáveis: $v_{i}^{\rho}(t)$ e $v_{i}^{\omega}(t)$. A primeira registra a partícula dona do nó $v_{i}$ no tempo $t$, ela toma o valor $\rho_{j}$ se ocupada pela partícula $\rho_{j}$ ou 0 se o nó $v_{i}$ está em um estado livre (o nó ainda não foi dominado por nenhuma partícula). A segunda variável $v_{i}^{\omega}(t)$ é o potencial do nó $v_{i}$ no tempo $t$, representando a força de domínio da partícula $\rho_{j}$ sobre nó $v_{i}$, i.e., um maior valor de $v_{i}^{\omega}(t)$ significa que $v_{i}$ é fortemente dominado por $\rho_{j}$, um valor menor representa uma dominância fraca e, especificamente, $v_{i}^{\omega}(t)=\omega_{\min }$ indica que o nó $v_{i}$ está em um estado livre, e será dominado pela primeira partícula que o visitar. A dinâmica dos vértices pode ser resumida pelas seguintes equações:

$$
\begin{aligned}
& v_{i}^{\rho}(t+1)=\left\{\begin{array}{lll}
v_{i}^{\rho}(t) & \text { se } & v_{i}^{\gamma}=0 \\
\rho_{j} & \text { se } & v_{i}^{\gamma}=1 \quad \text { e } \quad v_{i}^{\omega}(t)=\omega_{\min }
\end{array}\right.
\end{aligned}
$$

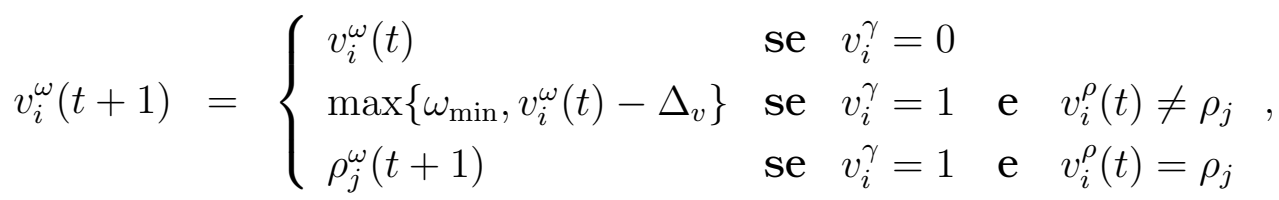

onde $\Delta_{v}$ é um parâmetro que controla a velocidade do decremento do potencial de um nó, e $v_{i}^{\gamma}$ é um valor binário que indica se o vértice $v_{i}$ está sendo visitado no instante $t$ por alguma partícula.

O processo de detecção de comunidade através da aplicação do modelo proposto pode ser descrito da seguinte maneira. Inicialmente, $k$ partículas são colocadas em $k$ vértices da rede escolhidos aleatoriamente. Cada partícula $\rho_{j}$ tem o potencial inicial $\rho_{j}^{\omega}(0)=\omega_{\min }$ e cada nó $v_{i}$ tem potencial inicial $v_{i}^{\omega}(t)=\omega_{\text {min }}$ também. Ainda no instante inicial, todos os vértices $v_{i}$ estão livres, i.e., $v_{i}^{\rho}(0)=$ 0 . Conforme o sistema executa, cada partícula escolhe um vértice vizinho para visitar (a regra descrevendo como escolher o vizinho será detalhada mais adiante) em cada iteração. A partícula encontra uma das seguintes situações para cada visita:

1. Se o vértice $v_{i}$ sendo visitado pela partícula $\rho_{j}$ ainda não tem dono $\left(v_{i}^{\rho}(t)=\right.$ 0 ), então o potencial de $\rho_{j}$ não é alterado, o dono de $v_{i}$ é marcado como $\rho_{j}$, i.e., $v_{i}^{\rho}(t)=\rho_{j}$ e o potencial do vértice $v_{i}$ se torna igual ao potencial da partícula $\rho_{j}$, i.e., $v_{i}^{\omega}(t)=\rho_{j}^{\omega}(t)$.

2. Se o vértice $v_{i}$ sendo visitado pela partícula $\rho_{j}$ pertence à própria partícula, i.e., $v_{i}^{\rho}(t)=\rho_{j} \neq 0$, o potencial da partícula $\rho_{j}$ aumenta aplicando-se 
a segunda linha da Equação (2.27), a posse do vértice $v_{i}$ é mantida como sendo da partícula $\rho_{j}$ e novamente o potencial do vértice $v_{i}$ recebe o potencial da partícula $\rho_{j}$.

3. Se o vértice $v_{i}$ sendo visitado pela partícula $\rho_{j}$ pertence a outra partícula, um choque ocorre e a partícula $\rho_{j}$ é rejeitada pelo nó $v_{i}$. Neste caso, o potencial de ambos, a partícula $\rho_{j}$ e o nó $v_{i}$, são diminuídos aplicando-se a terceira linha da Equação (2.27) e a segunda linha da Equação (2.29), respectivamente. Se $\rho_{j}^{\omega}(t)$ é reduzido abaixo de $\omega_{\min }$, ele é reiniciado para um nó escolhido aleatoriamente e seu potencial é ajustado para o nível mínimo, $\omega_{\min }$. Se o potencial do nó $v_{i}$ é reduzido para $\omega_{m i n}$, sua posse é ajustada para 0 , indicando que o nó pode ser ocupado por qualquer partícula.

Desta forma, a posse de um vértice é fortalecida se ele for visitado pela mesma partícula freqüentemente, e é reduzida ou mesmo mudada se ele for freqüentemente visitado por outras partículas. O processo continua até que um estado de equilíbrio dinâmico seja atingido. Neste caso, o equilíbrio dinâmico é alcançado quando, a partir de certo momento, a maioria dos vértices não sofrer mais mudança com relação a seus domínios. Uma ilustração do processo de detecção de comunidades por este método é apresentada na Figura 2.4 .

Para escolher o vértice vizinho a ser visitado, a partícula escolhe um dos seguintes tipos de movimento: o movimento aleatório ou o movimento determinístico. O primeiro supõe que a partícula não tem nenhum conhecimento sobre a estrutura da rede, e portanto seleciona aleatoriamente um vizinho para visitar (retornar imediatamente para o último nó visitado não é permitido, a menos que o grau do nó seja um); por outro lado, o segundo caso faz com que a partícula sempre visite um vizinho que já seja dominado por ela. É definida uma probabilidade $0 \leq p_{\text {det }} \leq 1$. Em cada iteração, cada partícula tem probabilidade $p_{\text {det }}$ de escolher o movimento determinístico e probabilidade $1-p_{\text {det }}$ de escolher o movimento aleatório. Portanto, conforme $p_{\text {det }}$ aumenta, o movimento determinístico tem maior probabilidade de ser aplicado. Em particular, o movimento das partículas é completamente aleatório se $p_{\text {det }}=0$, e é totalmente determinístico se $p_{\text {det }}=1$.

\subsection{Aprendizado Semi-Supervisionado}

O aprendizado semi-supervisionado tem recebido um interesse crescente nos últimos anos. Esta é uma das classes de técnicas de aprendizado entre as duas maiores categorias: o aprendizado supervisionado e o aprendizado 


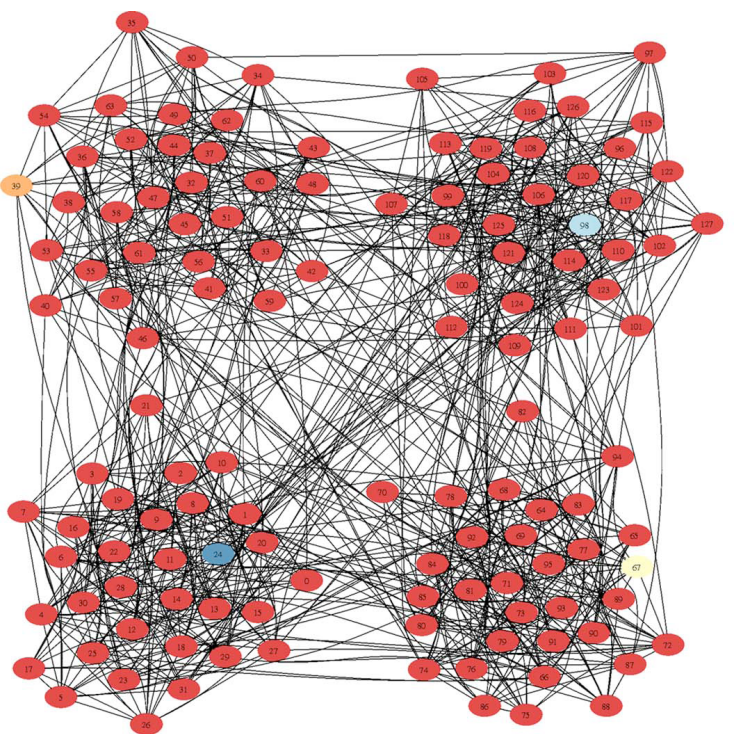

(a)

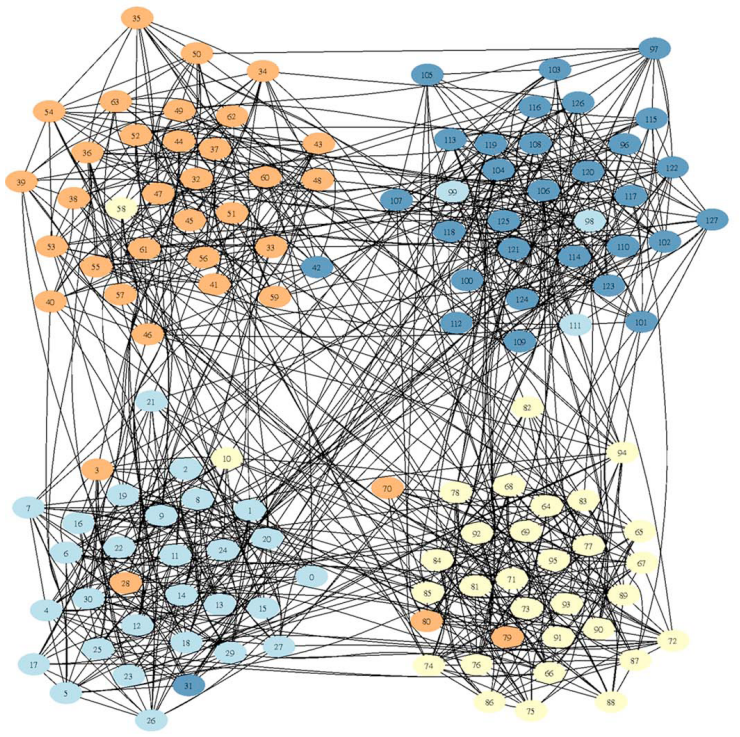

(c)

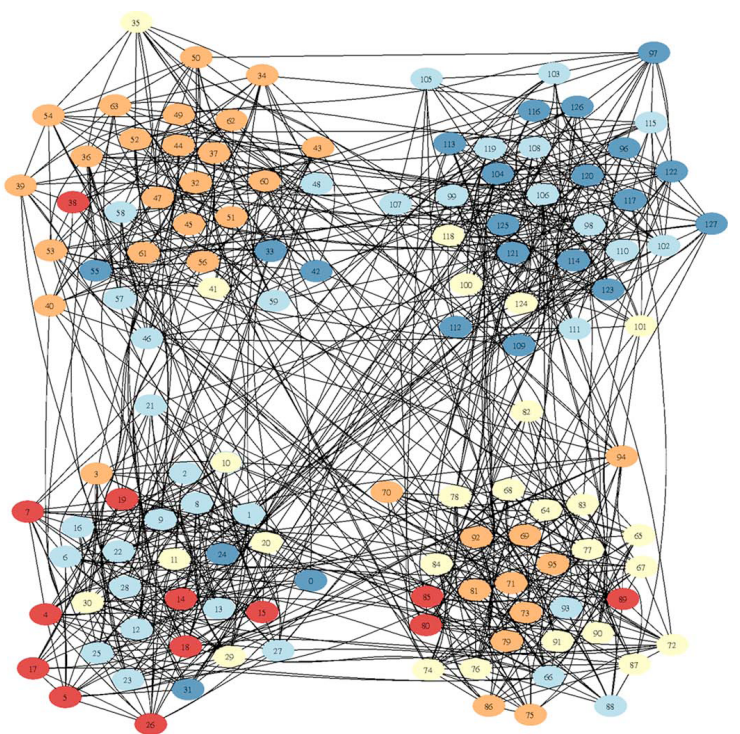

(b)

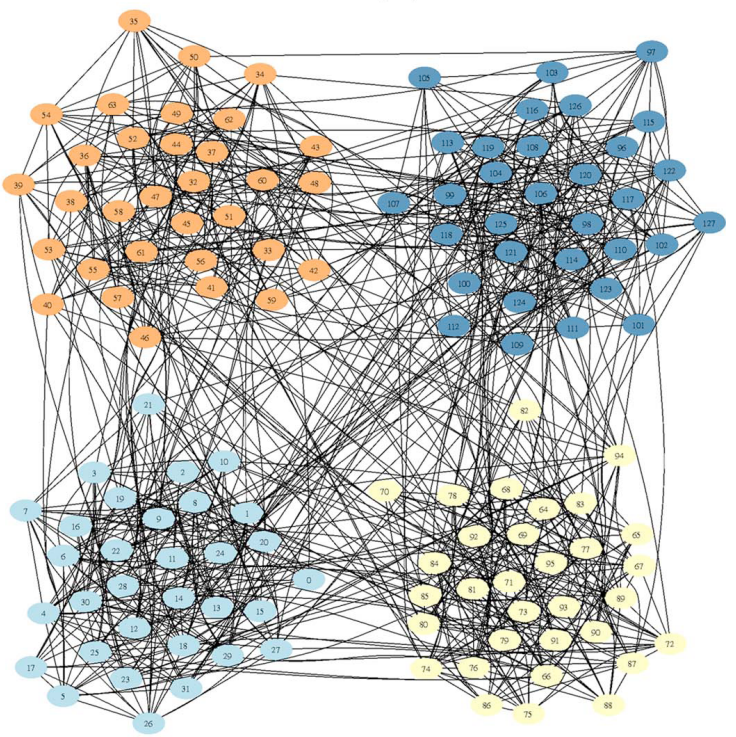

(d)

Figura 2.4: Processo de detecção de comunidades pelo método de competição de partículas. O número de nós é $N=128$, o número de comunidades é $M=4$. O grau médio da rede é $\langle k\rangle=16$. (a) Configuração inicial. Quatro partículas representadas pelas cores amarelo, azul claro, laranja e azul escuro são aleatoriamente colocadas na rede. A cor vermelha representa vértices livres. (b) Iteração 250. (c) Iteração 3500. (d) Iteração 7000 (Quiles et al., 2008). 
não supervisionado. No aprendizado supervisionado, um algoritmo aprende uma função a partir dos dados de entrada, os quais consistem em pares de itens de dados e seus respectivos rótulos, de forma que após aprender de uma certa quantidade de exemplos de treinamento, o algoritmo pode predizer os rótulos de novos dados. Por outro lado, no aprendizado não supervisionado, todos os itens de dados são não rotulados e o objetivo é determinar sua estrutura intrínseca. Algoritmos de aprendizado de máquina em geral têm sido aplicados com sucesso para resolver problemas de mineração de dados, reconhecimento de padrões, bioinformática, predição de séries temporais, e outros (Mitchell, 1997; Bishop, 2006; Alpaydin, 2004; Witten \& Frank, 2005; Hinton \& Sejnowski, 1999; Cios et al., 2007; Aggarwal \& Yu, 2009; Wolff et al., 2009).

Hoje em dia, as bases de dados sendo processadas estão ficando cada vez maiores. Em muitas situações, apenas um pequeno subconjunto dos itens de dados pode ser efetivamente rotulados. Isto acontece porque o processo de rotulagem é freqüentemente caro, demorado e requer o envolvimento intenso de especialistas humanos. Como resultado, conjunto de dados parcialmente rotulados são freqüentemente encontrados. Técnicas de aprendizado supervisionado não podem lidar com este tipo de problema porque elas assumem que todos ou quase todos os itens de dados são rotulados para o processo de treinamento. Por outro lado, técnicas de aprendizado não supervisionado ignoram informações de rótulo dos itens de dados. Portanto, em tais casos, métodos de aprendizado semi-supervisionado se tornam interessantes. Eles tratam este problema específico combinando poucos itens de dados rotulados com uma grande quantidade de dados não rotulados para produzir melhores classificadores, ao mesmo tempo em que requerem menor esforço humano (Zhu, 2005; Chapelle et al., 2006b; Abney, 2008).

O aprendizado semi-supervisionado é bastante indicado para muitas aplicações, como o reconhecimento de fala, a classificação de páginas da Internet e o seqüenciamento de proteínas (Chapelle et al., 2006b). Em reconhecimento de fala, custa quase nada gravar grandes quantidades de dados, mas rotulálos requer que um humano ouça e digite uma transcrição. Bilhões de páginas da Internet estão disponíveis para processamento direto, mas para classificálas humanos precisam lê-las, tornando esta tarefa praticamente impossivel. Finalmente, seqüências de proteínas são adquiridas de maneira fácil e rápida hoje em dia (por seqüenciamento de genoma, busca computacional de gene, e tradução automática), mas resolver uma estrutura tridimensional (revelando como os aminoácidos estão arranjados), ou determinar as funções de uma simples proteína pode levar anos de trabalho científico.

O aprendizado semi-supervisionado acontece da seguinte forma. Tipicamente, existe um conjunto de dados $\chi=\left\{\mathbf{x}_{1}, \mathbf{x}_{2}, \ldots, \mathbf{x}_{l}, \mathbf{x}_{l+1}, \ldots, \mathbf{x}_{n}\right\} \subset \mathbb{R}^{m}$ e um 
conjunto de rótulos $L=\{1,2, \ldots, c\}$, sendo que os primeiros $l$ pontos $\mathbf{x}_{i}(i \leq l)$ tem rótulos conhecidos, ou seja, $y_{i} \in L$, e o restante dos pontos $\mathbf{x}_{u}(l<u \leq n)$ tem os rótulos desconhecidos, ou seja, $y_{u}=\emptyset$. O objetivo é designar um rótulo para cada amostra não rotulada.

Nas subseções a seguir, faremos uma revisão de algumas das principais categorias de métodos de aprendizado semi-supervisionado existentes.

\subsubsection{Auto Treinamento}

$\mathrm{O}$ auto treinamento ${ }^{13}$ é uma das formas mais primitivas de aprendizado semi-supervisionado, que também é conhecida como auto aprendizado ${ }^{14}$ ou bootstrapping. Neste tipo de aprendizado um classificador é treinado utilizando os poucos dados rotulados, como no aprendizado supervisionado. Esse classificador é então usado para classificar os dados não rotulados. Os dados não-rotulados que tiverem seus rótulos preditos com maior confiança serão adicionados ao conjunto de treinamento. O classificador é então re-treinado com esse novo conjunto de dados de treinamento. Este processo é repetido até que todos os dados sejam rotulados. O desempenho de tais métodos depende bastante do classificador utilizado no procedimento ( $\mathrm{Zhu}, 2005$; Chapelle et al., 2006b). Uma desvantagem é que eventuais erros de classificação serão propagados para todas as iterações subseqüentes. Alguns algoritmos evitam que erros de classificação sejam reforçados "desaprendendo" dados rotulados cuja confiança caia abaixo de um certo nível.

A idéia do auto treinamento vêm aparecendo na literatura há bastante tempo (Scudder, 1965; Fralick, 1967; Agrawala, 1970). Posteriormente foi aplicada a diversas tarefas de processamento de linguagem natural. Yarowsky (1995) utilizou o auto treinamento para desambiguação de palavras em inglês que tem mesma grafia mas diferentes significados. Riloff et al. (2003) utilizouo para identificar substantivos subjetivos para distinguir entre sentenças objetivas e subjetivas. Mais tarde, uma análise mais profunda do algoritmo de Yarowsky (1995) foi apresentada por Abney (2004) e estendida por Haffari \& Sarkar (2007).

\subsubsection{Co-Treinamento}

No Co-Treinamento ${ }^{15}$ (Blum \& Mitchell, 1998; Mitchell, 1999) assume-se que: (a) o conjunto de atributos pode ser dividido em dois subconjuntos; (b) cada subconjunto de atributos é suficiente para treinar um bom classificador; e (c) ambos os subconjuntos são condicionalmente independentes dada

\footnotetext{
${ }^{13}$ do inglês: self-training

${ }^{14}$ do inglês: self-learning

15 do inglês: co-training
} 
a classe. Inicialmente, dois classificadores separados são treinados com os dados rotulados de cada um dos dois subconjuntos de atributos, respectivamente. Os classificadores então classificam os dados não rotulados. Em seguida, de maneira semelhante ao que ocorre no auto treinamento, os dados não rotulados cujos rótulos preditos por um classificador forem os mais confiáveis são usados para treinar o outro classificador. Cada classificador é então re-treinado com os dados adicionais fornecidos pelo outro classificador, e o processo se repete.

Os dois classificadores precisam concordar tanto nos dados rotulados quanto nos dados não rotulados. A confiabilidade dos rótulos preditos pelos classificadores depende da qualidade dos subconjuntos de atributos com que eles foram treinados, ou seja, precisam haver atributos que apresentem valores distintos para amostras de classes diferentes. Além disso, é preciso que os subconjuntos de atributos sejam condicionalmente independentes para que as amostras cujo rótulo predito seja confiável em um classificador, estejam bem separadas no espaço de atributos do outro classificador.

Zhou \& Li $(2005,2007)$ propuseram o tri-treinamento ${ }^{16}$ que usa três classificadores. Se dois deles concordam na classificação de uma dada amostra não rotulada, então essa classificação é usada para treinar o terceiro classificador. Dessa forma não é necessário medir explicitamente a confiança nos rótulos fornecidos por qualquer classificador. Este método pode ser aplicado em bases de dados sem diferentes visões e sem restrições nos tipos de classificadores e, portanto, pode ser aplicado mais amplamente que o co-treinamento.

\subsubsection{Modelos Generativos}

Os modelos generativos são uma das formas mais antigas de aprendizado semi-supervisionado. Neles assume-se que um modelo $p(x, y)=p(y) p(x \mid y)$ onde $p(x \mid y)$ é uma distribuição com mistura identificável como, por exemplo, um modelo de mistura Gaussiano (Zhu, 2005). Com uma grande quantidade de dados não rotulados, os componentes da mistura podem ser identificados, e então, idealmente precisaríamos de apenas um exemplo rotulado em cada componente para determinar completamente a mistura da distribuição, como pode ser visto na Figura 2.5. Se assumirmos que o modelo de mistura é Gaussiano podemos utilizar o algoritmo de Maximização de Expectativa (ME) ${ }^{17}$ para encontrar os parâmetros da Gaussiana correspondente aos modelos de mistura para cada classe. A única diferença para o algoritmo ME padrão, usado em agrupamento, é que a "variável oculta" associada com cada exemplo rotulado não é realmente oculta, mas sim conhecida e igual ao rótulo da classe

\footnotetext{
${ }^{16}$ do inglês: tri-training

${ }^{17}$ do inglês: Expectative Maximization (EM)
} 
(Chapelle et al., 2006b). Nigam et al. (2000) aplicou o algoritmo ME em um problema de classificação de texto, mostrando que o desempenho quando são utilizados também os dados não rotulados é melhor do que o desempenho obtido quando são utilizados apenas os dados rotulados. Fujino et al. (2005) estendeu os modelos de mistura generativos incluindo um termo de correção de bias e um treinamento diferente utilizando o princípio da máxima entropia.

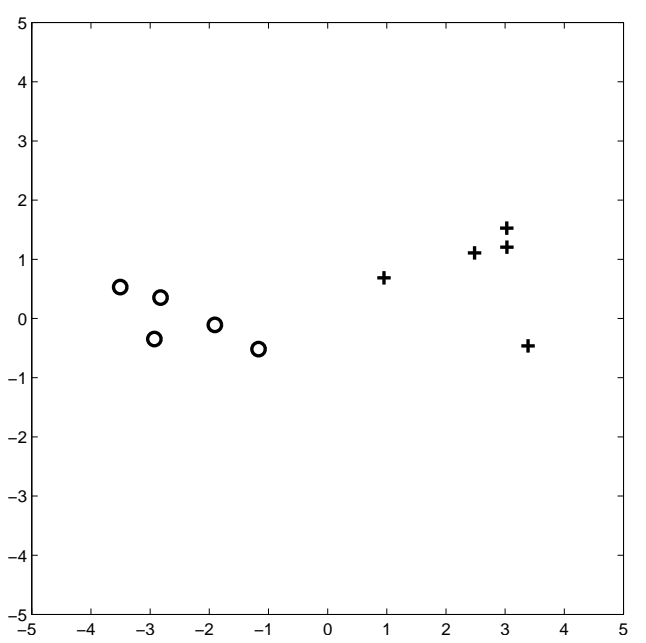

(a)

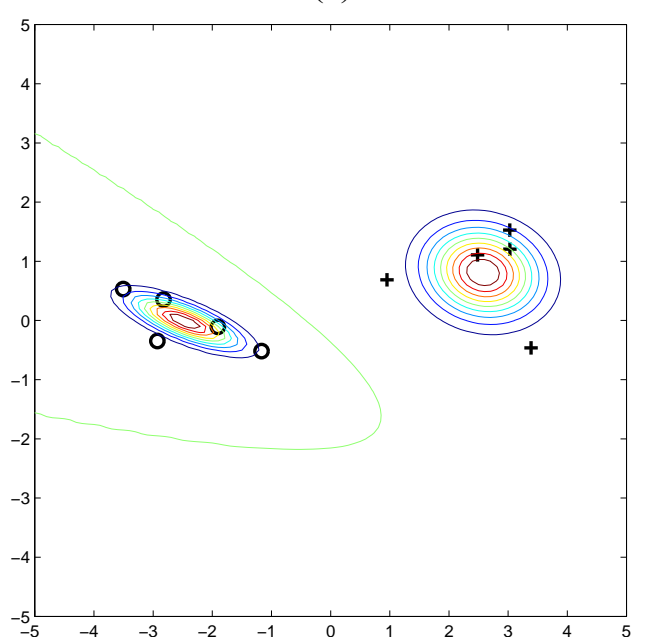

(c)

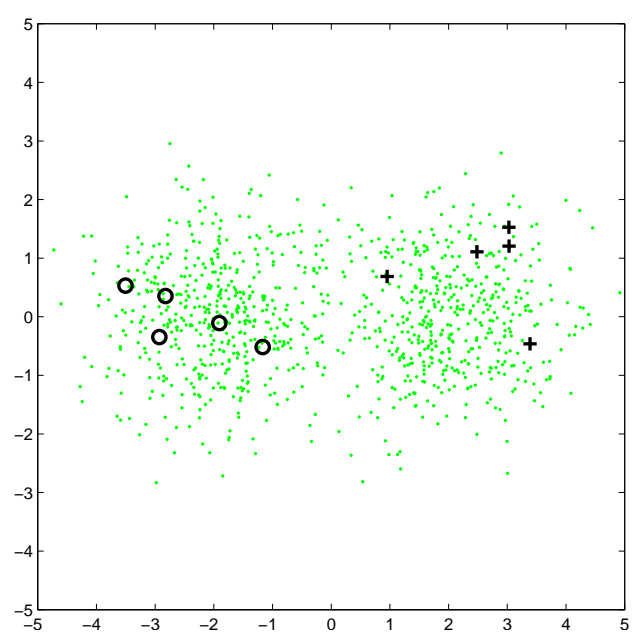

(b)

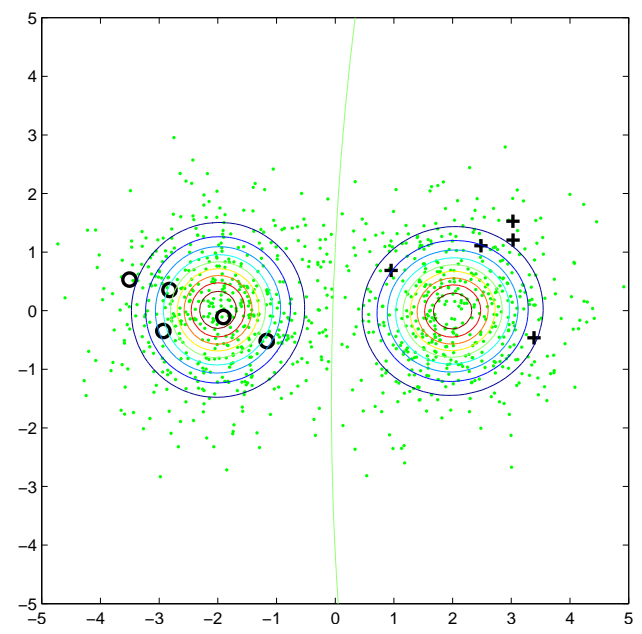

(d)

Figura 2.5: Um problema de classificação binário em aprendizado semisupervisionado. Se assumirmos que cada classe tem distribuição Gaussiana, podemos usar os dados não rotulados para ajudar a estimar os parâmetros: (a) dados rotulados; (b) dados rotulados e não rotulados; (c) modelo aprendido a partir dos dados rotulados; (d) modelo aprendido a partir dos dados rotulados e não rotulados (Zhu, 2005). 


\subsubsection{Agrupar e Rotular}

As técnicas de agrupar e rotular ${ }^{18}$ (Demiriz et al., 1999; Dara et al., 2002) consistem em utilizar técnicas de agrupamento tradicionais para encontrar a distribuição das classes de toda a base de dados. Em seguida, cada grupo encontrado pode ser rotulado com o rótulo presente na maioria dos dados prérotulados. Estes algoritmos tendem a funcionar bem quando os algoritmos de agrupamento escolhidos combinam com a distribuição real dos dados (Zhu, 2005).

\subsubsection{Separação de Baixa Densidade}

A categoria dos métodos de separação de baixa densidade ${ }^{19}$ é composta de algoritmos que tentam implementar a hipótese de separação de baixa densidade, ou seja, tais métodos assumem que a fronteira de decisão está em uma região de baixa densidade considerando todos os dados (rotulados e não rotulados). A abordagem mais comum para atingir este objetivo é o uso de algoritmos que maximizem essa margem, como é o caso das support vector machines (SVM). O método para maximizar a margem tanto dos dados rotulados quanto dos dados não rotulados é chamado de transductive SVM (ou TSVM) (Vapnik, 2008). A TSVM estende as SVM tradicionais que utilizam somente dados rotulados. O objetivo é encontrar rótulos para os dados não rotulados de modo que a fronteira tenha a máxima margem tanto nos dados originais quanto nos dados não rotulados (que agora estarão rotulados). De forma intuitiva, os dados não rotulados guiam a fronteira para longe de regiōes densas. O maior problema desse método é que encontrar uma solução exata para o TSVM é um problema na categoria NP-difícil, de forma que os esforços tem se concentrado em encontrar algoritmos de aproximação eficientes. As TSVM também podem ser vistas como uma SVM com um termo de regularização adicional nos dados não rotulados (Zhu, 2005).

Chapelle \& Zien (2005) propuseram o $\nabla T S V M$, que aproxima a função de perda com uma função Gaussiana, realizando busca no gradiente descendente do espaço primal. Sindhwani et al. (2006) e Chapelle et al. (2006a) utilizam frameworks de otimização, inspirados em técnicas de recozimento ${ }^{20}$, que iniciam com um problema de otimização simplificado que é gradualmente transformado no problema original ao longo do tempo. Outras variações do TSVM também foram propostas por Collobert et al. (2006), Sindhwani \& Keerthi (2006) e Xu et al. (2008).

\footnotetext{
18 do inglês: cluter-and-label

19 do inglês: low-density separation (LDS)

${ }^{20}$ do inglês: annealing
} 


\subsubsection{Métodos Baseados em Grafos}

Nos últimos anos, a área de pesquisa mais ativa em aprendizado semisupervisionado tem sido a de métodos baseados em grafos (Chapelle et al., 2006b). Os métodos desta categoria são representados por nós de um grafo, onde as arestas tem seu peso relacionado com a distância entre os pares de nós. Os nós rotulados são utilizados para propagar informações de rótulos para os demais. Desta forma, os métodos dessa categoria assumem que existe suavidade dos rótulos no grafo.

Os métodos dessa categoria utilizam um grafo $\mathbf{G}=(\mathbf{V}, \mathbf{E}) \cdot \mathbf{V}=\left\{v_{1}, v_{2}, \ldots, v_{n}\right\}$ é o conjunto de nós, onde cada vértice $v_{i}$ corresponde a uma amostra $x_{i}$. $\mathbf{E} \rightarrow \mathbb{R}$ é o conjunto de ligações $\left(v_{i}, v_{j}\right)$ cujos pesos podem ser representados por uma matriz de adjacências $\mathbf{W}$ onde $w_{i j}$ indica a similaridade entre $v_{i}$ e $v_{j}$. Esta similaridade depende do método utilizado, e normalmente é definida usando uma função Gaussiana (também chamada de núcleo de calor ${ }^{21}$ ou núcleo $\mathrm{RBF}^{22}$ ), e assim a matriz de adjacência seria:

$$
W_{i j}=\left\{\begin{array}{cl}
\exp \left(\frac{-\left\|\mathbf{x}_{i}-\mathbf{x}_{j}\right\|^{2}}{2 \sigma^{2}}\right) & \text { se existe aresta entre } v_{i} \text { e } v_{j} \\
0 & \text { caso contrário }
\end{array} .\right.
$$

onde $\|$.$\| é qualquer medida de distância e \sigma$ pode ser definido empiricamente ou através de heurísticas. Também é possível utilizar um grafo sem peso, e nesse caso $W_{i j}=1$ no primeiro caso da Equação (2.30). Outra possibilidade bastante utilizada é conectar cada nó apenas aos seus $k$ vizinhos mais próximos usando alguma medida de distância.

Diversos métodos propostos nesta categoria funcionam de maneira iterativa, ou seja, a estrutura do grafo é utilizada para gradualmente espalhar os rótulos dos nós rotulados para todo o restante do grafo. A cada iteração, cada nó espalha as informações de rótulos que possui para seus vizinhos, até que haja convergência.

Um algoritmo deste tipo foi proposto por Zhu \& Ghahramani (2002) e está descrito no Algoritmo 2.6. Ele estima rótulos tanto nos dados rotulados quanto nos dados não rotulados, que são denotados por $\hat{Y}=\left(\hat{Y}_{l}, \hat{Y}_{u}\right)$, onde $\hat{Y}_{l}$ pode ser diferente dos rótulos originais $Y_{l}=\left(y_{1}, y_{2}, \ldots, y_{l}\right)$, mas neste caso optou-se por forçar $\hat{Y}_{l}=Y_{l}$.

Bengio et al. (2006) propuseram um esquema de propagação um pouco diferente, mostrado no Algoritmo 2.7. Este método é inspirado no método iterativo de Jacobi para sistemas lineares e é similar ao Algoritmo 2.6, exceto pelos detalhes a seguir:

\footnotetext{
${ }^{21}$ do inglês: heat kernel

${ }^{22}$ sigla para radial basis function ou função de base radial em português
} 


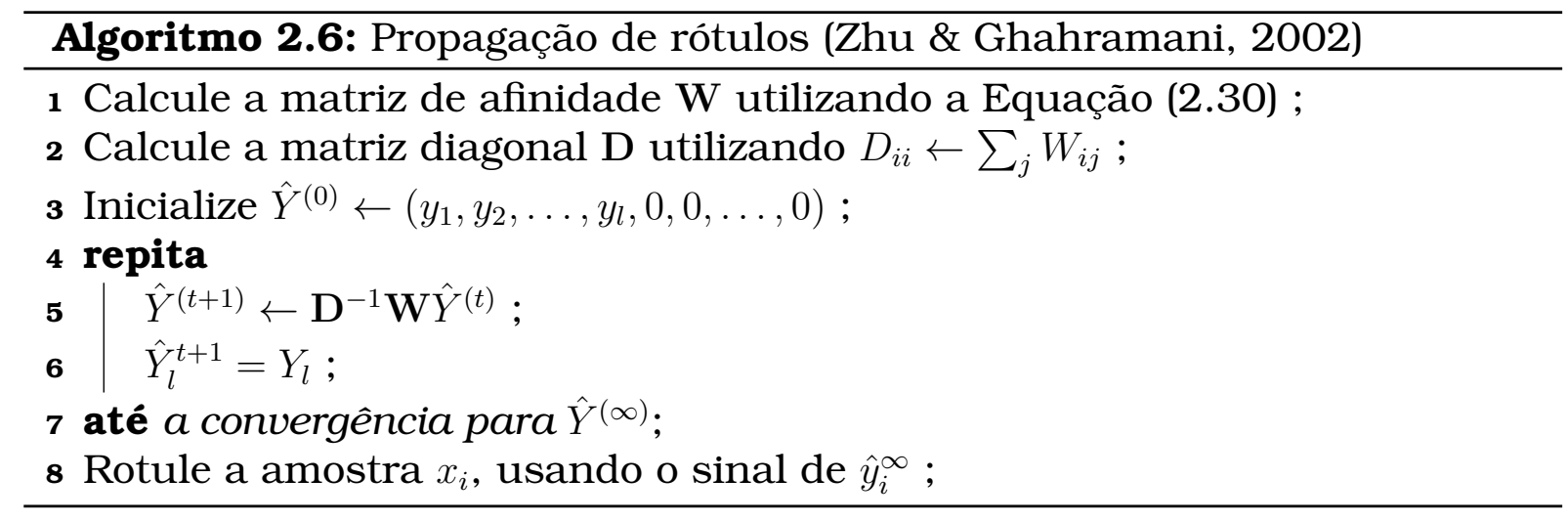

- Utiliza-se $W_{i i}=0$, que normalmente funciona melhor;

- Permite-se $\hat{Y}_{l} \neq Y_{l}$, que pode ser útil em casos de sobreposição de classes;

- Usa-se um termo de regularização adicional $\epsilon$ para melhorar a estabilidade numérica.

Algoritmo 2.7: Propagação de rótulos inspirada no algoritmo de iteração de Jacobi (Bengio et al., 2006)

1 Calcule a matriz de afinidade $\mathrm{W}$ utilizando a Equação (2.30), mas com $\mathbf{W}_{i i}=0$;

2 Calcule a matriz diagonal D utilizando $D_{i i} \leftarrow \sum_{j} W_{i j}$;

3 Escolha um parâmetro $\alpha \in(0,1)$ e um $\epsilon>0$ pequeno ;

$4 \mu \leftarrow \frac{\alpha}{1-\alpha} \in(0,+\infty)$;

5 Calcule a matriz diagonal A usando $A_{i i} \leftarrow I_{[l]}(i)+\mu D_{i i}+\mu \epsilon$;

6 Inicialize $\hat{Y}^{(0)} \leftarrow\left(y_{1}, y_{2}, \ldots, y_{l}, 0,0, \ldots, 0\right)$;

7 repita $\hat{Y}^{(t+1)} \leftarrow \mathbf{A}^{-1}\left(\mu \mathbf{W} \hat{Y}^{(t)}+\hat{Y}^{(0)}\right)$ até a convergência para $\hat{Y}^{(\infty)}$;

8 Rotule a amostra $x_{i}$, usando o sinal de $\hat{y}_{i}^{\infty}$;

Bengio et al. (2006) mostra que o passo de iteração do Algoritmo 2.7 pode ser reescrito para um exemplo rotulado $(i \leq l)$ :

$$
\hat{y}^{(t+1)} \leftarrow \frac{\sum_{j} W_{i j} \hat{y}_{j}^{(t)}+\frac{1}{\mu} y_{i}}{\sum_{j} W_{i j}+\frac{1}{\mu}+\epsilon},
$$

e para um exemplo não rotulado $(l+1 \leq i \leq n)$ :

$$
\hat{y}^{(t+1)} \leftarrow \frac{\sum_{j} W_{i j} \hat{y}_{j}^{(t)}}{\sum_{j} W_{i j}+\epsilon},
$$

de forma que as equações podem ser vistas como a média ponderada do rótulo atual dos vizinhos, onde para os exemplos rotulados também é adicionado o rótulo inicial. $\epsilon$ é um parâmetro de regularização que evita que o denominador se torne muito pequeno. 
Outro método similar, conhecido como Método de Consistência Local e Global $^{23}$, foi proposto por Zhou et al. (2004) e é mostrado no Algoritmo 2.8. Em cada passo de iteração um nó recebe contribuição de seus vizinhos, ponderada pelo peso das arestas, e uma pequena contribuição dada pelos valores iniciais.

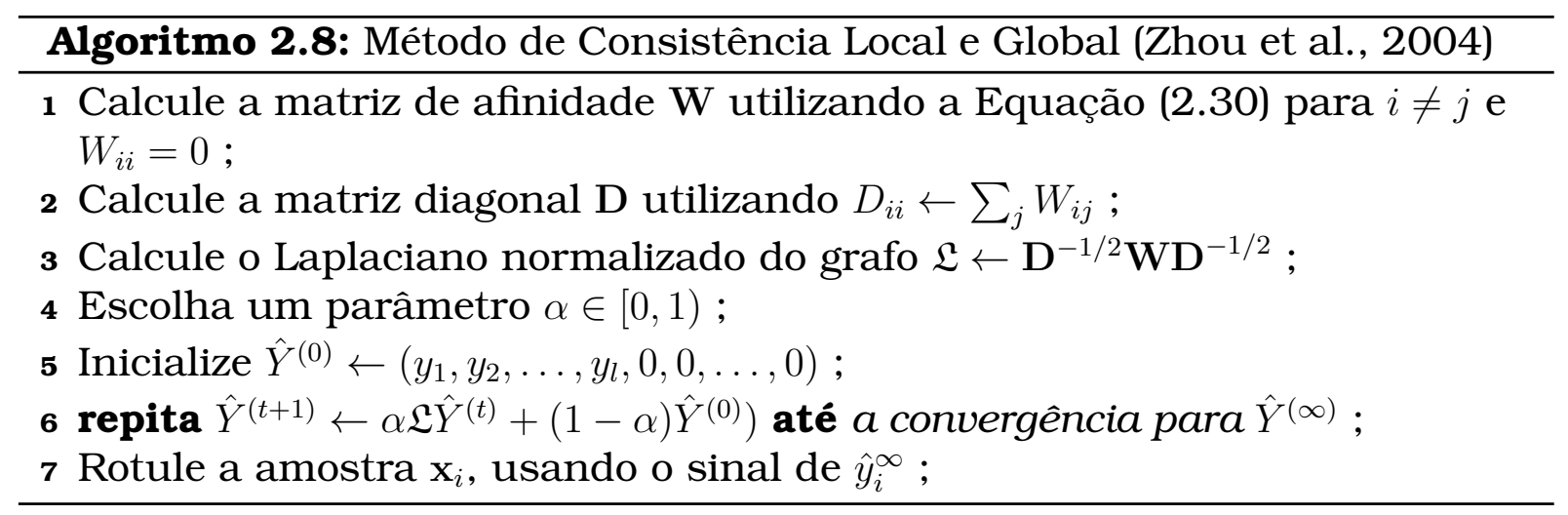

A Figura 2.6 mostra uma base de dados artificial cuja estrutura e posição dos nós rotulados não permite que métodos de classificação tradicionais como Support Vector Machines (SVM) e $k$-vizinhos mais próximos obtenham uma boa classificação. A mesma base de dados é classificada corretamente pelo Método de Consistência Global e Local, como pode ser observado na Figura 2.7.

A taxa de convergência destes três algoritmos depende de propriedades específicas do grafo tais como seus autovalores e seu Laplaciano. Em geral, podemos esperar que a complexidade computacional seja da ordem de $O\left(k n^{2}\right)$ no pior caso, onde $k$ é o grau médio do grafo. No caso de uma matriz de peso densa, o tempo computacional será cúbico em $n$ (Bengio et al., 2006).

\section{Regularização em Grafos}

Muitos métodos baseados em grafos podem ser vistos como estimando uma função $f$ no grafo, que deve satisfazer duas condições ao mesmo tempo: 1) ela deve aproximar os rótulos dos dados rotulados, e 2) ela deve ser suave em todo o grafo. Isto pode ser expresso como um framework de regularização onde o primeiro termo é uma função de perda e o segundo termo é um regularizador. Ou seja, para tais métodos, minimizar uma determinada função de custo quadrático derivada do grafo equivale ao correspondente algoritmo iterativo. Dessa forma, vários métodos baseados em grafos são parecidos, diferindo apenas em sua escolha particular de função de perda e regularizador (Zhu, 2005; Bengio et al., 2006). Por exemplo, Zhou et al. (2004) propõem um framework de regularização, equivalente ao Algoritmo 2.8, baseado na seguinte função de 


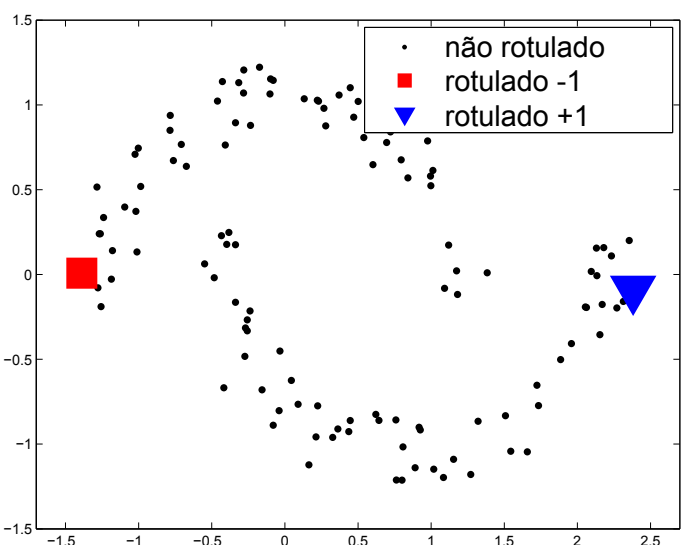

(a)

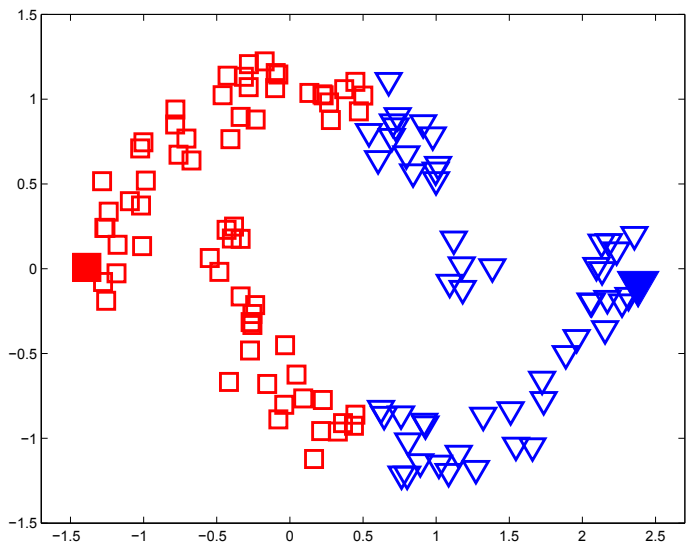

(c)

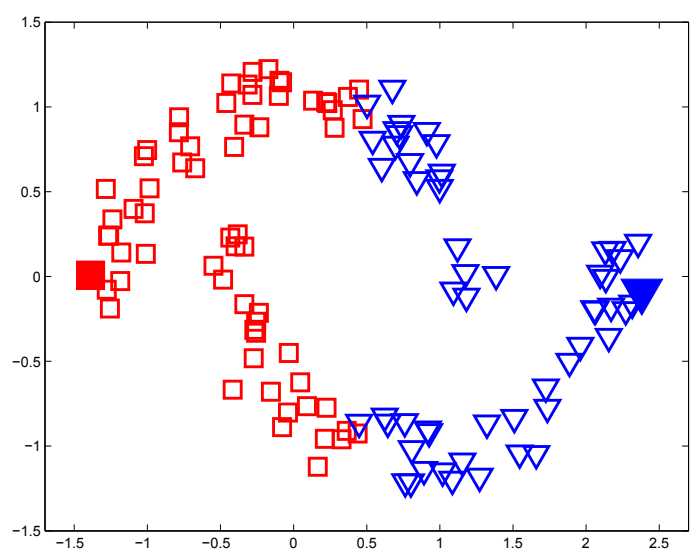

(b)

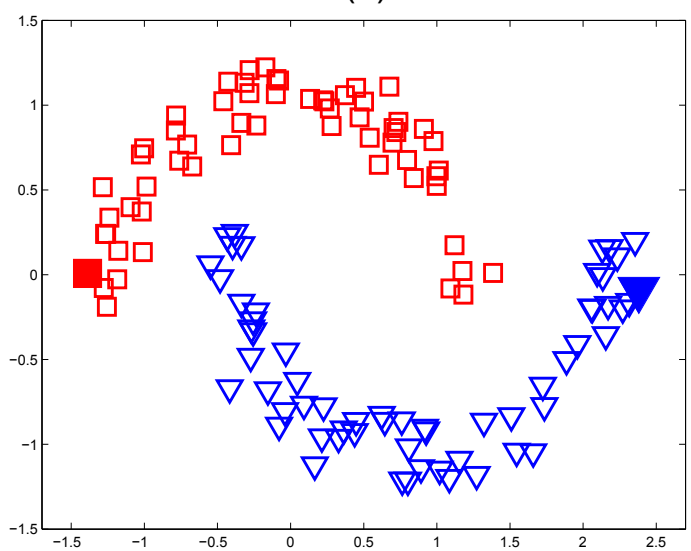

(d)

Figura 2.6: Classificação de um problema com duas classes em forma de banana por métodos tradicionais: (a) base de dados de entrada; (b) classificação usando Support Vector Machines (SVM); (c) classificação usando $k$-vizinhos mais próximos; (d) classificação ideal (Zhou et al., 2004).

custo a ser minimizada:

$$
\mathcal{Q}(\hat{Y})=\frac{1}{2}\left(\sum_{i, j=1}^{n} W_{i j}\left\|\frac{1}{\sqrt{D_{i i}}} \hat{Y}_{i}-\frac{1}{\sqrt{D_{i i}}} \hat{Y}_{j}\right\|^{2}+\mu \sum_{i=1}^{n}\left\|\hat{Y}_{i}-Y_{i}\right\|^{2}\right),
$$

onde $\mu>0$ é o parâmetro de regularização. O primeiro termo do lado direito da função de custo é a constante de suavidade, a qual significa que uma boa função de classificação não deve diferir muito entre pontos próximos. $O$ segundo termo é uma restrição de ajuste, que significa que uma boa função de classificação não deve diferir muito dos rótulos iniciais. O balanço entre essas duas restrições que competem entre si é capturada pelo parâmetro $\mu$. Note que a restrição de ajuste contém tanto dados rotulados quanto não rotulados.

Blum \& Chawla (2001); Zhu et al. (2003); Zhou et al. (2004); Belkin et al. (2004, 2005); Joachims (2003) também propuseram métodos semelhantes aos já apresentados, que também são equivalentes a frameworks de regularização e diferem apenas na escolha particular da função de perda e do regularizador. 


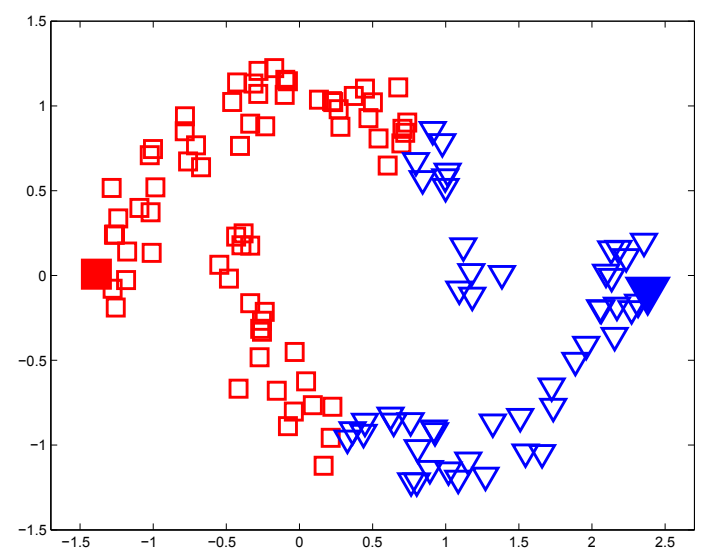

(a)

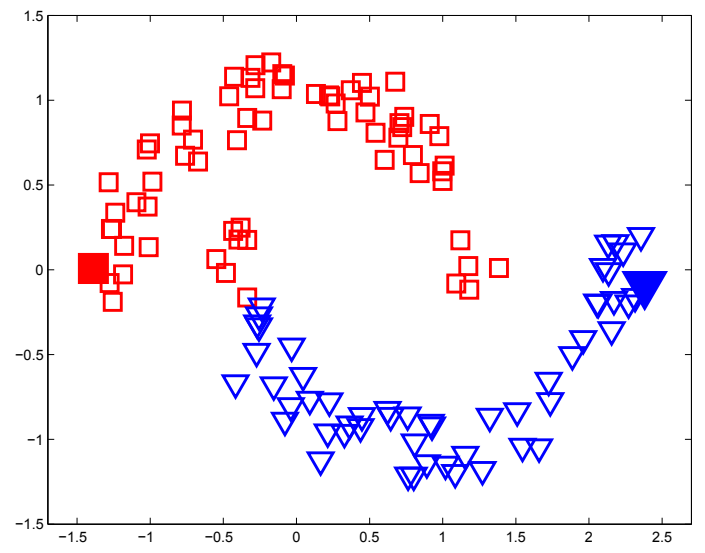

(c)

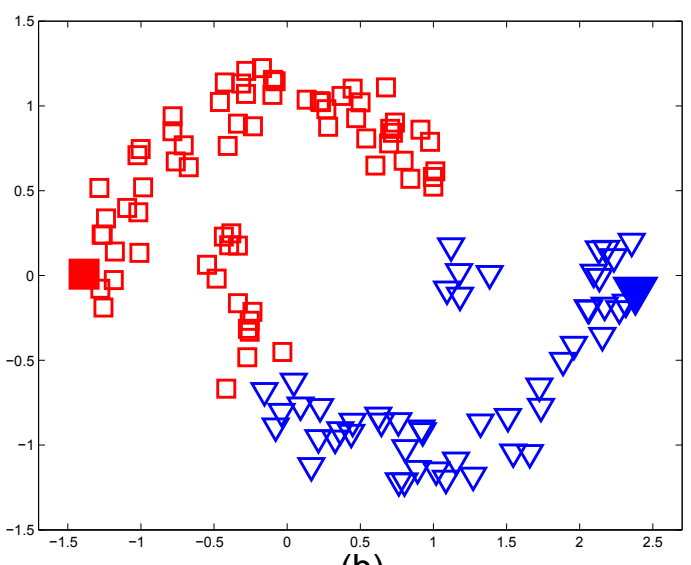

(b)

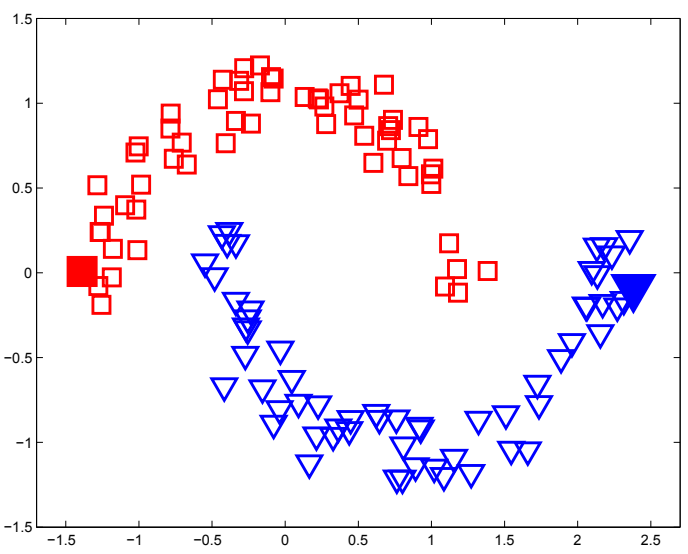

(d)

Figura 2.7: Classificação de um problema com duas classes em forma de banana pelo Método de Consistência Local e Global. Cada figura representa a classificação em um dado instante de tempo: (a) $t=10$; (b) $t=50$; (c) $t=100$; (d) $t=400$ (Zhou et al., 2004).

\section{Caminhadas Aleatórias}

Um tipo de algoritmo diferente, mas também baseado em propagação de rótulos através de grafos foi proposto por Szummer \& Jaakkola (2002). Eles utilizam caminhadas aleatórias de Markov $^{24} \mathrm{em}$ um grafo gerado a partir dos dados utilizando a Equação (2.30), onde as probabilidades de transição de um vértice $i$ para um vértice $j$,

$$
p_{i j}=\frac{W_{i j}}{\sum_{k} W_{i k}}
$$

é utilizada para estimar as probabilidades dos rótulos das classes. Cada ponto $\mathbf{x}_{i}$ é associado com uma probabilidade $P(y=1 \mid i)$ de estar na classe 1. Dado um ponto $\mathbf{x}_{k}$, podemos computar a probabilidade $P^{(t)}\left(y_{\text {inicio }}=1 \mid k\right)$ que iniciando de um dado ponto de classe $y_{\text {inicio }}=1$ chegaremos a $x_{k}$ após $t$ passos de 
caminhada aleatória utilizando

$$
P^{(t)}\left(y_{\text {inicio }}=1 \mid k\right)=\sum_{i=1}^{n} P(y=1 \mid i) P_{0 \mid t}(i \mid k),
$$

onde $P_{0 \mid t}(i \mid k)$ é a probabilidade de andar do vértice equivalente ao ponto $\mathbf{x}_{i}$ ao vértice equivalente ao ponto $\mathbf{x}_{k}$ após $t$ passos de caminhada aleatória. $\mathbf{x}_{k}$ será classificado na classe 1 se $P^{(t)}\left(y_{\text {inicio }}=1 \mid k\right)>0,5$, caso contrário será classificado na classe -1 . Os autores propuseram dois métodos para estimar as probabilidades, um baseado no algoritmo ME e outro em um critério de maximização de margem (Szummer \& Jaakkola, 2002).

O desempenho deste algoritmo é bastante dependente da escolha do parâmetro $t$, que é a quantidade de passos da caminhada (Zhu, 2005; Bengio et al., 2006). Métodos semelhantes também foram propostos por Zhu \& Ghahramani (2002); Zhu et al. (2003). Grady (2006) utilizou um método de caminhadas aleatórias para fazer segmentação interativa de imagens. Outros métodos de caminhada aleatória semelhantes também foram abordados por Maila \& Shi (2001a,b).

Apesar de muitos métodos de aprendizado semi-supervisionado baseados em grafos terem sido desenvolvidos, a maioria deles tem ordem de complexidade computacional alta $\left(O\left(n^{3}\right)\right)$, de forma que sua aplicação é limitada a base de dados pequenas e médias (Zhu, 2005). Conforme as bases de dados se tornam maiores, o desenvolvimento de métodos de aprendizado mais eficientes é bastante significativo.

\subsection{Sistemas Dinâmicos}

O conceito de sistemas dinâmicos tem suas origens na mecânica Newtoniana. Um sistema dinâmico pode ser definido como uma fórmula matemática que descreve a evolução de estados de um sistema no decorrer do tempo. $O$ tempo pode ser uma variável contínua ou discreta, de forma que a fórmula é uma equação diferencial ou uma equação diferença, respectivamente. Para determinar o estado para todos os tempos futuros é necessário iterar essa relação muitas vezes, cada uma avançando um pequeno espaço no tempo. 
Um sistema dinâmico contínuo de primeira ordem é dado por:

$$
\begin{aligned}
\frac{d x_{1}}{d t} & =F_{1}\left(x_{1}, x_{2}, \ldots, x_{N}\right), \\
\frac{d x_{2}}{d t} & =F_{2}\left(x_{1}, x_{2}, \ldots, x_{N}\right), \\
& \vdots \\
\frac{d x_{N}}{d t} & =F_{N}\left(x_{1}, x_{2}, \ldots, x_{N}\right)
\end{aligned}
$$

onde $t$ determina o tempo e $N$ é a dimensão do sistema. $F$ pode ser uma função linear ou não-linear, quando $F$ é linear temos um sistema dinâmico linear, e quando $F$ é não linear temos um sistema dinâmico não-linear. Essa equação pode ser reescrita na forma vetorial:

$$
\begin{aligned}
\dot{\mathbf{x}} & =F(\mathbf{x}, \mu) \\
\mathbf{x}\left(t_{0}\right) & =\mathbf{x}_{0}
\end{aligned}
$$

onde $\mathrm{x} \in U \subset \mathbb{R}^{N}$ é o vetor de estados, $\mu \in V \subset \mathbb{R}^{P}$ é o vetor de parâmetros e $U$ e $V$ são conjuntos abertos em $\mathbb{R}^{N}$ e $\mathbb{R}^{P}$ respectivamente com $F: \mathbb{R}^{N} \rightarrow \mathbb{R}^{N}$. O ponto sobre $\mathrm{x}$ na Eq. (2.37) indica $\frac{d}{d t}$, $\mathrm{x}_{0}$ é o estado inicial e a função $F$ descreve como o sistema evolui no tempo.

Partindo de qualquer estado inicial de $\mathbf{x}_{0}$ no tempo $t_{0}$, o sistema alcançará um futuro estado $\mathbf{x}\left(t, t_{0}, x_{0}\right)$ para $t>0$. O caminho gerado pela mudança contínua de estados no espaço de fase é chamado de órbita ou trajetória. Se $F$ é uma função contínua e diferenciável, existe uma única solução para a Eq. (2.37) dada o estado inicial $\mathrm{x}_{0}$ (Ott, 1994).

Um sistema dinâmico com tempo discreto pode ser especificado pela seguinte equação:

$$
\begin{aligned}
\mathbf{x}(t+1) & =F(\mathbf{x}(t), \mu), \\
\mathbf{x}(0) & =\mathbf{x}_{0}
\end{aligned}
$$

onde $\mathrm{x} \in \mathbb{R}^{N}, \mu \in \mathbb{R}^{P}, t \in Z^{+}$corresponde a um número inteiro que denota o tempo, e a função $F: \mathbb{R}^{N} \rightarrow \mathbb{R}^{N}$. x representa o vetor de estados, $\mu$ representa o vetor de parâmetros, $\mathbf{x}_{0}$ é o estado inicial e a função $F$ descreve como o sistema evolui no tempo.

Os sistemas dinâmicos também poder ser classificados como autônomos e não-autônomos. Em um sistema dinâmico autônomo a evolução de variáveis não depende explicitamente do tempo $t$. Um sistema dinâmico discreto autônomo pode ser representado da seguinte forma:

$$
\mathbf{x}(t+1)=F(\mathbf{x}, \mu)
$$


$\operatorname{com} F: \mathbb{R}^{N} \rightarrow \mathbb{R}^{N}$. Por conseguinte, em um sistema dinâmico não-autônomo, a evolução depende explicitamente do tempo $t$, de modo que a função $F$ da equação (2.39) recebe um termo extra (que é o tempo $t$ ) e assume a seguinte forma:

$$
\mathbf{x}(t+1)=F(t, \mathbf{x}, \mu)
$$

$\operatorname{com} F: \mathbb{Z}^{+} \times \mathbb{R} \times \mathbb{R} \rightarrow \mathbb{R}$.

\subsubsection{Comportamento Assintótico}

Um dos principais interesses no estudo de sistemas dinâmicos é o estudo do comportamento assintótico, ou seja, o comportamento que o sistema dinâmico assume quando $t \rightarrow \infty$. Nesse contexto os sistemas dinâmicos podem apresentar vários tipos de atratores. De forma qualitativa, um atrator é uma região ou um ponto no espaço de estados do sistema para onde as trajetórias convergem a partir de um conjunto de condições iniciais. Os tipos de atratores mais comuns são: ponto fixo, ciclo limite, quase-periódico e caótico.

A seguir são ilustrados cada um dos tipos de atratores citados, utilizando como exemplo um mapa logístico. O mapa logístico é um sistema dinâmico discreto, não-linear, unidimensional e autônomo, dado pela equação:

$$
x(t+1)=a x(t)(1-x(t))
$$

onde $t$ representa o tempo discreto, $x$ é a variável de estado e $a$ é chamado parâmetro de bifurcação. Na Figura 2.8 pode ser observado o diagrama de bifurcação para o mapa logístico, através dele é possivel observar a transição entre os diversos tipos de comportamentos dinâmicos que este mapa pode apresentar, dependendo do parâmetro de bifurcação $a$.

\section{Dinâmica de Ponto Fixo}

A dinâmica de ponto fixo também é conhecida como dinâmica estacionária. Um ponto fixo, também conhecido como ponto de equilíbrio, é um estado no qual um sistema livre de perturbações permanece indefinidamente, uma vez que o tenha atingido.

Em um sistema dinâmico contínuo, os pontos fixos são os pontos x em que:

$$
\dot{\mathbf{x}}=F(\mathbf{x}(t))=\mathbf{0} .
$$

Em um sistema dinâmico discreto, os pontos fixos são os pontos x em que:

$$
\mathbf{x}(t+1)=\mathbf{x}(t)
$$

A Figura 2.9 apresenta a trajetória (série temporal) do mapa logístico da Eq. 


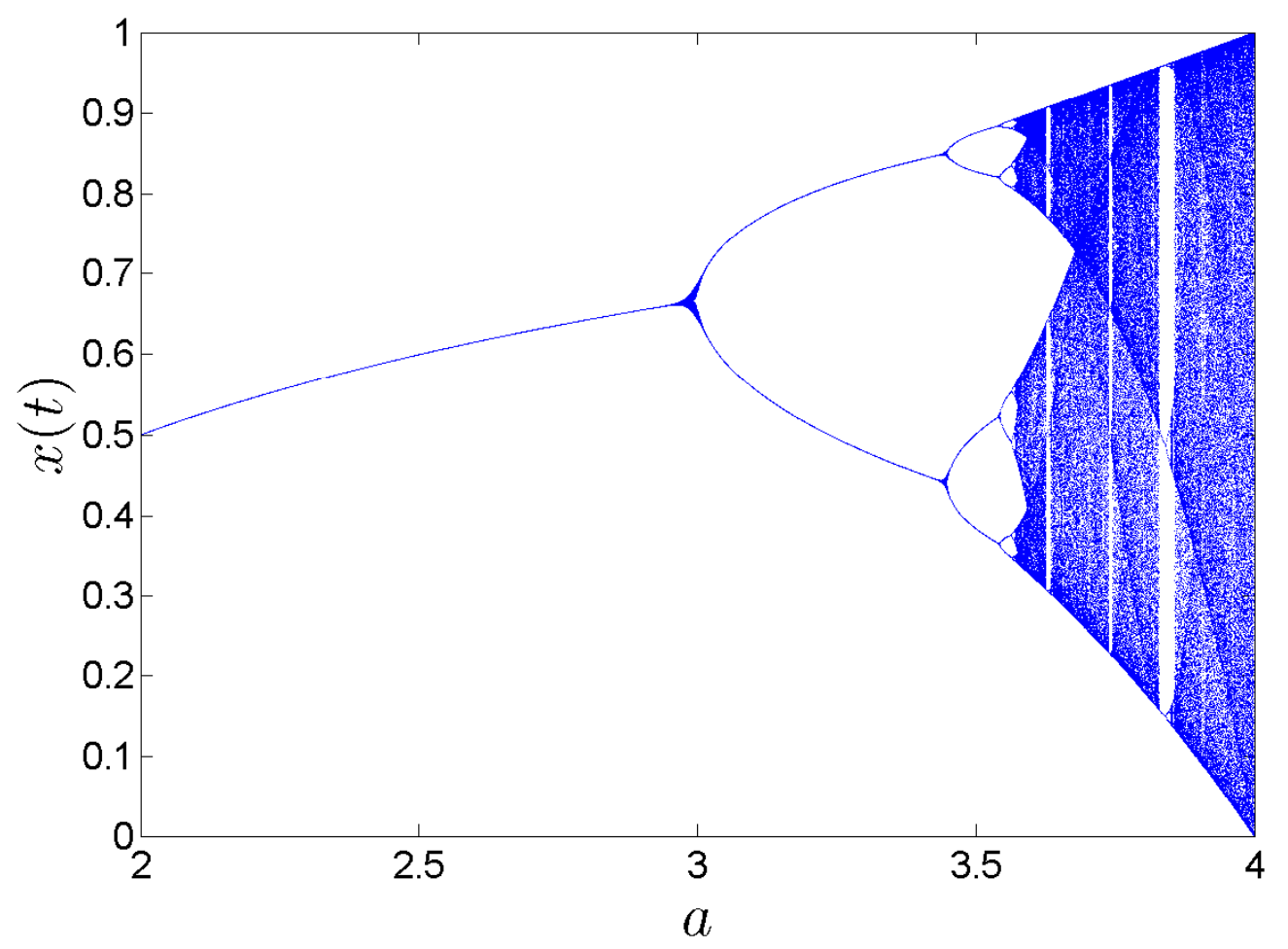

Figura 2.8: Diagrama de bifurcação para o mapa logístico.

(2.41) quando o coeficiente de bifurcação $a=2,8$ e a condição inicial $x(0)=$ 0,1 . É possível observar que após algumas iterações, o estado do sistema permanece fixo em $x(t)=0,6429$, ou seja, ele converge para esse ponto fixo.

\section{Dinâmica Ciclo Limite}

A dinâmica periódica ou dinâmica de ciclo limite caracteriza-se por um tipo de atrator no qual o comportamento do sistema se repete ao longo do tempo. O número de iterações entre repetições é o período do ciclo, e os pontos de um ciclo limite são chamados pontos periódicos. Um ciclo de período $n$ ocorre se a seguinte condição é satisfeita:

$$
\mathbf{x}(t+n)=\mathbf{x}(t) \quad \text { mas } \quad \mathbf{x}(t+j) \neq \mathbf{x}(t) \quad \text { para } \quad j=1,2,3, \ldots, n-1 .
$$

Por exemplo, a condição de um ciclo com período 2 é:

$$
\mathbf{x}(t+2)=\mathbf{x}(t) \quad \text { e } \quad \mathbf{x}(t+1) \neq \mathbf{x}(t) .
$$

Outra maneira de descrever um comportamento periódico é:

$$
F^{n}(\mathbf{x})=\mathbf{x}
$$

onde $F^{n}$ representa a $n$-ésima iteração da função $F: F(F(F(\ldots F(\mathbf{x}))))$ onde $f(\mathbf{x})$ 


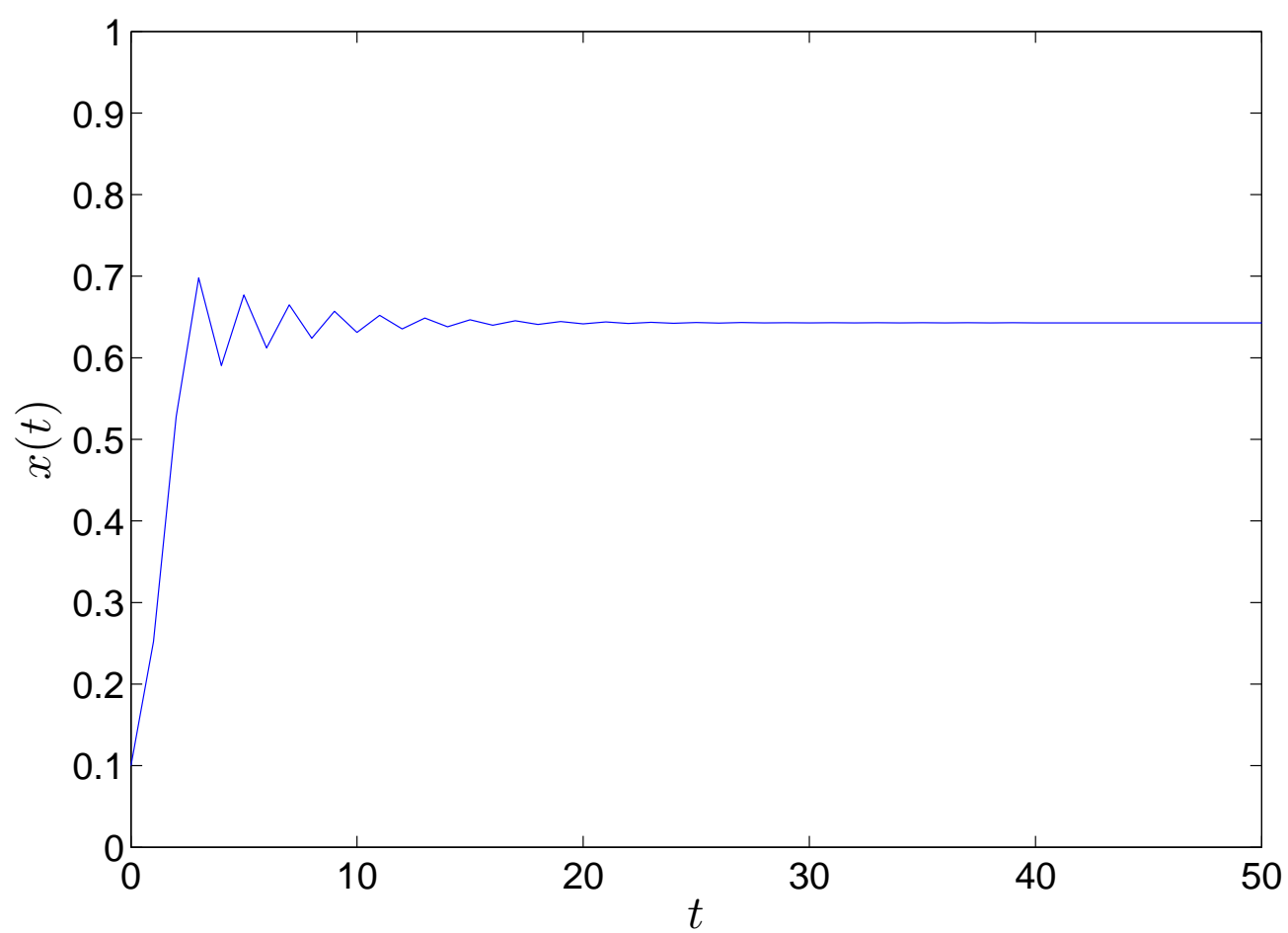

Figura 2.9: Dinâmica de Ponto Fixo no mapa logístico com coeficiente de bifurcação $a=2,8$.

é repetido $n$ vezes.

A Figura 2.10 apresenta uma trajetória do mapa logístico descrito na Eq. (2.41) quando $a=3,4$. Com essa configuração o sistema apresenta um comportamento periódico com um ciclo de período 2 .

Na Figura 2.11 também é apresentada uma trajetória periódica, mas com $a=3,5$. Nesse caso o sistema apresenta um ciclo de período 4 .

\section{Dinâmica Quase-Periódica}

A dinâmica quase-periódica é assim chamada pois as trajetórias quaseperiódicas se assemelham a trajetórias periódicas, porém na dinâmica quaseperiódica nenhum estado se repete para $t \rightarrow \infty$.

A Figura 2.12 ilustra o comportamento quase-periódico de uma trajetória do mapa logístico descrito na Eq. (2.41) quando $a=3,82$. Nela é possível observar uma trajetória semelhante a periódica, porém sem repetição de estados.

\section{Dinâmica Caótica}

Qualitativamente, o caos pode ser definido como uma dinâmica limitada não-periódica em um sistema determinístico com grande sensibilidade a condição inicial do sistema (Kaplan \& Glass, 1995). Essas características estão 


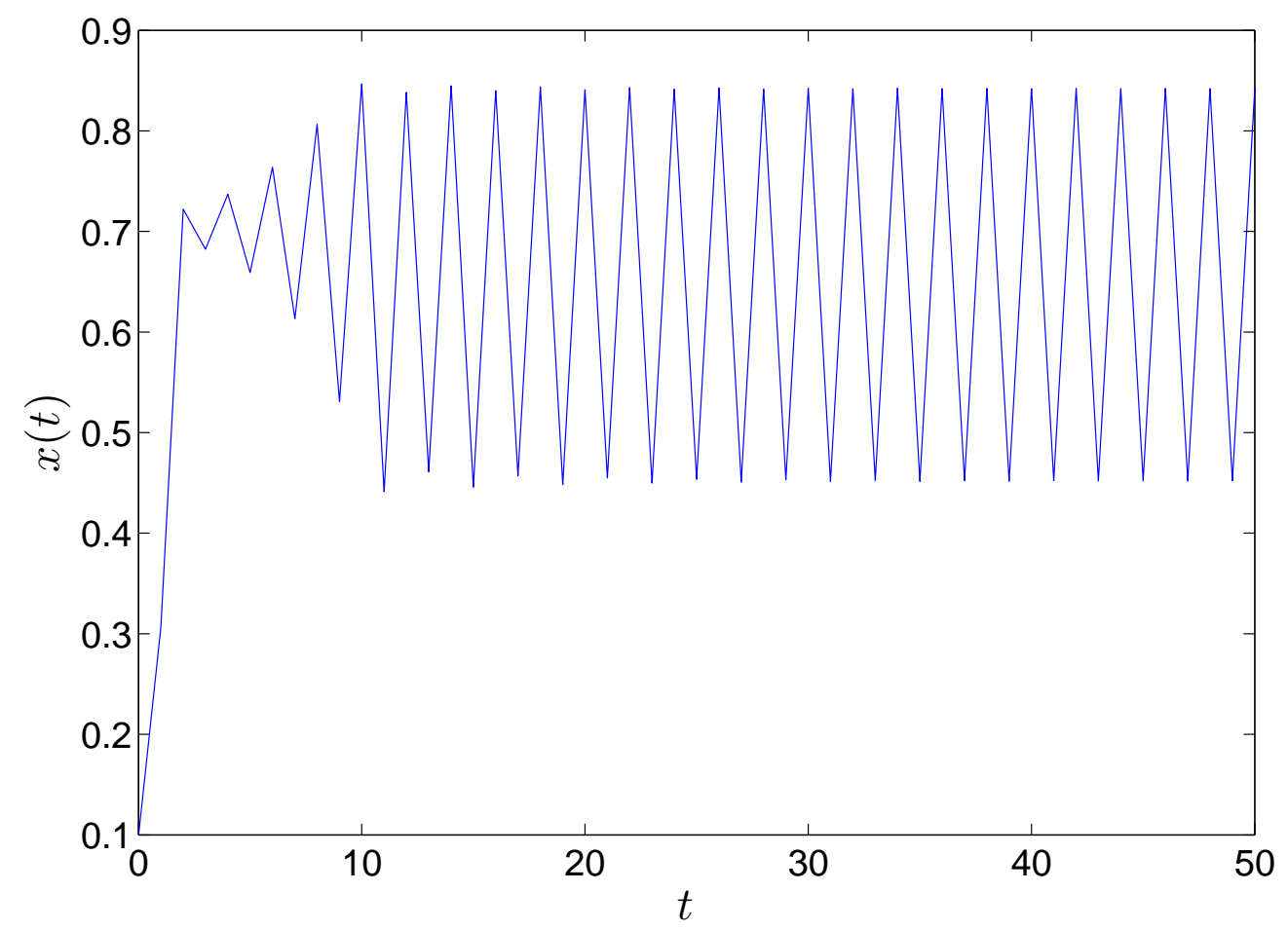

Figura 2.10: Dinâmica de Ciclo Limite no mapa logístico com coeficiente de bifurcação $a=3,4$ e 2 pontos periódicos.

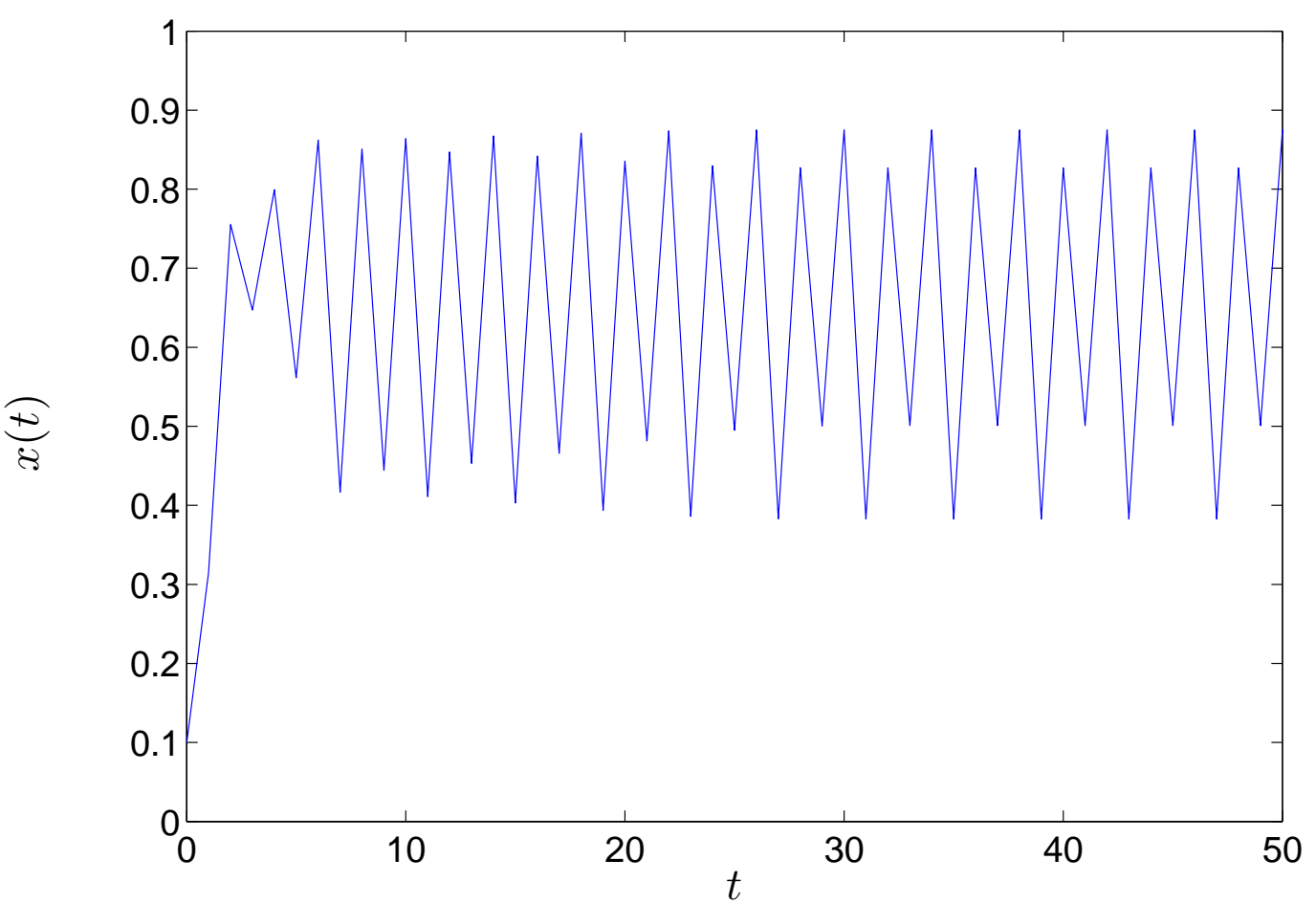

Figura 2.11: Dinâmica de Ciclo Limite no mapa logístico com coeficiente de bifurcação $a=3,5$ e 4 pontos periódicos. 


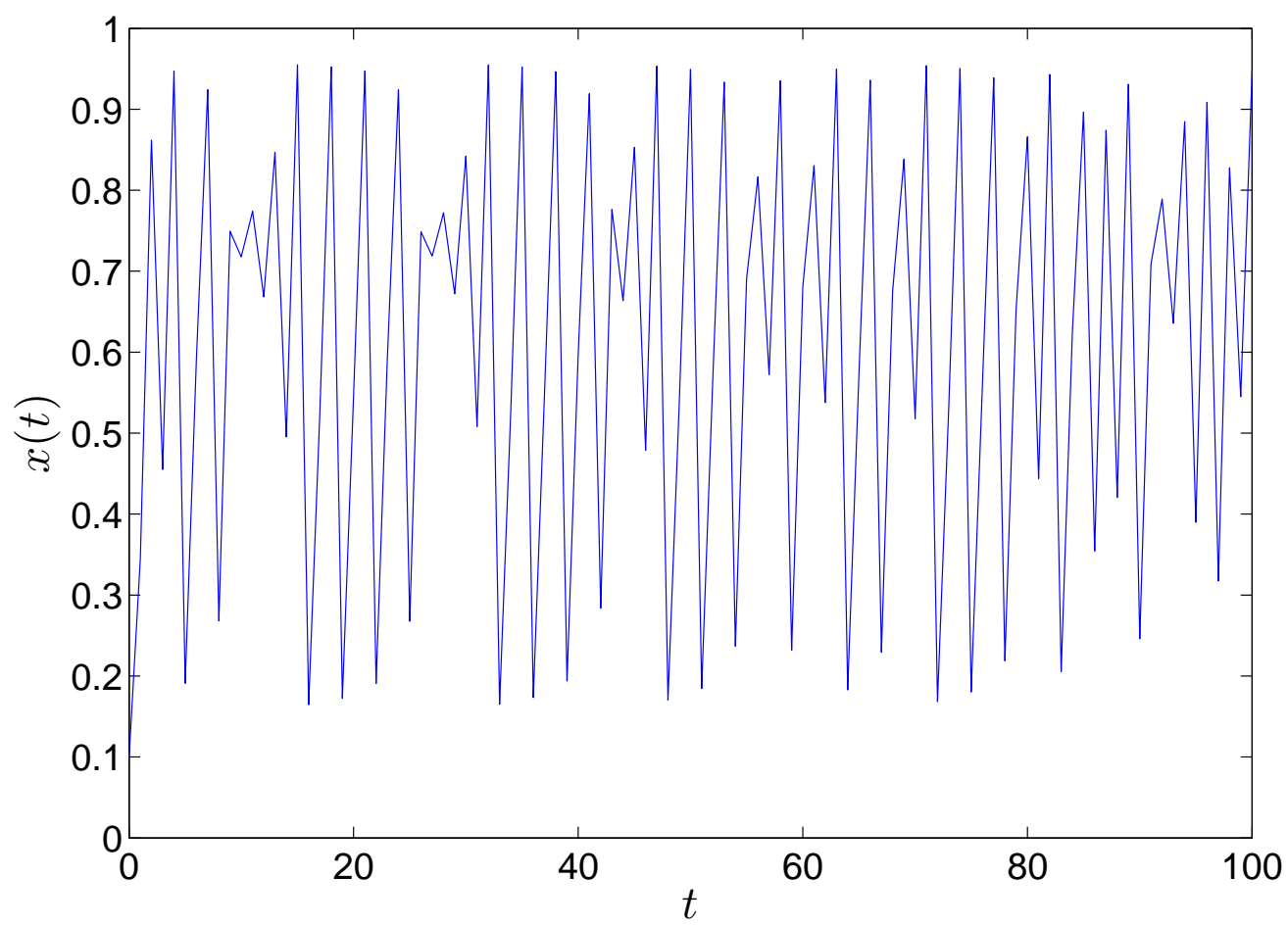

Figura 2.12: Dinâmica Quase-Periódica no mapa logístico com coeficiente de bifurcação $a=3,82$.

detalhadas abaixo:

Limitado Com evolução do sistema para $t \rightarrow \infty$ a variável de estado permanece em sub-espaço limitado, ou seja, não diverge para $\pm \infty$. Por exemplo, no caso do mapa logístico com coeficiente de bifurcação $a=4,0$ e condição inicial $x(t)=0,1$ a variável de estado permanece restrita no intervalo fechado $x \in[0,1]$, conforme ilustrado na Figura 2.13.

Não Periódico Um estado do sistema nunca ocorre mais de uma vez. É importante considerar que ao simular tais sistemas em computadores com precisão finita, um estado pode eventualmente ser repetido.

Determinístico O sistema é governado por regras bem definidas, não aleatórias, de modo que para cada $\mathbf{x}(t)$ existe um único $\mathbf{x}(t+1)$.

Sensivel a condição inicial Este é um aspecto essencial do caos. Dois pontos inicialmente próximos terão trajetórias totalmente diferentes com o decorrer do tempo. Este fenômeno, também conhecido como efeito borboleta, é ilustrado na Figura 2.14, onde são mostradas duas trajetórias caóticas de mapas logísticos com coeficiente de bifurcação $a=4,0$. A trajetória representada pelas duas linhas tem condição inicial $x_{1}(0)=0,1$ e $x_{2}(0)=0,100001$. Após poucas iterações as trajetórias se separam e seguem caminhos bastante diferentes. 


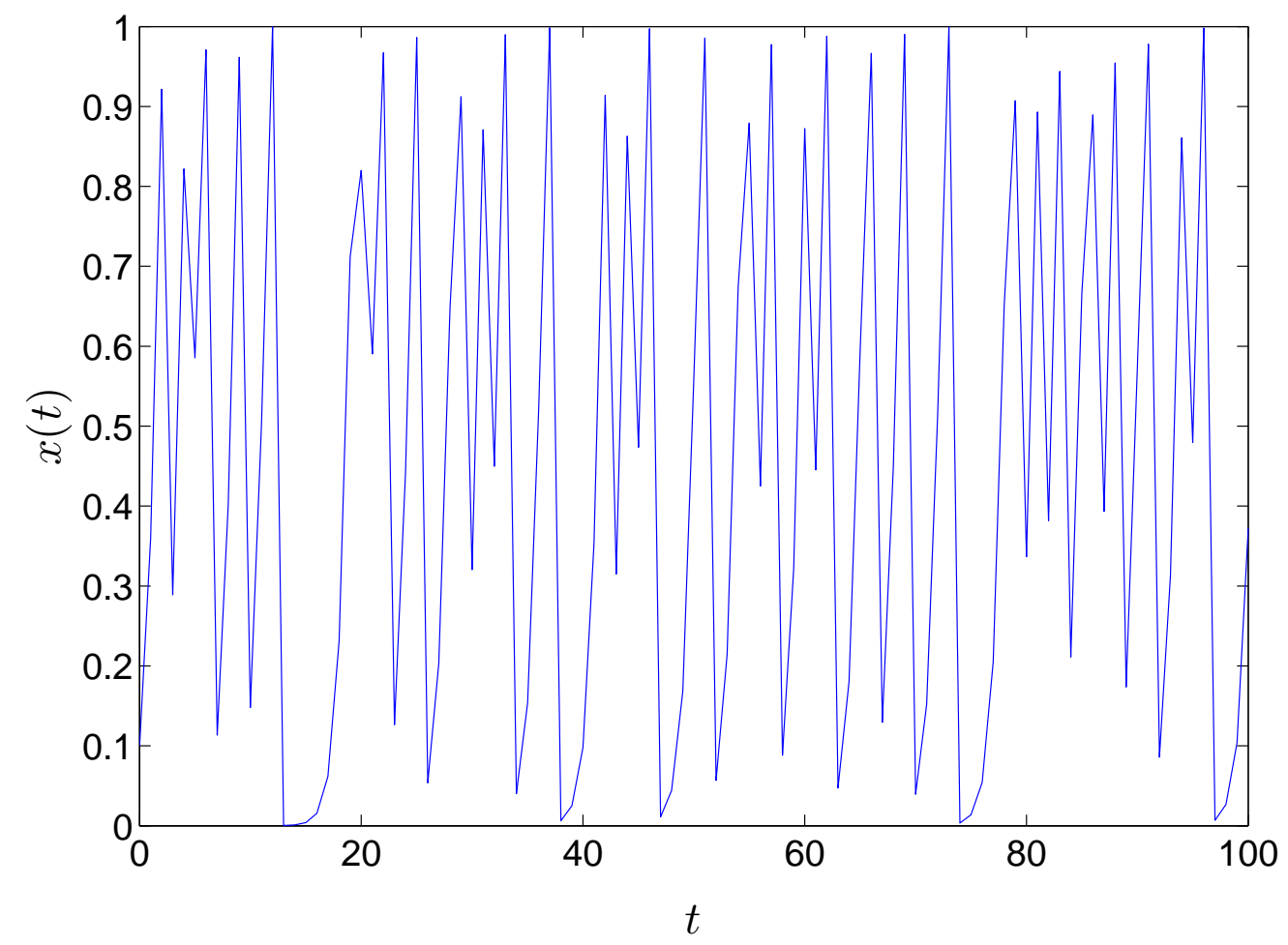

Figura 2.13: Dinâmica Caótica com coeficiente de bifurcação $a=4,0$.

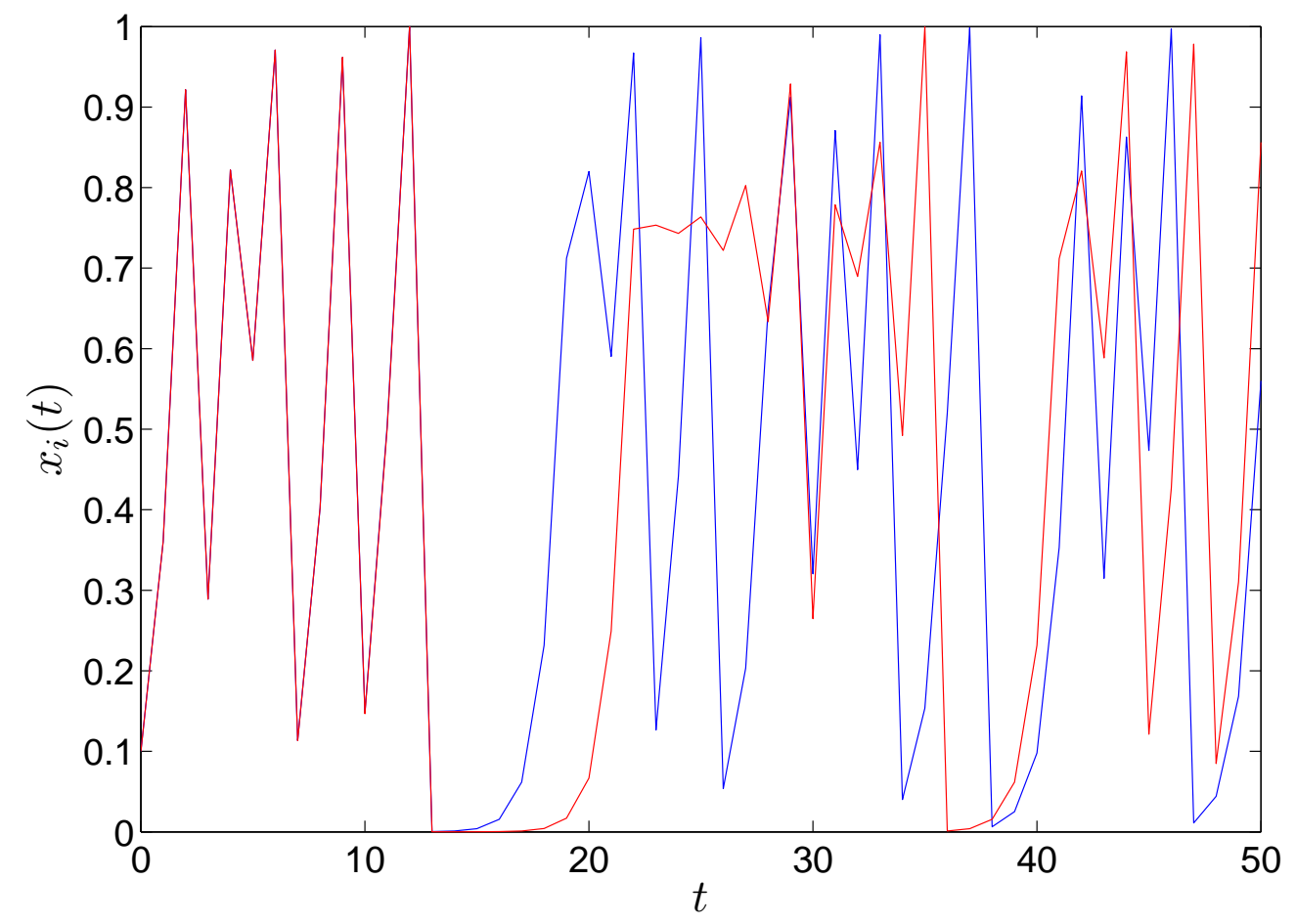

Figura 2.14: Duas trajetórias caóticas de mapas logísticos com coeficiente de bifurcação $a=4,0$ e condições iniciais $x_{1}(0)=0,1$ e $x_{2}(0)=0,100001$. 
O caos descreve um tipo complexo de dinâmica em sistemas dinâmicos não lineares. O comportamento caótico parece irregular e quase aleatório, como se o sistema fosse extremamente complexo ou estivesse sendo influenciado por um ruído externo. Porém mesmo sistemas não-lineares simples podem apresentar comportamento bastante complexo (Kaplan \& Glass, 1995).

É importante destacar que mesmo com os sistemas sendo determinísticos, o comportamento caótico fornece um extraordinário problema de previsibilidade, em que é muito difícil prever os estados futuros de um sistema em curto prazo e impossível de prevê-los a longo prazo. Isto resulta da divergência exponencial que acontece entre trajetórias próximas, de modo que qualquer ruído ou imprecisão na condição inicial leva o sistema a se comportar de maneira totalmente diferente. Assim, a menos que a condição inicial possa ser definida com absoluta precisão, o comportamento de um sistema caótico é indeterminável em longo prazo.

Através do diagrama de bifurcação mostrado na Figura 2.8 é possivel observar que ao aumentar o valor de $a$ o mapa logístico transita entre os diversos tipos de comportamentos dinâmicos apresentados. No ponto $a=3$ o mapa logístico passa de uma dinâmica de ponto fixo para uma dinâmica periódica de período 2. Este ponto é chamado de estado de duplicação de período. Outro estado de duplicação é encontrado quando a se aproxima de 3,5 , nesse caso o mapa logístico continua apresentando uma dinâmica periódica, porém o período dobra, passando de 2 para 4. Para $a>3,5$ o sistema começa a apresentar comportamentos bastante complexos, variando de órbitas com período maior que 4 até órbitas caóticas.

Outra forma de verificar se um sistema está em um comportamento caótico é através da análise dos Expoentes de Lyapunov (Ott, 1994), que é definido da seguinte forma:

$$
\lambda_{i}=\lim _{k \rightarrow \infty} \frac{1}{k} \ln \left|\mathbf{D}_{k}\left(\mathbf{x}_{i}\right) \mathbf{u}_{i}\right|
$$

onde $k$ é o número de iterações em que o sistema é observado, $\lambda_{i}$ é o $i$-ésimo expoente de Lyapunov do mapa $N$-dimensional, $\mathbf{D}_{k}$ é uma matriz formada pelos $N$ autovalores da matriz $\mathbf{J}$ definida e $\mathbf{u}_{i}$ são os autovetores associados aos autovalores da matriz $\mathbf{D}_{k}$. A matriz $J$ é dada por:

$$
\mathbf{J}(\mathbf{x})=\prod_{t=t_{0}}^{k} J(\mathbf{x}(t))
$$

onde $J(\mathbf{x}(t))$ é a matriz Jacobiana do mapa no instante $t$.

Expoentes de Lyapunov positivos indicam que o sistema está em uma dinâmica caótica, ou seja, se ao menos um dos $N$ expoentes de Lyapunov for positivo o sistema pode ser considerado caótico. Valores negativos indicam 
que o sistema está em uma dinâmica periódica ou de ponto-fixo. Quando o expoente é um valor nulo, o sistema se encontra em uma dinâmica quaseperiódica ou em uma mudança qualitativa do sistema representada por um ponto de bifurcação.

Para o mapa logístico unidimensional apresentado na Eq. (2.41) o expoente de Lyapunov é definido por:

$$
\lambda=\lim _{k \rightarrow \infty} \frac{1}{k} \sum_{t=t_{0}}^{k} \ln \left|f^{\prime}(x(t))\right|,
$$

onde $f^{\prime}(x(t))$ é a derivada primeira do mapa logístico da Equação (2.41) e é dada por:

$$
f^{\prime}(x(t))=a(1-2 x(t)) .
$$

A Figura 2.15 mostra os coeficientes de Lyapunov para o mapa logístico.

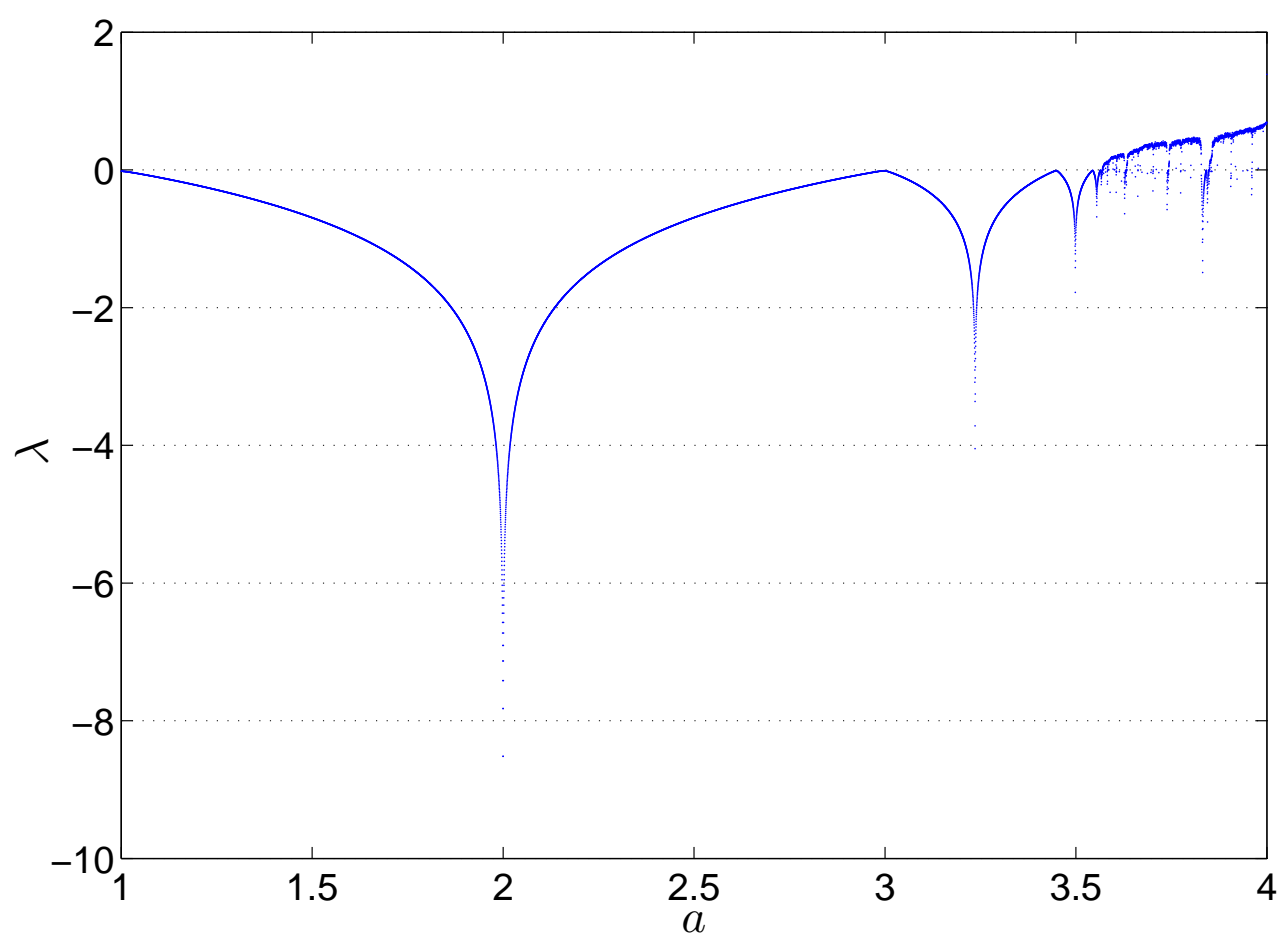

Figura 2.15: Expoentes de Lyapunov para o mapa logístico da Equação (2.41).

\subsubsection{Sincronização em Sistemas Caóticos}

Sincronização é uma característica básica de sistemas não-lineares. O pesquisador holandês Christiaan Huygens foi o primeiro a observar e descrever este fenômeno em dois osciladores periódicos acoplados, mais precisamente em dois relógios de pêndulo pendurados em um suporte comum, uma viga de madeira em uma casa. Ele observou que os pêndulos oscilavam exatamente 
na mesma freqüência e com uma diferença de fase de 180 graus. Quando um dos pêndulos era perturbado, a sincronização se restabelecia em um período de meia hora e permanecia indefinidamente (Bennett et al., 2002).

Os sistemas caóticos têm como característica um comportamento imprevisível a longo prazo, porém é possível forçar dois sistemas caóticos a se "travarem" um ao outro e permanecerem sincronizados (Pecora et al., 1997), através da utilização de um sinal condutor comum ou através de um acoplamento. A sincronização de sistemas caóticos foi descoberta por Fujisaka \& Yamada (1983), e tem sido um tópico de grande interesse desde o início da década de 1990 com o trabalho de Pecora \& Carroll (1990). Esse interesse aumentou ainda mais quando Hayes et al. (1994) mostraram ser possivel codificar mensagens dentro de sistemas caóticos, demonstrando seu potencial para sistemas de comunicação.

Existem diferentes tipos de sincronização para sistemas caóticos: sincronização completa, sincronização por fase ${ }^{25}$, sincronização com atraso ${ }^{26}$, sincronização antecipatória $^{27}$, e sincronização generalizada ${ }^{28}$. A sincronização completa é definida como a completa coincidência de trajetórias de sistemas caóticos individuais acoplados, ou seja, dados os vetores de variáveis $\mathrm{x}$ e y representado dois sistemas dinâmicos, eles estarão completamente sincronizados se $|x(t)-y(t)| \rightarrow 0$ conforme $t \rightarrow \infty$. A sincronização por fase é definida como uma perfeita sincronização das fases de subsistemas oscilatórios utilizando uma pequena força de acoplamento, enquanto as amplitudes permanecem não relacionadas (Rosenblum et al., 1996). A sincronização com atraso ocorre em subsistemas oscilatórios utilizando uma força de acoplamento mais forte até que os sistemas se tornem idênticos em fase e amplitude, porém com um deslocamento no tempo (Rosenblum et al., 1997). A sincronização antecipatória ocorre em esquemas de acoplamentos unidirecionais e produz um comportamento onde a saída do sistema de resposta antecipa a saída do sistema dirigente (Voss, 2000). Finalmente, a sincronização generalizada implica que a trajetória de um subsistema é função da trajetória de outro(s) (Hramov \& Koronovskii, 2005; Uchida et al., 2003).

Nas subseções a seguir serão mostrados alguns detalhes e exemplos utilizando sincronização completa e sincronização por fase.

\section{Sincronização Completa}

A sincronização completa se caracteriza pela completa coincidência das trajetórias de dois ou mais sistemas acoplados. Matematicamente, se $x$ e $y$ são

\footnotetext{
25 do inglês: phase synchronization

26 do inglês: lag synchronization

27 do inglês: anticipating synchronization

28 do inglês: generalized synchronization
} 
dois sistemas dinâmicos, dizemos que eles estão completamente sincronizados se $|x(t)-y(t)| \rightarrow 0$ conforme $t \rightarrow \infty$.

Para demonstrar a sincronização completa utilizaremos inicialmente o mapa logístico da Equação (2.41), que é um sistema dinâmico discreto. E em seguida será mostrado também o oscilador neural Wilson-Cowan, que é um sistema dinâmico contínuo.

Dois mapas logísticos podem ser acoplados da seguinte forma:

$$
\begin{aligned}
& x_{1}(t)=(1-\varepsilon) f\left(x_{1}(t)\right)+\varepsilon f\left(x_{2}(t)\right), \\
& x_{2}(t)=(1-\varepsilon) f\left(x_{2}(t)\right)+\varepsilon f\left(x_{1}(t)\right),
\end{aligned}
$$

onde $\varepsilon$ é um parâmetro chamado força de acoplamento e $f(x)$ é o mapa logístico da Equação (2.41). Na Figura 2.16 vemos as séries temporais de dois mapas logísticos acoplados $\operatorname{com} \varepsilon=0,45$, bem como a diferença entre eles. É possível observar que as trajetórias coincidem após algumas iterações.

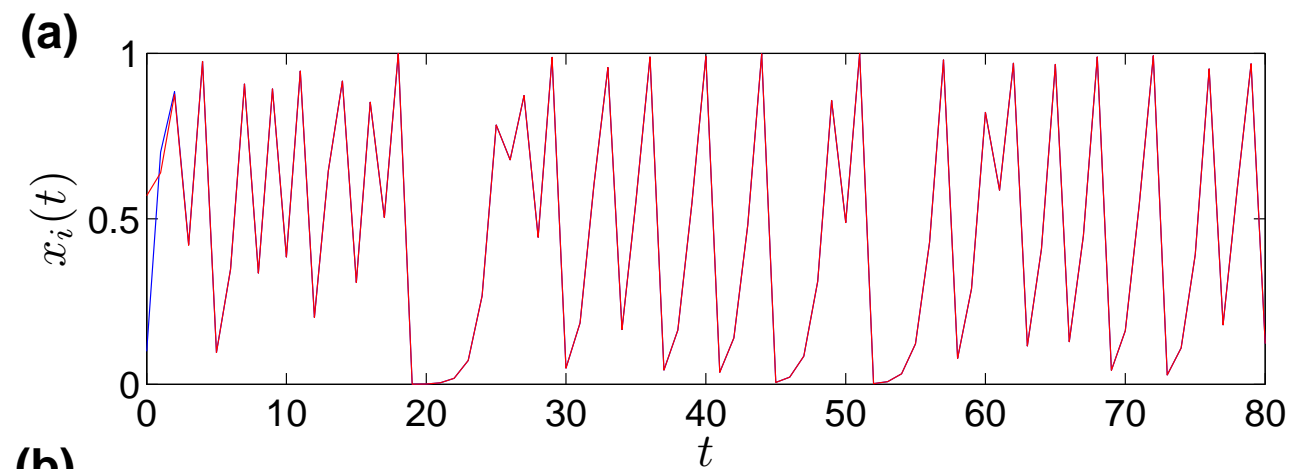

(b)

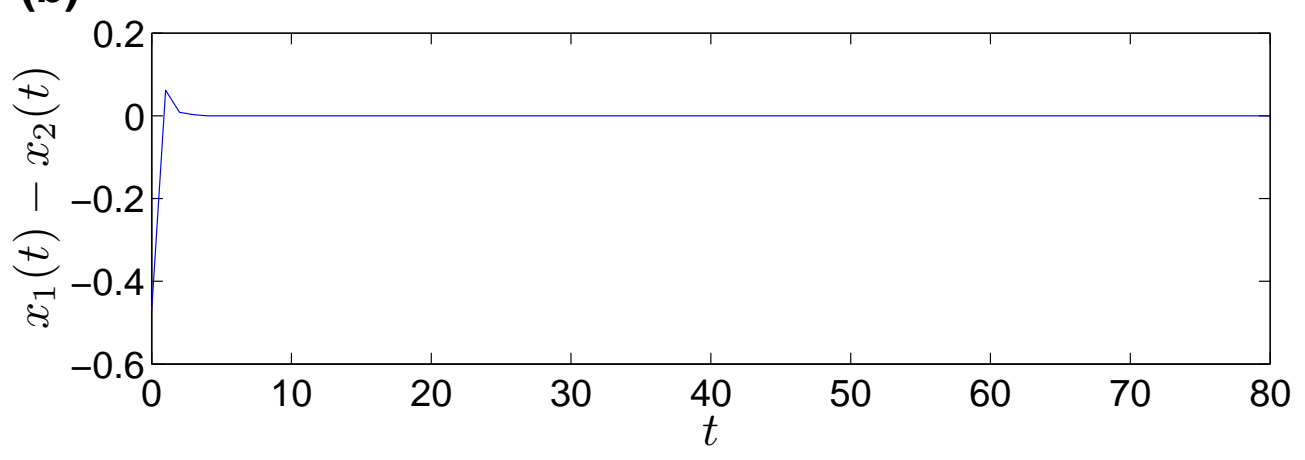

Figura 2.16: Dois mapas logísticos acoplados $\operatorname{com} \varepsilon=0,45$. (a) Séries temporais dos dois osciladores juntos (b) Diferença entre os dois osciladores.

A Figura 2.17 também mostra dois mapas logísticos acoplados, porém nesse caso $\varepsilon=0,23$, um acoplamento muito fraco e portanto as trajetórias permanecem separadas.

A Equação (2.51) pode ser estendida para acoplar diversos mapas logísticos 


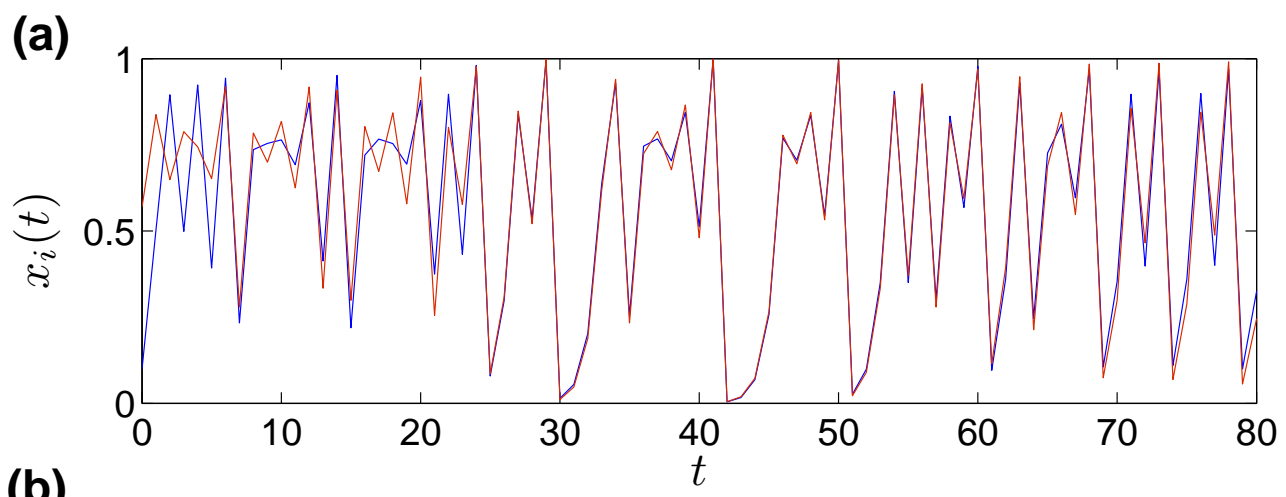

(b)

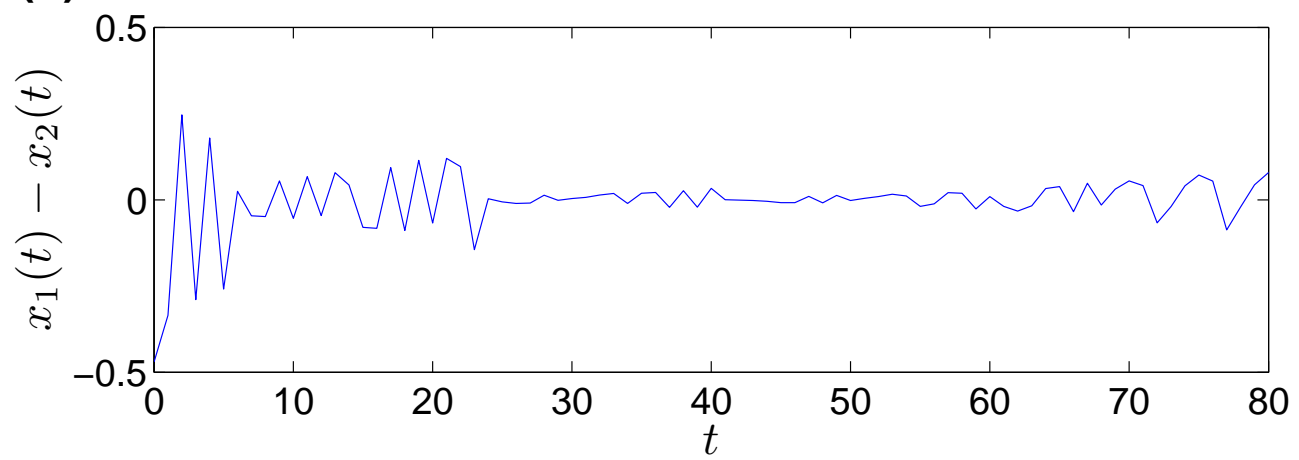

Figura 2.17: Dois mapas logísticos acoplados $\operatorname{com} \varepsilon=0,23$. (a) Séries temporais dos dois osciladores juntos (b) Diferença entre os dois osciladores.

globalmente, assumindo a seguinte forma:

$$
x_{i}(t+1)=(1-\varepsilon) f\left(x_{i}(t)\right)+\frac{\varepsilon}{N} \sum_{j=1}^{N} f\left(x_{j}(t)\right),
$$

onde $N$ é a quantidade de mapas. Tal arranjo é conhecido como GCM (Globally Coupled Map) e tem despertado interesse em diversas áreas, incluindo dinâmica evolutiva e neurodinâmica (Kaneko, 1994). Zhao et al. (2004) estenderam o GCM com um acoplamento adaptativo para aplicá-lo em agrupamento de pixels, este modelo está descrito na Seção 2.3.4

Para mostrar a sincronização completa em sistemas contínuos será utilizado o oscilador de Wilson-Cowan, que tem sido bastante usado na modelagem de redes neurais. Ele é modelado como um laço de retorno entre uma unidade excitatória e uma inibitória como segue:

$$
\begin{aligned}
\dot{x} & =-a x+G\left(c x+e y+I-\theta_{x}\right), \\
\dot{y} & =-b y+G\left(d x+f y-\theta_{y}\right), \\
G(v) & =\frac{1}{1+e^{-v / T}},
\end{aligned}
$$

onde $a$ e $b$ são parâmetros de decaimento (números positivos) de $x$ e $y$ respectivamente, $c$ e $f$ são parâmetros auto-excitatórios; $e$ é a força de acoplamento 
da unidade inibitória $y$ para a unidade excitatória $x$, e é um valor negativo para garantir que a variável $y$ haja como inibitória. A força de acoplamento de $x$ para $y$ é dada por $d$. $\theta_{x}$ e $\theta_{y}$ são limiares das unidades $x$ e $y$ respectivamente. $G(\bullet) \in[0,1]$ é uma função sigmoidal e $T$ define a sua inclinação. $I$ é um estímulo externo. Se $I$ é uma constante, não existe caos, pois será um fluxo bidimensional contínuo. Para obter um oscilador caótico, o estímulo externo precisa ser definido como uma função periódica:

$$
I(t)=A \cos (t)
$$

onde $A$ é a amplitude da função dirigente.

Os experimentos mostrados a seguir utilizam os parâmetros constantes: $A=1,2, a=1,0, b=0,001, c=1,0, d=0,6, e=-2,5, f=0,0, \theta_{x}=0,2, \theta_{y}=0,15$ e $T=0,025$, os mesmos valores utilizados por Wang (1995) e Zhao et al. (2000). Como pode ser observado nas Figuras 2.18 e 2.19, com esses parâmetros o oscilador Wilson-Cowan apresenta um comportamento caótico. As equações diferenciais foram resolvidas numericamente usando o método Runge-Kutta (RK4) (Press et al., 2002) com o tamanho de passo definido em $0,01$.
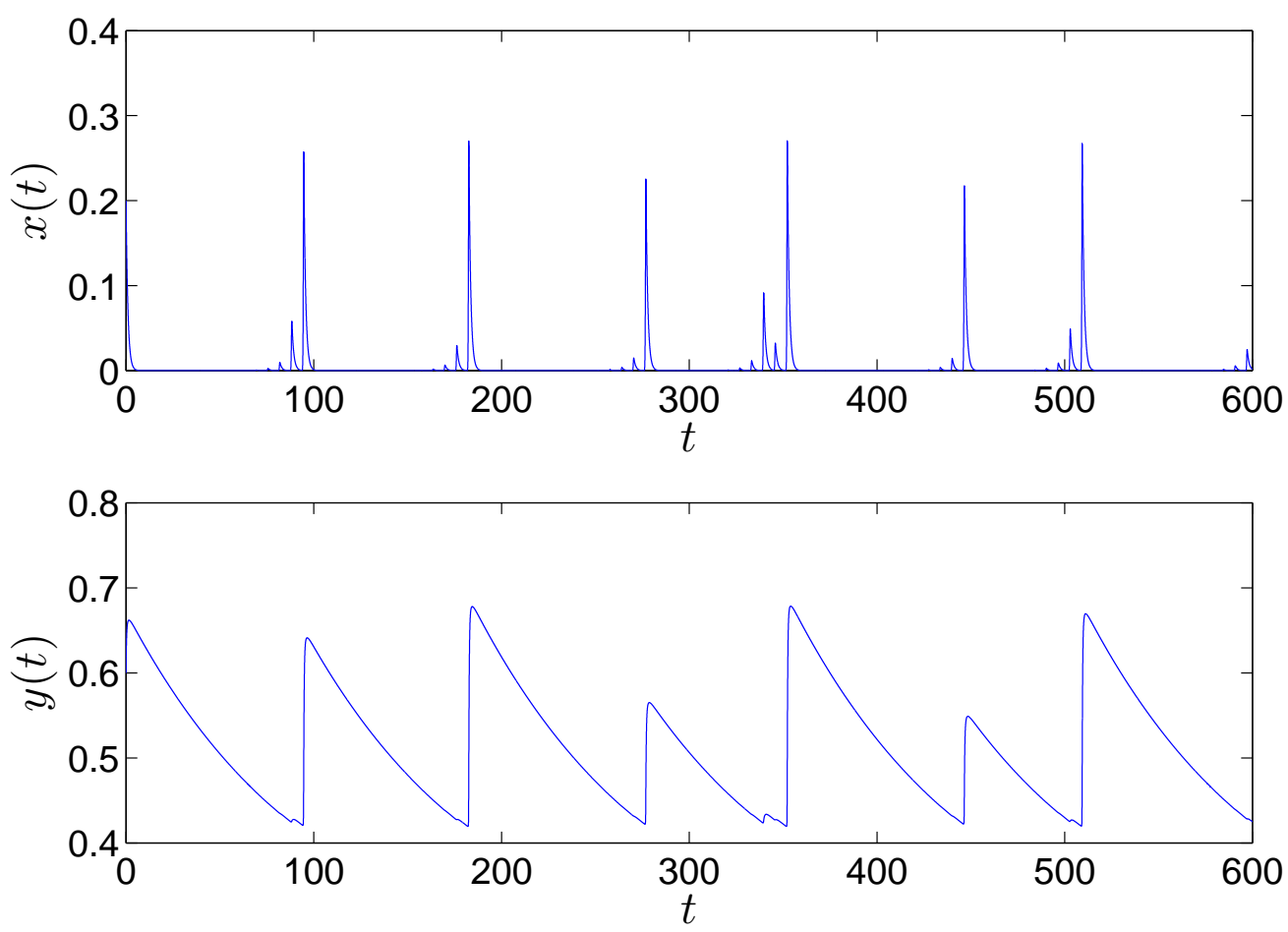

Figura 2.18: Série Temporal das unidades $x$ e $y$ de um Oscilador WilsonCowan.

Para demonstrar a sincronização entre osciladores Wilson-Cowan utilizaremos dois osciladores acoplados da seguinte forma, conforme proposto por 


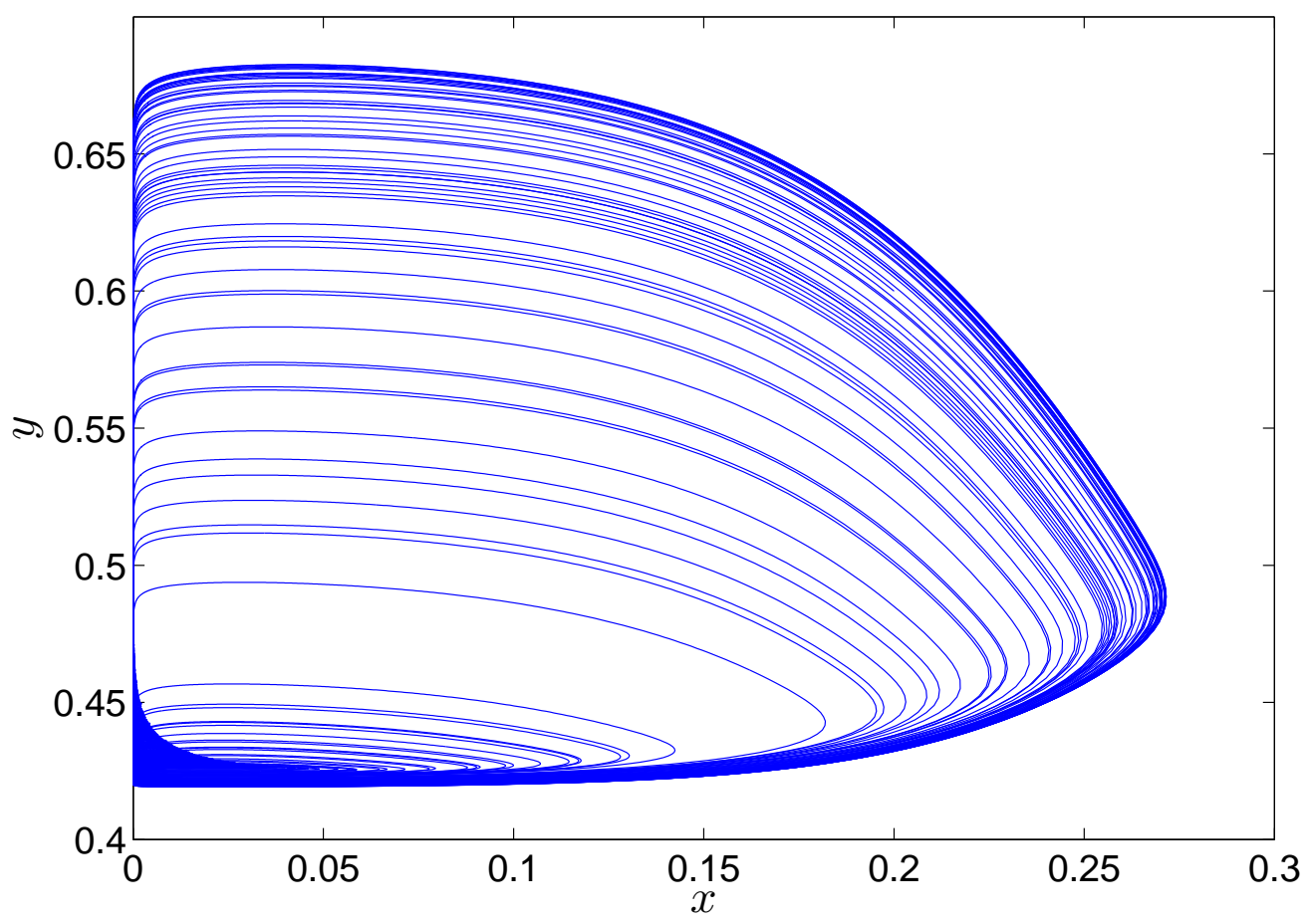

Figura 2.19: Trajetória de fase de um Oscilador Wilson-Cowan.

Zhao et al. (2000):

$$
\begin{aligned}
\dot{x_{1}} & =a x_{1}+G\left(c x_{1}+e y_{1}+I-\theta_{x}\right)+k\left(x_{2}-x_{1}\right), \\
\dot{y_{1}} & =-b y_{1}+G\left(d x_{1}+f y_{1}-\theta_{y}+k\left(y_{2}-y_{1}\right),\right. \\
\dot{x_{2}} & =a x_{1}+G\left(c x_{2}+e y_{2}+I-\theta_{x}\right)+k\left(x_{1}-x_{2}\right), \\
\dot{y_{2}} & =-b y_{1}+G\left(d x_{2}+f y_{2}-\theta_{y}+k\left(y_{1}-y_{2}\right),\right. \\
G(v) & =\frac{1}{1+\exp [-v(v / T)]}, \\
I & =\cos (t),
\end{aligned}
$$

onde $k$ é a força de acoplamento, e os outros parâmetros são os mesmos já citados. A Figura 2.20 mostra as séries temporais e diferenças de dois osciladores acoplados com $k=0,5$. É possível observar que após uma pequena fase transiente há uma completa coincidência das trajetórias, indicando a sincronização completa.

Zhao \& Breve (2008) mostraram matematicamente ser possivel sincronizar osciladores Wilson-Cowan com parâmetros não exatamente iguais. A Figura 2.21 mostra as séries temporais e a diferença entre dois osciladores acoplados com parâmetros com pequenas diferenças. É possível observar que mesmo no regime de sincronização ainda há pequenas diferenças entre os dois osciladores (como pode ser observado no gráfico interno da Figura 2.21(b)) indicando uma sincronização imperfeita. Porém, a diferença é muito pequena para ser 

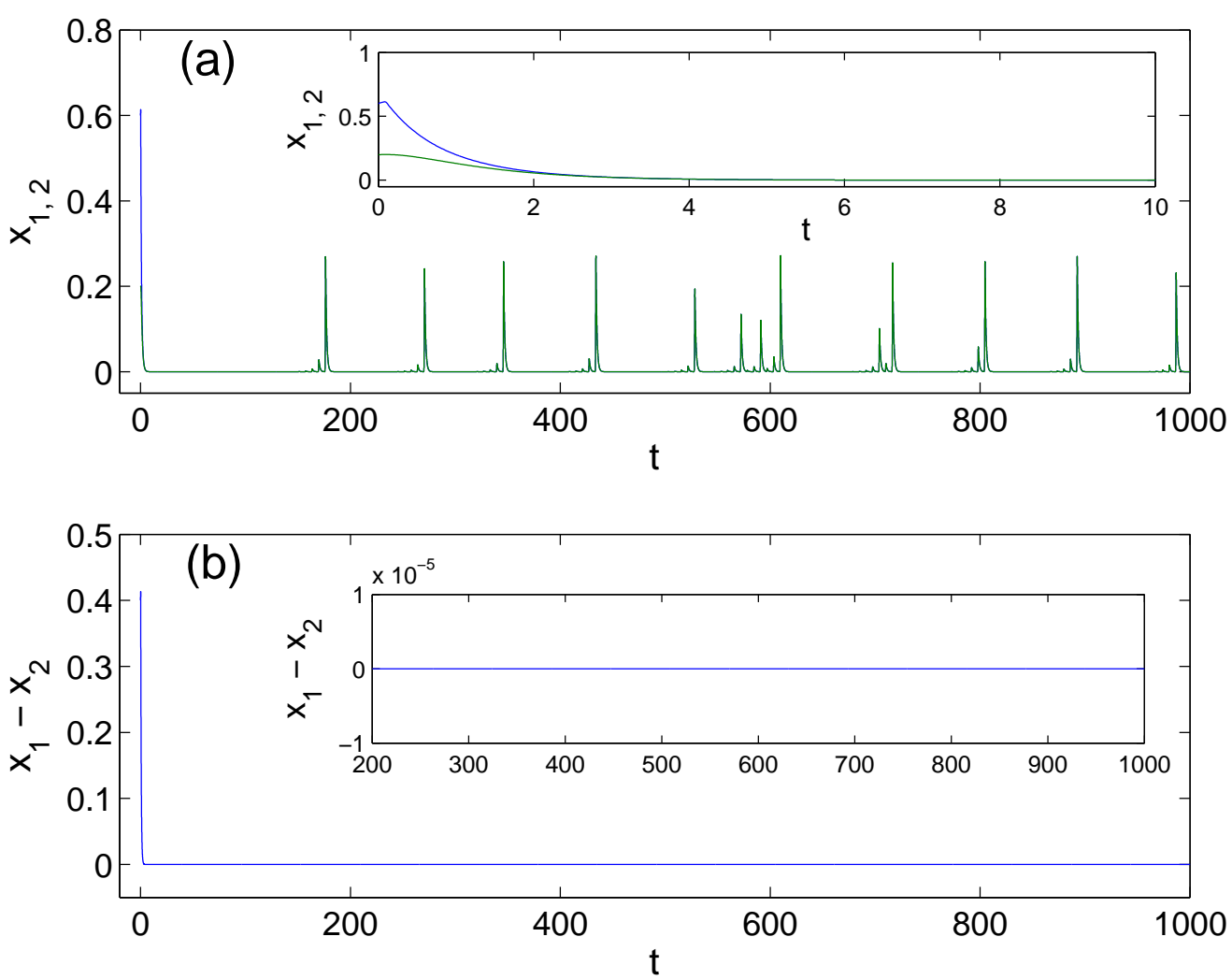

Figura 2.20: Dois osciladores Wilson-Cowan acoplados com $k=0,5$. (a) Séries temporais da unidade $x$ de dois osciladores juntos. O gráfico interno mostra uma ampliação das primeiras 10 unidades de tempo. (b) Diferença da variável $x$ dos dois osciladores. O gráfico interno mostra essa diferença em uma escala mais fina.

observada na escala da Figura 2.21(a). A Figura 2.22 mostra que essa diferença pode ser reduzida, mas não eliminada, mesmo usando uma força de acoplamento muito forte.

\section{Sincronização por Fase}

A sincronização por fase é obtida quando existe uma perfeita sincronização das fases de subsistemas oscilatórios utilizando uma pequena força de acoplamento (em relação à força utilizada na sincronização completa), enquanto as amplitudes podem permanecer não relacionadas (Rosenblum et al., 1996). Sejam dois osciladores caóticos com fases definidas por $\phi_{1}$ e $\phi_{2}$. Dizemos que ambos estão sincronizados se a diferença entre suas respectivas fases $\phi_{1}-\phi_{2}$ é limitada, por exemplo: $\left|\phi_{1}-\phi_{2}\right|<M$, conforme $t \rightarrow \infty$ (Pikovsky et al., 2001).

Para demonstrar a sincronização por fase utilizaremos o oscilador de Rössler (Rössler, 1976), que é um sistema dinâmico contínuo tri-dimensional. O oscilador de Rössler é um sistema de três dimensões proposto por Rössler 

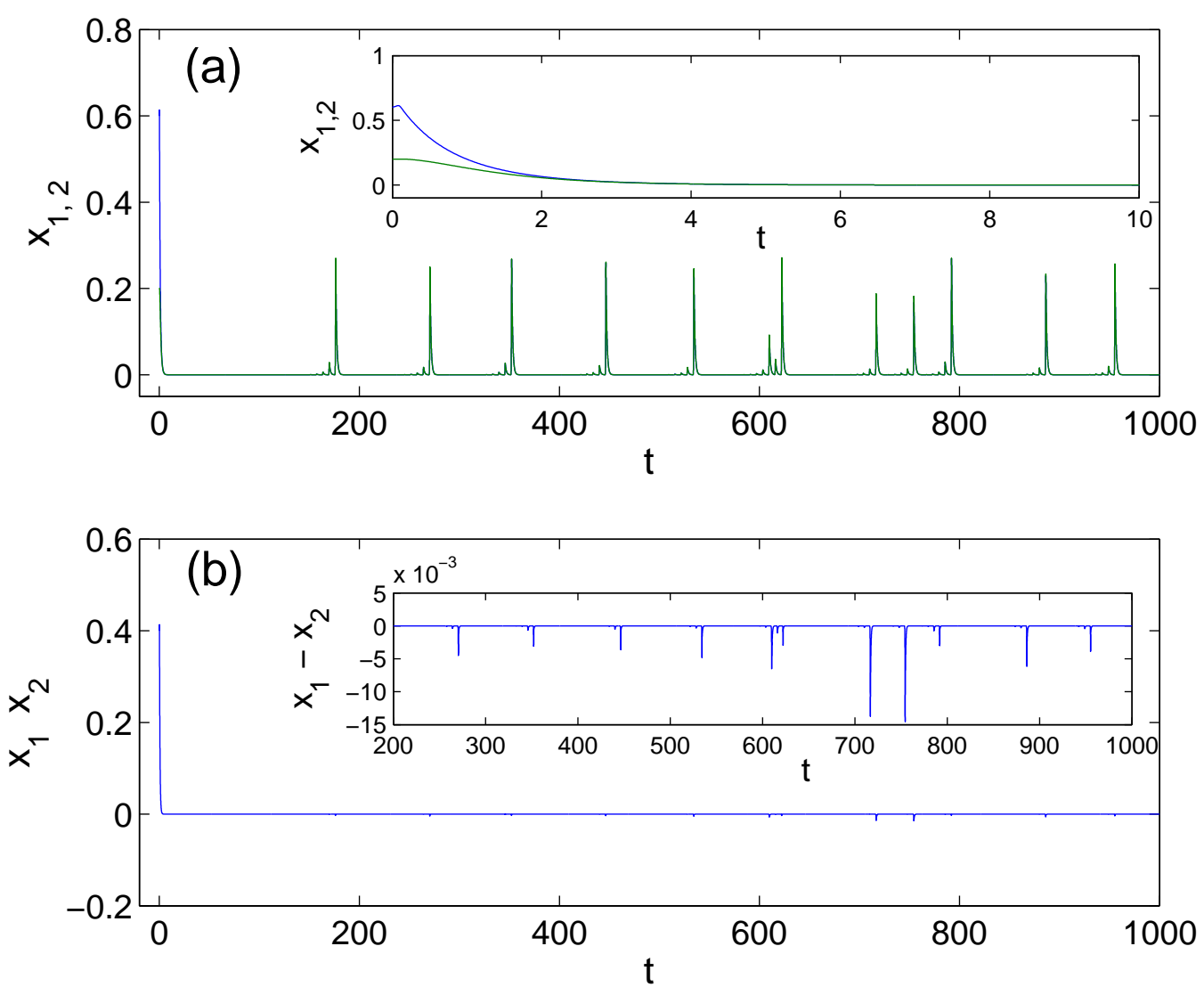

Figura 2.21: Dois osciladores Wilson-Cowan acoplados com $\theta_{x 1}=0,2$ e $\theta_{x 2}=0,201$, onde $\theta_{x 1}$ e $\theta_{x 2}$ são os parâmetros $\theta_{x}$ dos osciladores 1 e 2 respectivamente, $k=0,5$ (a) Séries temporais da unidade $x$ de dois osciladores juntos. O gráfico interno mostra uma ampliação das primeiras 10 unidades de tempo. (b) Diferença da variável $x$ dos dois osciladores. O gráfico interno mostra essa diferença em uma escala mais fina.

(1976) e é definido da seguinte forma:

$$
\begin{aligned}
\dot{x} & =-y-z, \\
\dot{y} & =x+a y, \\
\dot{z} & =b+z(x-c),
\end{aligned}
$$

onde $(x, y, z) \in \mathbb{R}^{3}$ são as variáveis dinâmicas e $a b$ e $c$ são parâmetros.

Os experimentos mostrados a seguir utilizam os seguintes parâmetros constantes: $a=0,15, b=0,2$ e $c=10$, valores utilizados por Rosenblum et al. (1996). Com esses parâmetros o oscilador de Rössler apresenta um comportamento caótico, como pode ser observado nas Figuras 2.23 e 2.24. As equações diferenciais foram resolvidas numericamente usando o método Runge-Kutta (RK4) (Press et al., 2002) com o tamanho de passo definido em 0,01. 

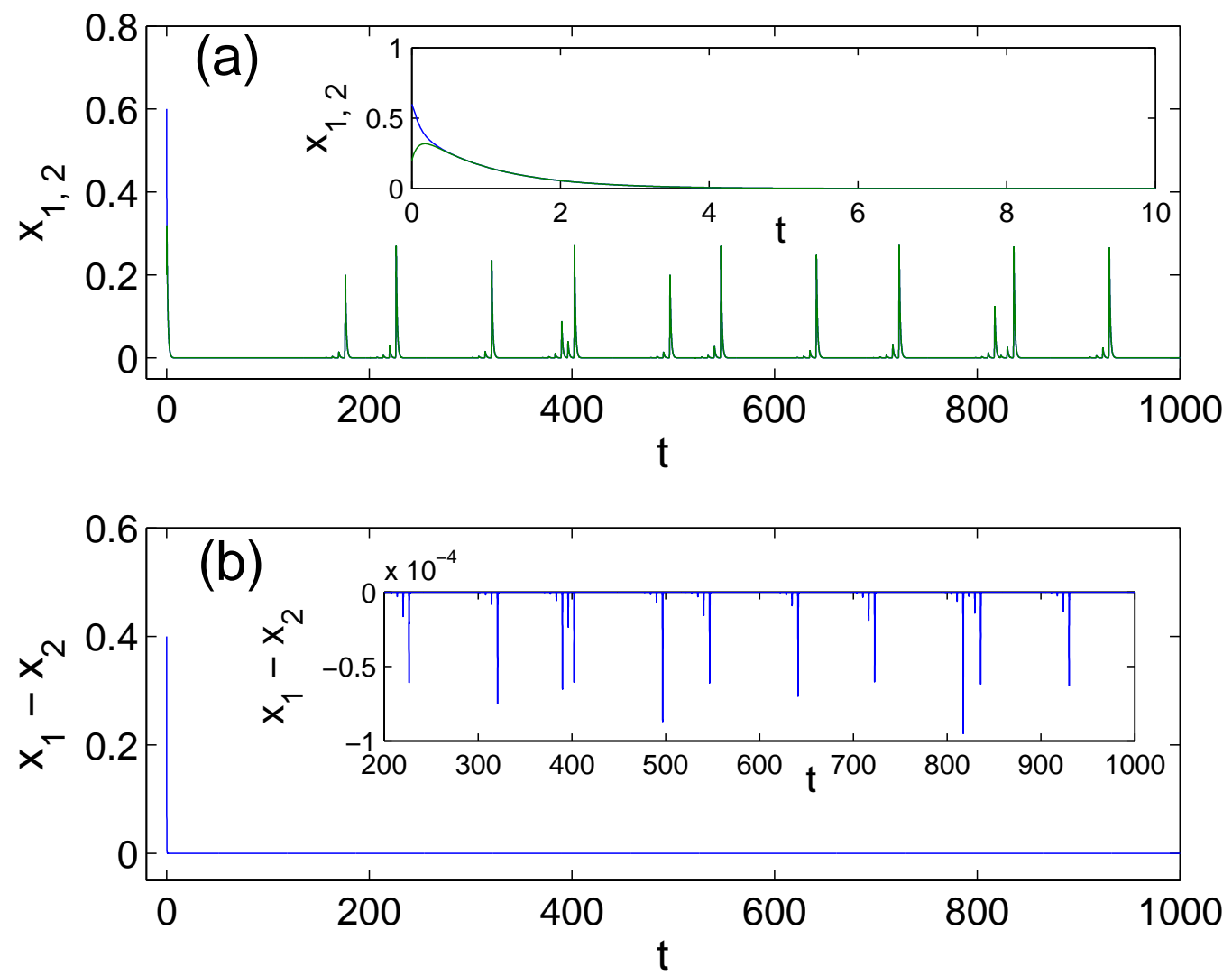

Figura 2.22: Dois osciladores Wilson-Cowan acoplados com $\theta_{x 1}=0,2 \mathrm{e}$ $\theta_{x 2}=0,201$, onde $\theta_{x 1}$ e $\theta_{x 2}$ são os parâmetros $\theta_{x}$ dos osciladores 1 e 2 respectivamente, $k=5,0$ (a) Séries temporais da unidade $x$ de dois osciladores juntos. O gráfico interno mostra uma ampliação das primeiras 10 unidades de tempo. (b) Diferença da variável $x$ dos dois osciladores. O gráfico interno mostra essa diferença em uma escala mais fina.

Para os osciladores de Rössler, a fase $\phi$ é definida da seguinte maneira:

$$
\phi=\Upsilon\left(\arctan \left(\frac{y}{x}\right)\right)
$$

onde $x$ e $y$ são variáveis do oscilador e $\Upsilon$ representa a função de "desembrulhar" 29 , de modo que $\phi$ é uma variável cujo valor está sempre crescendo. Na Figura 2.25 pode ser observado o valor de $\phi$ ao longo do tempo para o mesmo oscilador mostrado nas Figuras 2.23 e 2.24 .

O acoplamento entre dois osciladores de Rössler é definido da seguinte 

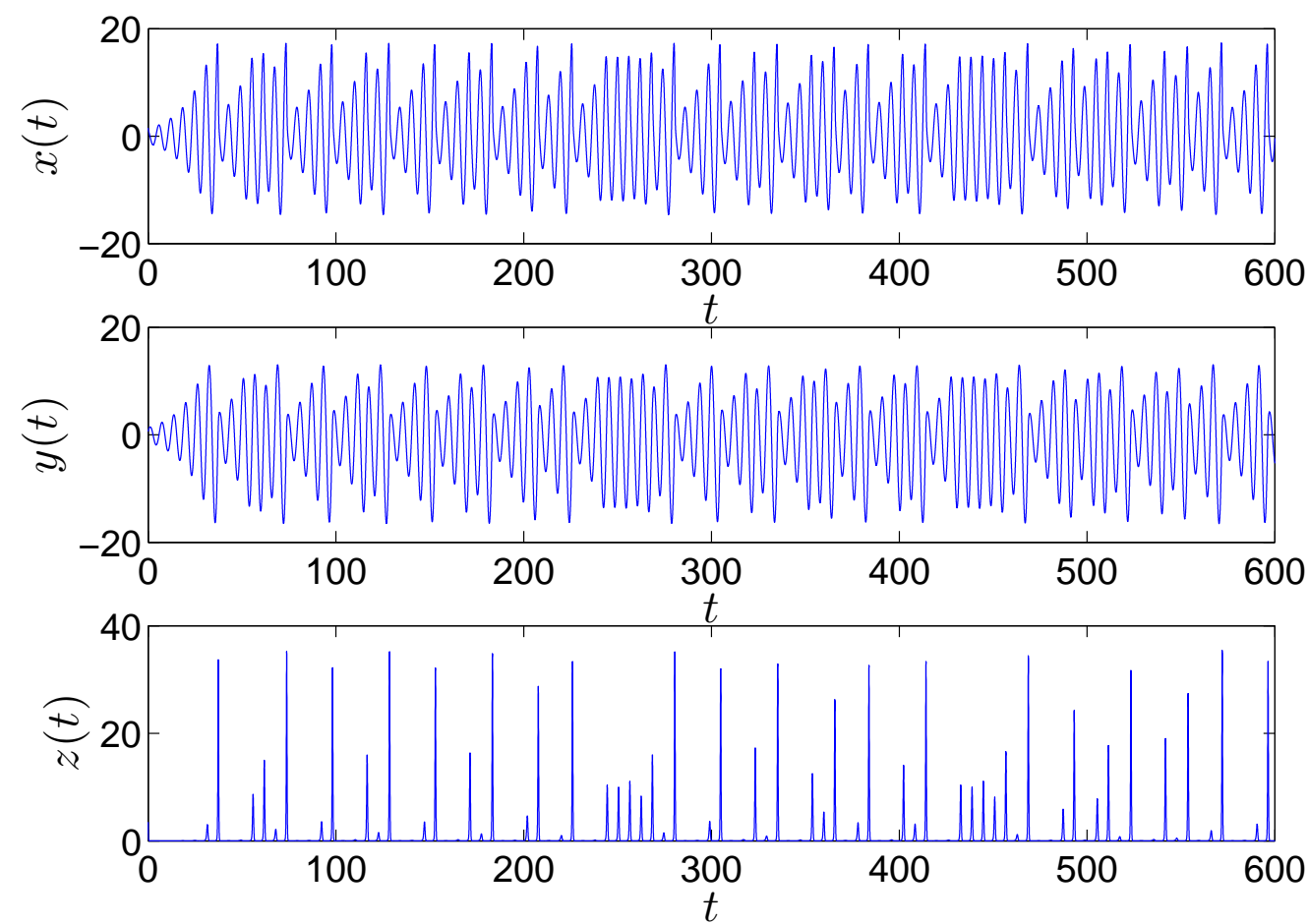

Figura 2.23: Série Temporal das unidades $x, y$ e $z$ de um Oscilador de Rössler.

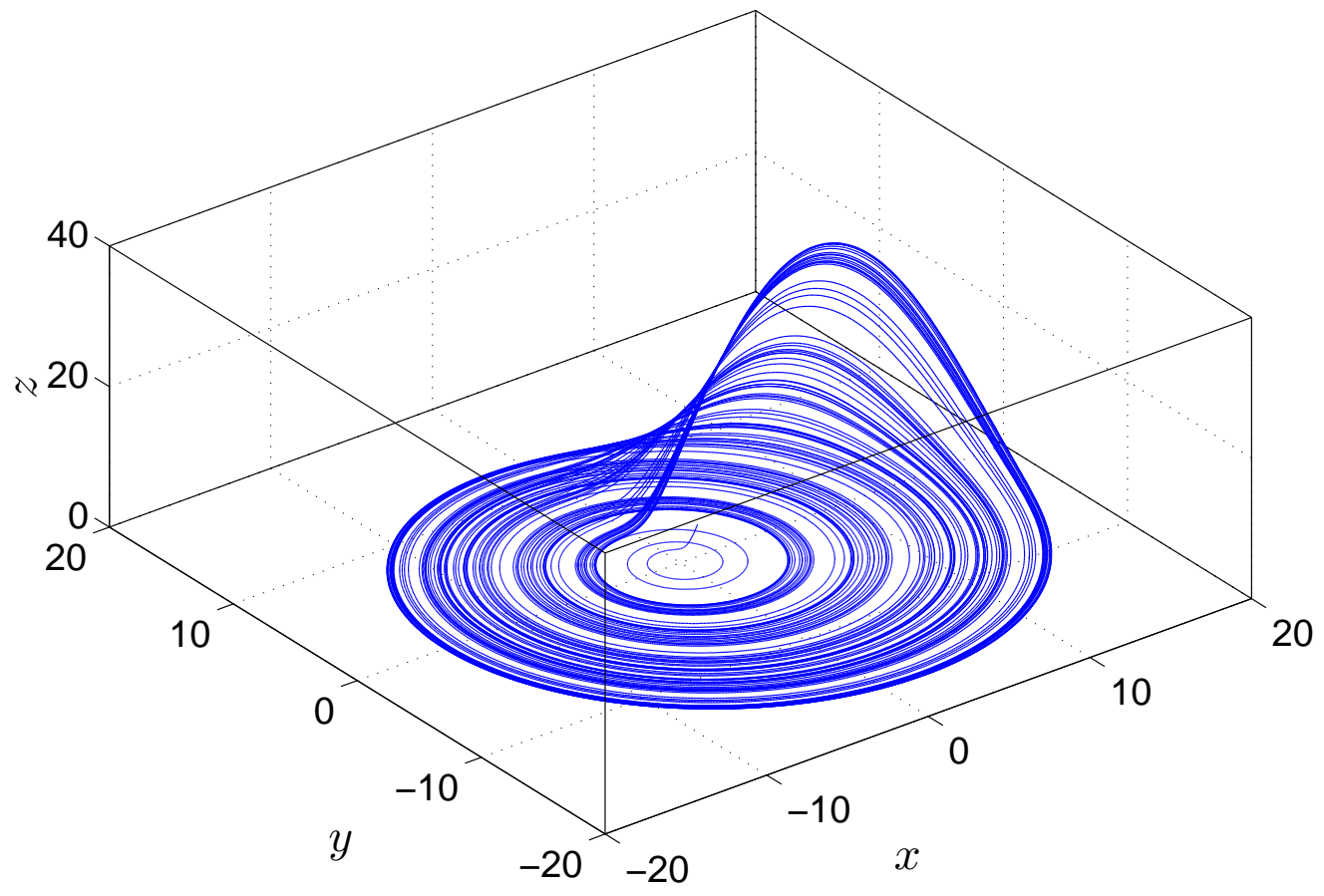

Figura 2.24: Trajetória de fase de um Oscilador de Rössler. 


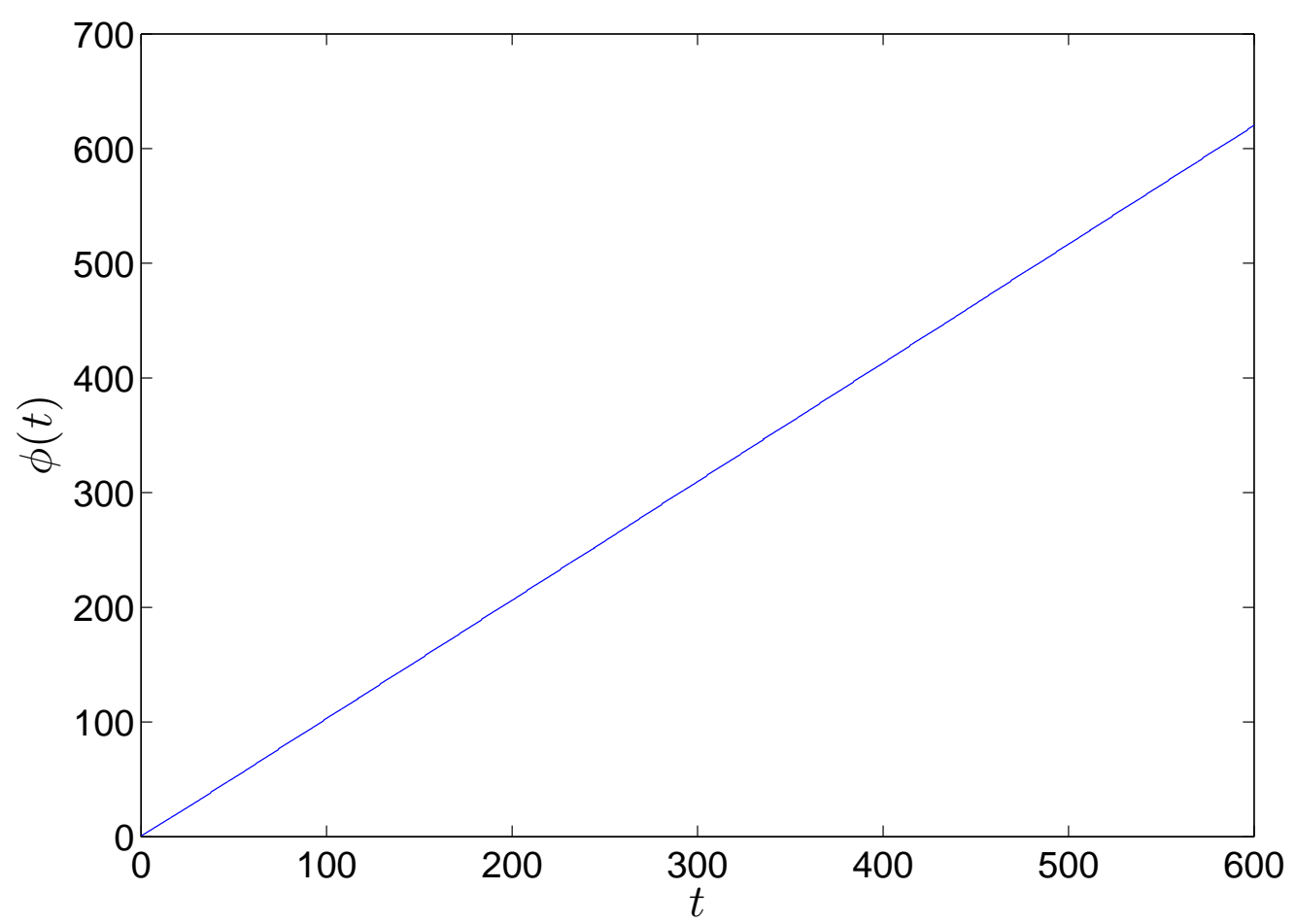

Figura 2.25: Fase acumulada do Oscilador de Rössler das Figuras 2.23 e 2.24.

forma (Rosenblum et al., 1996):

$$
\begin{aligned}
& \dot{x_{1}}=-\omega_{1} y_{1}-z_{1}+k\left(x_{2}-x_{1}\right), \\
& \dot{y_{1}}=\omega_{1} x_{1}+a y_{1}, \\
& \dot{z_{1}}=b+z\left(x_{1}-c\right), \\
& \dot{x_{2}}=-\omega_{2} y_{2}-z_{2}+k\left(x_{1}-x_{2}\right), \\
& \dot{y_{2}}=\omega_{2} x_{2}+a y_{2}, \\
& \dot{z_{2}}=b+z\left(x_{2}-c\right),
\end{aligned}
$$

onde o parâmetro $\omega$ é introduzido para governar a diferença de freqüência, de modo que dois osciladores não acoplados, com diferentes valores para $\omega$, apresentem freqüências distintas, e $k$ é a força de acoplamento. Seja $\Delta \omega=$ $\left|\omega_{1}-\omega_{2}\right|$, dado um $\Delta \omega$ fixo, conforme $k$ aumenta pode ser observado uma transição de um regime assíncrono, ou seja, $\left|\phi_{1}-\phi_{2}\right| \rightarrow \infty$ conforme $t \rightarrow \infty$ para um regime de sincronização por fase, onde a diferença entre fases não aumenta com o tempo $\left(\left|\phi_{1}-\phi_{2}\right| \leq 2 \pi \operatorname{com} t \rightarrow \infty\right)$. Essa transição é ilustrada na Figura 2.26. É importante ressaltar que ao contrário da sincronização completa onde as variáveis dinâmicas coincidem, na sincronização por fase as variáveis $x_{1}$ e $x_{2}, y_{1}$ e $y_{2}$, e $z_{1}$ e $z_{2}$ não coincidem conforme pode ser observado na Figura 2.27. 


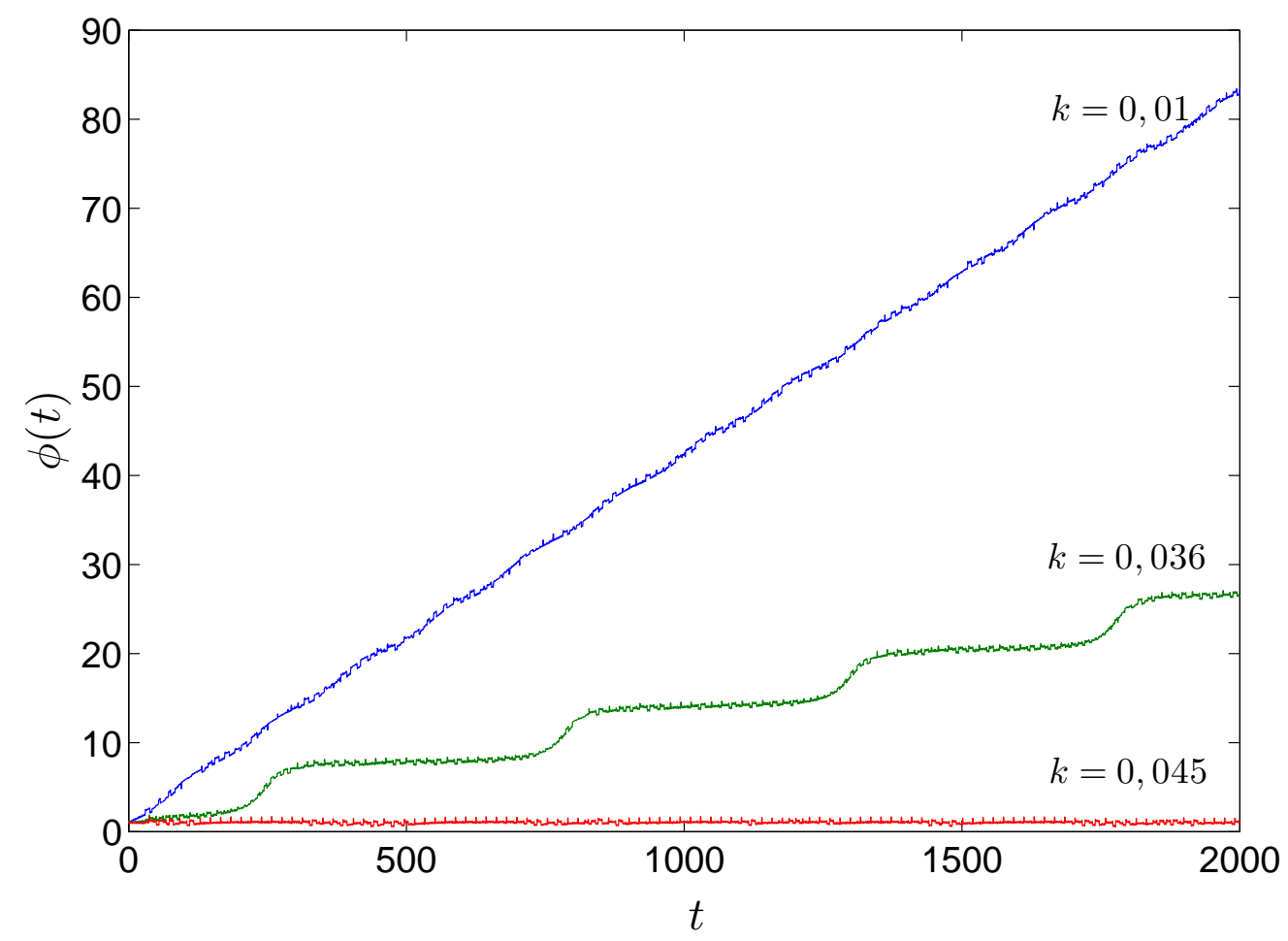

Figura 2.26: Diferença de fase entre dois Osciladores de Rössler acoplados ao longo do tempo mostrando o regime não sincronizado $(k=0,01)$, quase sincronizado $(k=0,036)$ e sincronizado $(k=0,045) . \Delta \omega=0,040\left(\omega_{1}=0,980\right.$, $\left.\omega_{2}=1,020\right)$.
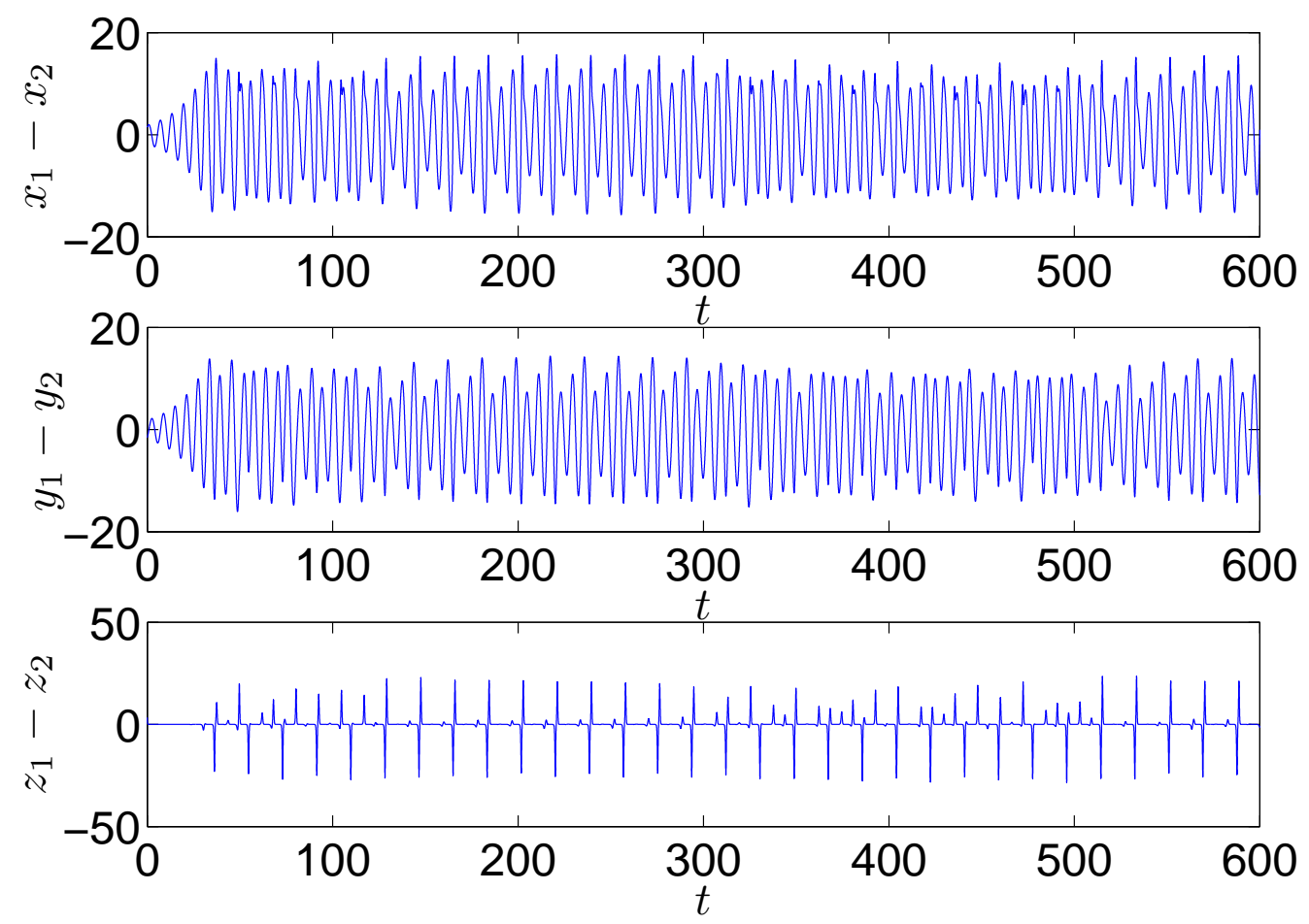

Figura 2.27: Diferença entre as variáveis $x, y \mathrm{e} z$ de dois Osciladores de Rössler acoplados com $k=0,045$ e $\Delta \omega=0,040\left(\omega_{1}=0,980, \omega_{2}=1,020\right)$. 


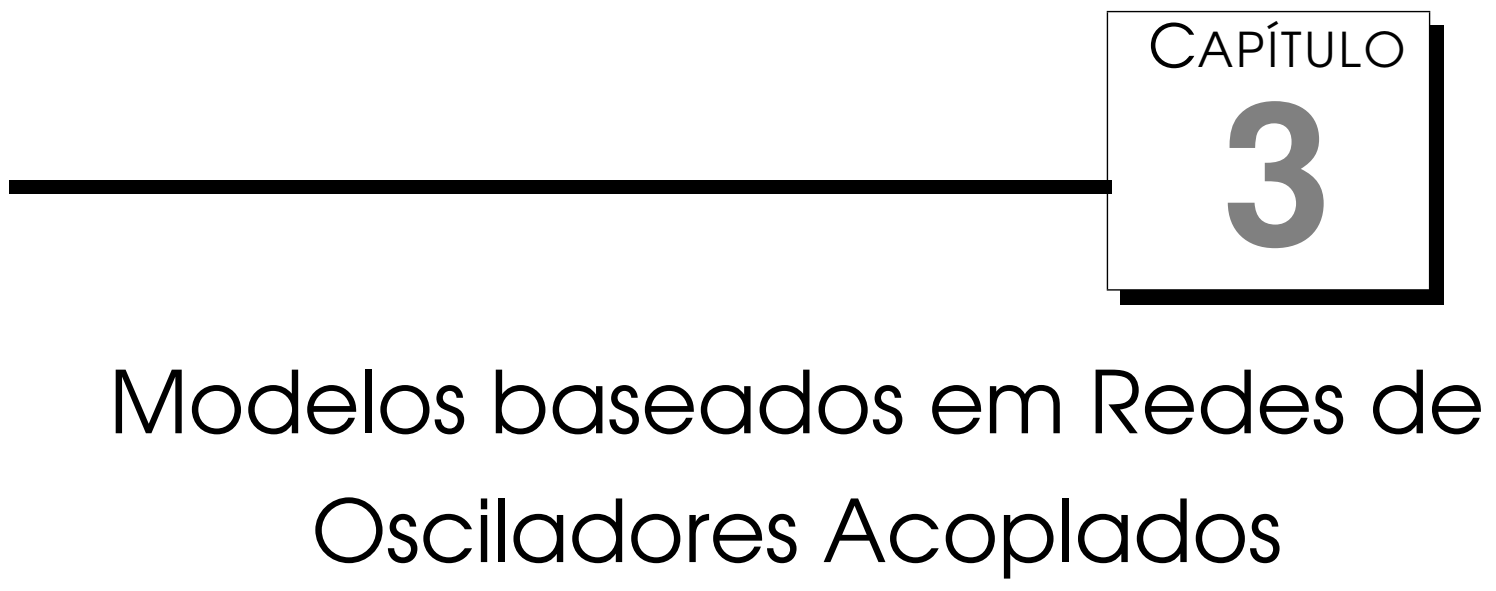

Neste capítulo são apresentados alguns resultados obtidos durante o desenvolvimento deste trabalho na aplicação de sistemas dinâmicos acoplados. Especificamente, osciladores acoplados em reticulados foram utilizados em tarefas de atenção visual (Zhao et al., 2007; Quiles et al., 2007a; Breve et al., 2009d,c), aproveitando as características de sincronização dos modelos. Na Seção 3.1 é discutida a tarefa abordada, que é parte essencial de diversos sistemas de visão computacional. Nas Seções 3.2 e 3.3 são apresentados dois dos modelos de atenção visual que foram desenvolvidos de forma incremental, ambos utilizando sincronização por fase entre osciladores caóticos.

\section{1 Aplicação dos Modelos em Atenção Visual}

Durante o desenvolvimento deste trabalho, foram criados diversos modelos de sincronização de osciladores organizados em redes, inicialmente utilizando sincronização completa (Zhao \& Breve, 2008; Zhao et al., 2007; Guiles et al., 2007a) e posteriormente utilizando sincronização por fase (Breve et al., 2009d,c). Tais modelos foram aplicados inicialmente em segmentação de imagens (Zhao \& Breve, 2008), e posteriormente foram estendidos para realizar tarefas de atenção visual (Zhao et al., 2007; Guiles et al., 2007a; Breve et al., 2009d,c). Estas são duas tarefas essenciais em diversos sistemas de visão computacional, sendo que ambas têm forte correlação com sistemas dinâmicos e sincronização entre osciladores, como será mostrado a seguir.

Diversos experimentos fisiológicos têm apontado uma forte evidência da 
existência de atividades rítmicas sincronizadas em diferentes áreas do cérebro de seres humanos, gatos e macacos (Eckhorn et al., 1988; Engel et al., 1991; Fries et al., 2001; Gong et al., 2003; Grey et al., 1989; Kim et al., 2007; Murthy \& Fetz, 1992). Foi sugerido que esta oscilação e sincronização neural tem um papel em problemas de combinação de atributos ${ }^{1}$ e segmentação. $O$ processamento através da oscilação síncrona está relacionado com a codificação temporal: um objeto é representado pela correlação temporal entre os disparos dos neurônios distribuídos no espaço (von der Malsburg, 1981). Especificamente, a solução para a segmentação de cenas nesta sugestão pode ser descrita pelas seguintes regras: os neurônios que processam diferentes atributos do mesmo objeto têm a mesma freqüência básica de oscilação (sincronização), enquanto neurônios que codificam diferentes objetos oscilam com fases diferentes ou aleatoriamente (dessincronização). Isto é chamado correlação oscilatória (Wang, 1995; Terman \& Wang, 1995). Existem dois mecanismos básicos funcionando simultaneamente em cada modelo de correlação oscilatória: sincronização e dessincronização. O primeiro serve para agrupar neurônios em objetos enquanto o segundo serve para distinguir um grupo de neurônios sincronizados (um objeto) dos outros. Portanto o maior desafio da correlação oscilatória é realizar estes dois mecanismos totalmente contrários ao mesmo tempo.

Os sistemas vivos também desenvolveram a capacidade de selecionar apenas informações relevantes do ambiente para alimentar seus sistemas sensoriais. Esta habilidade está relacionada principalmente com a capacidade de processamento limitada do hardware neuronal disponivel para muitas tarefas, como compreensão de cena. Segundo Tsotsos et al. (1995), os processos visuais de nível alto e intermediário parecem selecionar parte da informação sensorial recebida do mundo e usar apenas os dados selecionados para os processamentos subseqüentes.

A atenção visual é um destes mecanismos que sistemas biológicos, tais quais os humanos, desenvolveram para obter a redução da informação visual fornecida. A atenção aparentemente otimiza o procedimento de busca selecionando um número de possíveis imagens candidatas e subconjuntos de atributos, os quais podem ser utilizados em tarefas como reconhecimento (Walther et al., 2005). A atenção visual parece ser um mecanismo eficiente e elegante para quebrar tarefas complexas, tais como compreensão de cena, em uma série de pequenas tarefas computacionais localizadas (Itti \& Koch, 2001). Ela também é responsável por reduzir a explosão combinatória resultante da análise de toda a informação visual que chega, possiveis relações entre imagens (Shic \& Scassellati, 2007; Tsotsos, 1992), para identificar a região da entrada

1 do inglês: feature binding 
visual onde o processamento é executado (foco de atenção) ao mesmo tempo que suprime informação visual irrelevante (Carota et al., 2004).

A atenção visual é gerada por uma combinação de informações vindas da retina e de áreas do início do córtex visual (atenção bottom-up, dependente da cena) bem como de sinais de retorno de áreas de fora do córtex visual (atenção top-down - dependente da tarefa) (Itti \& Koch, 2001; Itti et al., 1998). A atenção bottom-up é um processo alimentado adiante ${ }^{2}$ formado apenas por atributos extraídos da imagem de entrada, como intensidade, cor, orientação e outros (Itti \& Koch, 2001). Toda essa informação é combinada para criar um mapa de saliência, o qual representa os pontos salientes na entrada visual. A atenção top-down é responsável por modular a competição de todos os estímulos dentro da entrada visual. Este último processo requer manter, em uma memória de curto prazo, a informação sobre localização, ou um objeto que está sendo usado como alvo da atenção, para influenciar os primeiros processos visuais (Deco \& Rolls, 2005).

A maioria dos modelos de atenção bottom-up tem relação com o conceito de mapa de saliência (Itti \& Koch, 2001). Nestes modelos, o primeiro estágio de processamento é responsável por decompor a imagem de entrada em um conjunto de mapas de atributos. Depois disso, um mapa de saliência é gerado por uma combinação destes mapas de atributos. O mapa de saliência é um mapa topográfico que representa, por quantidades escalares, todos os pontos salientes em todo o estímulo visual de entrada (Itti \& Koch, 2001; Itti et al., 1998). O principal propósito deste mapa é guiar o mecanismo de seleção, o qual é responsável por entregar o foco de atenção para uma região específica da imagem.

von der Malsburg (1981) propôs um mecanismo onde objetos são representados pela correlação temporal das atividades de disparo de neurônios distribuídos e codificando diferentes atributos de um objeto. Uma maneira natural de codificar a correlação temporal é usando sincronização de osciladores, onde cada oscilador codifica alguns atributos de um objeto (Terman \& Wang, 1995; von der Malsburg \& Schneider, 1986; Wang, 2005). Com base na teoria de von der Malsburg, Wang e seus colaboradores desenvolveram a teoria de correlação oscilatória para segmentação de cenas chamado LEGION ${ }^{3}$ (Wang, 1995; Campbell \& Wang, 1996; Wang \& Terman, 1997; Campbell et al., 1999), que pode ser descrita pela seguinte regra: os neurônios que processam diferentes atributos do mesmo objeto estão sincronizados, enquanto neurônios que codificam diferentes objetos estão dessincronizados. Este modelo foi estendido para diversas áreas, incluindo segmentação de imagem, determinação de movimento e percepção (Wang, 2005). Porém, a capacidade de segmentação

\footnotetext{
2 do inglês: feedforward

3 sigla de Locally Excitatory Globally Inhibitory Oscillator Network
} 
(número de segmentos que podem ser produzidos em uma determinada cena) é limitado a cerca de 12 objetos (Terman \& Wang, 1995; Campbell \& Wang, 1996). Mais tarde, este problema foi resolvido com duas abordagens: Wang \& Terman (1997) propuseram um novo e eficiente algoritmo baseado no LEGION, enquanto Campbell \& Wang (1996) introduziram uma versão modificada do LEGION na qual cada elemento é um oscilador do tipo integra-e-dispara ${ }^{4}$. Ambos os modelos podem potencialmente segmentar muitos grupos. Outra abordagem para distinguir trajetórias sincronizadas e conseqüentemente conseguir uma capacidade de segmentação ilimitada é utilizar as propriedades do caos e sincronização caótica (Hansel \& Sompolinsky, 1992; Zhao et al., 2000; Zhao \& Macau, 2001). No modelo proposto por Zhao et al. (2000), um rede de osciladores caóticos acoplados é empregada e cada objeto em uma dada cena é representado por uma trajetória caótica sincronizada. Conseqüentemente todas essas trajetórias caóticas podem ser separadas devido a alta sensibilidade às condições iniciais, que é a principal característica do caos, e o fato de que a trajetória caótica é densa em seu conjunto invariante. Com este procedimento, os autores alegam que o modelo tem capacidade ilimitada de segmentação de objetos. O papel da sincronização em funções do cérebro tem recebido suporte de descobertas neurobiológicas (Jermakowicz \& Casagrande, 2007). Por exemplo, já foi mostrado que a atenção visual está fortemente relacionada com sincronização, na qual a coerência entre neurônios que respondem ao mesmo estímulo é aumentada (Fries et al., 2001; Kim et al., 2007; Buia \& Tiesinga, 2006; Niebur \& Koch, 1994).

Muitos modelos de atenção visual bottom-up foram propostos, porém o mecanismo usado por estes modelos são implementados com uma rede neural do tipo Vencedor-Leva-Tudo ${ }^{5}$, onde apenas um neurônio é ativado e não é o objeto todo que se torna saliente. Por exemplo, no modelo proposto por Itti et al. (1998), quando um neurônio recebe o foco de atenção, um círculo com raio fixo é considerado a região de atenção do modelo. Neste caso não é possível dar atenção para objetos mais complexos e linearmente não separáveis. Para lidar com essa limitação, novos mecanismos de seleção de objetos devem ser desenvolvidos.

Há basicamente dois tipos de abordagem para modelos computacionais de atenção visual. Um deles é baseado em localização e o outro é baseado em objetos (Wang, 2005). A maioria dos modelos de atenção visual são implementados usando mecanismos do tipo Vencedor-Leva-Tudo, os quais são compativeis com a teoria baseada em localização. Neste caso, apenas um único neurônio é ativado e, como resultado, a atenção é direcionada para um ponto ou pequena área, mas não para um objeto inteiro ou o componente de

4 do inglês: integrate-and-fire

5 do inglês: Winner-Take-All 
um objeto (Itti et al., 1998). Teorias baseadas em objetos consideram objetos como a unidade básica de percepção, agindo como um conjunto no processo competitivo por atenção (Desimone \& Duncan, 1995; Roelfsema et al., 1998; O’Craven et al., 1999; Wang, 1999). Esta abordagem não apenas recebe suporte de experimentos comportamentais e neurobiológicos, que mostram que a seleção de objetos tem um papel central na visão de primatas (Roelfsema et al., 1998; Richard et al., 2008; Wang et al., 2005), como também combinam com a nossa experiência no dia-a-dia.

Alguns modelos de atenção visual propuseram o uso de sincronização completa entre osciladores para representar objetos (Wang, 1999; Kazanovich \& Borisyuk, 2002; Quiles et al., 2007b). Porém o fenômeno de sincronização observado em experimentos reais raramente representa uma sincronização completa. Portanto, outras formas de sincronização devem ser levadas em consideração. Particularmente, a sincronização por fase é um modelo de interação recíproca, o qual se acredita que seja a chave para a integração neurológica no cérebro. Evidências diretas dando suporte a sincronização por fase como mecanismo básico para integração no cérebro foram fornecidos por estudos intensos em ligação visual (Varela et al., 2001).

Durante o desenvolvimento deste trabalho vários modelos de atenção visual foram desenvolvidos, de forma incremental, utilizando-se de osciladores caóticos acoplados e organizados em redes, especificamente em reticulado. Tais modelos evoluíram de modelos de segmentação previamente criados (Zhao \& Breve, 2008), e dois dos principais deles foram escolhidos para serem apresentados nas próximas seções. Dessa forma, nas Seções 3.2 e 3.3 são apresentados dois modelos de atenção visual baseados em sincronização por fase de osciladores Rössler (Breve et al., 2009d,c). É importante ressaltar que, em contraste com outros modelos de seleção de objetos baseados em osciladores (Wang, 1999; Kazanovich \& Borisyuk, 2002), esses modelos são os primeiros a usar sincronização por fase caótica.

Os modelos desenvolvidos têm como objetivo atender os seguintes requisitos essenciais para um sistema de Seleção Visual:

- Considerando como entrada um ou uma combinação de atributos (mapa de saliência), a rede neural precisa realçar (selecionar) a região da imagem onde o foco de atenção deve ser direcionado;

- Todos as outras localizações da entrada visual precisam ser suprimidas pelo sistema, de modo que o foco de atenção seja mantido em apenas um dos objetos ativos;

- O foco de atenção precisa ser mudado para as demais localizações ativas. Isso significa que a rede neural precisa implementar um tipo de sistema 
de habituação onde a presença de um estímulo vencedor fixo precisa ser seguida de uma progressiva diminuição de sua resposta, permitindo que outros estímulos se tornem ativos.

\subsection{Atenção Visual com Sincronização por Fase em Redes de Osciladores}

No modelo apresentado nesta seção, utilizamos um reticulado de osciladores Rössler para realizar a tarefa de atenção visual. Cada pixel da imagem corresponde a um oscilador, que são acoplados aos seus vizinhos quando a diferença entre eles está abaixo de um limiar. Dessa forma, após um determinado período, osciladores que correspondem ao mesmo objeto estarão sincronizados por fase.

Para realizar a tarefa de atenção visual, introduzimos um mecanismo que modifica a freqüência dos osciladores Rössler, passando de uma dinâmica caótica para uma dinâmica periódica para caracterizar a atenção. Utilizar sincronização por fase em modelos de atenção visual é particularmente interessante, pois vários modelos de atenção visual já foram propostos utilizando sincronização completa entre osciladores para representar objetos (Wang, 1999; Kazanovich \& Borisyuk, 2002; Quiles et al., 2007b), porém o fenômeno de sincronização observado em experimentos reais raramente representa uma sincronização completa. Como mencionado anteriormente, a sincronização por fase é um modelo de interação recíproca, que se acredita que seja o mecanismo chave para integração de neurônios no cérebro. E há evidências diretas dando suporte à sincronização como mecanismo básico para integração no cérebro (Varela et al., 2001). Os detalhes deste modelo e alguns resultados de simulação serão mostrados a seguir, nas Seções 3.2.1 e 3.2.2, respectivamente.

\subsection{Descrição do Modelo}

Este modelo utiliza uma grade de osciladores de Rössler acoplados localmente aos seus respectivos vizinhos com a forma de acoplamento da Equação (2.58), em um modelo governado pelas seguintes equações:

$$
\begin{aligned}
& \dot{x}_{i, j}=-\omega_{i, j} y_{i, j}-z_{i, j}+k \Delta x_{i, j}, \\
& \dot{y}_{i, j}=\omega_{i, j} x_{i, j}+a y_{i, j} \\
& \dot{z}_{i, j}=b+z_{i, j}\left(x_{i, j}-c\right) .
\end{aligned}
$$


onde $(i, j)$ é um ponto da grade com $1 \leq i \leq N, 1 \leq j \leq M$. $k$ é a força de acoplamento. $\omega$ é utilizado para codificar a intensidade dos pixels, conforme será elucidado mais adiante. Os parâmetros constantes são fixos em $a=0,15$, $b=0,2$ e $c=10 . \Delta x_{i, j}$ é o termo de acoplamento, que é definido por:

$$
\begin{aligned}
\Delta x_{i, j}= & \gamma_{i-1, j-1 ; i, j}\left(x_{i-1, j-1}-x_{i, j}\right)+ \\
& \gamma_{i-1, j ; i, j}\left(x_{i-1, j}-x_{i, j}\right)+ \\
& \gamma_{i-1, j+1 ; i, j}\left(x_{i-1, j+1}-x_{i, j}\right)+ \\
& \gamma_{i, j-1 ; i, j}\left(x_{i, j-1}-x_{i, j}\right)+ \\
& \gamma_{i, j+1 ; i, j}\left(x_{i, j+1}-x_{i, j}\right)+ \\
& \gamma_{i+1, j-1 ; i, j}\left(x_{i+1, j-1}-x_{i, j}\right)+ \\
& \gamma_{i+1, j ; i, j}\left(x_{i+1, j}-x_{i, j}\right)+ \\
& \gamma_{i+1, j+1 ; i, j}\left(x_{i+1, j+1}-x_{i, j}\right),
\end{aligned}
$$

onde

$$
\gamma_{i, j ; p, q}= \begin{cases}1, & \text { se o elemento }(i, j) \text { está acoplado com }(p, q) \\ 0, & \text { caso contrário. }\end{cases}
$$

A rede é organizada de modo que cada pixel da imagem corresponde a um elemento da grade, e o parâmetro $\omega_{i, j}$ desse elemento codifica a intensidade (nível de cinza) do pixel correspondente uniformemente no intervalo $\left[\begin{array}{ll}0,9 & 1,1\end{array}\right]$. Conforme o sistema executa, os neurônios se auto-organizam de acordo com um critério de similaridade pré-definido, tal que as conexões entre pares de osciladores vizinhos correspondentes a pixels com tons de cinza similares serão mantidas, enquanto que as conexões entre osciladores que correspondem a pixels com diferentes tons de cinza serão eliminadas. Conseqüentemente, todos os neurônios pertencendo ao mesmo segmento terão suas fases sincronizadas, enquanto suas amplitudes permanecerão não correlacionadas. Ao mesmo tempo, neurônios pertencentes a diferentes segmentos terão suas fases divergindo ao longo do tempo, possibilitando a segmentação.

Para implementar o mecanismo de atenção primeiramente foi observado que a freqüência dos osciladores de Rössler pode ser controlada mudando o parâmetro $\omega$ na Equação (3.1). Foi analisado o diagrama de bifurcação de osciladores de Rössler variando o parâmetro $\omega$ conforme mostrado na Figura 3.1. Nesta figura é possível observar que quando $\omega$ tem um valor baixo o oscilador apresenta comportamento caótico com algumas janelas periódicas. Com valores maiores de $\omega$ o oscilador passa a apresentar um comportamento periódico.

Na Figura 3.2 são mostradas séries temporais de osciladores de Rössler 


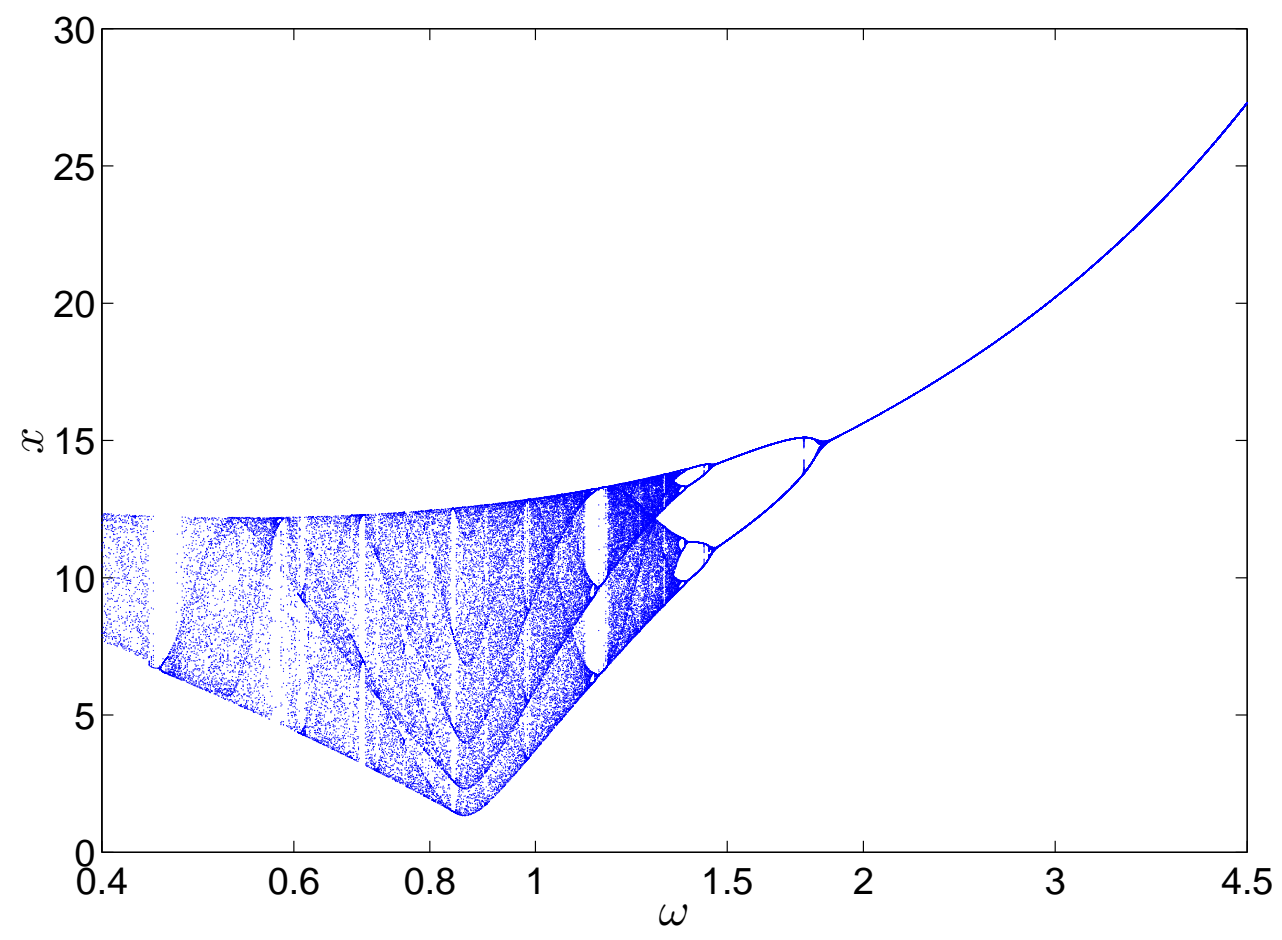

Figura 3.1: Diagrama de bifurcação de um oscilador Rössler variando o parâmetro $\omega . \Delta \omega=0,001$.

com diferentes valores para o parâmetro $\omega$. Nesta figura é possível observar que conforme $\omega$ aumenta, a freqüência de oscilação também aumenta. Nos 3 últimos casos o oscilador apresenta comportamento periódico, e a além do aumento de freqüência também é observado um aumento de amplitude. O campo $z$ foi escolhido por seu comportamento de silêncio e disparo, que é mais fácil de observar nas figuras que o comportamento quase senoidal dos campos $x$ e $y$.

Este modelo faz uso dessas mudanças oscilatórias para determinar a atenção visual, o que significa que osciladores sincronizados correspondendo ao objeto saliente irão apresentar comportamento periódico e alta freqüência, enquanto os osciladores correspondentes aos demais objetos irão permanecer com freqüências bem menores e comportamento caótico.

Para obter este comportamento, os osciladores executam inicialmente com um valor fixo de $\omega$, definido de acordo com a intensidade do pixel correspondente, para que haja a sincronização por fase dos osciladores correspondentes ao mesmo objeto. Após um período transiente os osciladores pertencentes a diferentes objetos terão fases distintas, o que permite separá-los, e aí o mecanismo de atenção se inicia. O grupo de osciladores com maior freqüência e amplitude corresponde ao objeto mais brilhante da cena, o que em nosso modelo corresponde ao objeto que irá obter o foco de atenção primeiro. Estes osciladores passarão a produzir um sinal de reforço para eles próprios e 


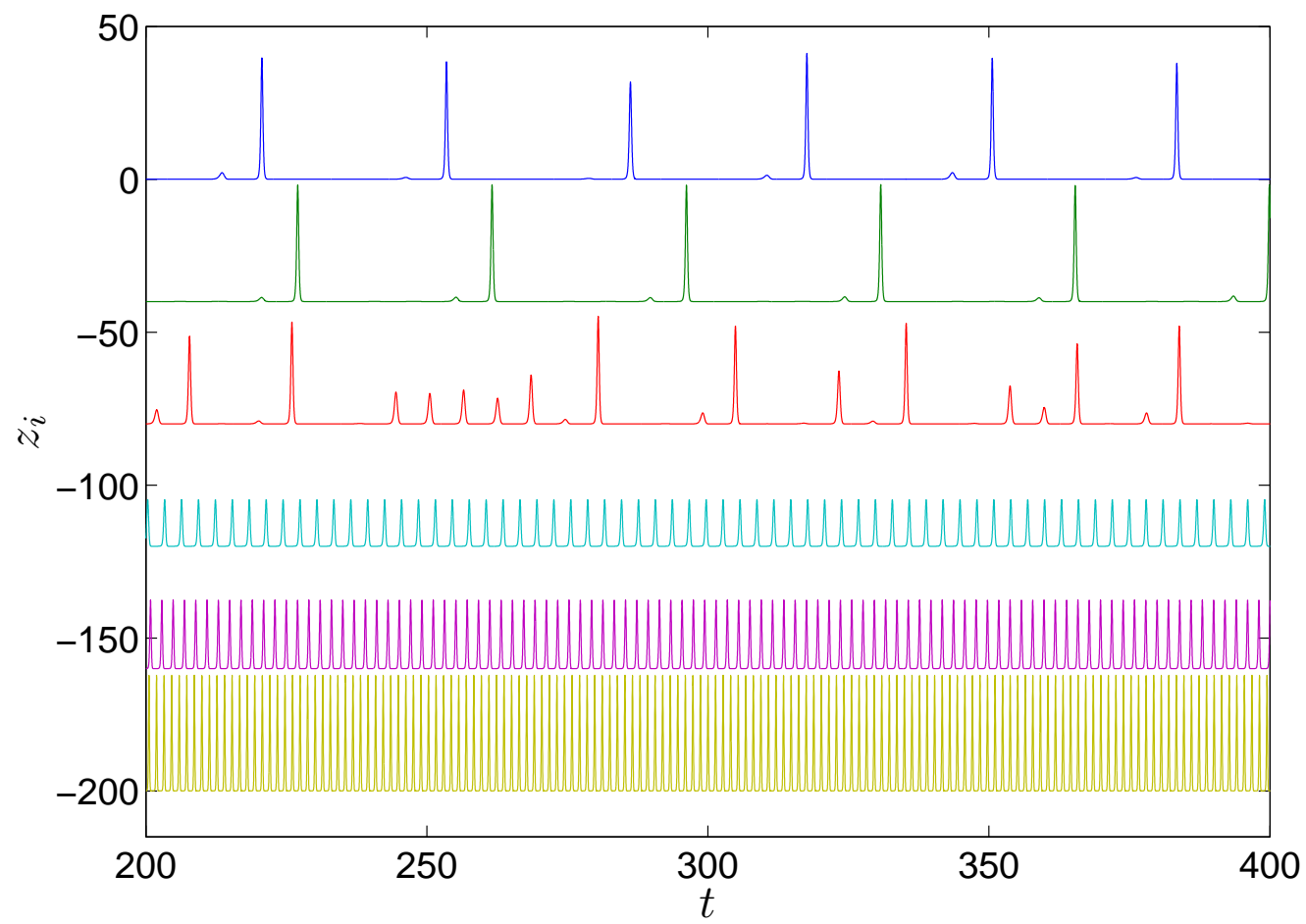

Figura 3.2: Atividades temporais de osciladores Rössler com $\omega=0,8, \omega=0,9$, $\omega=1,0, \omega=2,0, \omega=3,0$ e $\omega=4,5$ respectivamente. A escala vertical do segundo ao sexto osciladores está deslocada para baixo em 40 .

para outros osciladores que estiverem sincronizados a eles por fase, ao mesmo tempo em que produzem um sinal inibitório para os osciladores que não estão sincronizados com eles. Após algum tempo os osciladores deste grupo terão uma freqüência e amplitude muito maior que a dos osciladores que não receberam o sinal de reforço.

O comportamento de reforço é definido pelas seguintes equações:

$$
\begin{gathered}
\omega_{i, j}(t)=\omega_{i, j}(t-1)+f\left(\left\|\phi_{i, j}(t)-\Phi(t)\right\|\right) \\
f(x)=\left\{\begin{array}{cc}
\alpha, & \text { se } x \leq 2 \pi, \\
-\alpha, & \text { se } x>2 \pi .
\end{array}\right. \\
\omega_{i, j_{\text {min }}} \leq \omega_{i, j}(t) \leq \omega_{\text {max }}
\end{gathered}
$$

onde $(i, j)$ é o índice do neurônio, $t$ é a variável de tempo, $\|x\|$ é a norma de $x, \Phi(t)$ é a maior fase entre todos os osciladores competindo por atenção no tempo $t, \alpha$ é uma constante pequena, $\omega_{i, j_{\min }}$ é uma constante definida pelo valor original de $\omega_{i, j}$ conforme definido pelo nível de cinza do pixel correspondente, $\omega_{\max }$ é uma constante com um valor que quando ajustado em $\omega$ produz uma freqüência de oscilação maior e comportamento periódico. 
Cada oscilador que recebe um sinal de reforço irá aumentar o valor de seu parâmetro $\omega$ proporcionalmente, enquanto osciladores que receberem um sinal de inibição irão diminuir o valor de seu parâmetro $\omega$. O valor máximo de $\omega$ que um oscilador pode assumir é $\omega_{\max }$, enquanto o valor mínimo é $\omega_{i, j_{\min }}$. Após algum tempo, os osciladores correspondendo ao objeto saliente irão disparar com muito mais freqüência que os outros, e em regime periódico, o que significa que o objeto correspondente é o saliente.

Um grupo de neurônios é considerado saliente quando seus parâmetros $\omega_{i, j}=\omega_{\max }$. Após algum tempo, o mecanismo de habituação é disparado. Ele é responsável por inibir este objeto e permitir uma mudança do foco de atenção para outro objeto saliente. Os objetos que já receberam atenção não competirão por atenção novamente até que todos os outros objetos da cena tenham recebido o foco de atenção. Sem o sinal de reforço os osciladores correspondentes ao antigo objeto saliente irão gradualmente decrescer seus parâmetros $\omega$ devido a ação do sinal inibitório do próximo objeto saliente, até que eles atinjam seu nível mínimo, o qual corresponde ao nível que eles possuíam antes do mecanismo de atenção ser iniciado.

Todos os objetos inibidos permanecem com comportamento caótico e uma pequena freqüência de oscilação. Quando todos os objetos salientes na cena de entrada já tiverem sido inibidos, todos os neurônios passarão a competir novamente pelo foco de atenção.

\subsubsection{Simulações Computacionais}

Para demonstrar a viabilidade do modelo proposto serão apresentados os resultados de dois experimentos com imagens sintéticas. Em ambas as simulações o nível de cinza das imagens foi codificado uniformemente no intervalo $\left[\begin{array}{ll}0,9 & 1,1\end{array}\right]$, e os seguintes parâmetros foram mantidos constantes: $a=0,15$, $b=0,2, c=10, \omega_{\max }=4,5, \alpha=0,02$ e $k=0,05$, os quais foram definidos empiricamente.

O primeiro experimento foi feito utilizando a imagem artificial mostrada na Figura 3.3a, que tem 5 objetos (incluindo o fundo) com diferentes tons de cinza. Na figura pode ser observado que os objetos são linearmente não separáveis. Apesar disso, os 5 objetos são corretamente segmentados e a Figura 3.3b mostra a fase de cada grupo de osciladores no tempo. Além disso, a Figura 3.4 mostra as atividades temporais de um oscilador de cada objeto, que está sincronizado por fase com os demais osciladores do mesmo objeto.

Após um período transiente, onde acontece a sincronização dos osciladores pertencentes ao mesmo objeto e a dessincronização dos osciladores pertencentes a objetos distintos, é possível observar na Figura 3.4 o comportamento do sistema entregando a atenção para um objeto específico e mudando o foco 


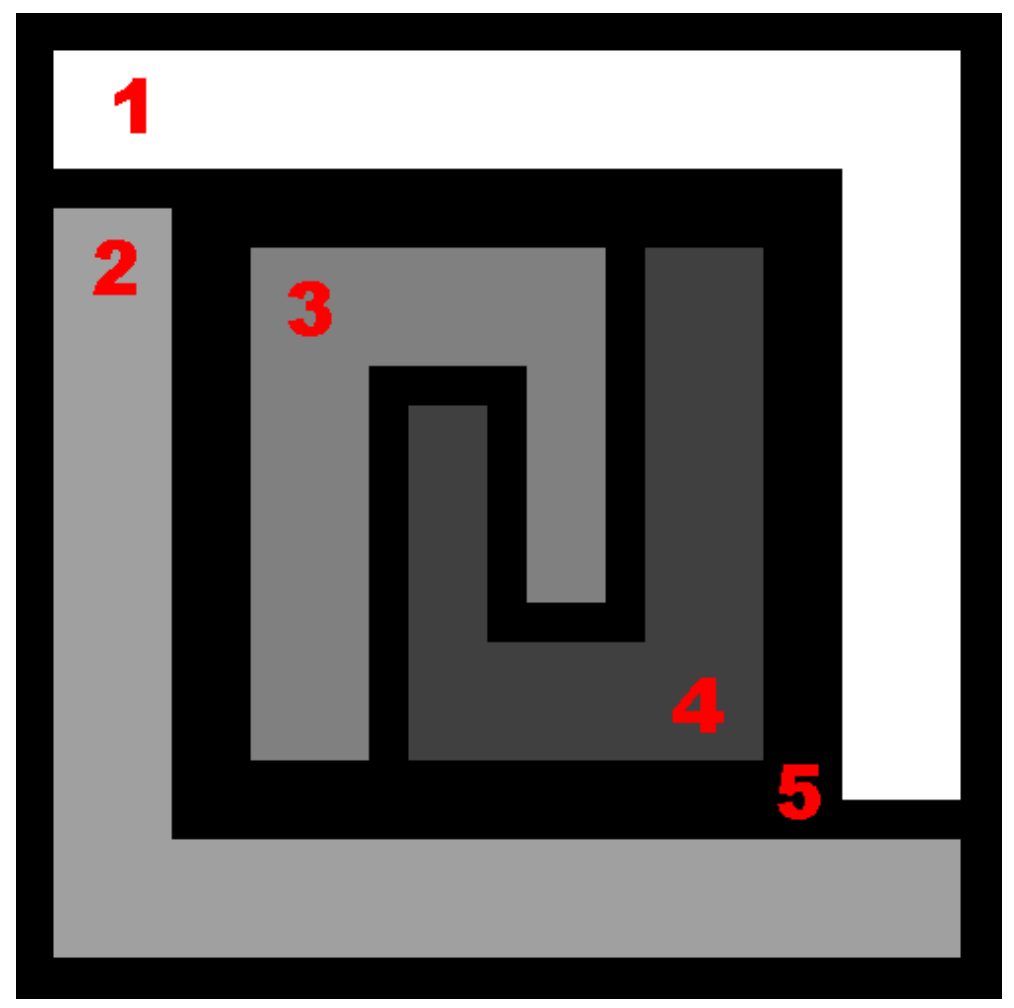

(a)

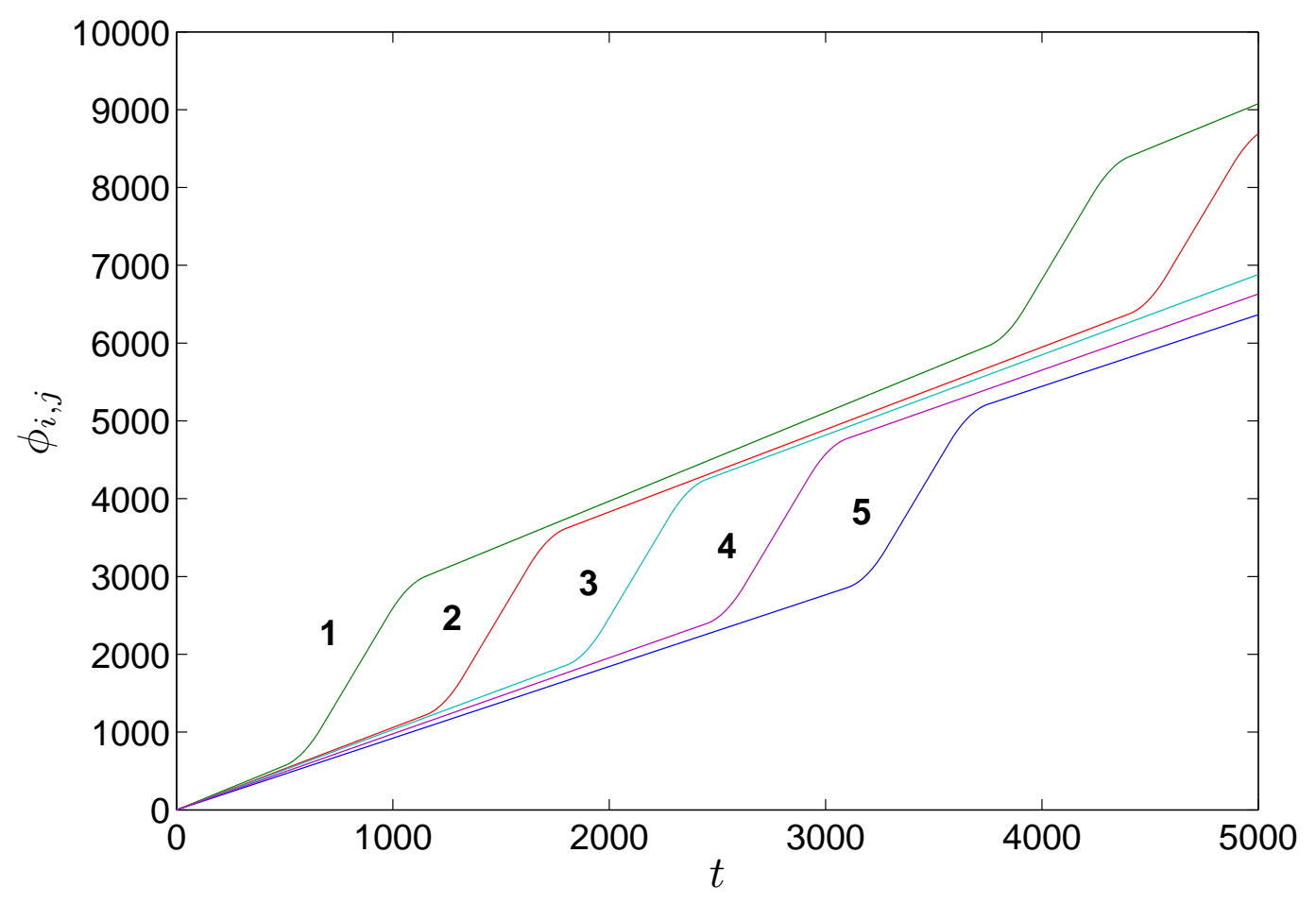

(b)

Figura 3.3: Atenção visual em imagem artificial com 5 objetos linearmente não separáveis (incluindo o fundo), $25 \times 25$ pixels: (a) Imagem original; (b) Medida de fase dos blocos de osciladores. Cada trajetória na figura representa um grupo de osciladores sincronizados por fase e corresponde a um segmento da imagem de entrada. 

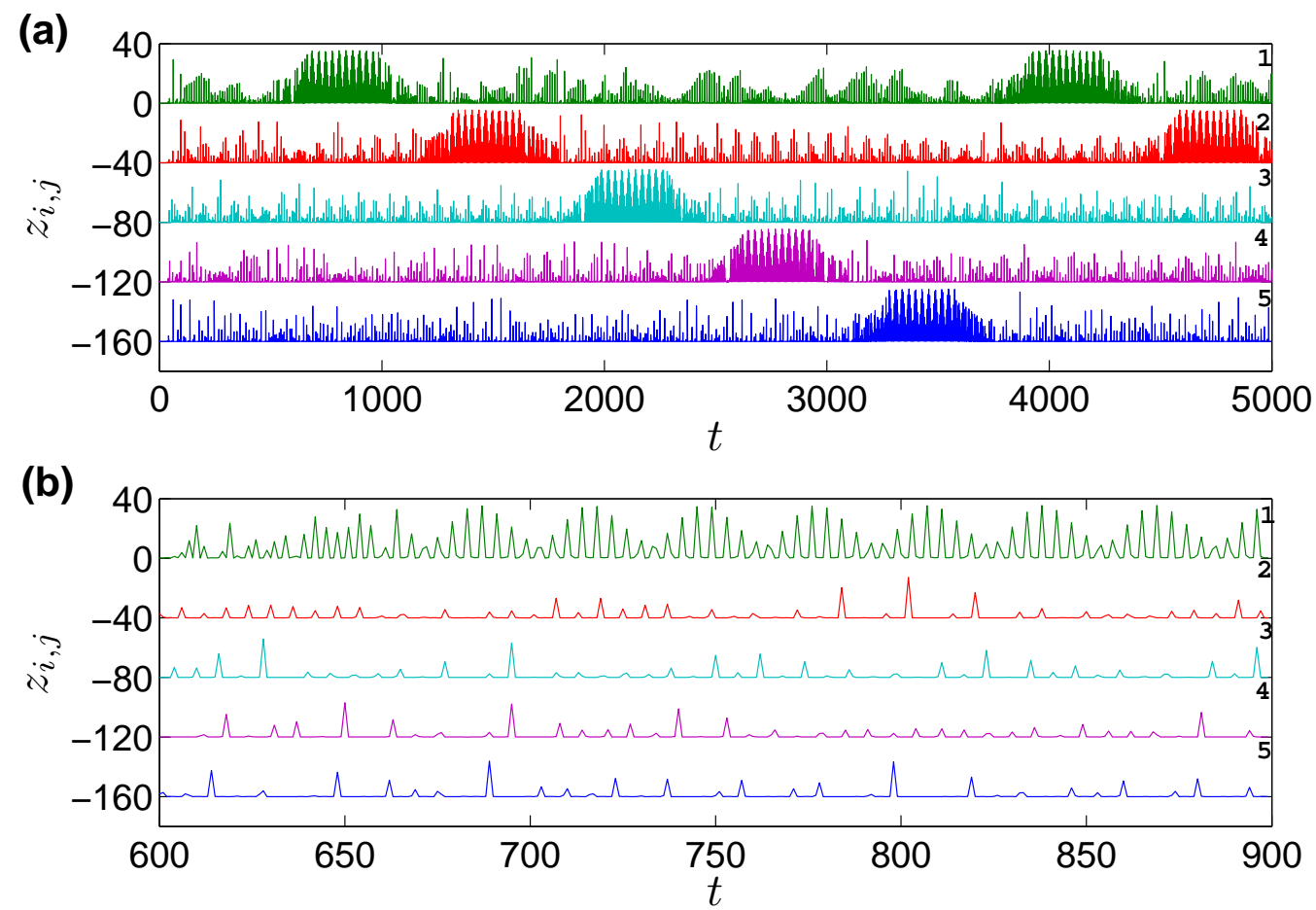

Figura 3.4: Atividades temporais dos blocos de osciladores. Cada linha na figura corresponde a um objeto da imagem de entrada da Figura 3.3a. A escala vertical do segundo ao quinto objeto está deslocada para baixo em 40 .

entre os objetos da imagem. Como mencionado acima, estas simulações consideram apenas a intensidade dos pixels como entrada. Assim, os objetos de maior intensidade receberão a atenção antes que os objetos de menor intensidade. Também é possivel observar na Figura 3.4b, em detalhes, o momento em que o primeiro objeto está recebendo atenção e seus osciladores estão com freqüência bem maior que os demais.

Além disso, na Figura 3.3b é possivel notar que quando um objeto recebe atenção o crescimento de fase dos osciladores correspondentes aumenta rapidamente. Após o objeto perder o foco de atenção, a taxa de crescimento de fase dos osciladores correspondentes volta ao patamar normal.

O segundo experimento foi realizado utilizando a imagem artificial mostrada na Figura 3.5a contendo 7 elementos com diferentes tons de cinza. A Figura 3.5b mostra a trajetória de fase de cada grupo de osciladores e a Figura 3.5c mostra a atividade temporal dos osciladores correspondentes a cada objeto. Novamente, é possível observar que o comportamento do sistema, onde a atenção é entregue para cada um dos sete elementos em diferentes instantes de tempo.

Em ambos os experimentos é possível verificar que a freqüência e a amplitude dos osciladores correspondentes aos objetos não destacados permanecem mais baixas, enquanto a freqüência e a amplitude dos osciladores correspondentes ao objeto com o foco de atenção aumentam bastante, como era 


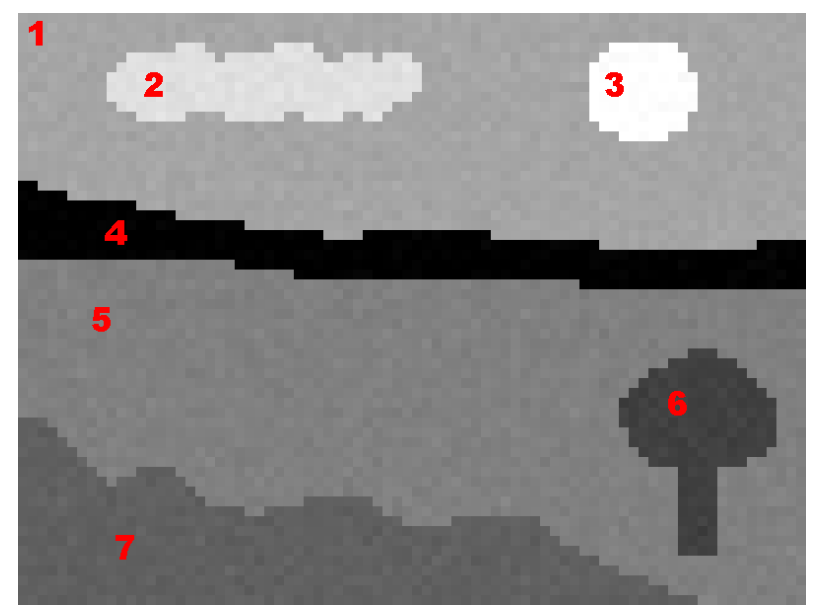

(a)

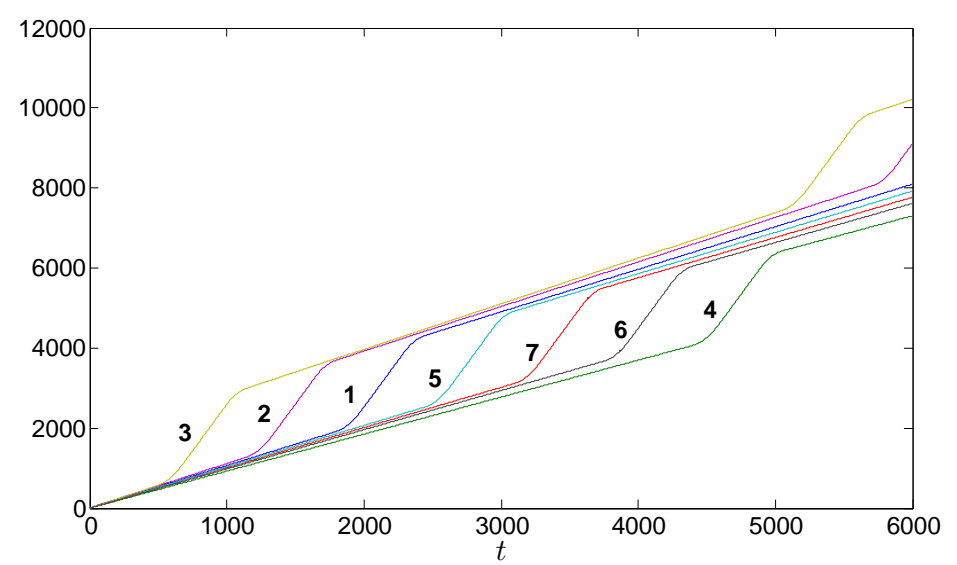

(b)

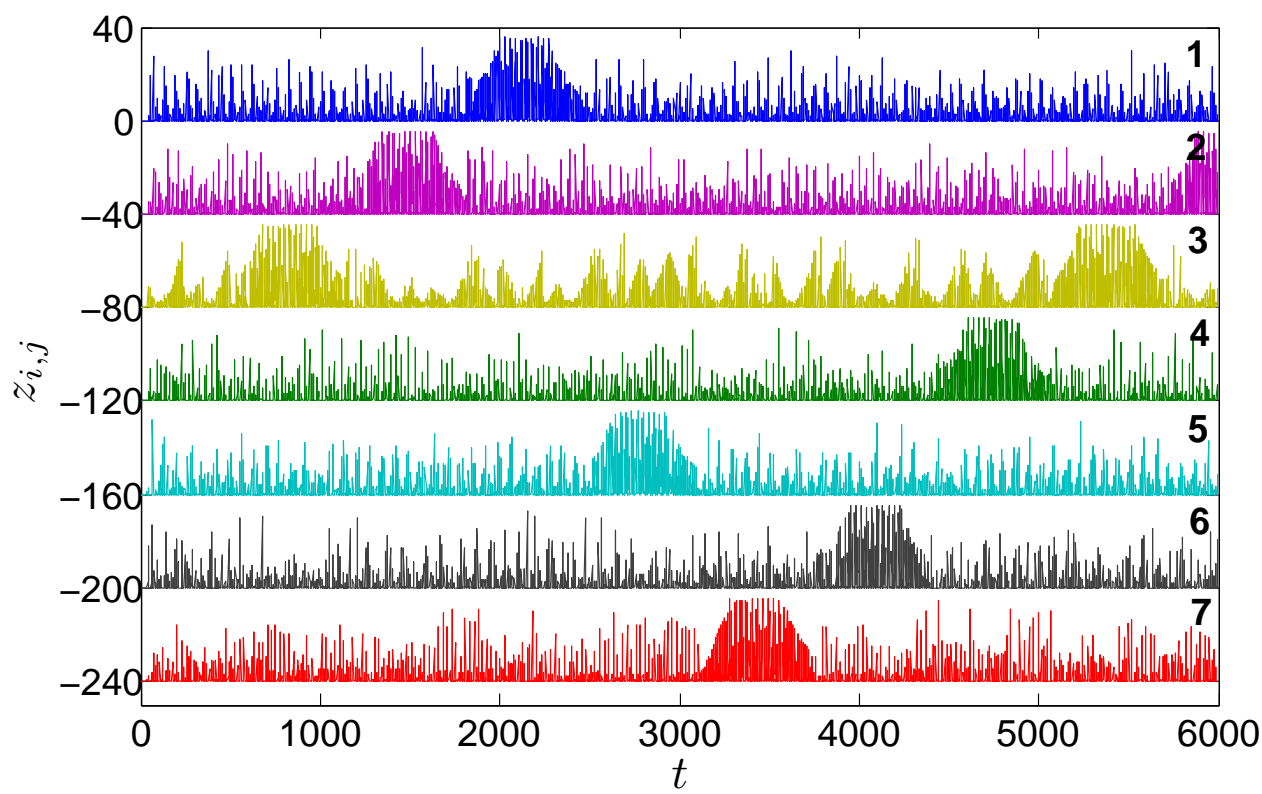

(c)

Figura 3.5: Atenção visual em imagem artificial com 7 segmentos, $80 \times 60$ pixels: (a) Imagem original; (b) Medida de fase dos blocos de osciladores. Cada trajetória na figura representa um grupo de osciladores sincronizados por fase e corresponde a um segmento da imagem de entrada; (c) Atividades temporais dos blocos de osciladores, cada linha na figura corresponde a um objeto da imagem de entrada, a escala vertical do segundo ao sétimo objeto está deslocada para baixo em 40 . 
esperado.

\subsection{Atenção Visual com Sincronização e Dessincroni- zação por Fase em Redes de Osciladores}

Este modelo (Breve et al., 2009c,d) também utiliza uma grade de osciladores de Rössler acoplados, como no modelo da seção anterior, porém a atenção visual é obtida de uma maneira diferente e mais plausivel do ponto de vista biológico: apenas o objeto que recebe atenção terá seus correspondentes osciladores sincronizados, enquanto os demais objetos terão seus correspondentes osciladores dessincronizados. Além disso, o objeto considerado saliente é aquele que tem maior contraste de cores e intensidade com relação a outras partes da imagem. Esta hipótese tem suporte direto de experimentos biológicos que mostram que o contraste entre atributos é mais importante que o valor absoluto desses atributos quando tarefas de busca visual são realizadas em sistemas visuais biológicos (Wolfe \& Horowitz, 2004; Yantis, 2005). Neste modelo, a segmentação ocorre em paralelo com o mecanismo de atenção, e apenas o objeto saliente é segmentado. Na Seção 3.3.1 são apresentados os detalhes deste modelo, e na Seção 3.3.2 são apresentados alguns resultados de simulações computacionais.

\subsection{Descrição do Modelo}

O modelo proposto é uma rede bi-dimensional de osciladores Rössler que é governada pelas seguintes equações:

$$
\begin{aligned}
\dot{x}_{i, j} & =-\omega_{i, j} y_{i, j}-z_{i, j}+k_{i, j}^{+} \Delta^{+} x_{i, j}+k_{i, j}^{-} \Delta^{-} x_{i, j}, \\
\dot{y}_{i, j} & =\omega_{i, j} x_{i, j}+a y_{i, j}, \\
\dot{z}_{i, j} & =b+z_{i, j}\left(x_{i, j}-c\right) .
\end{aligned}
$$

onde $(i, j)$ é um ponto de grade com $1 \leq i \leq N, 1 \leq j \leq M . k_{i, j}^{+} \in\left[0, k_{\max }^{+}\right] \mathrm{e}$ $k_{i, j}^{-} \in\left[0, k_{\max }^{-}\right]$são forças de acoplamento positivas e negativas, respectivamente. Elas são configuradas de acordo com o contraste do pixel, como será descrito mais adiante. $\omega_{i, j}$ também é usado para codificar o contraste do pixel $(i, j)$, como também será explicado mais adiante. $k_{\max }^{+}$and $k_{\max }^{-}$são definidos de acordo com a cena. $\Delta^{+} x_{i, j}$ e $\Delta^{-} x_{i, j}$ são os termos de acoplamento positivos e 
negativos, respectivamente. Eles são definidos por:

$$
\begin{aligned}
\Delta^{ \pm} x_{i, j}= & \gamma_{i-1, j-1 ; i, j}\left(x_{i-1, j-1}-x_{i, j}\right)+ \\
& \gamma_{i-1, j ; i, j}\left(x_{i-1, j}-x_{i, j}\right)+ \\
& \gamma_{i-1, j+1 ; i, j}\left(x_{i-1, j+1}-x_{i, j}\right)+ \\
& \gamma_{i, j-1 ; i, j}\left(x_{i, j-1}-x_{i, j}\right)+ \\
& \gamma_{i, j+1 ; i, j}\left(x_{i, j+1}-x_{i, j}\right)+ \\
& \gamma_{i+1, j-1 ; i, j}\left(x_{i+1, j-1}-x_{i, j}\right)+ \\
& \gamma_{i+1, j ; i, j}\left(x_{i+1, j}-x_{i, j}\right)+ \\
& \gamma_{i+1, j+1 ; i, j}\left(x_{i+1, j+1}-x_{i, j}\right),
\end{aligned}
$$

onde

$$
\gamma_{i, j ; p, q}= \begin{cases}1, & \text { se o oscilador }(i, j) \text { está acoplicado com }(p, q), \\ 0, & \text { caso contrário. }\end{cases}
$$

As conexões positivas em $\Delta^{+}$entre pares de osciladores vizinhos com cores similares serão mantidas, enquanto que que as conexões entre osciladores com cores muito diferentes serão cortadas. As conexões negativas em $\Delta^{-}$estão sempre ligadas, o que significa que cada oscilador está sempre conectado aos seus 8 vizinhos mais próximos, com exceção dos osciladores das bordas.

O esquema de segmentação e seleção de objetos é descrito abaixo. Dada a imagem de entrada, a rede é organizada de forma que cada oscilador representa um pixel da imagem, ou seja, ele recebe um estímulo do seu pixel correspondente na imagem. Neste modelo, o estímulo é representado pelo contraste relativo do pixel $R_{i, j}$. Para determiná-lo é preciso primeiramente calcular o contraste absoluto $C_{i, j}$ para cada pixel:

$$
C_{i, j}=\frac{\sum_{d} w^{d}\left|F_{i, j}^{d}-F_{\text {avg }}^{d}\right|}{\sum_{d} w^{d}}
$$

onde $(i, j)$ é o índice do pixel, $F_{i, j}^{d}$ é o valor do atributo $d$ do pixel $(i, j)$ normalizado no intervalo $[0,1]$, $w^{d}$ é o peso do atributo $d$, e $F_{\text {avg }}^{d}$ é o valor médio para o atributo $d$, o qual é dado por:

$$
F_{\mathrm{avg}}^{d}=\frac{1}{N \cdot M} \sum_{i=1}^{i=N} \sum_{j=1}^{j=M} F_{i, j}^{d} .
$$

Nos experimentos 4 atributos foram utilizados, $F^{I}, F^{R}, F^{G}$ e $F^{B}$, os quais correspondem aos valores de intensidade (I) e aos componentes vermelho (R), verde (G) e azul (B) de cada pixel, respectivamente. Os pesos são configurados para $w^{I}=3, w^{R}=1, w^{G}=1$, e $w^{B}=1$. 
Finalmente, o contraste relativo é definido da seguinte forma:

$$
R_{i, j}=\exp \left(-\frac{\left(1-C_{i, j}\right)^{2}}{2 \sigma^{2}}\right)
$$

onde $\sigma$ é definido de acordo com o problema.

Uma vez que o contraste relativo esteja obtido, ele é usado para modelar os parâmetros do oscilador, de forma que o oscilador que corresponde ao objeto mais saliente (com maior contraste) será sincronizado devido ao acoplamento positivo $k_{i, j}^{+}$forte e ao acoplamento negativo $k_{i, j}^{-}$fraco. Ao mesmo tempo, os osciladores que correspondem a objetos não salientes terão acoplamento positivo fraco e acoplamento negativo forte, de forma que não sincronizarão. Especificamente, os parâmetros são definidos com as seguintes regras:

$$
\begin{gathered}
k_{i, j}^{+}=k_{\max }^{+} R_{i, j}, \\
k_{i, j}^{-}=k_{\max }^{-}\left(1-R_{i, j}\right), \\
\omega_{i, j}=1-\frac{\Delta_{\omega}}{2}+\Delta_{\omega} C_{i, j},
\end{gathered}
$$

onde $\omega_{i, j}$ varia no intervalo $\left[1-\frac{\Delta \omega}{2}, 1+\frac{\Delta \omega}{2}\right]$ e $\Delta \omega$ é configurado de acordo com a cena.

Nos osciladores que correspondem a pixels com maior contraste, a força de acoplamento negativa tende a zero $\left(k_{i, j}^{-} \rightarrow 0\right)$, portanto o objeto formado por pixels de alto contraste praticamente não são afetados por forças negativas, ao mesmo tempo em que forças positivas mantém os osciladores sincronizados em fase. De maneira semelhante, nos osciladores que correspondem a pixels com menos contraste, a força de acoplamento negativa é mais forte $\left(k_{i, j}^{-} \rightarrow k_{\max }^{-}\right)$ e, portanto, estes osciladores irão repelir uns aos outros. Finalmente, apenas os osciladores correspondendo ao objeto saliente irão permanecer com suas trajetórias sincronizadas em fase, enquanto que outros objetos terão suas trajetórias com diferentes fases.

Pela nossa experiência diária, sabemos que não é possível manter a atenção em um único objeto por muito tempo, ou seja, o foco de atenção precisa mudar para outros objetos ativos. Este mecanismo pode ser implementado no modelo usando a Equação (3.16) no lugar da Equação (3.12). Neste caso, todas as outras equações são mantidas. 


$$
R_{i, j}=\exp \left(-\frac{\left(1-t / t_{e n d}-C_{i, j}\right)^{2}}{2 \sigma^{2}}\right)
$$

onde $t_{\text {end }}$ é o tempo total da simulação. A Equação (3.12) define o contraste fixo, ou seja, apenas o objeto com o contraste mais alto ganha e a atenção permanece nele para sempre; enquanto que a Equação (3.16) define um contraste em movimento, ou seja, o sistema irá destacar vários objetos com diferentes níveis de contraste. A Equação 3.16 é na verdade uma convolução entre o contraste absoluto $C$ e uma função Gaussiana variando no tempo.

\subsubsection{Simulações Computacionais}

A seguir, serão apresentados alguns resultados de simulações computacionais com imagens sintéticas e reais, primeiramente com o mecanismo de habituação e mudança de foco desligado e depois com ele ligado. Os seguintes parâmetros são mantidos constantes para todos os experimentos: $k_{\max }^{+}=0,05$ e $k_{\text {max }}^{-}=0,02$.

Primeiramente, faremos simulações com três imagens artificiais mostradas na Figura 3.6 com complexidade visual crescente. O primeiro experimento é realizado na imagem mostrada na Figura 3.6a, com 15 objetos, 14 deles são azuis e apenas um é amarelo (localizado na segunda linha, quarta coluna) e, portanto, se tornando o objeto saliente. Os parâmetros livres são os seguintes: $\sigma=0,4$ e $\Delta \omega=0,2$. A Figura 3.7a mostra o comportamento de 20 osciladores (pixels) escolhidos aleatoriamente de cada objeto, onde cada linha corresponde a um oscilador. Tons escuros representam os menores valores para o componente $x$ do oscilador correspondente, enquanto tons claros representam os valores mais altos. Das linhas 161 a 180 podemos ver que os osciladores correspondendo ao objeto saliente estão sincronizados por fase (veja o padrão formado), enquanto que os demais osciladores permanecem com suas fases não correlacionadas. A Figura 3.7b mostra o crescimento de fase acumulada dos osciladores através do tempo, e pode ser notado que as fases dos osciladores que correspondem ao objeto saliente têm um crescimento mais rápido e também formam uma plataforma plana, enquanto que os outros osciladores tem um crescimento de fase mais lento e formam um padrão irregular. A Figura 3.7c mostra que o desvio padrão da fase acumulada do objeto saliente não cresce, indicando que a sincronização por fase ocorre entre os osciladores que representam o objeto saliente, enquanto que o desvio padrão da fase acumulada dos osciladores que correspondem aos outros objetos cresce continuamente, indicando que não está ocorrendo sincronização por fase. As Figuras 3.7d e 3.7e mostram retratos da fase de dois oscilado- 
res selecionados aleatoriamente, o primeiro pertencendo a um dos objetos de fundo e o segundo pertencendo ao objeto saliente. Destas figuras, podemos observar que os osciladores ainda apresentam comportamento caótico após o processo de sincronização acontecer.

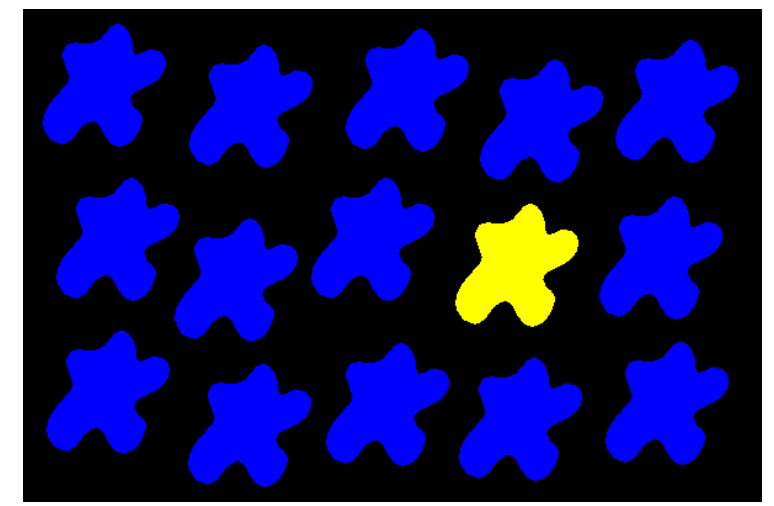

(a)

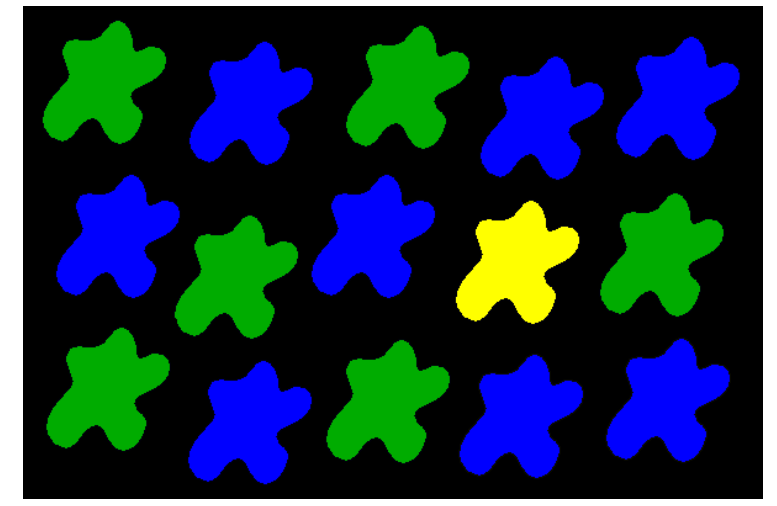

(b)

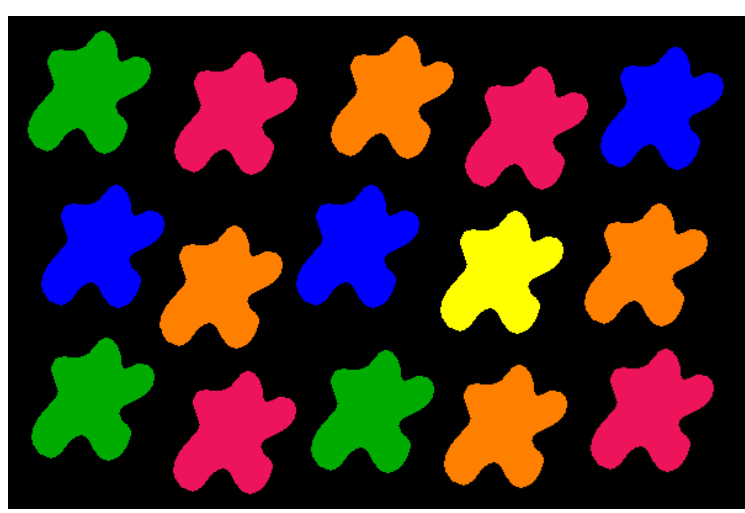

(c)

Figura 3.6: Atenção visual em imagens artificiais com 15 objetos cada, e diferentes níveis de contraste: (a) alto contraste; (b) contraste médio; (c) baixo contraste.

O segundo experimento é realizado usando a imagem artificial mostrada na Figura 3.6b. Como na Figura 3.6a, há 15 objetos, e novamente o amarelo (segunda linha, quarta coluna) é o saliente. Porém, neste caso há menos contraste entre o objeto saliente e os outros objetos. Os parâmetros livres são configurados da seguinte forma: $\sigma=0,4$ e $\Delta \omega=0,2$, os mesmos valores que foram utilizados no experimento anterior, para que seja possível observar o que acontece quando há menos contraste na cena. A Figura 3.8a mostra o comportamento de 20 osciladores (pixels) escolhidos aleatoriamente de cada objeto, onde cada linha corresponde a um oscilador. Das linhas 161 a 180, podemos observar que os osciladores que correspondem ao objeto saliente novamente formam um padrão indicando que estão sincronizados por fase, porém, neste caso, as fases dos osciladores que correspondem aos outros objetos não são completamente não correlacionadas. Na verdade, alguns dos osciladores até mostram comportamento de sincronização por fase, o que significa que 


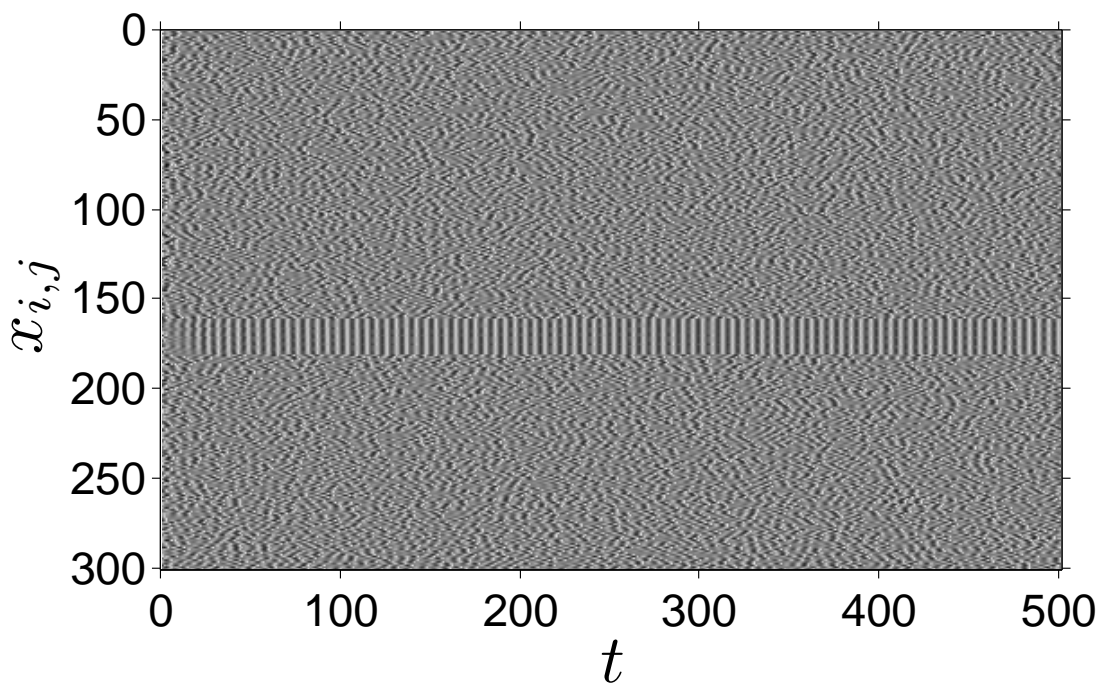

(a)

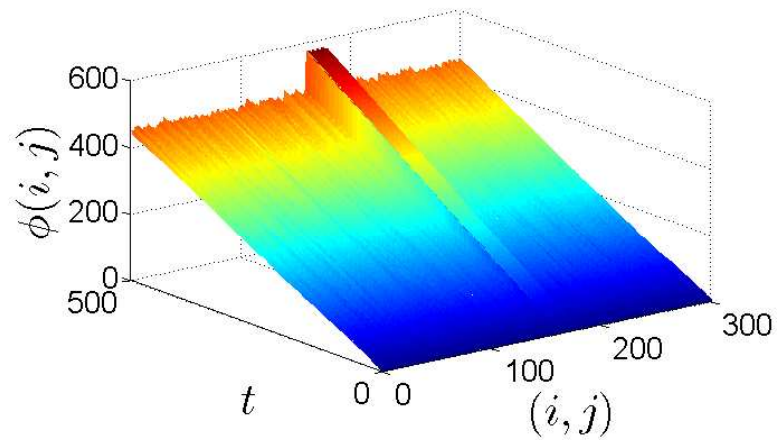

(b)

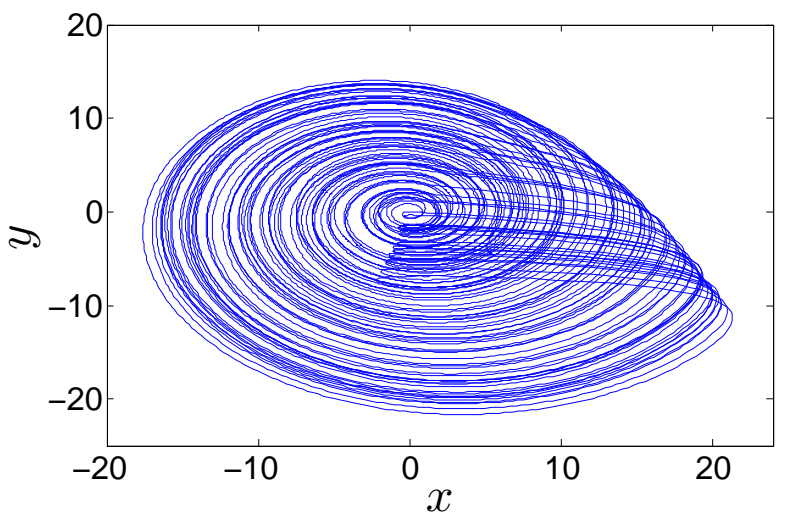

(d)

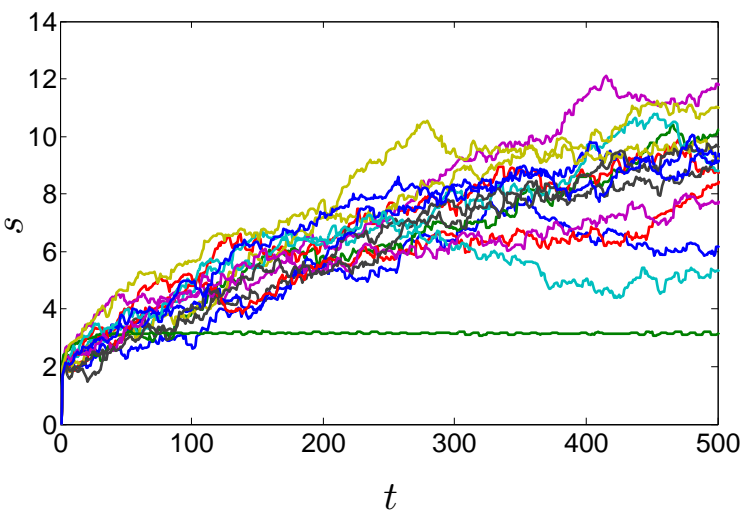

(c)

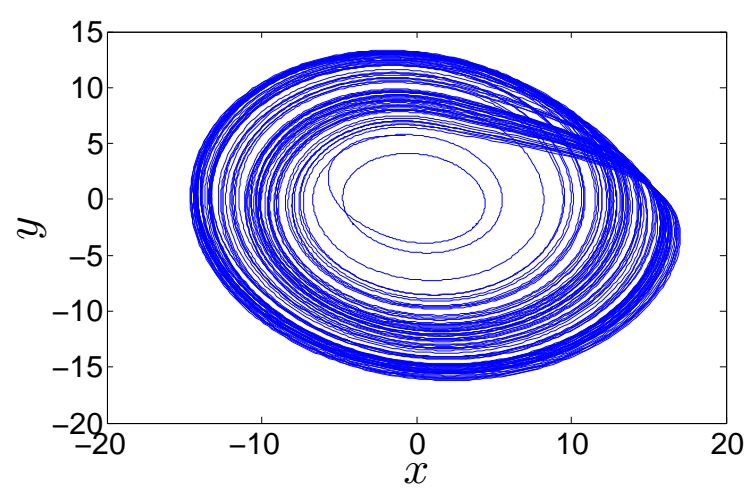

(e)

Figura 3.7: Resultados observados com a imagem artificial de alto contraste: (a) Comportamento dos osciladores; (b) Crescimento de fase; (c) Séries temporais do desvio-padrão de fase de cada objeto; (d) Retrato de um oscilador selecionado aleatoriamente dos objetos de fundo; (e) Retrato de fase de um oscilador selecionado aleatoriamente do objeto saliente. 
não foram suficientemente inibidos. A Figura 3.8b mostra o crescimento de fase acumulada dos osciladores ao longo do tempo. Podemos observar que não apenas os osciladores que correspondem ao objeto saliente, mas também alguns osciladores que correspondem a objetos não salientes formam grupos sincronizados. Note que podemos evitar este comportamento configurando um valor menor para $\sigma$, compensando o menor contraste na cena. Para confirmar essa hipótese, executamos o mesmo experimento novamente com os mesmos parâmetros, exceto pelo $\sigma$, cujo valor é diminuído de 0,4 para 0,25 . Os resultados são mostrados nas Figuras 3.8c e 3.8d, e agora podemos observar que o objeto saliente conseguiu inibir completamente a sincronização dos outros objetos, como era esperado.

Seguindo para o terceiro experimento, na Figura 3.6c temos uma imagem artificial com ainda menos contraste, o objeto amarelo (segunda linha, quarta coluna) é novamente o objeto saliente, mas agora há outros objetos claros de outras cores ao redor. Primeiramente, executamos a simulação usando os parâmetros do último experimento: $\Delta \omega=0,2$ e $\sigma=0,25$ e os resultados são mostrados nas Figuras 3.9a e 3.9b, onde podemos observar que $\sigma=0,25$ não é suficiente para inibir todos os objetos ao redor. Conseqüentemente, diminuímos $\sigma$ para 0,1 , e os novos resultados são mostrados pelas Figuras $3.9 \mathrm{c}$ e 3.9d, onde podemos observar que agora o objeto saliente conseguiu inibir completamente os demais.

O próximo experimento é realizado usando a imagem real mostrada na Figura 3.10a. Os parâmetros livres são os seguintes: $\sigma=0,5$ e $\Delta \omega=0,02$. A Figura 3.10b mostra o comportamento de 300 osciladores (pixels) escolhidos aleatoriamente da imagem, sendo que as primeiras 150 linhas correspondem às "folhas" e as outras 150 linhas correspondem à "flor". As Figuras 3.10c e 3.10d mostram que a sincronização por fase ocorre entre os osciladores representando o objeto "flor", enquanto nenhuma sincronização por fase é observada entre os outros osciladores. Portanto, o objeto "flor" é selecionado, o que está de acordo com nossa inspeção visual. Novamente, as Figuras 3.10e e 3.10f mostram que a trajetória dos osciladores ainda é caótica após o processo de sincronização acontecer.

Agora apresentamos alguns experimentos usando o mecanismo de troca que muda o foco de atenção de um objeto para outro. Na Figura 3.11a, mostramos uma imagem artificial com duas espirais. Os parâmetros livres são os seguintes: $\sigma=0,3$ e $\Delta \omega=0,2$. A Figura 3.11b mostra o comportamento de 150 osciladores (pixels selecionados aleatoriamente de cada objeto, onde cada linha corresponde a um oscilador. Das linhas 1 a 150 podemos observar que os osciladores correspondendo ao objeto amarelo são o primeiro grupo a sincronizar por fase. Após algum tempo, eles perdem sua sincronização e acontece 


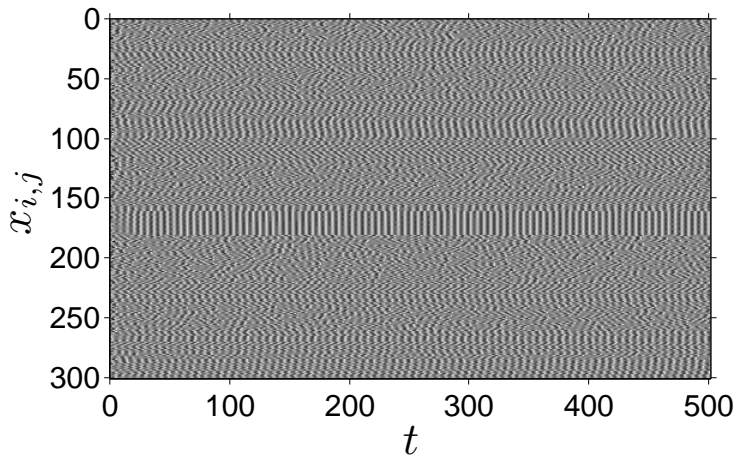

(a)

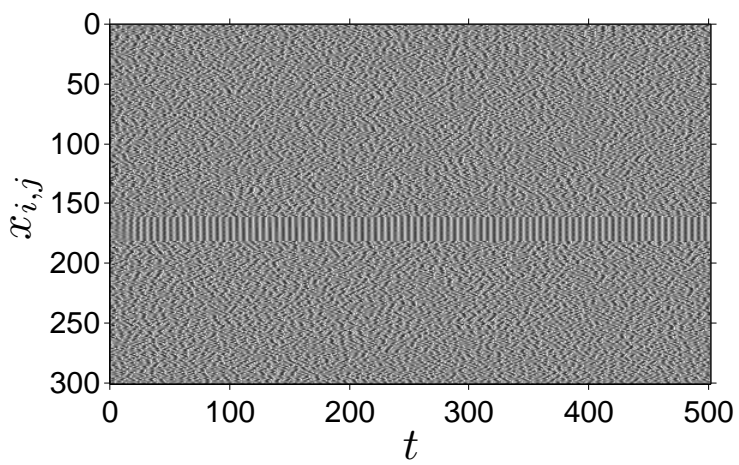

(c)

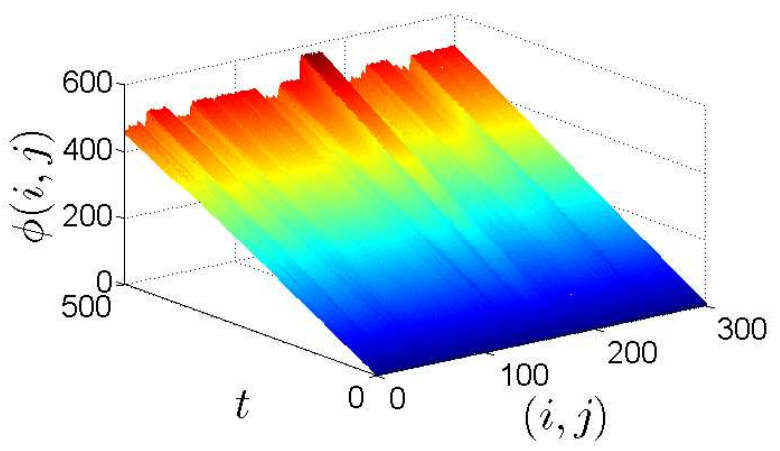

(b)

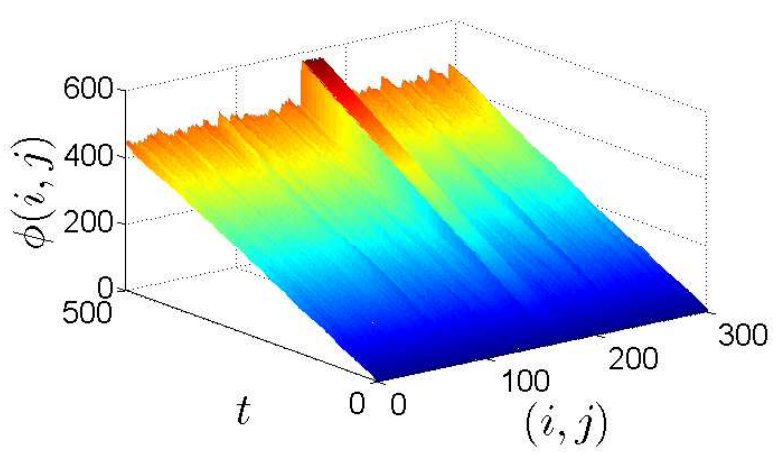

(d)

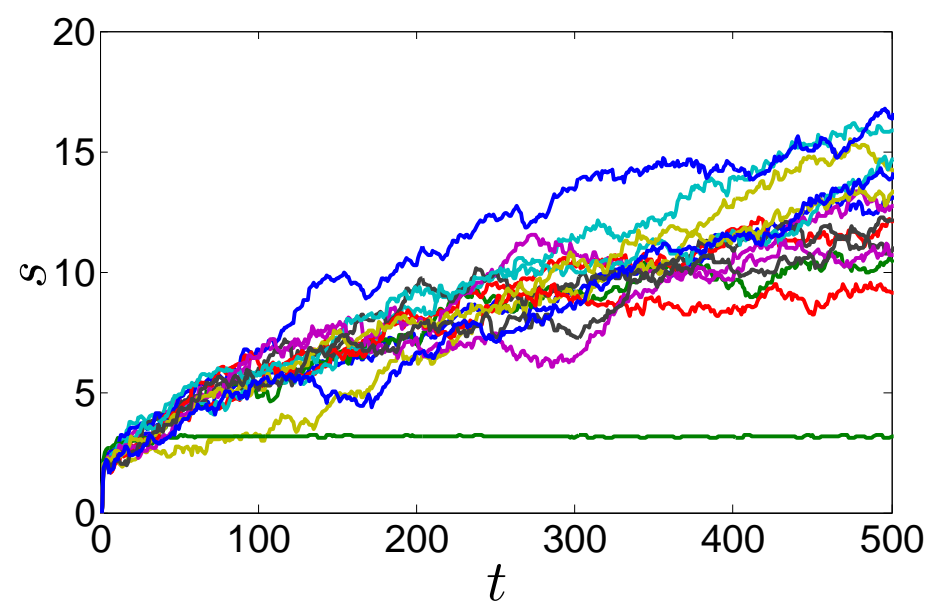

(e)

Figura 3.8: Resultados observados com a imagem artificial de médio contraste: (a) Comportamento dos osciladores, $\sigma=0,40$; (b) Crescimento de fase, $\sigma=$ 0,40; (c) Comportamento dos Osciladores, $\sigma=0,25$; (d) Crescimento de fase, $\sigma=0,25$; (e) Séries temporais do desvio-padrão de fase de cada objeto, $\sigma=0.25$. 


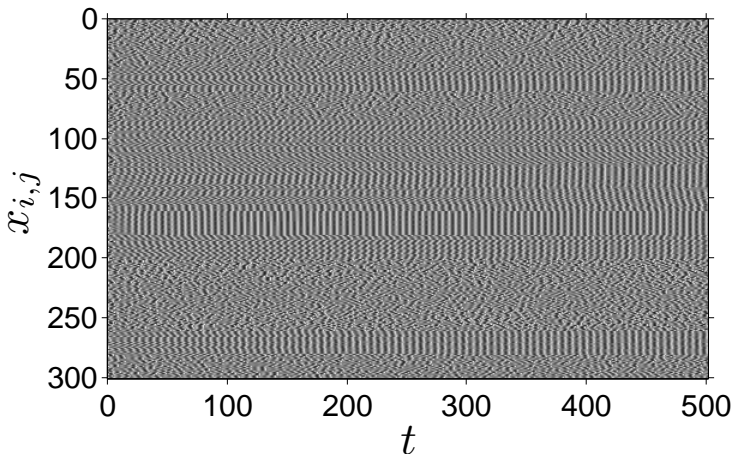

(a)

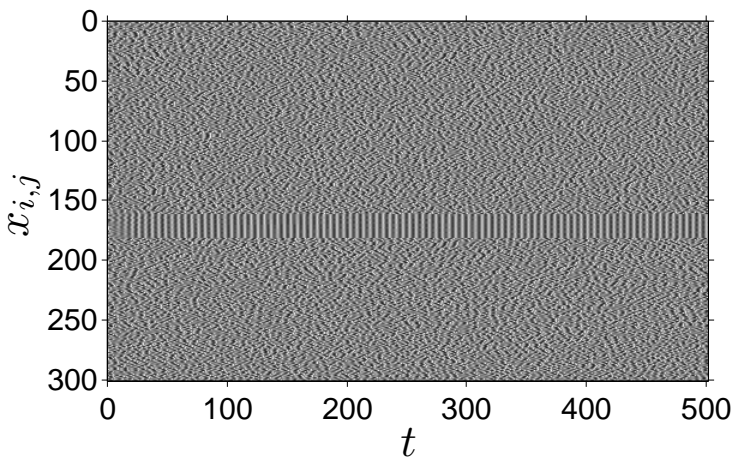

(c)

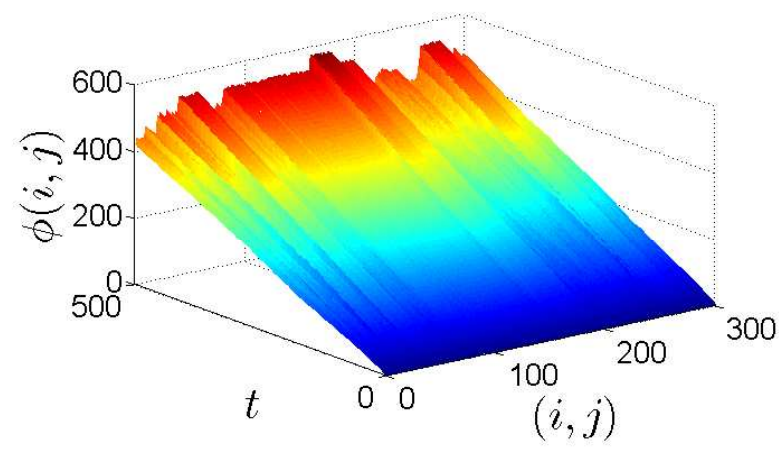

(b)

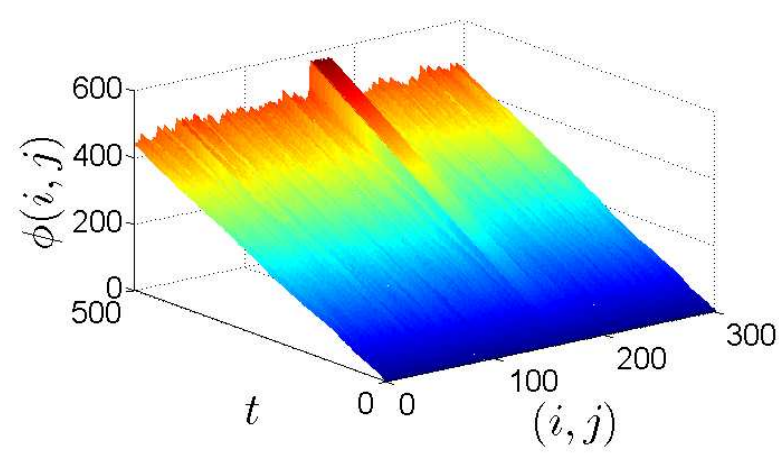

(d)

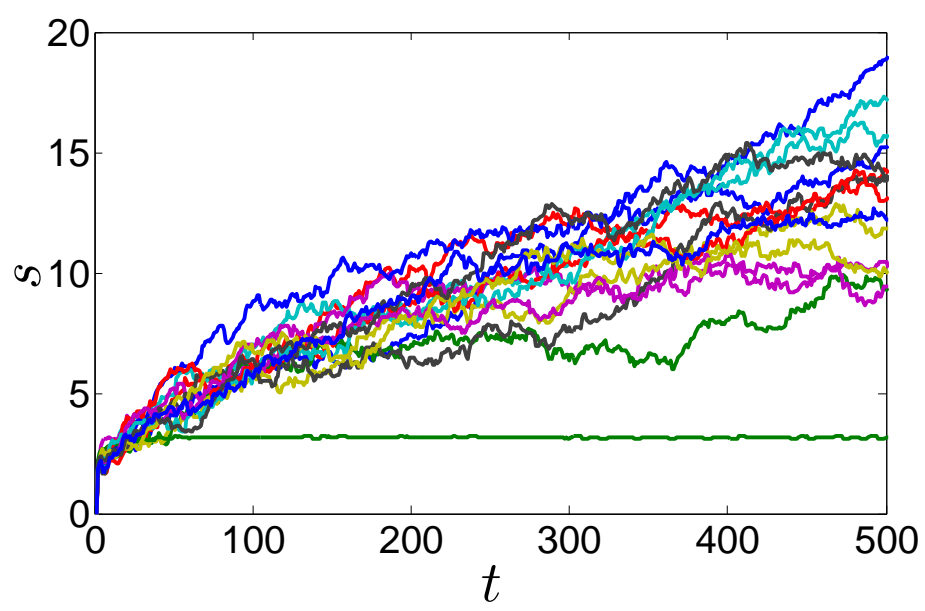

(e)

Figura 3.9: Resultados observados com a imagem artificial de baixo contraste: (a) Comportamento dos osciladores, $\sigma=0,25$; (b) Crescimento de fase, $\sigma=$ 0,25; (c) Comportamento dos Osciladores, $\sigma=0,25$; (d) Crescimento de fase, $\sigma=0,10$; (e) Séries temporais do desvio-padrão de fase de cada objeto, $\sigma=0,10$. 


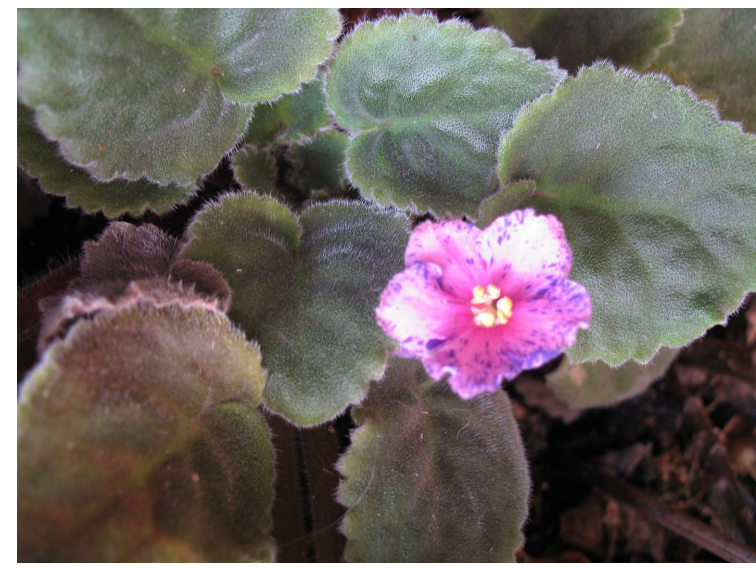

(a)

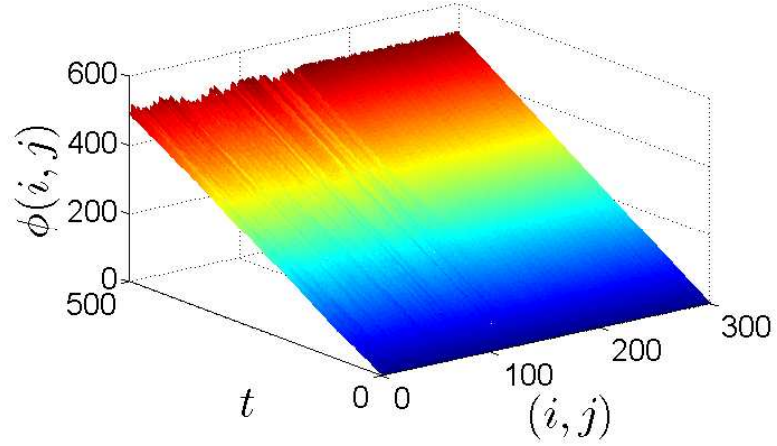

(c)

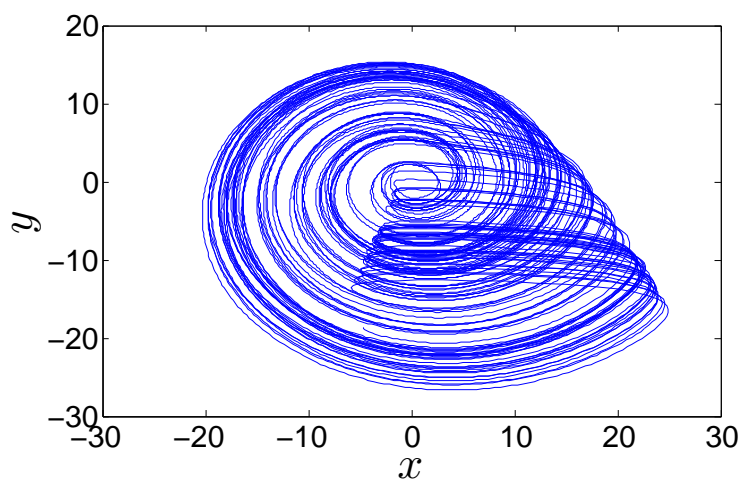

(e)

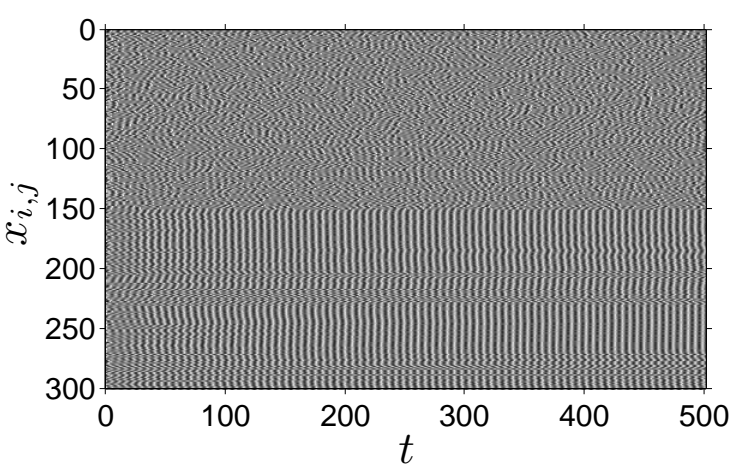

(b)

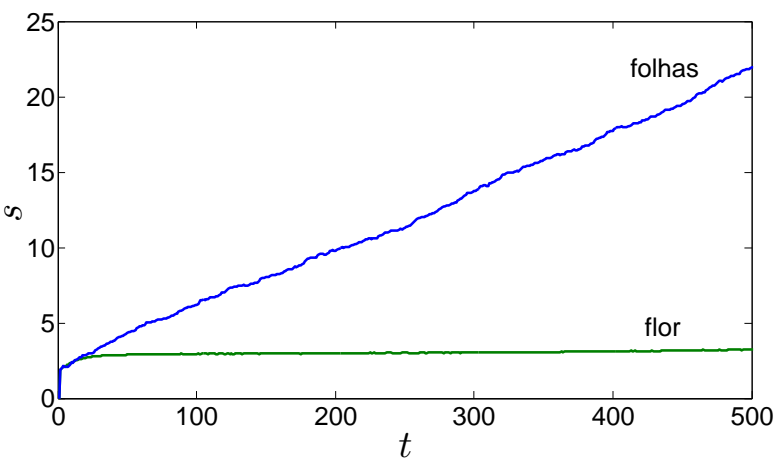

(d)

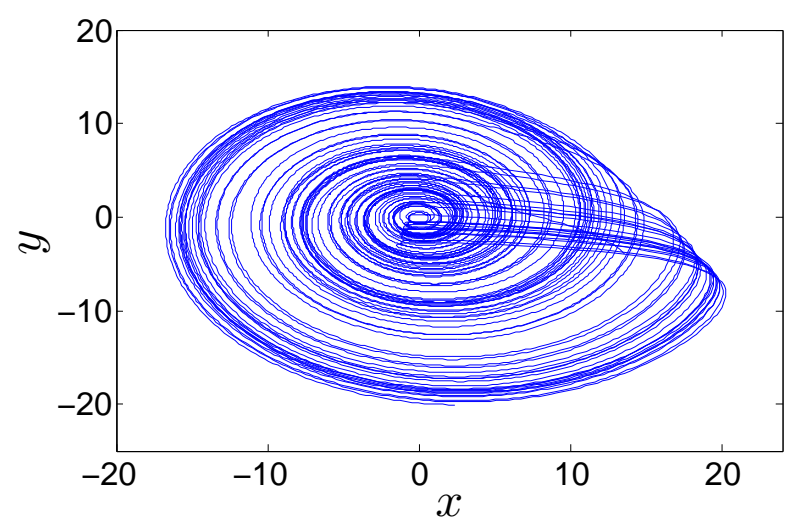

(f)

Figura 3.10: Atenção visual com imagem real - "Flor Gloxínia": (a) Imagem fonte; (b) Comportamento dos osciladores; (c) Crescimento de fase; (d) Séries temporais do desvio padrão de fase de cada objeto; (e) Retrato de fase de um oscilador selecionado aleatoriamente dos objetos de fundo. (f) Retrato de fase de um oscilador selecionado aleatoriamente do objeto saliente. 
a sincronização por fase do segundo grupo (linhas 151 a 300), que correspondem ao objeto verde. A Figura 3.11c mostra o desvio padrão do crescimento de fase dos dois grupos de osciladores, respectivamente. Nós percebemos que quando um objeto é saliente o desvio padrão de fase dos osciladores correspondentes forma um platô, indicando que eles estão sincronizados por fase. Ao mesmo tempo, quando um objeto não é saliente, o desvio padrão de fase dos osciladores correspondente cresce continuamente.

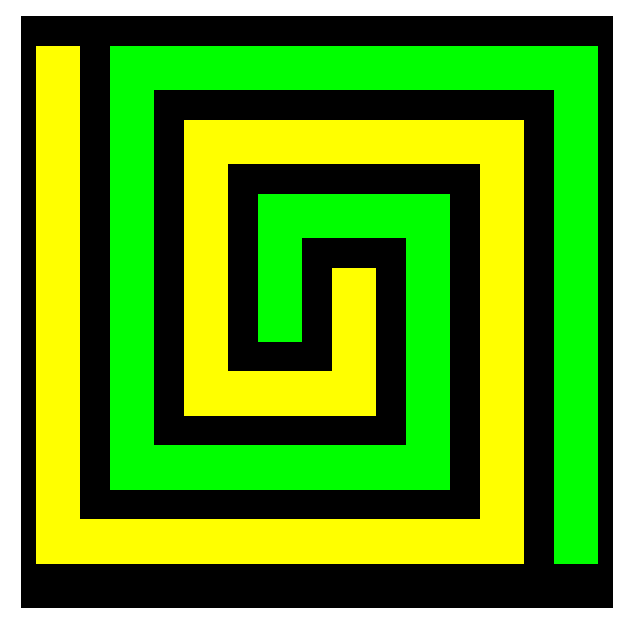

(a)

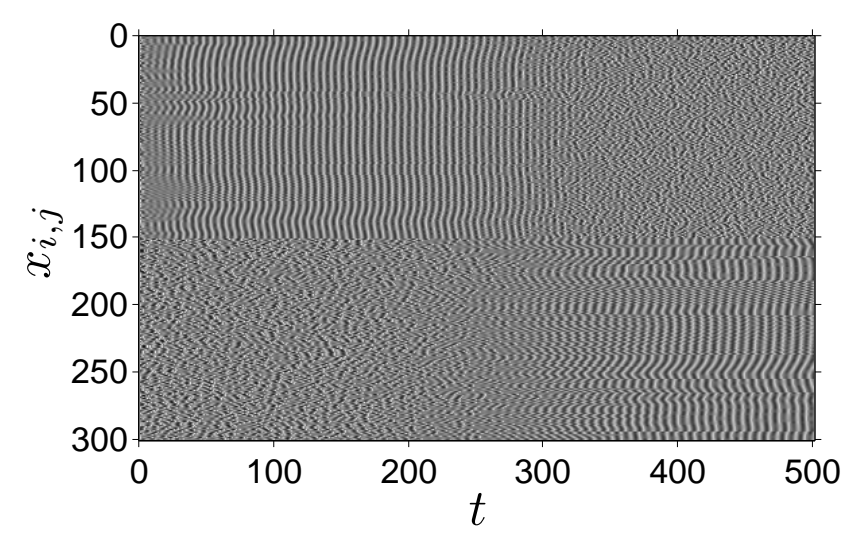

(b)

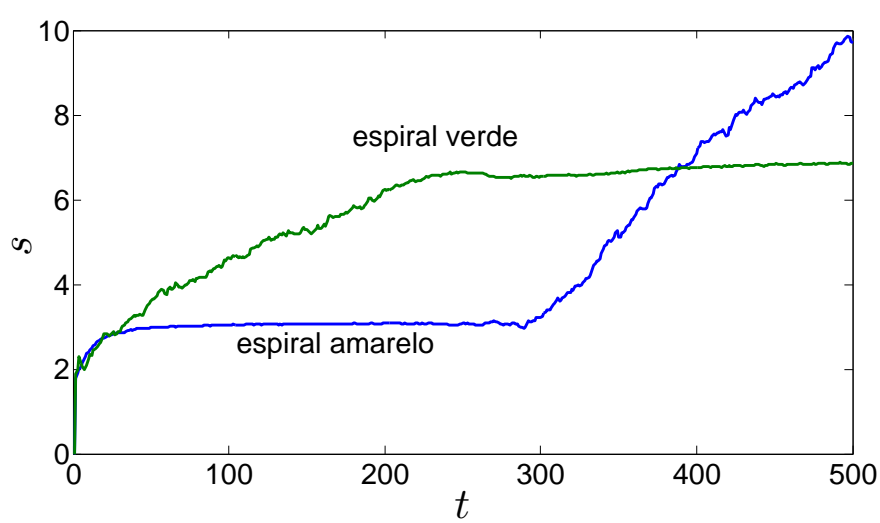

(c)

Figura 3.11: Atenção visual em imagem artificial - "Espirais": (a) Imagem fonte; (b) Comportamento dos osciladores; (c) Séries temporais do desvio padrão de fase de cada objeto.

Agora aplicamos o mecanismo de troca para a imagem do mundo real mostrada na Figura 3.12a. Nesta figura, o objeto saliente é o "cachorro", o qual tem uma forma irregular e é cercado pela "grama", que também tem forma irregular. Os parâmetros livres são: $\sigma=0,1$ e $\Delta \omega=0,02$. A Figura 3.12b mostra o comportamento de 300 osciladores (pixels) escolhidos aleatoriamente da imagem. As primeiras 150 linhas correspondem à "grama" e as outras 150 linhas correspondem ao "cachorro". Podemos observar que a Figura 3.12b pode ser dividida em três estágios: o primeiro estágio acontece do tempo zero até aproximadamente 200, onde nenhum objeto está saliente (nenhuma sincronização por fase é observada); o segundo estágio acontece aproximadamente do 
tempo 200 até aproximadamente o tempo 350, onde os osciladores que correspondem ao objeto "cachorro" estão sincronizados por fase e portanto o objeto "cachorro" é o saliente neste estágio; o terceiro estágio começa aproximadamente no tempo 350 e vai até o tempo 500, onde os osciladores correspondendo ao objeto "cachorro" perdem a sincronização e, ao mesmo tempo, os osciladores que correspondem ao objeto "grama" se tornam sincronizados. A Figura $3.12 \mathrm{c}$ mostra o desvio padrão do crescimento de fase acumulada através do tempo. Novamente, podemos observar que o sistema entrega a atenção primeiramente ao "cachorro", e após algum tempo, muda para a "grama". 


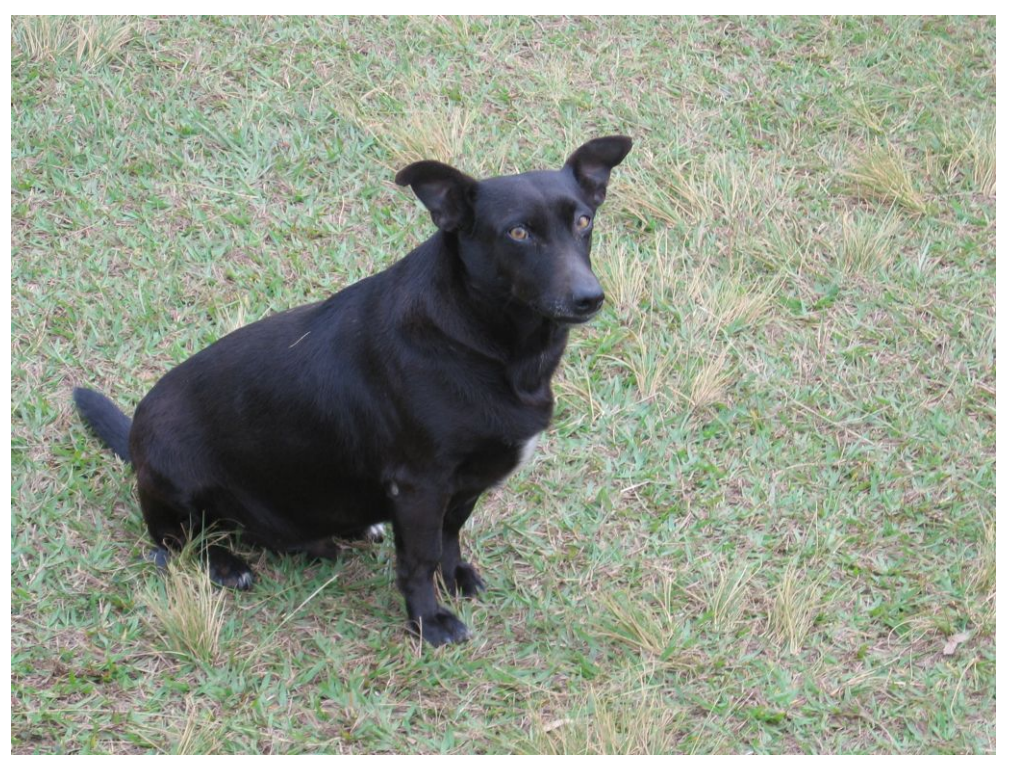

(a)

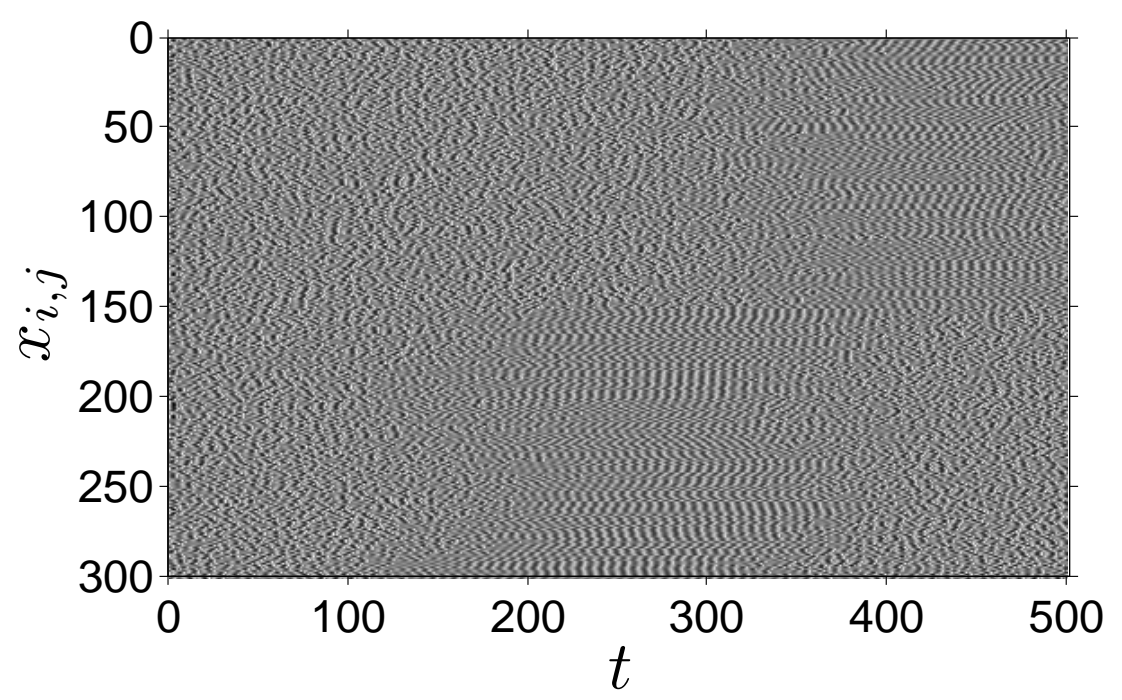

(b)

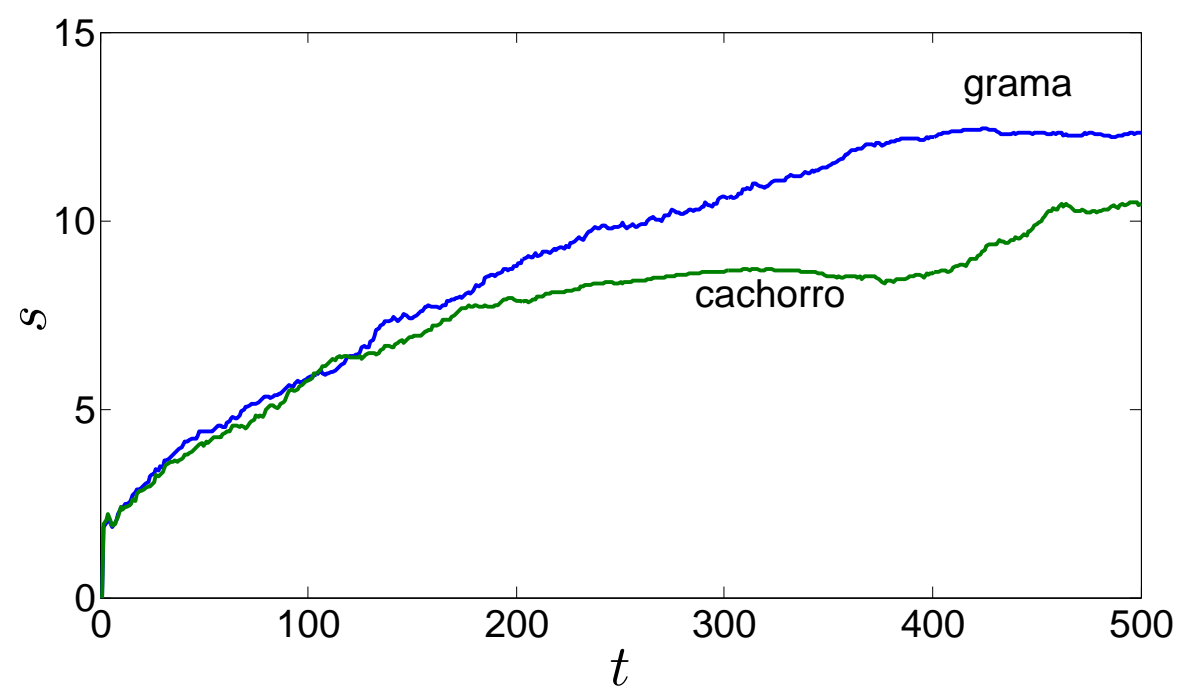

(c)

Figura 3.12: Atenção visual em imagem real - "Cachorro": (a) Imagem fonte; (b) Comportamento dos osciladores; (c) Séries temporais do desvio padrão de fase de cada objeto. 
CAPÍTULO 4

\section{Modelos baseados em \\ Movimentação de Partículas em Redes Complexas}

Neste capítulo são apresentados os resultados obtidos com modelos de aprendizado baseados em movimentação de partículas em redes complexas. Durante o desenvolvimento deste trabalho, foram desenvolvidos novos modelos de aprendizado baseados em grafos e movimentação de partículas, para serem aplicados em redes complexas. Especificamente, foi criado um modelo para detecção de comunidades sobrepostas em redes complexas (Breve et al., 2009b), o qual é apresentado na Seção 4.1. Em seguida, este modelo foi estendido para realizar classificação de dados em redes complexas utilizando aprendizado semi-supervisionado, que também é bastante interessante no caso de redes grandes, onde normalmente é possivel rotular manualmente apenas um pequeno número de vértices. Assim foram gerados dois novos modelos de aprendizado semi-supervisionado, desenvolvidos de forma incremental, o primeiro utilizando apenas competição entre partículas (Breve et al., 2009a), e o segundo utilizando um esquema único de competição e cooperação entre partículas (Breve et al., 2009e). Este segundo modelo é apresentado na Seção 4.2. 


\subsection{Detecção de Comunidades Sobrepostas em Re- des Complexas com Competição de Partículas}

A detecção de comunidades é um dos problemas de mineração de dados que surgiram com os avanços na computação e com o interesse crescente em redes complexas, que estuda redes de larga escala com estruturas topológicas não triviais, como redes sociais, redes de computadores, redes de telecomunicação, redes de transporte, e redes biológicas (Newman, 2003; Dorogovtsev \& Mendes, 2003; Bornholdt \& Schuster, 2006). Muitas destas redes são naturalmente divididas em comunidades ou módulos e, portanto, descobrir a estrutura destas comunidades se tornou um tópico de estudo importante (Newman \& Girvan, 2004; Newman, 2006; Duch \& Arenas, 2006; Reichardt \& Bornholdt, 2004; Danon et al., 2005).

A noção de comunidades em redes é direta, elas são definidas como um subgrafo cujos nós estão densamente conectados entre si, mas esparsamente conectados com o restante da rede. Porém, na prática há casos comuns onde alguns nós em uma rede podem pertencer a mais de uma comunidade. Por exemplo: em redes sociais de amizade, indivíduos podem estar em várias comunidades: suas famílias, seus colegas de trabalho, seus colegas de classe, etc. Estes nós são freqüentemente chamados de nós sobrepostos ${ }^{1}$, e a maioria dos algoritmos de detecção de comunidades conhecidos não podem detectálos. Conseqüentemente, descobrir a estrutura de comunidades sobrepostas em redes complexas se torna um tópico de pesquisa importante em mineração de dados (Zhang et al., 2007a; Palla et al., 2005; Zhang et al., 2007b).

O modelo apresentado nesta seção (Breve et al., 2009b) é uma extensão da abordagem de competição de partículas proposta por Guiles et al. (2008), e apresentada na Seção 2.3.5, a qual é usada para detectar comunidades em redes. Algumas partículas caminham em uma rede, competindo com as outras pela posse de nós, ao mesmo tempo em que rejeitam partículas intrusas. Após um número de iterações, cada partícula estará confinada em uma comunidade da rede, portanto as comunidades podem ser divididas examinando a qual partícula cada nó pertence. O novo modelo não apenas pode detectar as estruturas de comunidade, como também pode descobrir as estruturas de comunidade sobrepostas. Para atingir este objetivo, as dinâmicas de nós e partículas foram modificadas e algumas novas variáveis foram introduzidas, dentre outros detalhes que serão descritos na Seção 4.1.1. Alguns resultados de simulações computacionais são apresentados na Seção 4.1.2.

1 do inglês: overlap nodes 


\subsubsection{Descrição do Modelo}

Seja a estrutura da rede representada como um grafo $G=(\mathbf{V}, \mathbf{E})$, com $\mathbf{V}=\left\{v_{1}, v_{2}, \ldots, v_{n}\right\}$, onde cada nó $v_{i}$ é um elemento de uma rede. A matriz de adjacência $\mathbf{W}$ define quais nós da rede estão interconectados:

$$
\begin{aligned}
& W_{i j}=1, \quad \text { se existe uma aresta entre os nós } i \text { e } j, \\
& W_{i j}=0, \quad \text { caso contrário, }
\end{aligned}
$$

e $W_{i i}=0$.

Então, criamos um conjunto de partículas $\mathbf{P}=\left(\rho_{1}, \rho_{2}, \ldots, \rho_{c}\right)$, no qual cada partícula corresponde a diferentes comunidades. Cada partícula $\rho_{j}$ tem uma variável $\rho_{j}^{\omega}(t) \in\left[\begin{array}{ll}\omega_{\min } & \omega_{\max }\end{array}\right]$ que é o potencial da partícula, caracterizando quanto a partícula pode afetar um nó no tempo $t$. Nos experimentos configuramos as constantes $\omega_{\min }=0$ e $\omega_{\max }=1$.

Cada nó $v_{i}$ tem duas variáveis $v_{i}^{\omega}(t)$, e $v_{i}^{\lambda}(t)$. A primeira variável é um vetor $\mathbf{v}_{i}^{\omega}(t)=\left\{v_{i}^{\omega_{1}}(t), v_{i}^{\omega_{2}}(t), \ldots, v_{i}^{\omega_{c}}(t)\right\}$ do mesmo tamanho de $\mathbf{P}$, onde cada elemento $v_{i}^{\omega_{j}}(t) \in\left[\begin{array}{ll}\omega_{\min } & \omega_{\max }\end{array}\right]$ corresponde ao nível de domínio instantâneo da partícula $\rho_{j}$ sobre o nó $v_{i}$. A soma dos níveis de domínio de um nó é sempre constante, porque as partículas aumentam seu nível de domínio, ao mesmo tempo em que diminuem o nível de domínio de outras partículas. Portanto, a seguinte equação é sempre válida:

$$
\sum_{j=1}^{c} v_{i}^{\omega_{j}}=\omega_{\max }+\omega_{\min }(c-1) .
$$

A segunda variável também é um vetor $v_{\mathbf{i}}^{\lambda}(t)=\left\{v_{i}^{\lambda_{1}}(t), v_{i}^{\lambda_{2}}(t), \ldots, v_{i}^{\lambda_{c}}(t)\right\}$ do mesmo tamanho de $\mathbf{P}$ e também representa níveis de domínio, mas ao contrário de $v_{i}^{\omega}(t)$ que denota níveis de domínio instantâneos, $v_{i}^{\lambda_{j}}(t) \in\left[\begin{array}{ll}0 & \infty\end{array}\right]$ denota o domínio em longo prazo, acumulado durante todo o processo. A partícula com maior nível de domínio em um dado nó não sobreposto após a última iteração do algoritmo é normalmente a partícula que visitou o nó mais vezes, mas isso nem sempre se aplica a nós sobrepostos, nos quais algumas vezes a partícula dominante pode facilmente mudar nas últimas iterações, e portanto não corresponde à partícula que dominou o nó por mais instantes de tempo. Portanto, a nova variável $v_{i}^{\lambda}(t)$ foi introduzida para definir o domínio nos nós considerando o processo todo. Usando uma analogia simples, podemos dizer que agora o campeão não é mais quem ganhou os últimos jogos, mas sim quem ganhou mais jogos durante todo o campeonato. Note que os níveis de domínio em longo prazo apenas aumentam e a soma de todos os níveis não é uma constante, os níveis são normalizados apenas no final das iterações. 
Iniciamos o algoritmo configurando o vetor de níveis iniciais de domínio instantâneo $v_{i}^{\omega}$ de cada partícula $\rho_{j}$ como segue:

$$
v_{i}^{\omega_{j}}(0)=\omega_{\min }+\left(\frac{\omega_{\max }-\omega_{\min }}{c}\right)
$$

o que significa que todos os nós iniciam com os níveis de domínio instantâneo de cada partícula configurados igualmente. Ao mesmo tempo, os níveis de domínio em longo prazo $v_{i}^{\lambda}(t)$ são todos configurados para zero:

$$
v_{i}^{\lambda_{j}}(0)=0
$$

A posição inicial de cada partícula $\rho_{j}^{v}(0)$ é configurada aleatoriamente para qualquer nó em $\mathbf{V}$, e o potencial inicial de cada partícula é configurado para ser valor mínimo, como segue:

$$
\rho_{j}^{\omega}(0)=\omega_{\min }
$$

Cada partícula irá escolher um vizinho para visitar baseado em uma regra aleatório-gulosa. A cada iteração, cada partícula irá escolher entre caminhada aleatória ou caminhada gulosa, onde caminhada aleatória significa que a partícula irá tentar se mover para qualquer vizinho escolhido aleatoriamente, isto é, a partícula $\rho_{j}$ tentará se mover para qualquer nó $v_{i}$ escolhido com as probabilidades definidas por:

$$
p\left(v_{i} \mid \rho_{j}\right)=\frac{W_{k i}}{\sum_{q=1}^{n} W_{q i}},
$$

onde $k$ é o índice do nó sendo visitado pela partícula $\rho_{j}$, portanto $W_{k i}=1$ se existe uma aresta entre o nó atual e $v_{i}$, e $W_{k i}=0$ caso contrário. A caminhada gulosa significa que a partícula irá tentar se mover para um vizinho com probabilidades configuradas de acordo com os níveis de domínio instantâneo, isto é, a partícula $\rho_{j}$ irá tentar se mover para qualquer vizinho $v_{i}$ escolhido com probabilidades definidas por:

$$
p\left(v_{i} \mid \rho_{j}\right)=\frac{W_{k i} v_{i}^{\omega_{j}}}{\sum_{q=1}^{n} W_{q i} v_{i}^{\omega_{j}}},
$$

e novamente, $k$ é o índice do nó sendo visitado pela partícula $\rho_{j}$.

A cada iteração, cada partícula tem probabilidade $p_{\text {det }}$ de escolher o movimento guloso e probabilidade $1-p_{\text {det }}$ de escolher o movimento aleatório, com $0 \leq p_{\text {det }} \leq 1$. Uma vez que o movimento aleatório ou guloso é escolhido, um vizinho alvo $\rho_{j}^{\tau}(t)$ será escolhido aleatoriamente com probabilidades definidas pela Equação 4.7 ou pela Equação 4.8 respectivamente.

Com relação a dinâmica dos nós, no tempo $t$, cada nível de domínio instan- 
tâneo $v_{i}^{\omega_{k}}(t)$ de cada nó $v_{i}$, o qual foi escolhido por uma partícula $\rho_{j}$ como seu alvo $\rho_{j}^{\tau}(t)$, é definido como:

$$
v_{i}^{\omega_{k}}(t+1)=\left\{\begin{array}{cl}
\max \left\{\omega_{\min }, v_{i}^{\omega_{k}}(t)-\frac{\Delta_{v} \rho_{j}^{\omega}(t)}{c-1}\right\} & \text { if } k \neq j \\
v_{i}^{\omega_{k}}(t)+\sum_{q \neq k} v_{i}^{\omega_{q}}(t)-v_{i}^{\omega_{q}}(t+1) & \text { if } k=j
\end{array},\right.
$$

onde $0<\Delta_{v} \leq 1$ é um parâmetro para controlar a taxa de mudança dos níveis de domínio instantâneos. Se $\Delta_{v}$ recebe um valor pequeno, os níveis de dominio mudam devagar, enquanto que se ele recebe um valor alto, os níveis de domínio mudam rapidamente. Cada partícula $\rho_{j}$ aumenta seu correspondente nível de domínio instantâneo $v_{i}^{\omega_{j}}$ do nó $v_{i}$ que ela escolheu como alvo, ao mesmo tempo em que diminui o nível de domínio instantâneo (deste mesmo nó) que corresponde às outras partículas, sempre respeitando a lei de conservação definida na Equação 4.3.

Com relação à dinâmica de partículas, no tempo $t$, cada potencial de partícula $\rho_{j}^{\omega}(t)$ é configurado como:

$$
\rho_{j}^{\omega}(t+1)=\rho_{j}^{\omega}(t)+\Delta_{\rho}\left(v_{i}^{\omega_{j}}(t+1)-\rho_{j}^{\omega}(t)\right)
$$

onde $v_{i}(t+1)$ é o nó que $\rho_{j}$ tem como alvo, $0<\Delta_{\rho} \leq 1$ é um parâmetro de controle para controlar a taxa de mudança do potencial das partículas. Conseqüentemente, cada partícula $\rho_{j}$ tem seu potencial $\rho_{j}^{\omega}$ configurado para aproximar o valor do nível de domínio instantâneo $v_{i}^{\omega_{j}}$ do nó que ela tem atualmente como alvo. Desta forma, cada partícula se fortalece quando ela está visitando um nó que ela domina, mas se enfraquece quando tenta invadir nós dominados por outras partículas.

Os níveis de domínio em longo prazo são ajustados apenas quando uma partícula seleciona o movimento aleatório. Esta regra é importante porque apesar do movimento guloso ser útil para evitar que as partículas abandonem sua vizinhança, ele também é um mecanismo que faz o nó receber mais visitas do nó que o domina atualmente. No movimento aleatório a partícula seleciona um alvo baseado apenas em sua vizinhança atual, e não nos níveis de domínio instantâneos, que são importantes para a detecção de comunidade, mas que são muito voláteis nos nós sobrepostos. Portanto, cada nó selecionado em um movimento aleatório por uma partícula $\rho_{j}$, tem seu nível de domínio em longo prazo $v_{i}^{\lambda_{j}}$ atualizado como segue:

$$
v_{i}^{\lambda_{j}}(t+1)=v_{i}^{\lambda_{j}}(t)+\rho_{j}^{\omega}(t)
$$

onde $v_{i}$ é o nó que a partícula $\rho_{j}$ tem como alvo. O aumento será sempre proporcional ao potencial do nó atual, o que é uma característica desejável pois a partícula provavelmente terá um maior potencial quando estiver chegando de 
sua própria vizinhança, e terá um potencial menor quando estiver chegando da vizinhança de outras partículas.

Deve ser notado que cada partícula somente visita o nó alvo se seu nível de domínio naquele nó for maior que todos os outros; caso contrário, um choque acontece e a partícula permanece no nó atual até a próxima iteração.

No final das iterações, os graus de pertinência $f_{i}^{j} \in\left[\begin{array}{ll}0 & 1\end{array}\right]$ de cada nó $v_{i}$ são calculados usando os níveis de domínio em longo prazo, como segue:

$$
f_{i}^{j}=\frac{v_{i}^{\lambda_{j}}(\infty)}{\sum_{q=1}^{c} v_{i}^{\lambda_{q}}(\infty)}
$$

onde $f_{i}^{j}$ representa o grau de pertinência do nó $v_{i}$ à comunidade $j$. O lado direito da equação apenas normaliza os valores dos níveis de domínio em longo prazo para compor os graus de pertinência, de forma que a soma dos graus de pertinência à cada classe de um determinado nó seja sempre 1 .

Em resumo, o método funciona como descrito no Algoritmo 4.1.

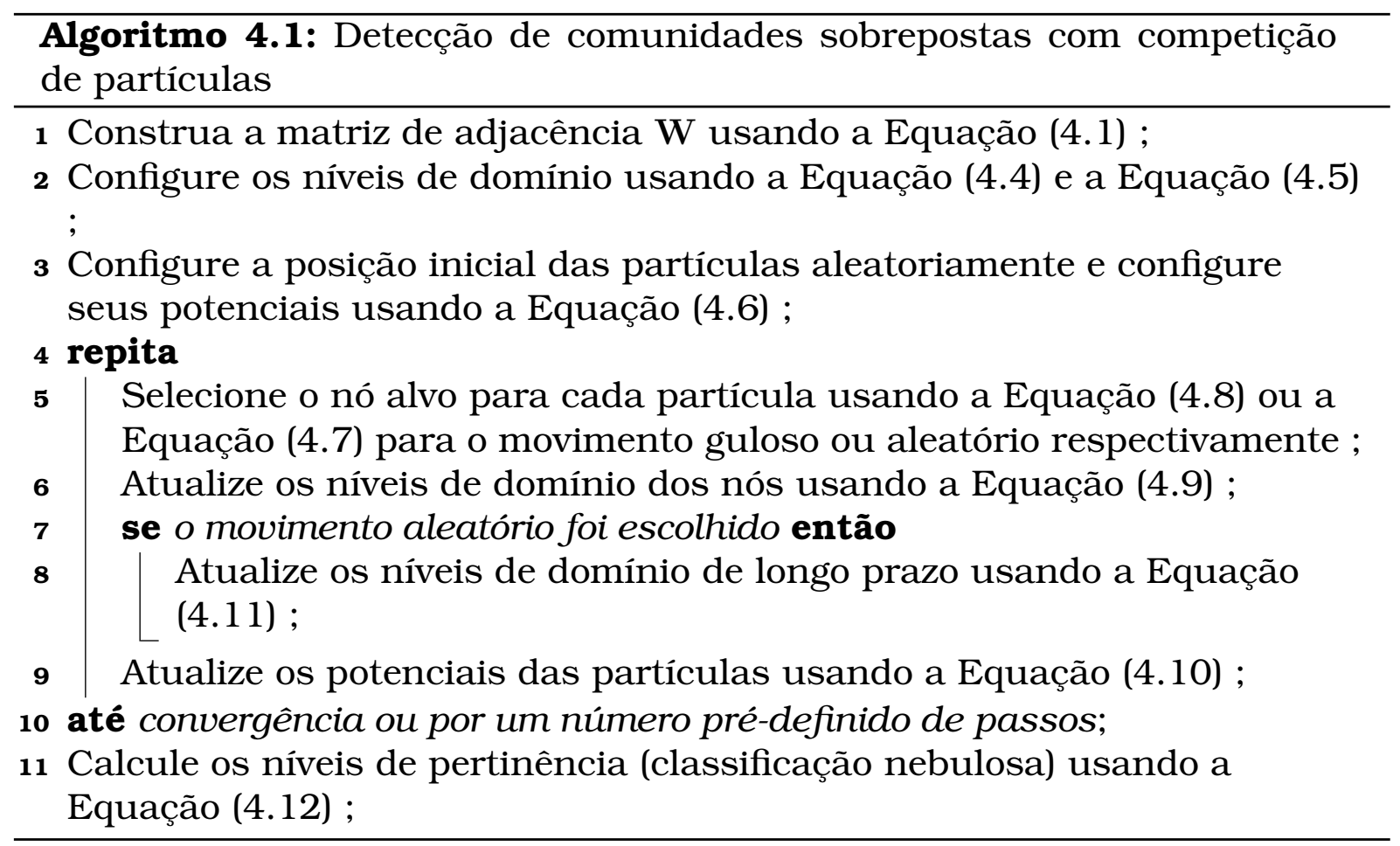

\subsubsection{Simulações Computacionais}

Para testar a capacidade de detecção de nós sobrepostos do nosso algoritmo, geramos um conjunto de redes com estrutura de comunidades usando o método proposto por Danon et al. (2005). Aqui todas as redes geradas têm $n=128$ nós, divididos em quatro comunidades contendo 32 nós cada. Pares de nós que pertencem a mesma comunidade são conectados com probabilidade $p_{i n}$, enquanto pares que pertencem a diferentes comunidades são conectados 
com probabilidade $p_{\text {out }}$. O grau médio dos nós $k$ é constante e configurado para 16. O valor de $p_{\text {out }}$ é escolhido de forma que a quantidade de conexões que um nó tem com nós de outra comunidade, $z_{\text {out }}$, pode ser controlada. Ao mesmo tempo, o valor de $p_{i n}$ é escolhido para manter o grau médio dos nós $k$ constante. Conseqüentemente, $z_{\text {out }} / k$ define a mistura das comunidades, $\mathrm{e}$ conforme $z_{\text {out }} / k$ aumenta a partir de zero, as comunidades se tornam mais difusas e difíceis de identificar. Em cada uma das redes geradas adicionamos um $129^{\circ}$ nó e criamos 16 conexões entre o novo nó e nós das comunidades, de forma que podemos facilmente determinar a classificação "nebulosa" esperada para este novo nó baseado na contagem de suas conexões com cada comunidade.

As redes foram geradas com $z_{\text {out }} / k=0,125,0,250$, e 0,375 e os resultados são mostrados nas Tabelas 4.1, 4.2, e 4.3 respectivamente. As primeiras colunas destas tabelas mostram o número de conexões que o $129^{\circ}$ nó tem com as comunidades A, B, C, e D, respectivamente. Note que em cada configuração o $129^{\circ}$ tem diferentes níveis de sobreposição, variando do caso onde ele pertence totalmente a uma única comunidade até o caso onde ele pertence a todas as quatro comunidades com praticamente o mesmo grau de pertinência. Da $2^{\mathrm{a}}$ à $5^{\mathrm{a}}$ coluna nós temos o grau nebuloso de pertinência do $129^{\circ}$ nó com relação às comunidades A, B, C, e D, respectivamente, obtidos pelo nosso algoritmo. Os valores apresentados são a média de 100 execuções com diferentes redes. Para estas simulações, os parâmetros foram configurados como segue: $p_{\text {det }}=0,5$, $\Delta_{v}=0,4$ e $\Delta_{\rho}=0,9$.

Tabela 4.1: Classificação nebulosa de um nó conectado em uma rede com 4 comunidades geradas com $z_{\text {out }} / k=0,125$

\begin{tabular}{|c|c|c|c|c|}
\hline Conexões & \multicolumn{4}{|c|}{ Classificação Nebulosa } \\
\hline A-B-C-D & A & B & C & D \\
\hline 16-0-0-0 & 0,9928 & 0,0017 & 0,0010 & 0,0046 \\
\hline $\mathbf{1 5 - 1 - 0 - 0}$ & 0,9210 & 0,0646 & 0,0079 & 0,0065 \\
\hline $\mathbf{1 4 - 2 - 0 - 0}$ & 0,8520 & 0,1150 & 0,0081 & 0,0248 \\
\hline $\mathbf{1 3 - 3 - 0 - 0}$ & 0,8031 & 0,1778 & 0,0107 & 0,0084 \\
\hline $\mathbf{1 2 - 4 - 0 - 0}$ & 0,7498 & 0,2456 & 0,0032 & 0,0014 \\
\hline $\mathbf{1 1 - 5 - 0}-0$ & 0,6875 & 0,3101 & 0,0016 & 0,0008 \\
\hline $\mathbf{1 0 - 6 - 0 - 0}$ & 0,6211 & 0,3577 & 0,0111 & 0,0101 \\
\hline $\mathbf{9 - 7 - 0 - 0}$ & 0,5584 & 0,4302 & 0,0011 & 0,0103 \\
\hline $\mathbf{8 - 8 - 0 - 0}$ & 0,4949 & 0,4944 & 0,0090 & 0,0017 \\
\hline $\mathbf{8 - 4 - 4 - 0}$ & 0,5025 & 0,2493 & 0,2461 & 0,0021 \\
\hline $\mathbf{7 - 4 - 4 - 1}$ & 0,4397 & 0,2439 & 0,2491 & 0,0672 \\
\hline $\mathbf{6 - 4 - 4 - 2}$ & 0,3694 & 0,2501 & 0,2549 & 0,1256 \\
\hline $\mathbf{5 - 4 - 4 - 3}$ & 0,3144 & 0,2491 & 0,2537 & 0,1828 \\
\hline $\mathbf{4 - 4 - 4 - 4}$ & 0,2512 & 0,2506 & 0,2504 & 0,2478 \\
\hline
\end{tabular}

Os resultados apresentados mostram que o método conseguiu identificar 
Tabela 4.2: Classificação nebulosa de um nó conectado em uma rede com 4 comunidades geradas com $z_{\text {out }} / k=0,250$

\begin{tabular}{|c|c|c|c|c|}
\hline Conexões & \multicolumn{4}{|c|}{ Classificação Nebulosa } \\
\hline A-B-C-D & A & B & C & D \\
\hline $\mathbf{1 6 - 0 - 0 - 0}$ & 0,9912 & 0,0027 & 0,0024 & 0,0037 \\
\hline $\mathbf{1 5 - 1 - 0 - 0}$ & 0,9318 & 0,0634 & 0,0026 & 0,0023 \\
\hline $\mathbf{1 4 - 2 - 0 - 0}$ & 0,8715 & 0,1219 & 0,0023 & 0,0044 \\
\hline $\mathbf{1 3 - 3 - 0 - 0}$ & 0,8107 & 0,1827 & 0,0036 & 0,0030 \\
\hline $\mathbf{1 2 - 4 - 0 - 0}$ & 0,7497 & 0,2437 & 0,0044 & 0,0022 \\
\hline $\mathbf{1 1 - 5 - 0 - 0}$ & 0,6901 & 0,3036 & 0,0034 & 0,0029 \\
\hline $\mathbf{1 0 - 6 - 0 - 0}$ & 0,6298 & 0,3654 & 0,0020 & 0,0028 \\
\hline $\mathbf{9 - 7 - 0}-0$ & 0,5584 & 0,4360 & 0,0026 & 0,0030 \\
\hline $\mathbf{8 - 8 - 0 - 0}$ & 0,4952 & 0,4985 & 0,0027 & 0,0036 \\
\hline $\mathbf{8 - 4 - 4 - 0}$ & 0,5060 & 0,2485 & 0,2427 & 0,0028 \\
\hline $\mathbf{7 - 4 - 4 - 1}$ & 0,4442 & 0,2477 & 0,2429 & 0,0652 \\
\hline $\mathbf{6 - 4 - 4 - 2}$ & 0,3762 & 0,2465 & 0,2514 & 0,1259 \\
\hline $\mathbf{5 - 4 - 4 - 3}$ & 0,3178 & 0,2500 & 0,2473 & 0,1849 \\
\hline $\mathbf{4 - 4 - 4 - 4}$ & 0,2470 & 0,2518 & 0,2489 & 0,2523 \\
\hline
\end{tabular}

Tabela 4.3: Classificação nebulosa de um nó conectado em uma rede com 4 comunidades geradas com $z_{\text {out }} / k=0,375$

\begin{tabular}{|c|c|c|c|c|}
\hline Conexões & \multicolumn{4}{|c|}{ Classificação Nebulosa } \\
\hline A-B-C-D & A & B & C & D \\
\hline $\mathbf{1 6 - 0 - 0 - 0}$ & 0,9709 & 0,0092 & 0,0108 & 0,0091 \\
\hline $\mathbf{1 5 - 1 - 0 - 0}$ & 0,9160 & 0,0647 & 0,0093 & 0,0101 \\
\hline $\mathbf{1 4 - 2 - 0 - 0}$ & 0,8571 & 0,1228 & 0,0104 & 0,0097 \\
\hline $\mathbf{1 3 - 3 - 0 - 0}$ & 0,8008 & 0,1802 & 0,0100 & 0,0090 \\
\hline $\mathbf{1 2 - 4 - 0 - 0}$ & 0,7422 & 0,2385 & 0,0095 & 0,0098 \\
\hline $\mathbf{1 1 - 5 - 0 - 0}$ & 0,6825 & 0,2958 & 0,0123 & 0,0093 \\
\hline $\mathbf{1 0 - 6 - 0 - 0}$ & 0,6200 & 0,3566 & 0,0111 & 0,0123 \\
\hline $\mathbf{9 - 7 - 0 - 0}$ & 0,5582 & 0,4181 & 0,0128 & 0,0109 \\
\hline $\mathbf{8 - 8 - 0 - 0}$ & 0,4891 & 0,4846 & 0,0130 & 0,0133 \\
\hline $\mathbf{8 - 4 - 4 - 0}$ & 0,5045 & 0,2437 & 0,2406 & 0,0113 \\
\hline $\mathbf{7 - 4 - 4 - 1}$ & 0,4397 & 0,2461 & 0,2436 & 0,0705 \\
\hline $\mathbf{6 - 4 - 4 - 2}$ & 0,3797 & 0,2471 & 0,2445 & 0,1287 \\
\hline $\mathbf{5 - 4 - 4 - 3}$ & 0,3175 & 0,2439 & 0,2473 & 0,1913 \\
\hline $\mathbf{4 - 4 - 4 - 4}$ & 0,2462 & 0,2494 & 0,2549 & 0,2495 \\
\hline
\end{tabular}


com precisão a pertinência dos nós sobrepostos. A precisão se torna mais baixa conforme $z_{\text {out }} / k$ aumenta, isto é esperado, pois um $z_{\text {out }} / k$ mais alto significa que as comunidades estão mais difusas e o nó observado pode estar conectado à nós que são eles próprios sobrepostos.

Baseado nestes dados, criamos uma medida de sobreposição para facilitar a ilustração da aplicação do algoritmo em redes mais complexas com muitos nós sobrepostos. Conseqüentemente, o índice de sobreposição $o_{i}$ para um nó $v_{i}$ é definido como:

$$
o_{i}=\frac{f_{i}^{j * *}}{f_{i}^{j *}}
$$

onde $j *=\arg \max _{j} f_{i}^{j}$ e $j * *=\arg \max _{j, j \neq j *} f_{i}^{j}$, ou seja, $j *$ e $j * *$ são o maior e o segundo maior graus de pertinência do nó, respectivamente; $o_{i} \in\left[\begin{array}{ll}0 & 1\end{array}\right]$, onde $o_{i}=0$ significa total confidência de que um nó pertence a uma única classe, enquanto $o_{i}=1$ significa que o nó está completamente indefinido entre duas ou mais comunidades.

Em seguida, aplicamos o algoritmo para um problema com 1000 elementos, divididos em quatro comunidades com 250 elementos em cada. Existem quatro núcleos gaussianos em um plano bi-dimensional e os elementos são distribuídos em torno deles. Para construir a rede, cada elemento é transformado em um nó da rede. Dois elementos $i$ e $j$ são conectados se sua distância Euclidiana $d(i, j)<1$. Os parâmetros do algoritmo são configurados como segue: $p_{\text {det }}=0,6, \Delta_{v}=0,4$ e $\Delta_{\rho}=0,9$. Na Figura 4.1 o índice de sobreposição de cada nó é indicado por suas cores. É fácil notar que quanto mais perto da fronteira da comunidade os nós estão, maior é o seu respectivo índice de sobreposição.

Finalmente, o algoritmo foi aplicado para a famosa rede do Clube de Caratê de Zachary (Zachary, 1977) e os resultados são mostrados na Figura 4.2. Os parâmetros do algoritmo são configurados como segue: $p_{\text {det }}=0,6, \Delta_{v}=0,4$ and $\Delta_{\rho}=0,9$. Novamente, o índice de sobreposição de cada nó é indicado por suas cores. Na Tabela 4.4 as classificações nebulosas de todos os nós desta rede são mostradas.

\subsection{Aprendizado Semi-Supervisionado em Redes Com- plexas com Competição e Cooperação entre Par- tículas}

Com o surgimento do campo de redes complexas e o estudo de redes cada vez maiores, é comum ter bases de dados onde apenas um pequeno subconjunto de amostras é rotulado. Isto acontece porque dados não rotulados são relativamente fáceis de coletar, mas rotulá-los é normalmente uma tarefa 


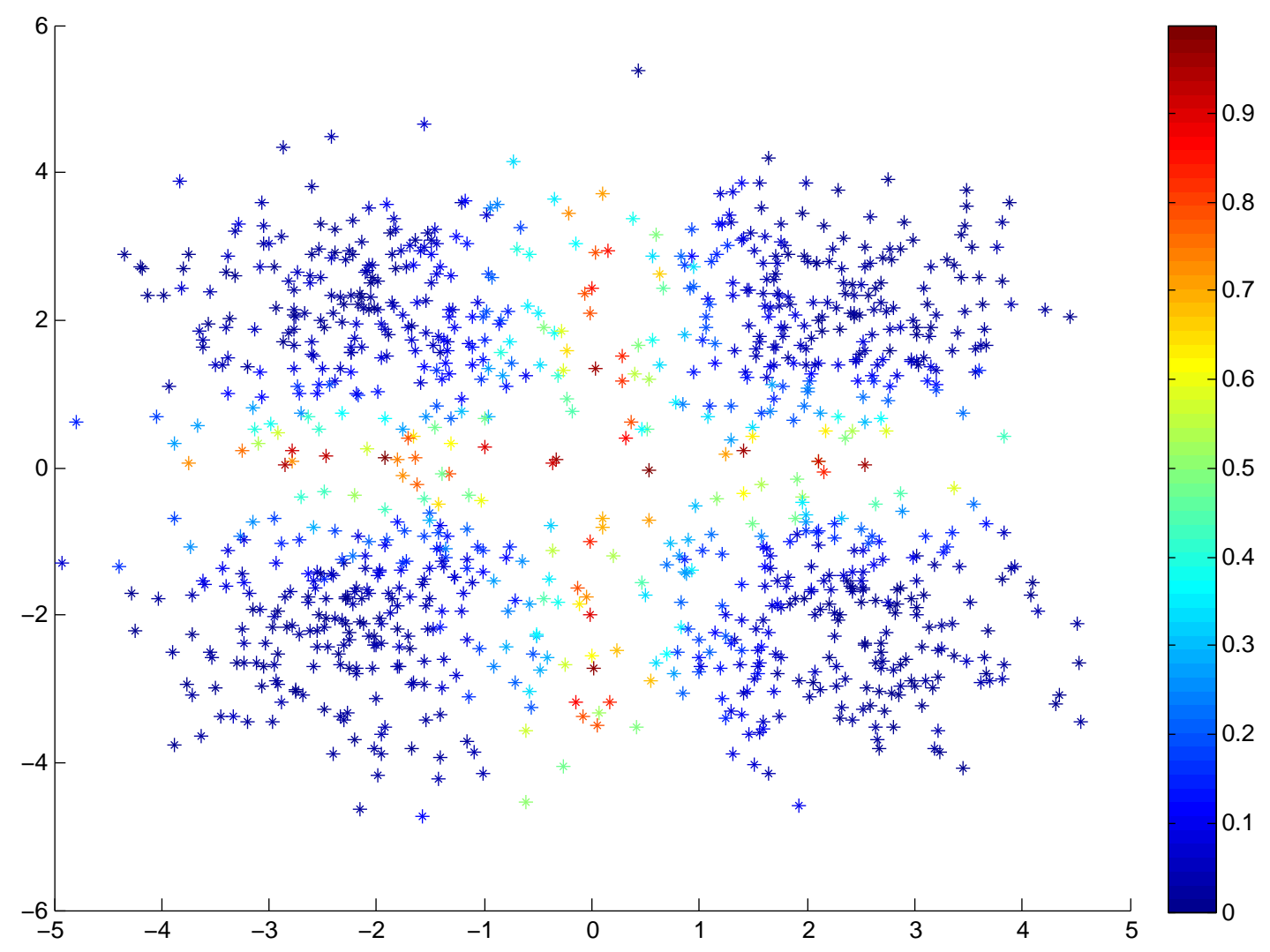

Figura 4.1: Problema de classificação com 1000 elementos divididos em quatro comunidades com sobreposição. As cores representam o índice de sobreposição de cada nó, detectados pelo método proposto.

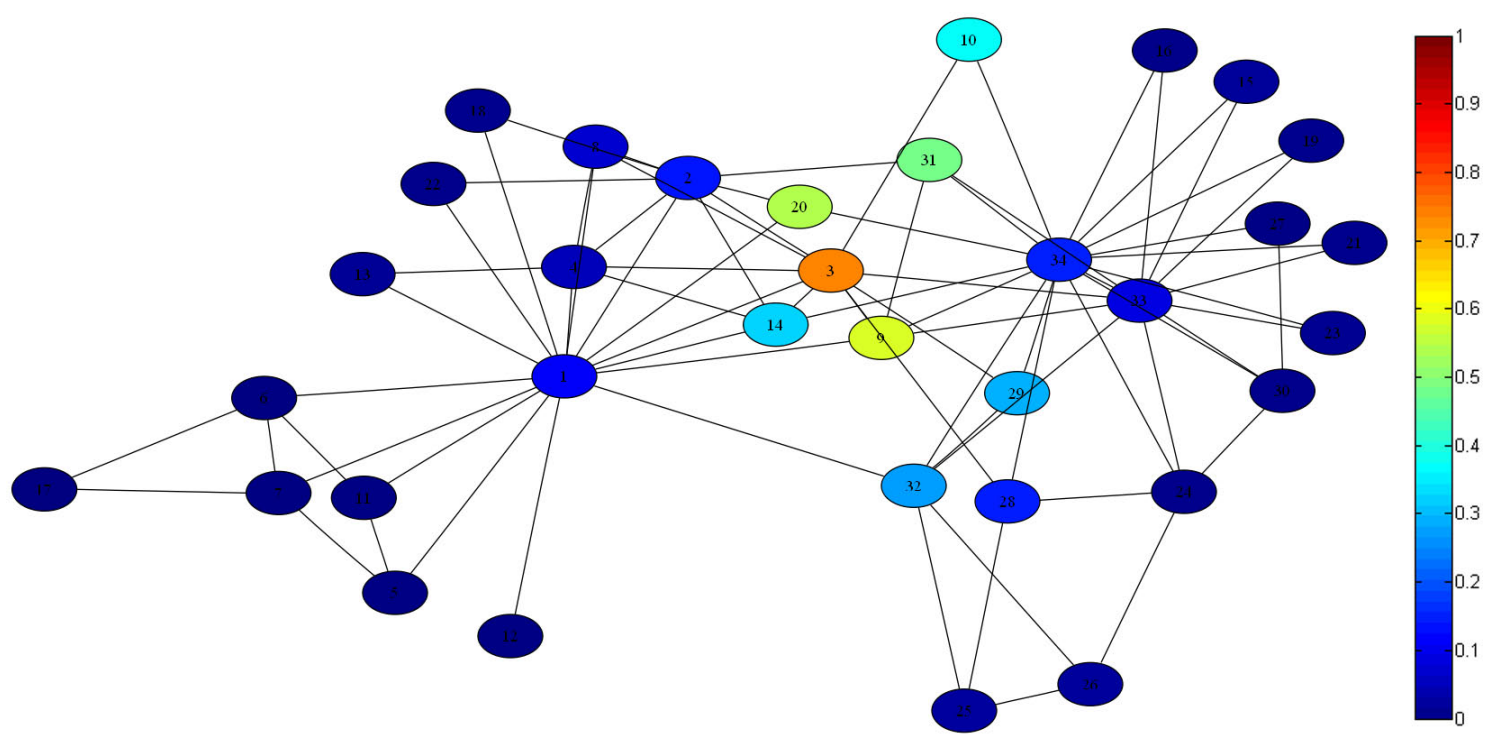

Figura 4.2: Classificação da Rede do Clube de Caratê de Zachary (Zachary, 1977). As cores representam o índice de sobreposição de cada nó, detectados pelo método proposto. 
Tabela 4.4: Classificação nebulosa da rede do clube de caratê de Zachary obtida pelo método proposto.

\begin{tabular}{|c|c|c|}
\hline Nó & Comunidade $\mathbf{A}$ & Comunidade B \\
\hline $\mathbf{1}$ & 0,8934 & 0,1066 \\
\hline $\mathbf{2}$ & 0,8744 & 0,1256 \\
\hline $\mathbf{3}$ & 0,5727 & 0,4273 \\
\hline $\mathbf{4}$ & 0,9470 & 0,0530 \\
\hline $\mathbf{5}$ & 0,9960 & 0,0040 \\
\hline $\mathbf{6}$ & 0,9979 & 0,0021 \\
\hline $\mathbf{7}$ & 0,9979 & 0,0021 \\
\hline $\mathbf{8}$ & 0,9282 & 0,0718 \\
\hline $\mathbf{9}$ & 0,3703 & 0,6297 \\
\hline $\mathbf{1 0}$ & 0,2750 & 0,7250 \\
\hline $\mathbf{1 1}$ & 0,9968 & 0,0032 \\
\hline $\mathbf{1 2}$ & 0,9957 & 0,0043 \\
\hline $\mathbf{1 3}$ & 0,9791 & 0,0209 \\
\hline $\mathbf{1 4}$ & 0,7510 & 0,2490 \\
\hline $\mathbf{1 5}$ & 0,0238 & 0,9762 \\
\hline $\mathbf{1 6}$ & 0,0100 & 0,9900 \\
\hline $\mathbf{1 7}$ & 1,0000 & 0,0000 \\
\hline $\mathbf{1 8}$ & 0,9861 & 0,0139 \\
\hline $\mathbf{1 9}$ & 0,0126 & 0,9874 \\
\hline $\mathbf{2 0}$ & 0,6452 & 0,3548 \\
\hline $\mathbf{2 1}$ & 0,0140 & 0,9860 \\
\hline $\mathbf{2 2}$ & 0,9877 & 0,0123 \\
\hline $\mathbf{2 3}$ & 0,0168 & 0,9832 \\
\hline $\mathbf{2 4}$ & 0,0106 & 0,9894 \\
\hline $\mathbf{2 5}$ & 0,0275 & 0,9725 \\
\hline $\mathbf{2 6}$ & 0,0262 & 0,9738 \\
\hline $\mathbf{2 7}$ & 0,0050 & 0,9950 \\
\hline $\mathbf{2 8}$ & 0,1319 & 0,8681 \\
\hline $\mathbf{2 9}$ & 0,2298 & 0,7702 \\
\hline $\mathbf{3 0}$ & 0,0123 & 0,9877 \\
\hline $\mathbf{3 1}$ & 0,3293 & 0,6707 \\
\hline $\mathbf{3 2}$ & 0,2188 & 0,7812 \\
\hline $\mathbf{3 3}$ & 0,0878 & 0,9122 \\
\hline $\mathbf{3 4}$ & 0,1342 & 0,8658 \\
\hline & & \\
\hline
\end{tabular}


cara, difícil ou demorada, pois requer o trabalho de especialistas humanos. Como já mencionado na Seção 2.4, técnicas de aprendizado supervisionado não podem lidar com este problema porque requerem que todos os dados de treinamento estejam rotulados. Técnicas de aprendizado não supervisionado também não podem ser aplicadas para resolver estes problemas porque ignoram informações de rótulo das amostras. Para resolver este problema surge uma nova classe de algoritmos de aprendizado de máquina, que é a classe dos algoritmos com aprendizado semi-supervisionado. Esta classe fica no caminho entre o aprendizado supervisionado e o não supervisionado, e lida com estes problemas combinando poucas amostras rotuladas com muitas amostras não rotuladas para produzir classificadores melhores ao mesmo tempo em que requer menor esforço humano (Zhu, 2005; Chapelle et al., 2006b). Diversos métodos de aprendizado semi-supervisionado foram apresentados na Seção 2.4 .

Técnicas de aprendizado semi-supervisionado convencionais, como as Transductive Support Vector Machines (TSVM) (Vapnik, 2008), apresentadas na Seção 2.4.5, podem identificar classes de formas bem definidas, mas normalmente falham em identificar classes de formas irregulares. Portanto, suposições quanto às distribuições das classes precisam ser feitas, as quais são normalmente desconhecidas a priori. Por outro lado, a maioria dos métodos baseados em grafos, apresentados na Seção 2.4.6, tem ordem de complexidade computacional alta $\left(O\left(n^{3}\right)\right)$, o que torna seu uso limitado a pequenas base de dados Zhu (2005). Esta é considerada uma séria deficiência porque técnicas de aprendizado semi-supervisionado são normalmente aplicadas a base de dados com muitos dados não rotulados. Além disso, muitos métodos baseados em grafo podem ser visto como frameworks de regularização que diferem apenas em suas escolhas particulares de função de perda e regularizador (Blum \& Chawla, 2001; Zhu et al., 2003; Zhou et al., 2004; Belkin et al., 2004, 2005; Joachims, 2003).

O modelo apresentado nesta seção (Breve et al., 2009e) também é uma extensão da abordagem de competição de partículas apresentada por Quiles et al. (2008) (apresentada na Seção 2.3.5) e do método apresentado na seção anterior. Tais modelos são usados para detectar comunidades em redes. Há várias partículas caminhando pela rede, competindo umas com as outras pela posse de nós, rejeitando partículas intrusas. Desta forma, após uma quantidade de iterações, cada partícula estará confinada dentro de uma comunidade da rede, de forma que as comunidades podem ser divididas analisando os nós que cada partícula possui.

Inicialmente modificamos as dinâmicas de nós e partículas, além de outros detalhes, gerando um modelo preliminar (Breve et al., 2009a) capaz de 
realizar classificação através de aprendizado semi-supervisionado, diferente do modelo original que usa aprendizado não supervisionado. Em resultados de simulações ele foi capaz de classificar dados linearmente não separáveis, executando bem mais rápido que outro método tradicional (Método de Consistência Global e Local, apresentado na Seção 2.4.6) devido à menor ordem de complexidade computacional, o que o torna capaz de classificar bases de dados maiores. Além disso, ele obteve resultados melhores que outros métodos quando um pequeno número de amostras de dados são rotuladas. A partir deste modelo preliminar foi gerado o modelo que é apresentado nesta seção (Breve et al., 2009e), onde introduzimos várias melhorias que serão apresentadas. Dentre elas, podemos destacar a introdução de um mecanismo de cooperação e comparação combinadas em um esquema único, baseado no comportamento social de animais e em esportes coletivos. Nesta nova versão utilizamos múltiplas partículas, organizadas em times, para representar cada classe. Partículas do mesmo time caminham pela rede de maneira cooperativa para propagar seus rótulos, enquanto partículas de times diferentes competem umas com as outras para determinar as bordas das classes. Outra novidade é que cada partícula tem um nó como casa, e elas mantém informações da distância entre suas respectivas casas e outros nós da rede, de forma que elas priorizam dominar suas respectivas vizinhanças, ajudar seus companheiros de equipe com suas vizinhanças, e eventualmente tentar invadir territórios de oponentes. Além disso, foram introduzidas mudanças na dinâmica de nós e partículas e na regra gulosa de escolha do nó alvo, que agora também considera a distância dos nós candidatos para o nó-casa da partícula.

Apesar de o modelo proposto ser baseado em grafos, ele é fundamentalmente diferente de outros modelos baseados em grafos da seguinte maneira. Modelos de aprendizado semi-supervisionado baseado em grafos tradicionais espalham seus rótulos de uma maneira global, ou seja, em cada passo do algoritmo a informação é propagada de todos os nós para todos os nós de acordo com os pesos das arestas. Em contraste, o modelo proposto aqui é baseado em um modelo de cooperação e colaboração entre partículas, e a propagação de rótulos acontece de maneira local, ou seja, a cada passo do algoritmo, cada partícula propaga seu rótulo para um vizinho escolhido pela regra aleatóriogulosa. Em outras palavras, a propagação de rótulos usada por outros métodos baseados em grafos manipulam todos os nós da rede a cada iteração, incluindo aqueles nós que já estão corretamente rotulados e não precisam de modificação. No nosso método, devido ao mecanismo de competição, cada partícula visita apenas uma porção dos nós que potencialmente pertence ao seu time, e não tem permissão para visitar nós definitivamente ocupados por outros times de partículas. Pode ser entendido que nosso método tem um 
efeito de dividir e conquistar embutido no esquema de cooperação e competição. Desta forma, cada partícula anda apenas em uma sub-rede e muitas operações redundantes são evitadas. Como resultado, o método proposto tem uma ordem de complexidade computacional menor, como será mostrado mais adiante.

Este é atualmente o último refinamento deste modelo para aplicação em aprendizado semi-supervisionado, portanto, além dos testes tradicionais, estudamos a complexidade computacional e de espaço, os parâmetros e a dinâmica temporal do modelo. Além disso, fizemos experimentos computacionais utilizando dados artificiais com diferentes distribuições, e realizamos um teste de desempenho com várias bases de dados comparando o algoritmo proposto com modelos que são o estado da arte em aprendizado semi-supervisionado, conforme será mostrado nas subseções a seguir. A Seção 4.2.1 descreve o modelo em detalhes. A Seção 4.2.2 analisa a complexidade computacional e de espaço do modelo proposto. A Seção 4.2.3 apresenta alguns resultados de experimentos computacionais. Na Seção 4.2.4 estendemos o modelo para fornecer saída nebulosa para classes sobrepostas e para realizar detecção de outliers. Finalmente, na Seção 4.2.5 apresentamos algumas simulações com dados biológicos bastante ruidosos extraindo características interessantes.

\subsection{Descrição do Modelo}

Nesta subseção, introduziremos o algoritmo de aprendizado semi-supervisionado baseado em redes. Primeiramente, o conjunto de dados de entrada é transformado em uma rede sem pesos e não direcionada. Então, um conjunto de partículas, cada uma delas representando um item de dado rotulado, são colocadas na rede. O subconjunto de partículas que tem o mesmo rótulo é chamado time. Cada nó da rede possui um vetor de elementos, cada um representando um nível de cada time de partículas. Conforme o sistema executa, cada partícula escolhe um nó vizinho para visitar usando a regra aleatório-gulosa. No nó alvo (o nó a ser visitado), o nível de domínio do time da partícula atual é aumentado, enquanto os níveis de domínio de outros times são diminuídos. Cada time de partículas tenta dominar a maior quantidade possivel de nós de maneira cooperativa, ao mesmo tempo que evita a invasão de partículas de outros times. No final do processo iterativo, cada item de dado não rotulado será rotulado de acordo com o rótulo do time que tiver o maior nível de domínio. Os detalhes desse processo serão mostrados nas subseções a seguir. 
Dado um conjunto de dados $\chi=\left\{x_{1}, x_{2}, \ldots, x_{l}, x_{l+1}, \ldots, x_{n}\right\} \subset \mathbb{R}^{m}$ e um correspondente conjunto de rótulos $L=\{1,2, \ldots, c\}$, os primeiros $l$ pontos $x_{i}(i \leq l)$ são rotulados, ou seja, $y_{i} \in L$ e os pontos restantes $x_{u}(l<u \leq n)$ não são rotulados, ou seja, $y_{u}=\emptyset$. O objetivo é atribuir um rótulo para cada uma das amostras não rotuladas.

Primeiramente, mostramos como é feita a formação da rede para um dado conjunto de dados. Definimos um grafo $\mathbf{G}=(\mathbf{V}, \mathbf{E}) \cdot \mathbf{V}=\left\{v_{1}, v_{2}, \ldots, v_{n}\right\}$ é o conjunto de nós, onde cada vértice $v_{i}$ corresponde a uma amostra $x_{i}$. E é o conjunto de ligações $\left(v_{i}, v_{j}\right)$, que pode ser representado por uma matriz de adjacências $\mathbf{W}$ :

$$
W_{i j}=\left\{\begin{array}{ll}
1 & \text { se }\left\|x_{i}-x_{j}\right\|^{2} \leq \sigma \text { e } i \neq j \\
0 & \text { se }\left\|x_{i}-x_{j}\right\|^{2}>\sigma \text { ou } i=j
\end{array},\right.
$$

onde $W_{i j}$ especifica se há uma aresta entre os pares de nós $x_{i}$ e $x_{j}$. $\sigma$ é um limiar que define a distância máxima entre $x_{i}$ e $x_{j}$ em que os nós $v_{i}$ e $v_{j}$ podem ser conectados, e \|.\| é uma função de distância.

Outro método para construir a matriz de adjacência é conectar cada nó $v_{i}$ com seus $k$ vizinhos mais próximos, portanto:

$$
W_{i j}=\left\{\begin{aligned}
1 & \text { se } x_{j} \text { está entre os } k \text { vizinhos } \\
\text { mais próximos de } x_{i} \text { ou vice-versa } & \\
0 & \text { caso contrário }
\end{aligned}\right.
$$

Para cada dado rotulado $x_{i} \in\left\{x_{1}, x_{2}, \ldots, x_{l}\right\}$, ou seu correspondente nó na rede $v_{i} \in\left\{v_{1}, v_{2}, \ldots, v_{l}\right\}$, uma partícula $\rho_{i} \in\left\{\rho_{1}, \rho_{2}, \ldots, \rho_{l}\right\}$ é gerada e sua posição inicial é definida como $v_{i}$. Portanto, o número de partículas é igual ao número de nós rotulados no conjunto de dados. Para simplificar, chamaremos o nó $v_{i}$ de nó-casa da partícula $\rho_{i}$ se $v_{i}$ é a posição inicial da partícula $\rho_{i}$. Cada partícula muda sua posição a cada iteração e a distância com relação ao nó-casa é registrada. Cada subconjunto de partículas geradas de amostras com um mesmo rótulo formam um time, colaborando umas com as outras e competindo com partículas de outros times.

Neste modelo, há dois tipos de dinâmicas: a dinâmica de partículas e a dinâmica de nós. Cada partícula $\rho_{j}$ vem com duas variáveis: $\rho_{j}^{\omega}(t)$ e $\rho_{\mathbf{j}}^{\mathbf{d}}(\mathbf{t})$. A primeira variável $\rho_{j}^{\omega}(t) \in[0,1]$ é a força da partícula caracterizando o quanto a partícula pode dominar um nó no tempo $t$. A segunda variável é uma tabela de distâncias, isto é, um vetor $\rho_{\mathbf{j}}^{\mathbf{d}}(\mathbf{t})=\left\{\rho_{i}^{d_{1}}(t), \rho_{i}^{d_{2}}(t), \ldots, \rho_{i}^{d_{n}}(t)\right\}$, onde cada elemento $\rho_{j}^{d_{i}}(t) \in[0, \quad n-1]$ corresponde à distância medida entre o nó-casa da partícula $\rho_{j}$ e o nó $v_{i}$. 
Cada nó $v_{i}$ tem uma variável $\mathbf{v}_{\mathbf{i}}^{\omega}(\mathbf{t})=\left\{v_{i}^{\omega_{1}}(t), v_{i}^{\omega_{2}}(t), \ldots, v_{i}^{\omega_{c}}(t)\right\}$, que é um vetor com o mesmo tamanho de $L$, onde cada elemento $v_{i}^{\omega_{\ell}}(t) \in[0,1]$ corresponde ao nível de domínio do time $\ell$ sobre o nó $v_{i}$. A soma dos níveis de domínio de cada nó é sempre constante, porque uma partícula aumenta o nível de domínio de seu próprio time, ao mesmo tempo em que diminui os níveis de domínio de outros times. Portanto, a seguinte relação é sempre verdadeira:

$$
\sum_{\ell=1}^{c} v_{i}^{\omega_{\ell}}=1
$$

Os níveis iniciais do vetor de domínio $\mathbf{v}_{\mathbf{i}}^{\omega}$ de cada nó $v_{i}$ é configurado como segue:

$$
v_{i}^{\omega_{\ell}}(0)= \begin{cases}1 & \text { se } y_{i}=\ell \\ 0 & \text { se } y_{i} \neq \ell \text { and } y_{i} \in L . \\ \frac{1}{c} & \text { se } y_{i}=\emptyset\end{cases}
$$

Os níveis de domínio iniciais de cada nó definidos na Equação (4.17) podem ser entendidos da seguinte forma: 1) Para cada nó correspondente a um dado rotulado, o nível de domínio do time dominante é configurado para o valor mais alto 1, enquanto que os níveis de domínio de outros times são configurados para o valor mais baixo 0 ; 2) Para cada nó correspondente a uma amostra não rotulada, os níveis de domínio de todas as partículas são configurados para o mesmo valor $\frac{1}{c}$, onde $c$ é o número de classes ou times de partículas. Uma ilustração dos níveis de domínio iniciais é mostrada pela Figura 4.3a.

A posição inicial de cada partícula é configurada para seu respectivo nócasa e a respectiva força inicial é configurada como segue:

$$
\rho_{j}^{\omega}(0)=1,
$$

ou seja, cada partícula começa sua caminhada com força máxima.

Finalmente, a tabela de distâncias de cada partícula é inicialmente configurada como segue:

$$
\rho_{j}^{d_{i}}(t)=\left\{\begin{array}{cc}
0 & \text { se } i=j \\
n-1 & \text { se } i \neq j
\end{array},\right.
$$

o que significa que as partículas conhecem apenas as distâncias para os nós que elas já visitaram ou tiveram como alvo; estas distâncias são recalculadas dinamicamente a cada movimento da partícula. Dessa forma, assume-se inicialmente que todas as distâncias têm o maior valor possivel $n-1$, exceto, obviamente, pela distância de seu nó-casa, que é zero desde o início. 

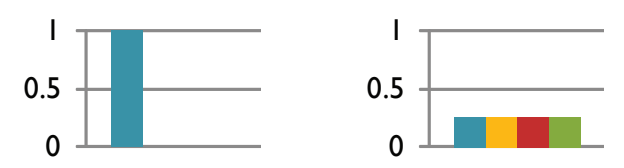

(a)

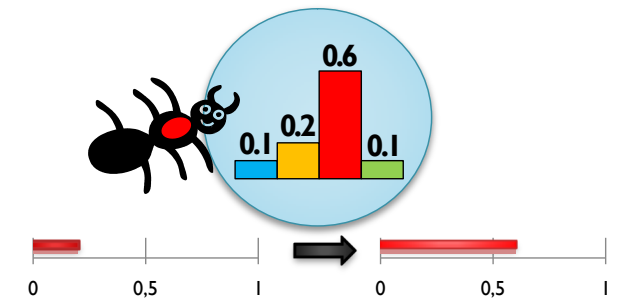

(b)

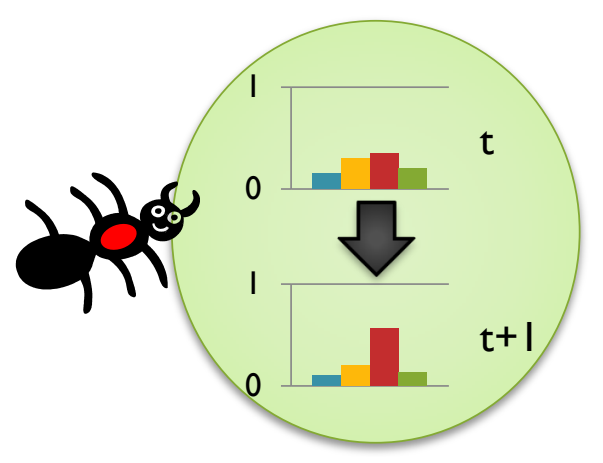

(d)

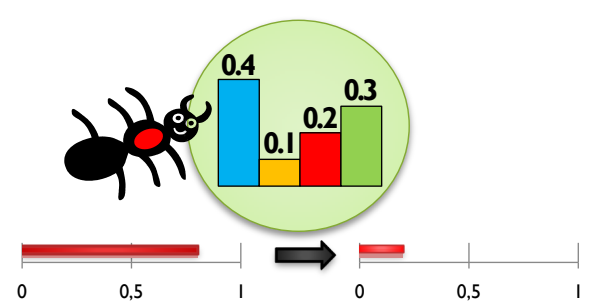

(c)

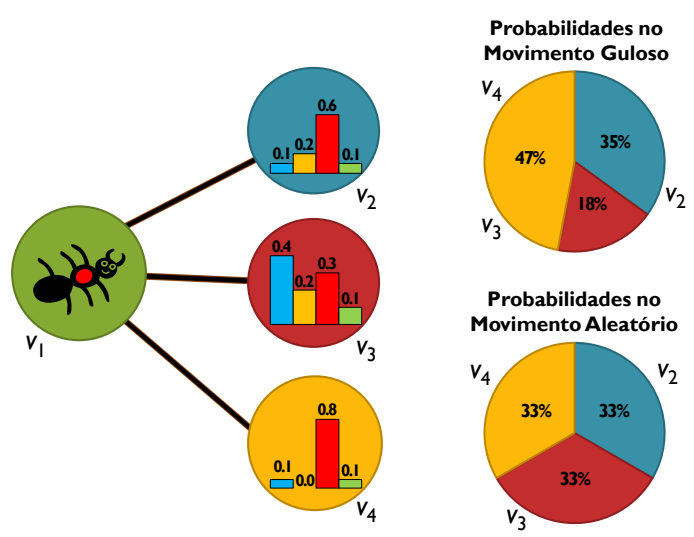

(e)

Figura 4.3: Ilustrações das dinâmicas de partículas e nós. (a) níveis de domínio iniciais para nós correspondente a uma amostra rotulada (esquerda) e uma amostra não rotulada (direita) em um problema de 4 classes; (b) uma partícula se fortalece se tiver como alvo um nó sendo dominado por seu próprio time; (c) uma partícula se enfraquece se tiver como alvo um nó sendo dominado por outro time; (d) uma partícula aumenta o nível de domínio de seu time no nó alvo enquanto diminui o nível de domínio de outros times; (e) probabilidades de nós serem escolhidos por uma partícula com o movimento guloso e o movimento aleatório, todos os nós candidatos têm a mesma distância do nó-casa da partícula.

\section{Dinâmica de Nós e Partículas}

Quanto a dinâmica de nós, na iteração $t$, cada partícula seleciona um nó alvo para visitar, e cada nó tem um vetor onde cada elemento representa o nível de domínio de um time de partículas. Partículas de diferentes times competem pela posse de nós da rede, portanto uma partícula aumentará o nível de domínio de seu time no nó alvo, ao mesmo tempo em que diminuirá os níveis de domínio de outros times no mesmo nó. A exceção são os nós rotulados, cujos níveis de domínio são fixos. Conseqüentemente, para cada nó $v_{i}$ selecionado como alvo, o nível de domínio $v_{i}^{\omega_{\ell}}(t)$ é atualizado como segue: 


$$
v_{i}^{\omega_{\ell}}(t+1)=\left\{\begin{array}{ll}
\max \left\{0, v_{i}^{\omega_{\ell}}(t)-\frac{\Delta_{v} \rho_{j}^{\omega}(t)}{c-1}\right\} & \text { se } y_{i}=\emptyset \mathrm{e} \ell \neq \rho_{j}^{f} \\
v_{i}^{\omega_{\ell}}(t)+\sum_{q \neq \ell} v_{i}^{\omega_{q}}(t)-v_{i}^{\omega_{q}}(t+1) & \text { se } y_{i}=\emptyset \mathrm{e} \ell=\rho_{j}^{f} \\
v_{i}^{\omega_{\ell}}(t) & \text { se } y_{i} \in L
\end{array},\right.
$$

onde $0<\Delta_{v} \leq 1$ é um parâmetro para controlar a taxa de mudança dos níveis de domínio e $\rho_{j}^{f}$ representa os rótulos das classes da partícula $\rho_{j}$. Se $\Delta_{v}$ recebe um valor baixo, os níveis de domínio dos nós mudam vagarosamente, enquanto que se $\Delta_{v}$ recebe um valor alto, os níveis de domínio dos nós mudam rapidamente. Cada partícula $\rho_{j}$ aumenta o nível de domínio de seu time $\left(v_{i}^{\omega_{\ell}}\right.$, $\ell=\rho_{j}^{f}$ ) no nó $v_{i}$ que tem como alvo, ao mesmo tempo em que diminui os níveis de domínio de outros times neste mesmo nó $\left(v_{i}^{\omega_{\ell}}, \ell \neq \rho_{j}^{f}\right)$, sempre respeitando a lei de conservação definida pela Equação (4.16). Os níveis de domínio de todos os nós rotulados $v_{i}^{\omega}$ são fixos, esta situação é definida pelo terceiro caso expressado na Equação (4.20). A Figura 4.3d ilustra o que acontece aos níveis de domínio quando uma partícula visita um nó que corresponde a uma amostra não rotulada.

Quanto a dinâmica de partículas, a partícula se fortalecerá quando tiver como alvo um nó sendo dominado pelo seu próprio time e se enfraquecerá quando tiver como alvo um nó dominado por outros times. Portanto, a cada iteração $t$, a força da partícula $\rho_{j}^{\omega}(t)$ é atualizada como segue:

$$
\rho_{j}^{\omega}(t+1)=v_{i}^{\omega_{\ell}}(t+1)
$$

onde $v_{i}$ é o nó alvo, e $\ell=\rho_{j}^{f}$, ou seja, $\ell$ é o rótulo de classe da partícula $\rho_{j}$. Conseqüentemente, cada partícula $\rho_{j}$ tem sua força $\rho_{j}^{\omega}$ configurada para o valor do nível de domínio de seu time $v_{i}^{\omega_{j}}$ no nó $v_{i}$. Desta forma, uma partícula se fortalece ao visitar um nó com alto nível de domínio de seu próprio time. Esta situação é ilustrada pela Figura 4.3b, onde uma partícula do time "vermelho" tem como alvo um nó dominado pelo mesmo time. Conseqüentemente, a força da partícula é aumentada. Por outro lado, a partícula se enfraquece ao tentar invadir um nó dominado por outro time. Este comportamento é ilustrado pela Figura 4.3c, onde uma partícula do time "vermelho" tem como alvo um nó dominado pelo time "amarelo”. Neste caso, a força da partícula é reduzida.

A tabela de distância é introduzida com o objetivo de manter as partículas informadas de quão longe elas estão de seu nó-casa, evitando que elas vão muito longe, o que deixaria suas vizinhanças suscetiveis a ataques de outras partículas. As distâncias, juntamente com os níveis de domínio, irão evitar que uma partícula perca toda sua força ao tentar passear por vizinhanças inimigas, e também mantê-la por perto para proteger sua própria vizinhança. Cada partícula $\rho_{j}$ atualiza sua tabela de distâncias $\rho_{j}^{d_{k}}(t)$ a cada iteração $t$ 
como segue:

$$
\rho_{j}^{d_{k}}(t+1)=\left\{\begin{array}{cl}
\rho_{j}^{d_{i}}(t)+1 & \text { se } \rho_{j}^{d_{i}}(t)+1<\rho_{j}^{d_{k}}(t) \\
\rho_{j}^{d_{k}}(t) & \text { caso contrário }
\end{array}\right.
$$

onde $\rho_{j}^{d_{i}}(t)$ e $\rho_{j}^{d_{k}}(t)$ são as distâncias para o nó-casa a partir do nó atual e a partir do nó alvo, respectivamente.

O cálculo da distância é simples: assumimos que todas as partículas têm inicialmente conhecimento limitado da rede, ou seja, elas sabem quantos nós existem na rede, mas não sabem como eles estão conectados, portanto assumimos que todos os nós podem ser alcançados em no máximo $n-1$ passos (a maior distância possível). Toda vez que uma partícula se move do nó atual para o nó alvo, ela checa a tabela de distâncias. Se a distância do nó alvo é maior que a distância do nó atual, a distância do nó alvo é atualizada para a distância do nó atual mais 1. Este método tem a vantagem de usar apenas distâncias conhecidas sem necessidade de recalcular.

Deve ser observado que uma partícula visita o nó alvo de fato apenas se o nível de domínio de seu próprio time é maior que os outros; caso contrário, um choque ocorrerá e a partícula permanecerá no nó atual até a próxima iteração. Este é o mecanismo de competição implementado no presente modelo.

\section{Caminhada Aleatório-Gulosa}

Como uma partícula escolhe um vizinho para visitar? Introduzimos duas regras governando este comportamento: caminhada aleatória e caminhada gulosa. Na caminhada aleatória, a partícula escolhe aleatoriamente qualquer vizinho para visitar sem se preocupar com os níveis de domínio ou distância do nó-casa. Este movimento é útil para exploração e aquisição de novos nós. Ao mesmo tempo, no movimento guloso, cada partícula prefere visitar aqueles nós que já são dominados por seu próprio time e que estão mais próximos de seus nós-casa. Este movimento é útil para defesa do território de seu time. As partículas devem exibir ambos os movimentos com o objetivo de atingir um equilíbrio entre comportamento exploratório e defensivo.

Conseqüentemente, na caminhada aleatória a partícula $\rho_{j}$ tenta se mover para qualquer nó $v_{i}$ com as mesmas probabilidades definidas por:

$$
p\left(v_{i} \mid \rho_{j}\right)=\frac{W_{q i}}{\sum_{\mu=1}^{n} W_{q \mu}},
$$

onde $q$ é o índice do nó atual da partícula $\rho_{j}$, portanto $W_{q i}=1$ se existe uma aresta entre o nó atual e qualquer nó $v_{i}$, e $W_{q i}=0$ caso contrário. No movimento guloso, a partícula tentará se mover para um vizinho com probabilidade definida pelo nível de domínio de seu time naquele vizinho, $\rho_{j}^{\omega_{\ell}}$, e pelo inverso 
da distância $\left(\rho_{j}^{d_{i}}\right)$ daquele vizinho, $v_{i}$, para seu nó-casa, $v_{j}$, de acordo com a seguinte expressão:

$$
p\left(v_{i} \mid \rho_{j}\right)=\frac{W_{q i} v_{i}^{\omega_{\ell}} \frac{1}{\left(1+\rho_{j}^{d_{i}}\right)^{2}}}{\sum_{\mu=1}^{n} W_{q \mu} v_{i}^{\omega_{\ell}} \frac{1}{\left(1+\rho_{j}^{d_{i}}\right)^{2}}}
$$

onde, novamente, $q$ é o índice do nó atual da partícula $\rho_{j}$ e $\ell=\rho_{j}^{f}$, onde $\rho_{j}^{f}$ é o rótulo da classe da partícula $\rho_{j}$. A Figura 4.3e ilustra algumas probabilidades calculadas usando estas regras.

A cada iteração, cada partícula tem probabilidade $p_{\text {grd }}$ de escolher o movimento guloso e probabilidade $1-p_{\text {grd }}$ de escolher o movimento aleatório, com $0 \leq p_{\text {grd }} \leq 1$. Uma vez que a escolha pelo movimento aleatório ou guloso é determinada, o nó vizinho alvo $\rho_{j}^{\tau}(t)$ será escolhido com as probabilidades definidas pela Equação (4.23) ou pela Equação (4.24), respectivamente.

\section{Critério de Parada}

Na maioria dos casos, após um número suficiente de passos, os nós internos de cada classe estarão completamente dominados por um único time. Porém, nós mais externos ainda sofrerão mudanças em seus níveis de domínio, e até mesmo mudanças do time dominante. Conseqüentemente, não podemos esperar uma convergência de todos os rótulos de nós em todos os casos, e assim devemos monitorar a média dos maiores níveis de domínio dos nós $\left(\left\langle v_{i}^{\omega \ell}\right\rangle, \ell=\arg \max _{q} v_{i}^{\omega_{q}}\right)$ e parar o algoritmo quando não houver aumento nesta quantidade.

De fato, o número de iterações requerido para estabilizar a média dos maiores níveis de domínio de cada nó é mais ou menos proporcional ao tamanho da rede (isto será mostrado na Subseção 4.2.3), portanto o algoritmo pode ser executado por um número pré-determinado de passos proporcional ao tamanho da rede. Mas note que a mistura da rede, que normalmente é desconhecida a priori em problemas do mundo real, também afeta o número de passos. Portanto, monitorar a média dos maiores níveis de domínio é um critério de parada mais seguro e eficiente.

\section{Olgoritmo}

No geral, o método proposto pode ser definido como mostrado no Algoritmo 4.2 .

As partículas do mesmo time colaboram umas com as outras no sentido de que elas trabalham juntas para aumentar o nível de domínio do time em um nó com o objetivo de dominar aquele nó. Mas elas ainda colocam a defesa de sua vizinhança em primeiro lugar, ou seja, os nós em torno de seus nós-casa. Porém, de vez em quando, eles podem visitar seus companheiros de equipe e 


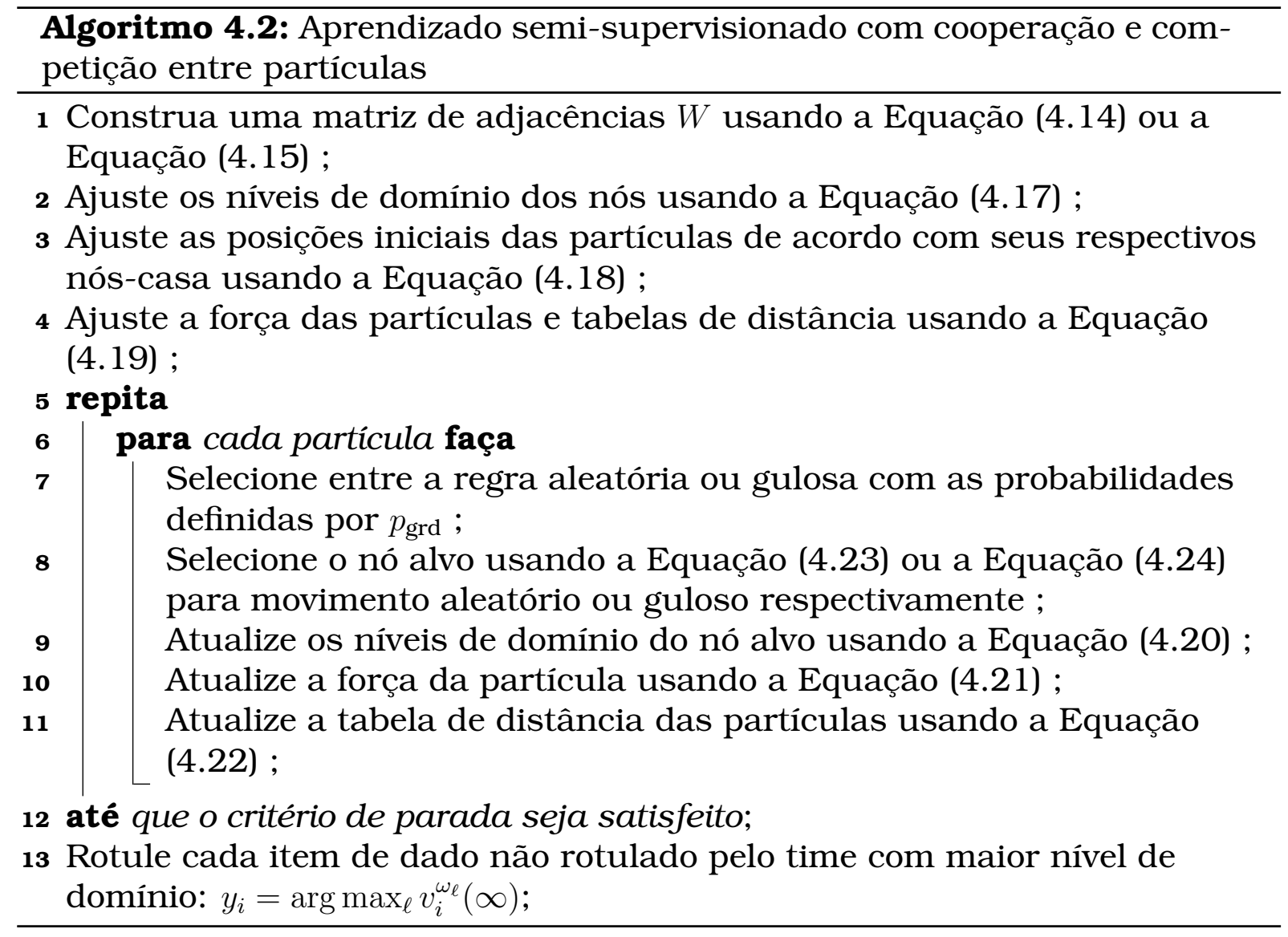

ajudá-los a defender seu território, e também poderão eventualmente receber ajuda de seus companheiros de equipe em sua própria área.

Tornar cada item de dado rotulado em uma partícula também é algo conveniente, pois a distribuição dos itens de dados rotulados entre classes é normalmente proporcional a distribuição entre classes dos itens não rotulados, visto que os itens rotulados foram normalmente selecionados aleatoriamente de toda a base de dados para serem rotulados por um especialista.

\subsubsection{Complexidade Computacional}

Nesta subseção, são fornecidas análises da complexidade computacional de tempo e espaço do Algoritmo 4.2. Nas subseções a seguir, será considerada primeiramente a complexidade computacional de tempo e em seguida a complexidade computacional de espaço.

\section{Complexidade Computacional de Tempo}

No início do Algoritmo 4.2, os Passos de 1 a 4 são executados e seu tempo de execução é dominado pelo Passo 1: construir uma matriz de adjacências a partir dos dados de entrada. Este passo tem ordem de complexidade $O\left(n^{2}\right)$. O Passo 5 define um laço que é repetido até a convergência, ou seja, o número de iterações do algoritmo. O Passo 6 é um laço interno e todos os passos 
restantes (Passos 7 a 12) estão dentro deste laço interno. Em outras palavras, os Passos 7 a 12 são ações a serem feitas por cada uma das $l$ partículas a cada iteração. Especificamente, no Passo 7 o algoritmo escolhe entre a regra aleatória ou gulosa para selecionar um vizinho para que a partícula visite, o que é executado em tempo constante $(O(1))$. No Passo 8, o algoritmo tem que calcular a probabilidade de escolha de cada vizinho, esta operação depende do número de vizinhos de cada nó, ou seja, sua ordem de complexidade é $O(\langle k\rangle)$, onde $\langle k\rangle$ é a média do grau dos nós da rede. Os Passos de 9 a 11 realizam atualizações nos níveis de domínio dos nós, força das partículas e tabela de distância das partículas, respectivamente. Estas são apenas operações com escalares com a partícula e nó escolhido e, portanto, levam tempo constante $(O(1))$. Neste ponto, concluímos que cada iteração do laço interno tem ordem de complexidade $O(\langle k\rangle)$. Note que $\langle k\rangle$ é definido pela escolha de $\sigma$ ou $k$ nas Equações (4.14) ou (4.15), respectivamente, e ele poder ser controlado para ser um número pequeno $(\langle k\rangle \ll n)$. Normalmente, o algoritmo apresenta bom desempenho de classificação quando a rede é esparsa. Conseqüentemente, o laço interno normalmente executa em tempo constante $O(1)$. Porém, se a rede não for esparsa, ou seja, se $\langle k\rangle$ é proporcional a $n$, então o laço interno executará na ordem de $O(n)$.

O laço interno (Passo 6) deve ser repetido para cada uma das $l$ partículas. O número de partículas é igual ao número de pontos de dados rotulados, o que é normalmente um número pequeno em problemas de aprendizado semisupervisionado $(l \ll n)$, ou seja, consideramos que $l$ não é proporcional a $n$, mas sim uma constante. Conseqüentemente, o laço interno para todas as partículas executa em tempo constante $O(1)$. Finalmente, o laço externo (Passo 5) é repetido até que o algoritmo converja, ou seja, até que a média do maior nível de domínio dos nós $\left(\left\langle v_{i}^{\omega \ell}\right\rangle, \ell=\arg \max _{q} v_{i}^{\omega_{q}}\right)$ converja. Considere uma rede com classes completamente separadas e cada classe (um subgrafo) tem uma ou mais partículas. A posse de cada nó pode ser determinada com apenas uma única visita e, portanto, o número de iterações do laço externo (Passo 5) é certamente $O(n)=C n$, onde $C$ é uma constante positiva proporcional ao nível de aleatoriedade no passeio da partícula. Se as classes estão conectadas, mas bem definidas, a posse de cada nó pode ser determinada por um número pequeno de visitas. Então, para ter todos os $n$ nós dominados por partículas, o número de iterações é novamente $O(n)=C n$. Pela mesma razão, esperamos que o número de iterações do laço externo (Passo 5) seja $O(n)=C n$, i.e., todos os $n$ nós são dominados por partículas em tempo constante de visitas.

Em resumo, se o grau médio $\langle k\rangle$ da rede é constante, os Passo 5 a 12 executam em tempo linear $O(n)$; se o grau médio é proporcional a $n$, os Passos 5 a 12 executam em $O\left(n^{2}\right)$. Em ambos os casos, a complexidade de tempo do 
algoritmo todo é determinada pelo Passo 1: construir a matriz de adjacência a partir dos dados de entrada, que é $O\left(n^{2}\right)$.

Agora fornecemos alguns resultados experimentais para checar nossa análise. Nas seguintes simulações, realizamos propagação de rótulos usando o algoritmo proposto diretamente em redes, ou seja, o Passo 1 não é executado. Sem considerar o Passo 1, esperamos que nosso algoritmo execute em ordem de tempo linear. Primeiramente geramos um conjunto de redes de entrada usando o método proposto por Danon et al. (2005) com tamanhos crescentes $(n=\{500,1000, \ldots, 5000\})$. Neste método de geração de rede, pares de nós pertencendo à mesma classe são ligados com probabilidade $p_{i n}$, enquanto que pares pertencendo à diferentes classes são conectados com probabilidade $p_{\text {out }}$. O valor de $p_{\text {out }}$ é escolhido de forma que a média do número de ligações de um nó para nós de qualquer outra classe, $z_{\text {out }}$, possa ser controlada. Ao mesmo tempo, o valor de $p_{i n}$ é escolhido de modo que o grau médio da rede $\langle k\rangle$ seja mantido constante. Portanto, $z_{\text {out }} /\langle k\rangle$ define a mistura das classes, e conforme $z_{\text {out }} /\langle k\rangle$ aumenta a partir de zero, as classes se tornam mais difusas e difíceis de identificar. Em todos os experimentos, os nós são igualmente divididos em $c=4$ classes, o grau médio dos nós é configurado para $\langle k\rangle=25$, e o subconjunto dos nós rotulados é ajustado para $l=50$, com seus componentes selecionados aleatoriamente. O algoritmo proposto é executado nestas redes medindo o número de iterações e o tempo necessário para atingir a convergência da média dos maiores níveis de domínio dos nós $\left(\left\langle v_{i}^{\omega \ell}\right\rangle, \ell=\arg \max _{q} v_{i}^{\omega_{q}}\right)$, critério de parada que foi explicado na Seção 4.2.1. O tempo é medido em um computador de mesa comum com um processador Intel Core 2 Quad modelo Q9450 e 4GB de RAM. O algoritmo é implementado utilizando o MATLAB. Os parâmetros são configurados para $p_{\text {grd }}=0,70$ e $\Delta_{v}=0,35$, os quais normalmente apresentam bons resultados, como será mostrado mais adiante. Os resultados são mostrados nas Figuras 4.4 e 4.5 para redes com misturas média $\left(z_{\text {out }} /\langle k\rangle=0,2\right)$ e alta $\left(z_{\text {out }} /\langle k\rangle=0,4\right)$, respectivamente. Analisando estas figuras, podemos perceber que a quantidade de iterações e o tempo aumentam linearmente conforme o tamanho da rede aumenta, o que confirma nossa análise.

Nossa análise mostra que a ordem de complexidade de tempo do algoritmo proposto é no máximo $O\left(n^{2}\right)$. Este atributo é bastante atrativo porque a maioria dos métodos de aprendizado semi-supervisionado baseados em grafo tem ordem de complexidade cúbica, ou seja, $O\left(n^{3}\right)$ Zhu (2005). Isto acontece porque os métodos baseados em grafo normalmente têm um mecanismo de propagação global de rótulos, ou seja, a cada iteração todos os nós do grafo são atualizados com regras pré-definidas, o que requer operações com matrizes com complexidade computacional cúbica. O método proposto é único no sen- 


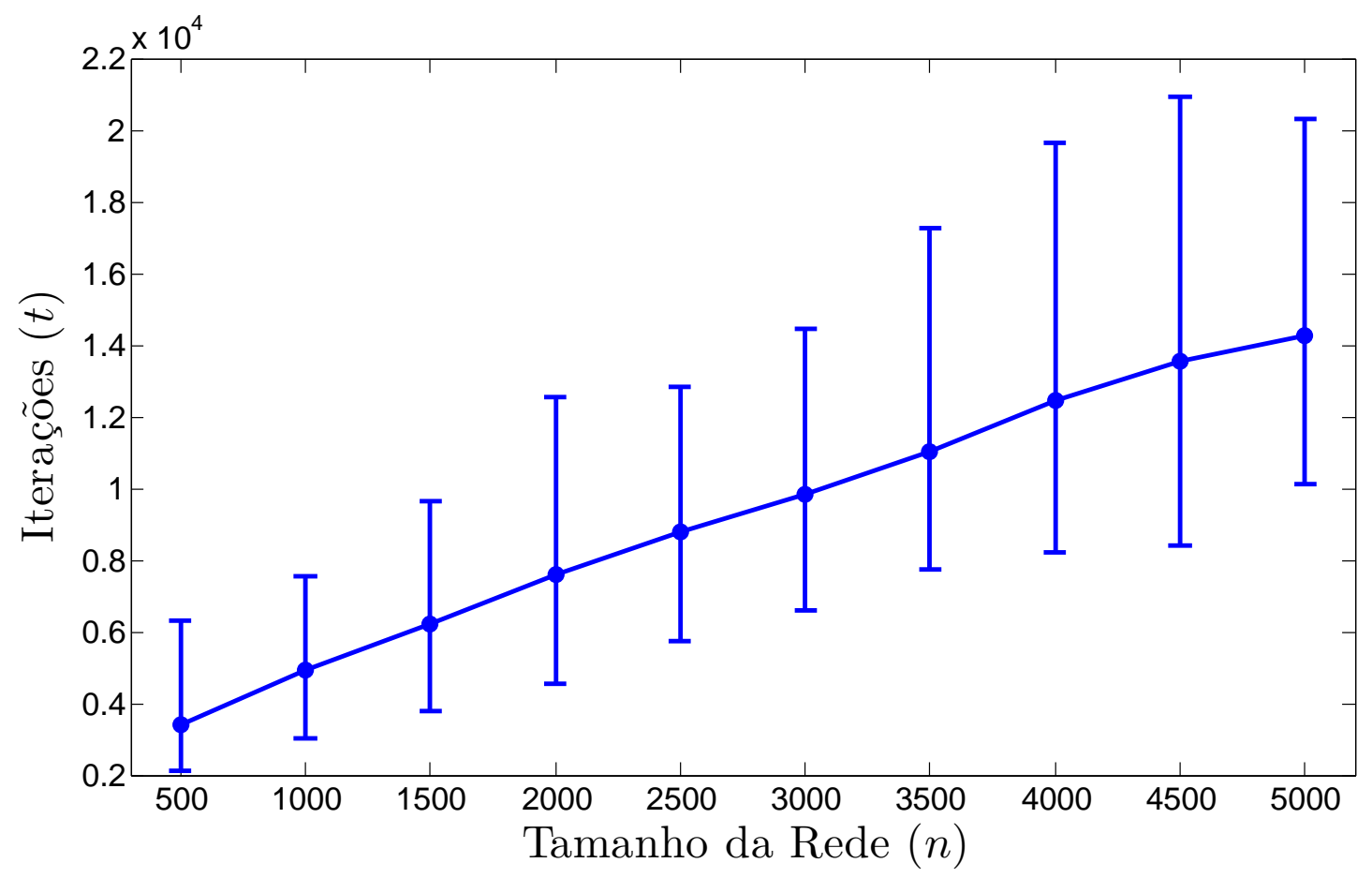

(a)

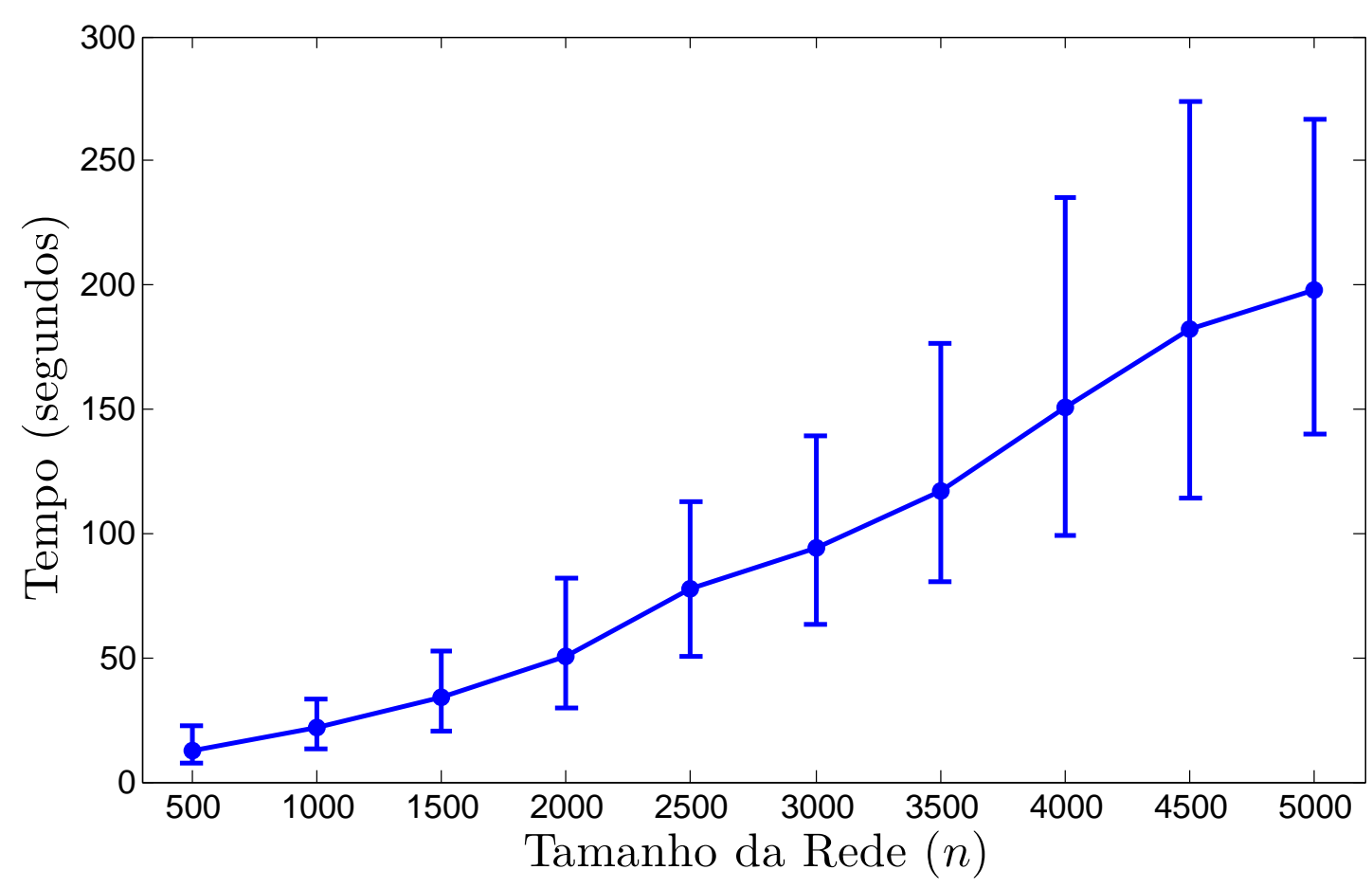

(b)

Figura 4.4: Análise de complexidade do método proposto em rede com média mistura: (a) Número de iterações e (b) tempo necessários para a convergência da média dos maiores níveis de domínio dos nós $\left(\left\langle v_{i}^{\omega \ell}\right\rangle, \ell=\arg \max _{q} v_{i}^{\omega_{q}}\right)$ com tamanho de rede $(n)$ crescente, $l=50,\langle k\rangle=25, z_{\text {out }}=5, z_{\text {out }} /\langle k\rangle=0,2$. Cada ponto na linha é uma média obtida em 100 execuções. As barras de erro representam valores máximo e mínimos. 


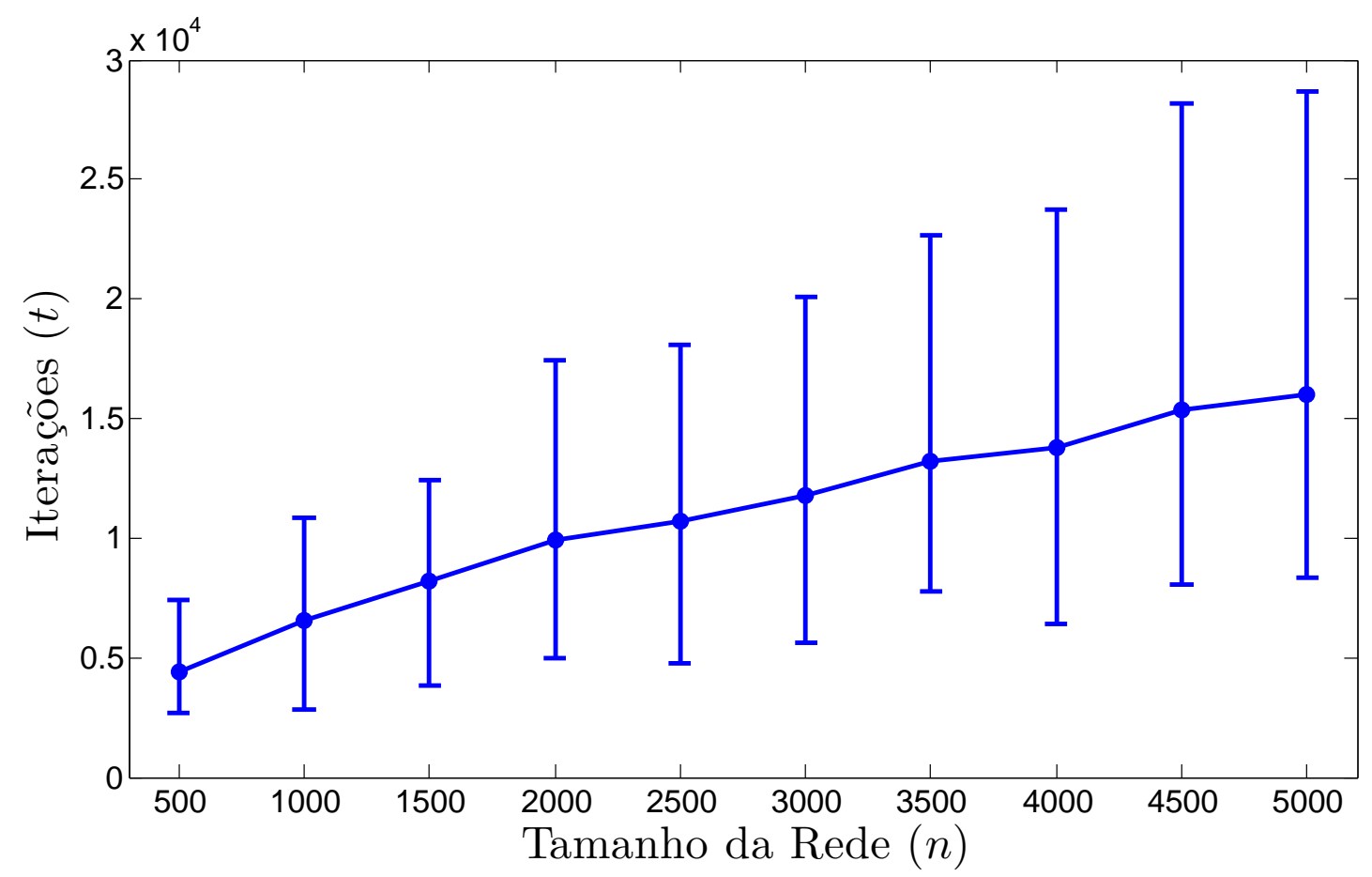

(a)

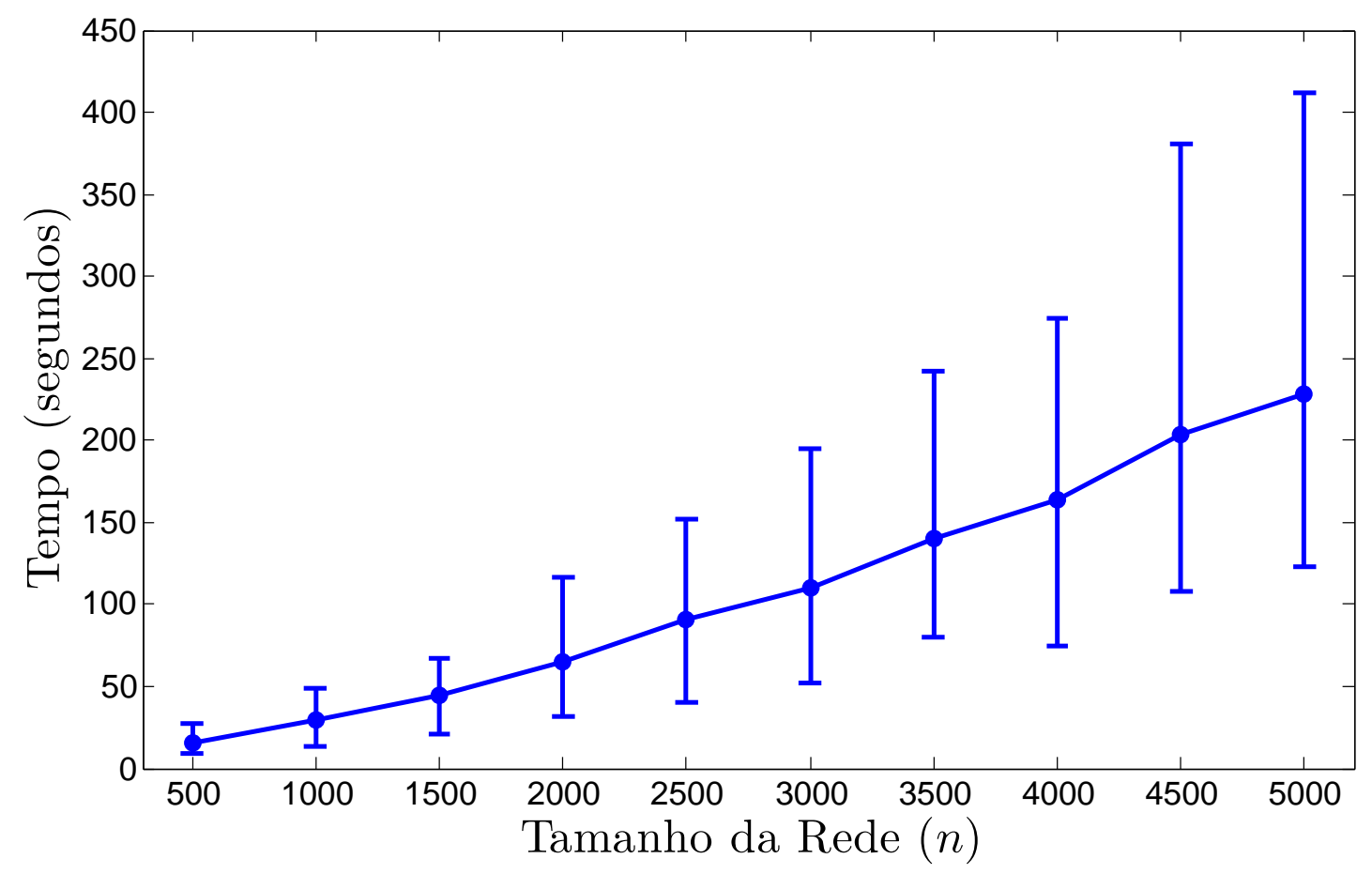

(b)

Figura 4.5: Análise de complexidade do método proposto em rede com alta mistura: (a) Número de iterações e (b) tempo necessários para a convergência da média dos maiores níveis de domínio dos nós $\left(\left\langle v_{i}^{\omega \ell}\right\rangle, \ell=\arg \max _{q} v_{i}^{\omega_{q}}\right)$ com tamanho de rede $(n)$ crescente, $l=50,\langle k\rangle=25, z_{\text {out }}=10, z_{\text {out }} /\langle k\rangle=0,4$. Cada ponto na linha é uma média obtida em 100 execuções. As barras de erro representam valores máximo e mínimos. 
tido de que ele propaga os rótulos localmente devido a competição entre partículas, evitando muitos passeios ou visitas desnecessários.

\section{Complexidade Computacional de Espaço}

Com relação aos requisitos de memória e complexidade de espaço, o algoritmo proposto usa as seguintes estruturas de dados: a matriz de adjacência utilizada para representar o grafo, as tabelas de distância, e os níveis de domínio dos nós. A matriz de adjacência tem tamanho $n^{2}$, e existe em todos os métodos baseados em grafo, mas o método proposto tem a vantagem de trabalhar com redes esparsas e sem peso, que podem ser implementadas utilizando listas de variáveis binárias para economizar espaço em memória. O grau médio dos nós $\langle k\rangle$ é definido pela escolha de $\sigma$ ou $k$ nas Equações (4.14) ou (4.15) respectivamente, e é normalmente um número pequeno $(\langle k\rangle \ll n)$ para que o algoritmo obtenha o melhor desempenho. Conseqüentemente, podemos considerar que a matriz de adjacência, implementada através de listas ligadas, cresce apenas linearmente conforme a rede cresce, ou seja, $\mathrm{O}(n)$. As tabelas de distâncias das partículas podem ser implementadas usando uma única matriz de inteiros sem sinal com tamanho n.l, porém é improvável que a partícula visite todos os nós da rede. Normalmente, cada partícula visitará apenas um pequeno subconjunto de nós durante toda a execução. Conseqüentemente não há necessidade de armazenar a distância de nós que nunca foram visitados. Isto leva a uma matriz de distâncias esparsa, que também pode ser implementada utilizando listas ligadas para economizar espaço em memória. A quantidade de nós rotulados $l$, e conseqüentemente o número de partículas, também é bem menor que o tamanho da rede $(l \ll n)$ na maioria dos casos práticos, portanto será $O(n)$ também. Finalmente, os níveis de domínio dos nós podem ser implementados usando uma única matriz de tamanho n.c, na qual o número de classes é muito menor que o tamanho da rede $(c \ll n)$, ou seja, $O(n)$. Além disso, três outras estruturas são armazenadas usando vetores simples: rótulos dos nós com tamanho $n$, e posição e força das partículas, ambos com tamanho $l$. A maioria dos algoritmos baseados em grafos utiliza redes com peso e não esparsas e, portanto, tem complexidade de espaço quadrática, ou seja, $O\left(n^{2}\right)$. Analisando as variáveis de nosso algoritmo podemos

perceber que a complexidade de espaço não será maior que $O\left(n^{2}\right)$ no pior caso, e será apenas $O(n)$ na maioria dos casos práticos.

\subsubsection{Simulações Computacionais}

Nesta subseção, apresentamos alguns resultados de experimentos usando o algoritmo proposto. Primeiramente, estudamos como os parâmetros influenciam o desempenho do algoritmo e a dinâmica temporal de nós e partículas. 
Então, alguns resultados de simulações de tarefas de classificação com aprendizado semi-supervisionado aplicando o modelo proposto a algumas base de dados artificiais são apresentados. Em seguida, passamos para alguns experimentos com base de dados do mundo real, cujos resultados são comparados com aqueles obtidos por métodos do estado da arte.

\section{Seleção de Parâmetros}

Nesta subseção, apresentamos algumas simulações computacionais com o objetivo de encontrar valores ótimos para os dois parâmetros do algoritmo $p_{\text {grd }}$ e $\Delta_{v}$ usando redes com diferentes tamanhos, misturas e conectividade, os quais foram gerados usando o método proposto por Danon et al. (2005), já explicado na Seção 4.2.2.

No primeiro conjunto de experimentos, geramos redes com misturas crescentes, $z_{\text {out }} /\langle k\rangle=\{0,125 ; 0,250 ; 0,375 ; 0,500\}$, enquanto mantemos tanto o tamanho da rede $n=128$ quanto o grau médio dos nós $\langle k\rangle=16$ constantes. Todos os nós são igualmente divididos em $c=4$ classes. $10 \%$ dos nós são selecionados aleatoriamente e apresentados para o algoritmo com seus respectivos rótulos, enquanto os demais são apresentados sem rótulos. Uma restrição imposta é que deve haver pelo menos um nó rotulado por classe. Os parâmetros são testados com valores crescentes $p_{\text {grd }}=\{0,00 ; 0,05 ; 0,10 ; \ldots ; 1,00\}$ e $\Delta_{v}=\{0,05 ; 0,10 ; 0,15 ; \ldots ; 1,00\}$. Todas as 420 combinações são testadas e cada uma delas é repetida 100 vezes para tirar uma média. Os resultados são apresentados nas Figuras 4.6a, 4.6b, 4.6c e 4.6d para $z_{\text {out }} /\langle k\rangle=0,125 ; 0,250$; 0, 375; e 0,500 respectivamente.

Analisando a Figura 4.6 notamos que ambos $p_{\text {grd }}=0$ e $p_{\text {grd }}=1$ levam a baixas taxas de classificação correta. Aqueles casos correspondem à caminhada completamente aleatória e à caminhada completamente gulosa, respectivamente, o que confirma que a combinação aleatório-gulosa na caminhada pode melhorar o desempenho do modelo. Também notamos que os parâmetros $p_{\text {grd }}$ e $\Delta_{v}$ dependem um do outro, porque conforme $p_{\text {grd }}$ aumenta, o algoritmo reduz seu comportamento de exploração, portanto um valor maior de $\Delta_{v}$ é requerido para ampliar as mudanças causadas pelos movimentos exploratórios. Observando as Figuras 4.6a a 4.6d notamos que há uma certa área no espaço de parâmetros em que o algoritmo alcança altas taxas de classificação correta. Esta área é relativamente grande quando a mistura da rede é baixa e fica menor conforme a mistura da rede aumenta, indicando que um ajuste mais fino dos parâmetros é requerido quando é tratado um problema difícil. De maneira interessante, não importa o quanto aumente a mistura dos dados, a combinação de $p_{\text {grd }}$ e $\Delta_{v}$ para conseguir boas classificações é quase fixa.

No segundo conjunto de experimentos, geramos redes com tamanhos cres- 


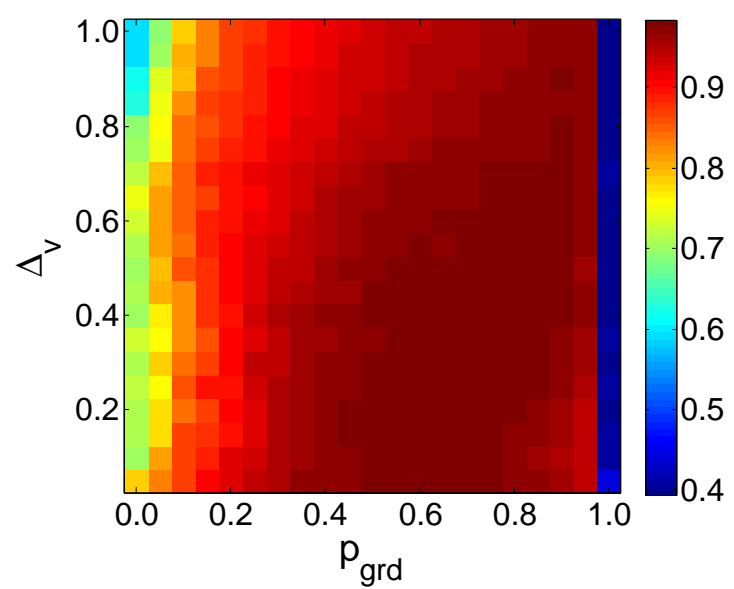

(a)

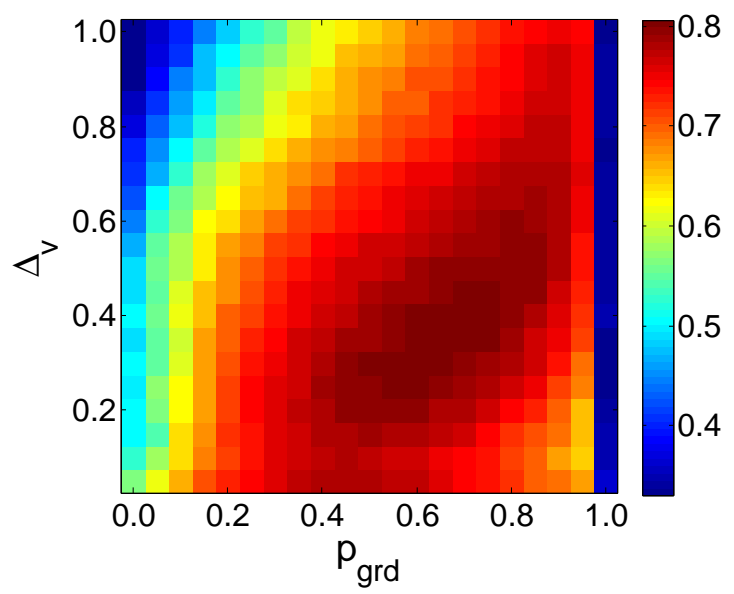

(c)

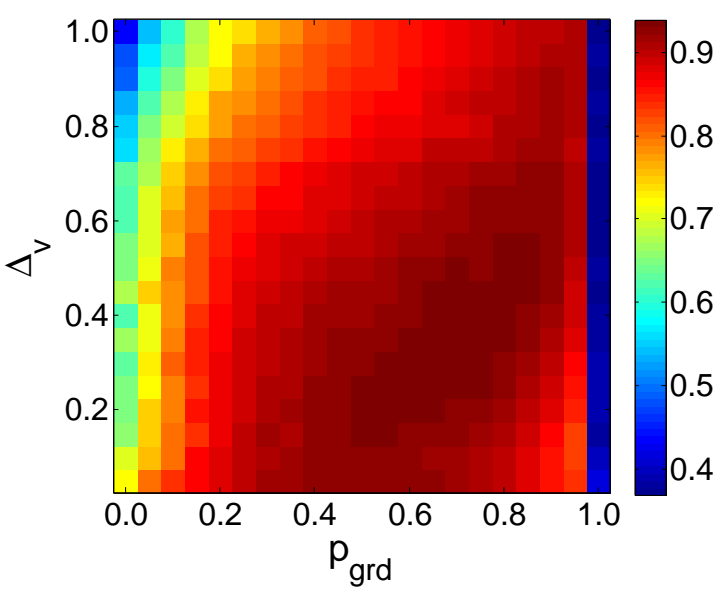

(b)

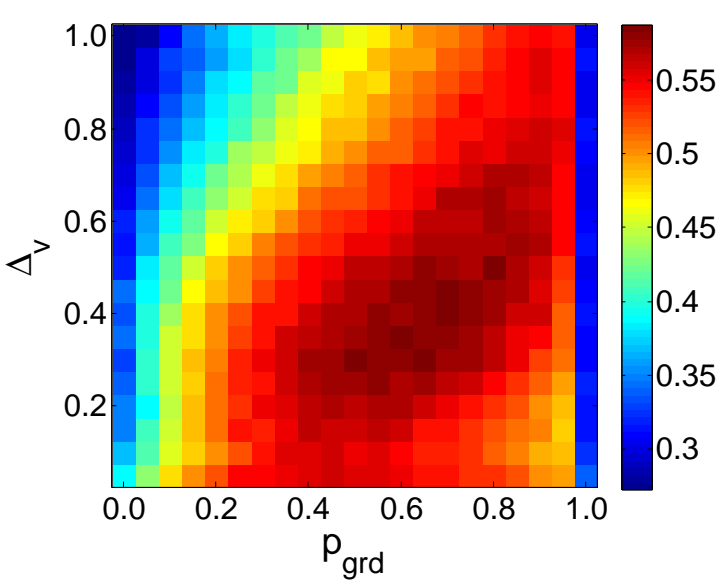

(d)

Figura 4.6: Taxa de classificação correta $\phi$ vs. $p_{\text {grd }}$ vs. $\Delta_{v}$ para redes com diferentes misturas $z_{\text {out }} /\langle k\rangle$. (a) $z_{\text {out }} /\langle k\rangle=0,125$; (b) $z_{\text {out }} /\langle k\rangle=0,250$; (c) $z_{\text {out }} /\langle k\rangle=$ 0,375 ; (d) $z_{\text {out }} /\langle k\rangle=0,500$. Os seguintes parâmetros são mantidos constantes em todas as simulações: $n=128, c=4,\langle k\rangle=16$. Cada ponto é uma média de 100 execuções.

centes, $n=\{64,128,192,256\}$, enquanto mantemos a mistura da rede $z_{\text {out }} /\langle k\rangle=$ 0, 250 constante e o grau médio dos nós proporcional ao tamanho da rede $\langle k\rangle=n / 8$. Outros valores, como o número de classes, o tamanho do subconjunto rotulado, os valores dos parâmetros e quantidade de repetições são os mesmos do experimento anterior. Os resultados são apresentados nas Figuras 4.7a, 4.7b, 4.7c e 4.7d para $n=64,128,192$ e 256 respectivamente. Neste caso, a área no espaço de parâmetros onde o algoritmo obtém bom desempenho se torna mais larga conforme o tamanho da rede aumenta.

No terceiro conjunto de experimentos, geramos redes com grau médio dos nós crescente, $\langle k\rangle=\{8,16,24,32\}$, enquanto mantemos ambos o tamanho da rede $n=128$ e a mistura $z_{\text {out }} /\langle k\rangle=0,250$ constantes. O número de classes, o tamanho do subconjunto rotulado, os valores dos parâmetros e a quantidade de repetições são as mesmas dos experimentos anteriores. Os resultados são 


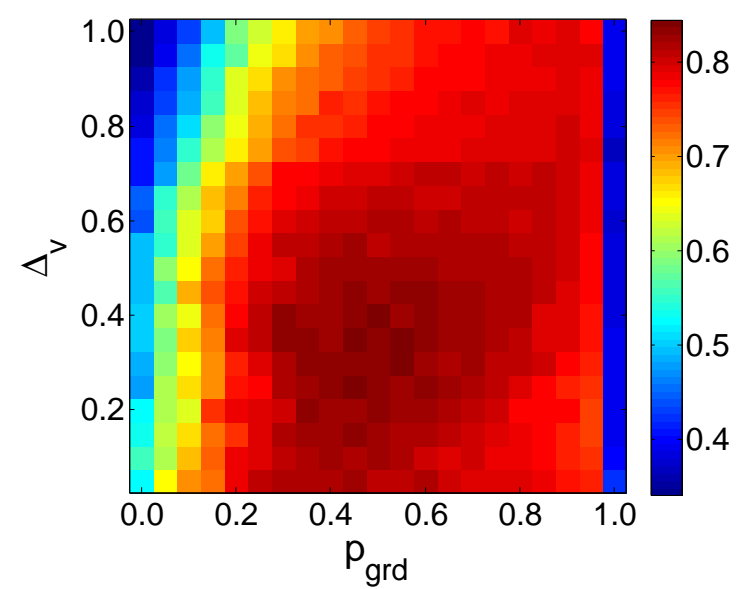

(a)

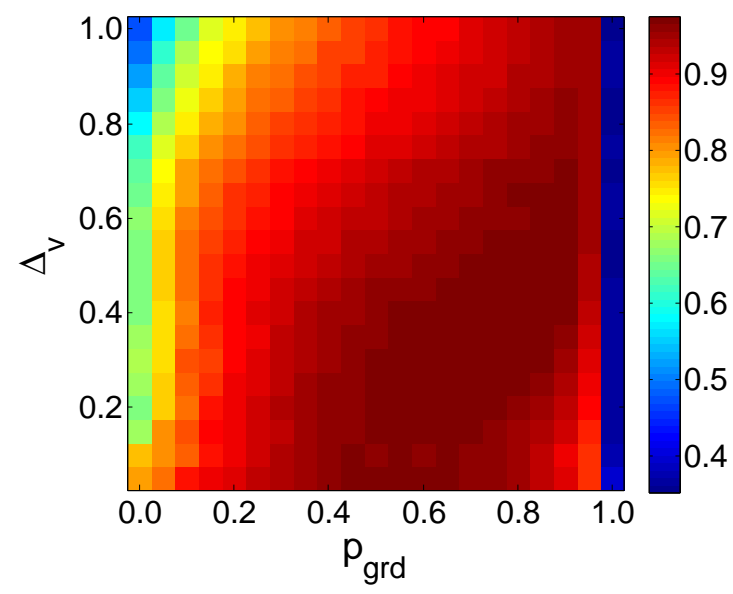

(c)

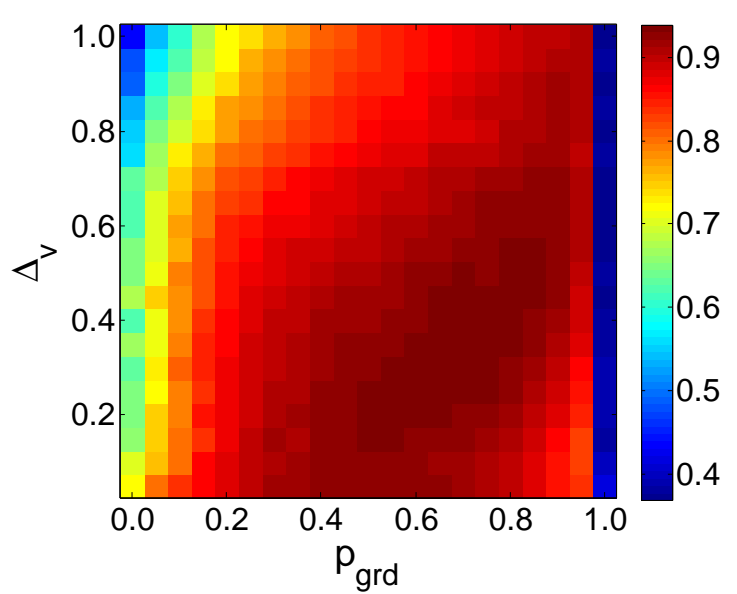

(b)

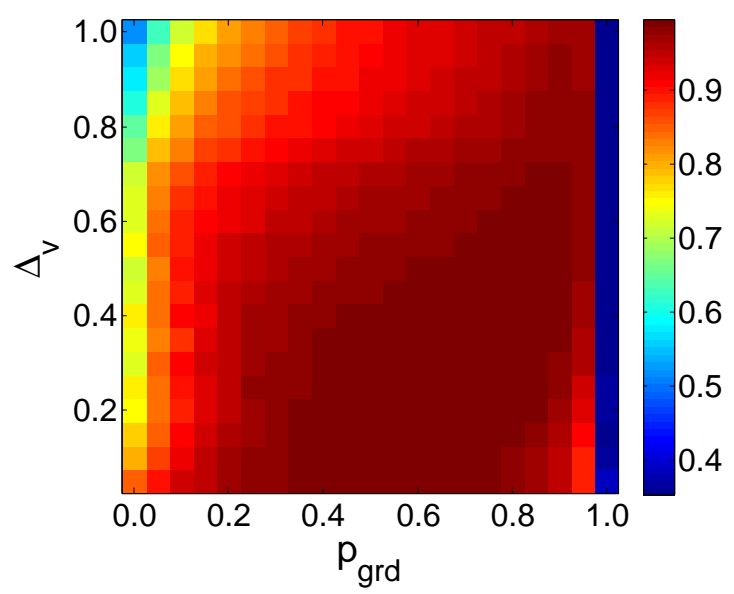

(d)

Figura 4.7: Taxa de classificação correta $\phi$ vs. $p_{\text {grd }}$ vs. $\Delta_{v}$ para redes com diferentes tamanhos $n$. (a) $n=64$; (b) $n=128$; (c) $n=192$; (d) $n=256$. Os seguintes parâmetros são mantidos constantes em todas as simulações: $z_{\text {out }} /\langle k\rangle=0,25$; $c=4 ;\langle k\rangle=n / 8$. Cada ponto é uma média de 100 execuções.

apresentados nas Figuras 4.8a, 4.8b, 4.8c e 4.8d para $\langle k\rangle=8,16,24$ e 32 respectivamente. Neste caso, a área no espaço de parâmetros onde o algoritmo tem bom desempenho se desloca levemente para a direita, o que significa que redes com grau médio de nós mais alto podem se beneficiar de valores ligeiramente mais altos para $p_{\text {grd }}$.

Das Figuras 4.6, 4.7, e 4.8 observamos que há uma área no espaço de parâmetros em torno de $p_{\text {grd }}=0,70$ e $\Delta_{v}=0,35$ em que o algoritmo normalmente apresenta bons resultados independentemente do tamanho da rede, mistura ou média do grau dos nós. Conseqüentemente, estes parâmetros podem ser considerados em problemas reais onde não há tempo para seleção de modelo. Note que ambos o tamanho da rede e o grau médio dos nós são medidas que são conhecidas a priori, portanto o usuário pode preferir ajustar os parâmetros heuristicamente de acordo com estas medidas. Se houverem nós rotulados suficientes, o usuário pode otimizar os parâmetros através de 


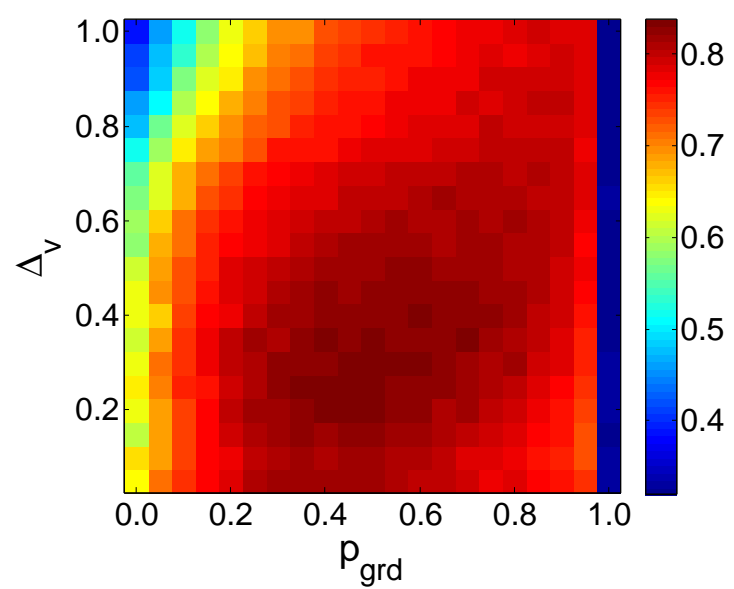

(a)

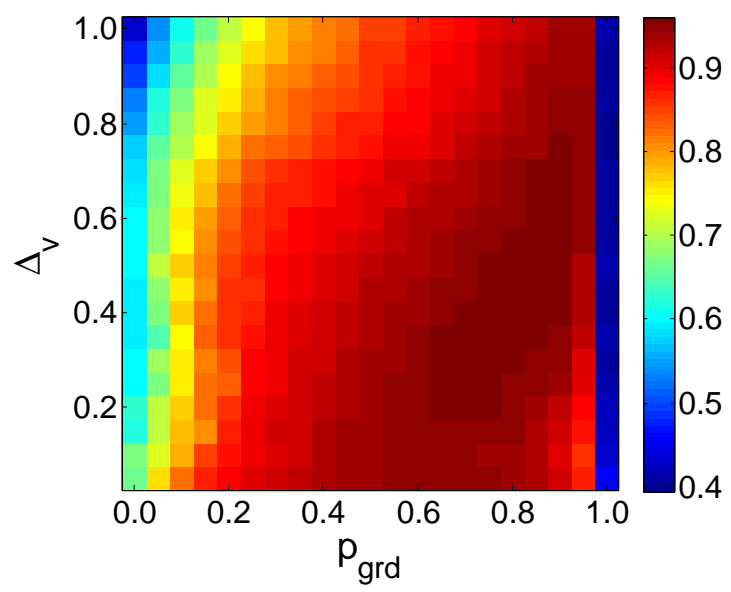

(c)

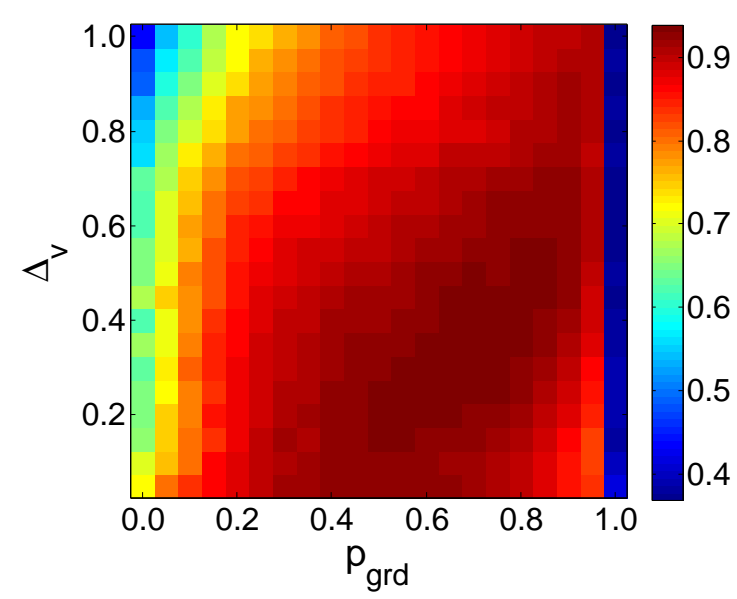

(b)

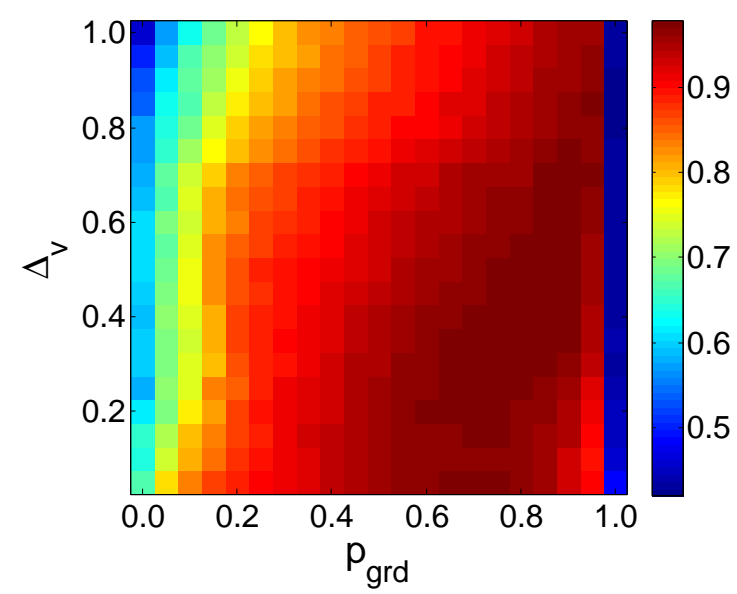

(d)

Figura 4.8: Taxa de classificação correta $\phi$ vs. $p_{\text {grd }}$ vs. $\Delta_{v}$ para diferentes valores de grau médio dos nós $\langle k\rangle$. (a) $\langle k\rangle=8$; (b) $\langle k\rangle=16$; (c) $\langle k\rangle=24$; (d) $\langle k\rangle=32$. Os seguintes parâmetros são mantidos constantes em todas as simulações: $n=128, z_{\text {out }} /\langle k\rangle=0,25 ; c=4 ;\langle k\rangle=n / 8$. Cada ponto é uma média de 100 execuções.

validação cruzada também.

\section{Dinâmica Temporal}

Com o objetivo de entender melhor a dinâmica temporal do modelo e a importância da regra aleatório-gulosa, executamos outro conjunto de experimentos. As Figuras 4.9a a 4.9c mostram a evolução temporal do modelo para cinco diferentes valores de $p_{\text {grd }}\left(p_{\text {grd }}=\{0,00 ; 0,25 ; 0,50 ; 0,75 ; 1,00\}\right)$. Nestes casos, o algoritmo é aplicado a redes geradas aleatoriamente usando o método proposto por Danon et al. (2005), como explicado na Subseção 4.2.2, com os seguintes parâmetros: $n=2048, l=64,\langle k\rangle=64, z_{\text {out }} /\langle k\rangle=0,25$, e $\Delta_{v}=0,35$.

A Figura 4.9a mostra as séries temporais da taxa de detecção correta $(\phi)$. Nela observamos que para o movimento completamente aleatório $\left(p_{\text {grd }}=0,00\right.$ ) ou para o movimento completamente guloso $\left(p_{\text {grd }}=1,00\right)$, a taxa de detecção 
correta é baixa. Este fenômeno era esperado porque quando $p_{\text {grd }}=0,00$ as partículas andam aleatoriamente o tempo todo e as distâncias para seus nós-casa não são levados em consideração. Neste caso, cada time de partículas domina uma classe e permanece dentro dela devido aos níveis de domínio, mas não há garantia que as partículas estarão na classe correta, ou seja, times podem trocar de territórios porque não têm seus nós-casa como referência. Por outro lado, se apenas a regra gulosa é aplicada $\left(p_{\text {grd }}=1\right)$, os resultados são sempre ruins. Isto ocorre porque, sem a regra aleatória, as partículas ficam presas em uma pequena região de nós já explorados, e raramente tentarão explorar nós desconhecidos. Além disso, uma vez que um nó seja totalmente dominado por um time, outros times jamais terão a chance de visitá-lo, porque as probabilidades calculadas pela Equação (4.24) serão sempre zero. Conseqüentemente, uma combinação adequada de comportamento aleatório e guloso é a melhor alternativa, onde a regra gulosa mantém as partículas em torno de seus respectivos nós-casa, defendendo sua vizinhança, enquanto que a regra aleatória permite que as partículas explorem nós previamente desconhecidos e compitam por nós dominados por outros times. O caso do movimento completamente guloso ( $p_{\text {grd }}=1,00$ ) leva muito tempo para converger, ao mesmo tempo que obtém resultados de classificação ruins.

A Figura $4.9 b$ mostra a média dos maiores níveis de domínio de todos os

nós $\left(\left\langle v_{i}^{\omega \ell}\right\rangle, \ell=\arg \max _{q} v_{i}^{\omega_{q}}\right)$. Nela podemos observar que os níveis de domínio aumentam rapidamente no início e depois de um certo número de iterações permanecem em um nível quase constante. O primeiro estágio corresponde a uma rápida dominância das partículas em suas respectivas vizinhanças, sem muita competição, e o segundo estágio corresponde a alta competição pelos nós próximos às bordas das classes antes que eles sejam totalmente dominados. A exceção é o caso de movimento completamente guloso $\left(p_{\text {grd }}=1,00\right)$, onde a média dos maiores níveis de domínio aumenta bem vagarosamente.

Finalmente, a Figura 4.9c mostra as séries temporais da média de força das partículas $\left(\left\langle\rho_{j}^{\omega}\right\rangle\right)$, que se torna maior conforme $p_{\text {grd }}$ aumenta. Isto ocorre porque as partículas perdem sua força quando elas tentam invadir nós dominados por outros times, e isto normalmente acontece no movimento aleatório. No caso do movimento completamente guloso $\left(p_{\text {grd }}=1,00\right)$ a competição é tão baixa que a média da força das partículas dificilmente baixa de um.

\section{Bases de Dados Artificiais}

Nesta seção, aplicamos o método proposto em algumas base de dados artificiais com diferentes distribuições de dados, que foram geradas usando o PRTools (Duin et al., 2007) e são apresentadas na Figura 4.10, com o objetivo de verificar a eficácia do método quando classificando estes tipos de dados. 


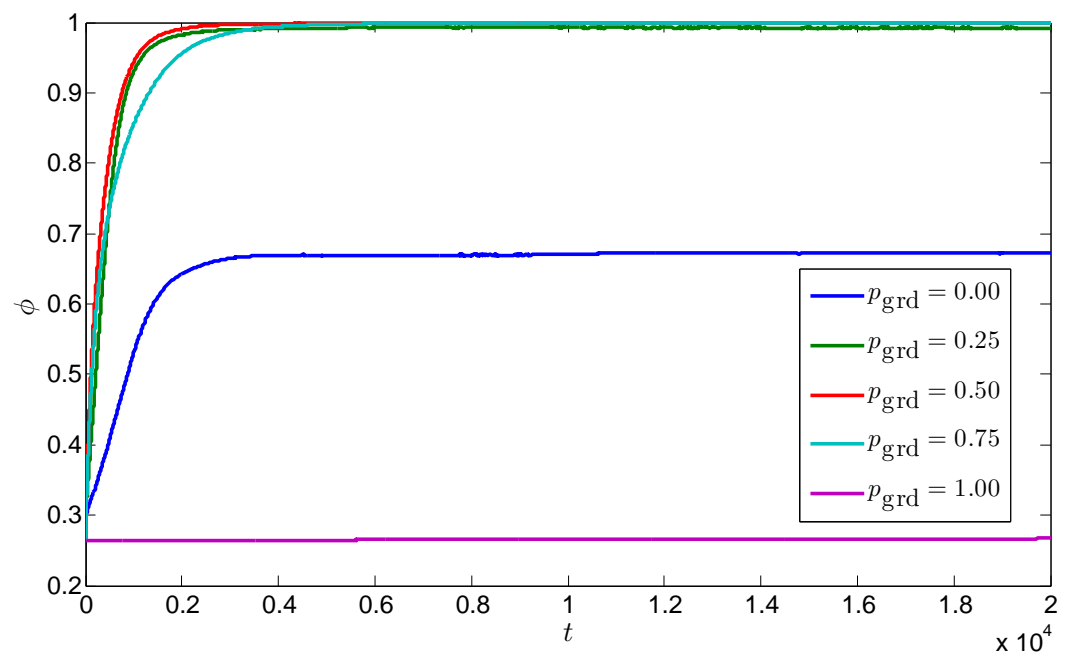

(a)

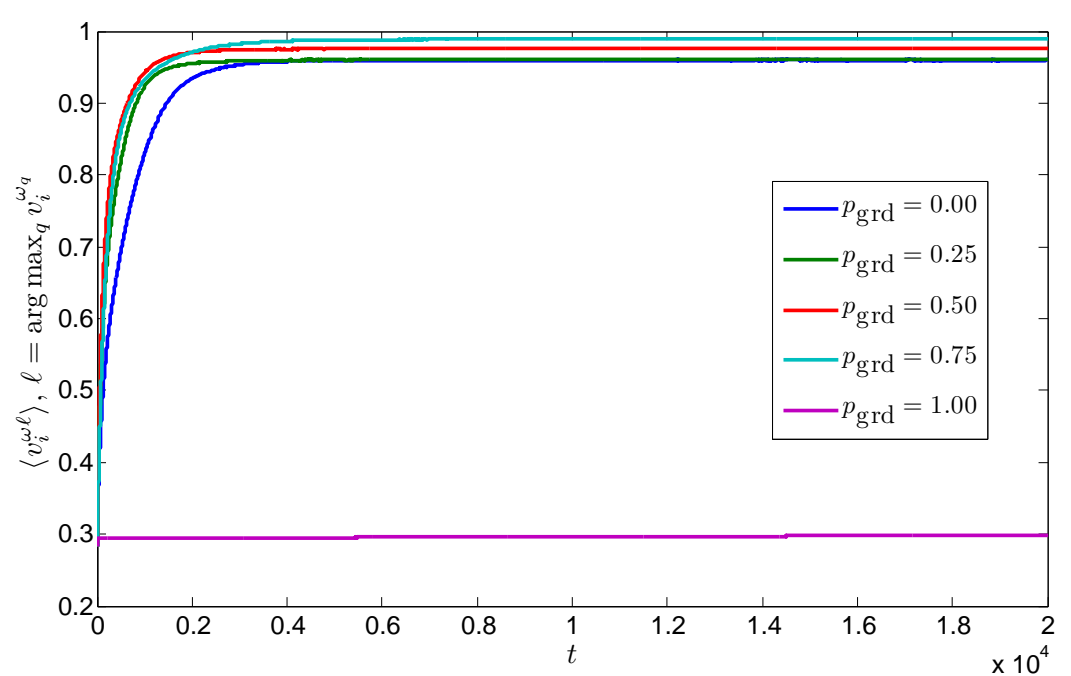

(b)

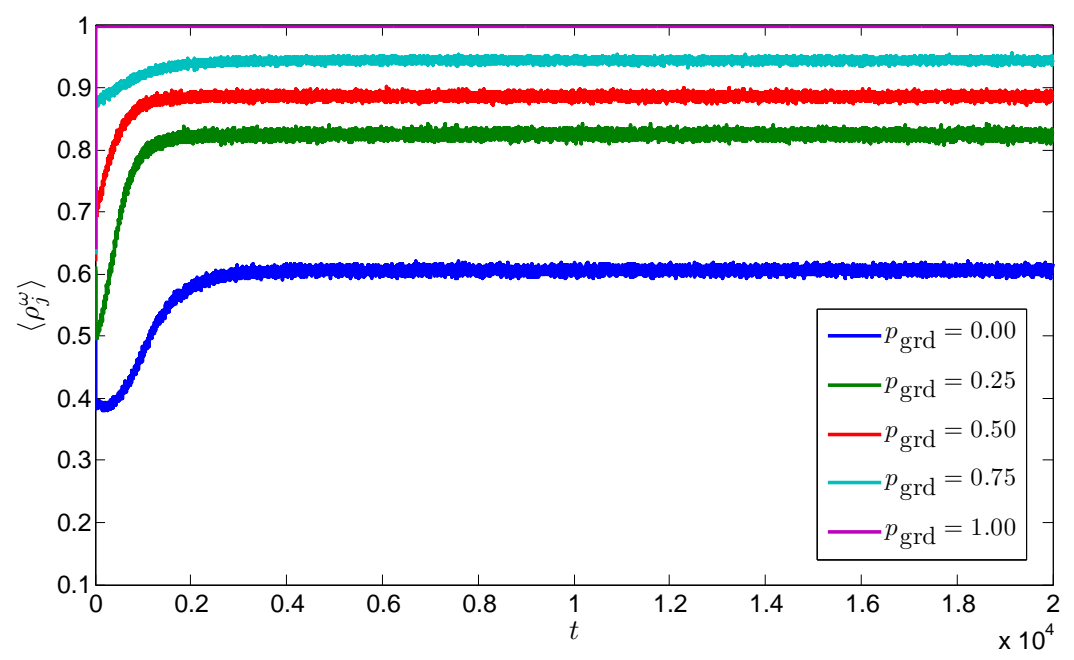

(c)

Figura 4.9: Séries temporais para diferentes valores de $p_{\text {grd }}$ (a) taxa de detecção correta (b) média do nível máximo de domínio dos nós (c) média da força das partículas. Cada ponto é uma média de 100 execuções usando redes geradas pelo método proposto por Danon et al. (2005) com os seguintes parâmetros: $n=2048, l=64,\langle k\rangle=64$ and $z_{\text {out }} /\langle k\rangle=0,25$. 
A primeira base de dados (Figura 4.10a) consiste de 2.000 amostras divididas igualmente em duas classes com forma de banana, 20 destas amostras (1\%) são selecionadas aleatoriamente como o subconjunto pré-rotulado. A segunda base de dados (Figura 4.10b) consiste de 1.000 amostras divididas igualmente em duas classes Highleyman, 100 dessas amostras (10\%) são selecionadas aleatoriamente para serem as amostras pré-rotuladas. A terceira base de dados (Figura 4.10c) consiste de 1.200 amostras divididas em duas classes Lithuanian, com 800 e 400 amostras respectivamente, neste caso 60 destas amostras (5\%) são aleatoriamente selecionadas para compor o subconjunto rotulado. Finalmente, a quarta base de dados (Figura 4.10d) consiste de 1.200 amostras igualmente divididas em classes com distribuição Gaussiana, 24 destas amostras (2\%) são selecionadas aleatoriamente para serem as amostras prérotuladas. Em todos os experimentos os seguintes parâmetros são mantidos constantes: $\Delta_{v}=0,35$ e $p_{\text {grd }}=0,70$, que correspondem a valores na faixa segura conforme descrito anteriormente. Os grafos são construídos a partir das bases de dados utilizando a Equação (4.15), com o parâmetro $k$ empiricamente ajustado para $k=20$ para todos os experimentos, exceto para o segundo onde $k=5$ é usado. O lado direito da Figura 4.10 mostra os estados finais da propagação de rótulos. Podemos observar que bons resultados são obtidos para todos os 4 casos, indicando que o algoritmo proposto é robusto para processar base de dados de diferentes distribuições.

\section{Teste de Desempenho}

Com o objetivo de verificar o desempenho do método proposto, este foi aplicado em 7 bases de dados padrões em aprendizado semi-supervisionado ${ }^{2}$. Algumas informações básicas sobre estas bases de dados estão disponíveis na Tabela 4.5. Para descrições detalhadas de cada uma delas, o leitor pode checar o livro de Chapelle et al. (2006b).

Tabela 4.5: Informações básicas das base de dados de teste

\begin{tabular}{lrrrl}
\hline Base de Dados & Classes & Dimensões & Pontos & Tipo \\
\hline g241c & 2 & 241 & 1500 & artificial \\
g241d & 2 & 241 & 1500 & artificial \\
Digit 1 & 2 & 241 & 1500 & artificial \\
USPS & 2 & 241 & 1500 & não balanceada \\
COIL & 6 & 241 & 1500 & \\
BCI & 2 & 117 & 400 & \\
Text & 2 & 11.960 & 1500 & esparsa \\
\hline
\end{tabular}

Para cada base de dados, há 10 ou 100 pontos de dados rotulados, e para

2 Disponíveis em http://www.kyb.tuebingen.mpg.de/ssl-book/benchmarks.html 

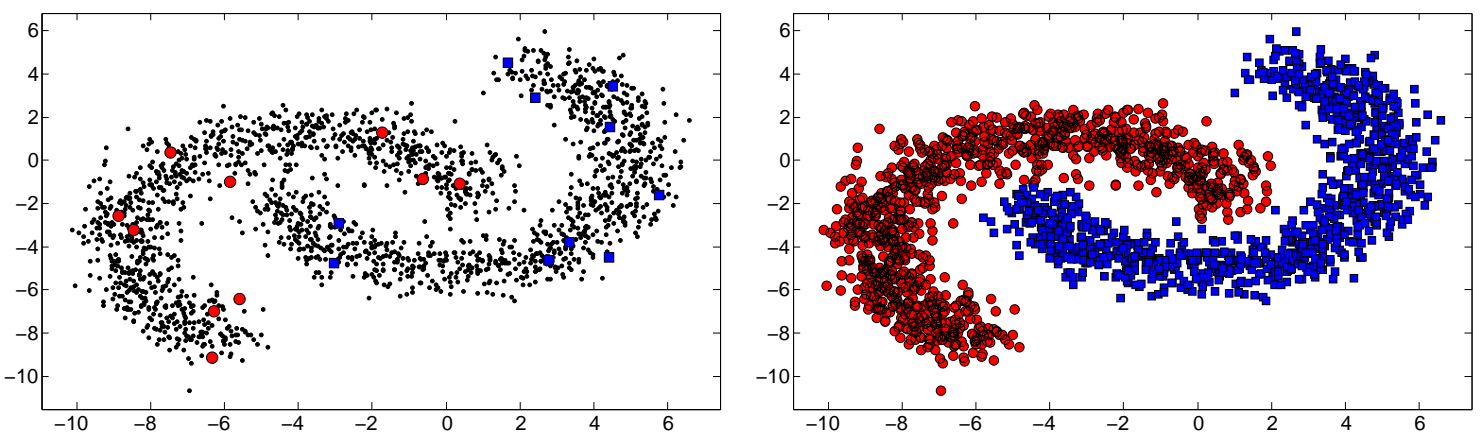

(a)
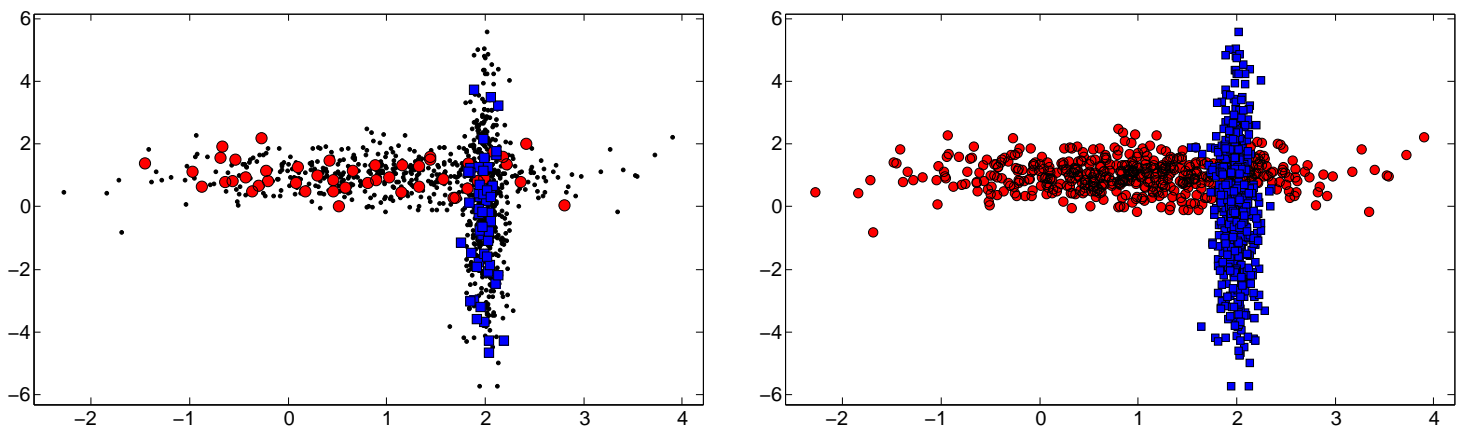

(b)
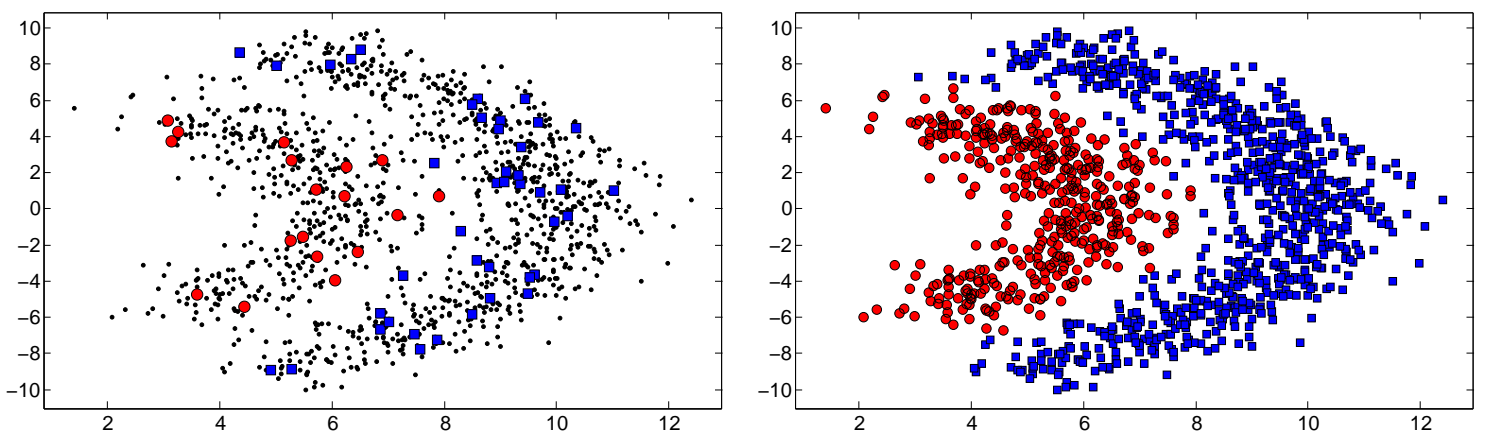

(c)
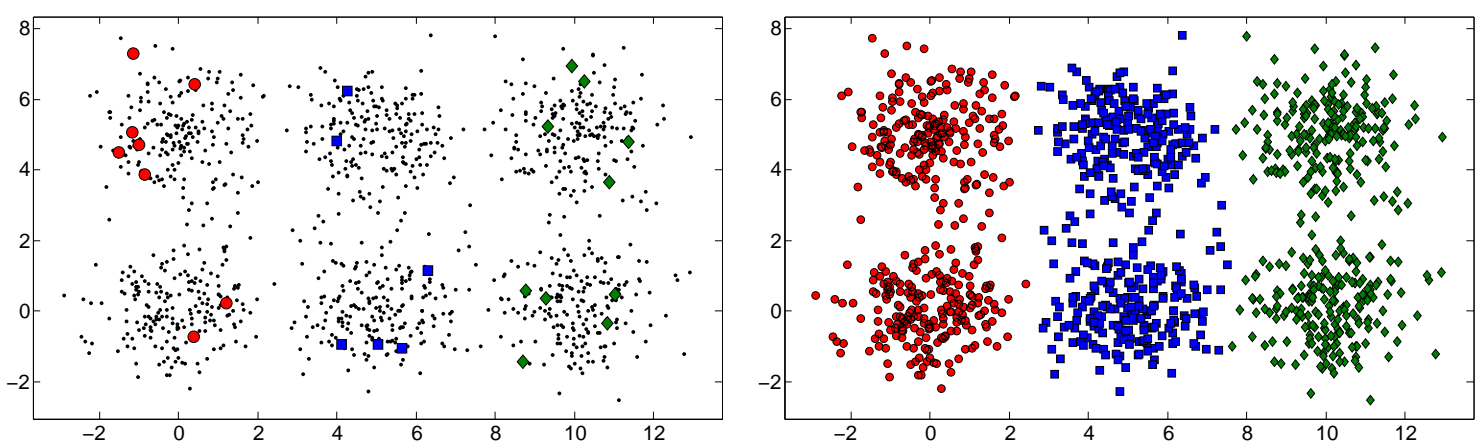

(d)

Figura 4.10: Classificação de bases de dados artificiais com: (a) 2.000 amostras dividias igualmente em duas classes com forma de banana; (b) 1.000 amostras divididas em duas classes Highleyman; (c) 1.200 amostras divididas em duas classes Lithuanian, com 800 e 400 amostras respectivamente; (d) 1.200 amostras igualmente divididas em três classes com distribuição Gaussiana. Os dados de entrada são representados à esquerda e a saída do algoritmo é representada à direita. Círculos (vermelho), quadrados (azuis), e losangos (verdes) representam os nós rotulados; pequenos pontos (preto) representam os nós não rotulados. 
cada caso 12 divisões são realizadas para particionar o conjunto de dados em pontos rotulados e não rotulados. É garantido que cada divisão contenha pelo menos um ponto rotulado de cada classe. Para efeito de comparação, incluímos os resultados de 13 métodos de aprendizado semi-supervisionado apresentados por Chapelle et al. (2006b). Os métodos Nearest Neighbor (1NN) e Linear SVM (SVM) (Vapnik, 1995) são usados como base. Os outros 11 algoritmos são aqueles que apresentaram o melhor desempenho em suas respectivas categorias e são apresentados na Tabela 4.6. As configurações detalhadas de cada método estão descritas em Chapelle et al. (2006b).

Tabela 4.6: Métodos de aprendizado semi-supervisionado usados para comparação de desempenho

\begin{tabular}{|c|c|c|}
\hline Abreviação & Método & Referências \\
\hline $\mathrm{MVU}+1-\mathrm{NN}$ & Maximum Variance Unfolding & $\begin{array}{l}\text { Weinberger \& Saul (2004); } \\
\text { Sun et al. (2006) }\end{array}$ \\
\hline $\mathrm{LEM}+1-\mathrm{NN}$ & Laplacian Eigenmaps & Belkin \& Niyogi (2003) \\
\hline $\mathrm{QC}+\mathrm{CMN}$ & $\begin{array}{l}\text { Quadratic Criterion and Class } \\
\text { Mass Regularization }\end{array}$ & $\begin{array}{l}\text { Belkin et al. (2004); Delal- } \\
\text { leau et al. (2005) }\end{array}$ \\
\hline Discrete Reg. & Discrete Regularization & Zhou \& Schölkopf (2006) \\
\hline TSVM & $\begin{array}{l}\text { Transductive Support Vector Ma- } \\
\text { chines }\end{array}$ & $\begin{array}{l}\text { Chapelle \& Zien (2005); } \\
\text { Joachims (2003) }\end{array}$ \\
\hline SGT & Spectral Graph Transducer & Joachims (2003) \\
\hline Cluster-Kernel & Cluster Kernels & Chapelle et al. (2003) \\
\hline Data-Dep. Reg. & Data-Dependent Regularization & $\begin{array}{l}\text { Corduneanu \& Jaakkola } \\
(2006)\end{array}$ \\
\hline LDS & Low-Density Separation & Chapelle \& Zien (2005) \\
\hline Laplacian RLS & $\begin{array}{l}\text { Laplacian Regularized Least Squa- } \\
\text { res }\end{array}$ & Sindhwani et al. (2005) \\
\hline CHM (normed) & Conditional Harmonic Mixing & Burges \& Platt (2006) \\
\hline
\end{tabular}

Nestes experimentos, usamos a Equação (4.15) para construir os grafos a partir das bases de dados, conseqüentemente temos que determinar os valores de três parâmetros, que são $p_{\text {grd }} \mathrm{e} \Delta_{v}$ do algoritmo, e $k$ para construir o grafo. Como os parâmetros dos 13 algoritmos utilizados na comparação foram otimizados para obter os resultados, optamos por otimizar também os parâmetros do método proposto. A otimização é realizada usando o algoritmo genético disponível no Global Optimization Toolbox do MATLAB, com seus parâmetros padrões. Os parâmetros do algoritmo propostos são otimizados dentro da seguinte faixa de valores: $0 \leq p_{\text {grd }} \leq 1 ; 0<\Delta_{v} \leq 1$; e $1 \leq k \leq 100$.

As Tabelas 4.7 e 4.8 reportam a média dos erros de teste dos 13 métodos e do método proposto aplicados às base de dados apresentadas na Tabela 4.5. 
Os valores obtidos para o método proposto são uma média de 100 execuções em cada um dos 12 subconjuntos. As Tabelas 4.7 e 4.8 mostram os erros de teste (\%) com 10 e 100 de pontos de treinamento, respectivamente. Observando estes resultados podemos perceber que o desempenho do método proposto é comparável ao dos métodos do estado da arte e, de maneira interessante, seu desempenho se torna relativamente melhor quando há menos nós rotulados nos dados de treinamento. Esta é uma característica desejável, pois métodos de aprendizado semi-supervisionado tratam justamente de conjuntos de dados com poucos dados rotulados.

Tabela 4.7: Erros de teste (\%) com 10 pontos de dados rotulados.

\begin{tabular}{lrrrrrrr}
\hline & g241c & g241d & Digit1 & USPS & COIL & BCI & Text \\
\hline 1-NN & 47,88 & 46,72 & 13,65 & 16,66 & 63,36 & 49,00 & 38,12 \\
SVM & 47,32 & 46,66 & 30,60 & 20,03 & 68,36 & 49,85 & 45,37 \\
MVU + 1-NN & 47,15 & 45,56 & 14,42 & 23,34 & 62,62 & 47,95 & 45,32 \\
LEM + 1-NN & 44,05 & 43,22 & 23,47 & 19,82 & 65,91 & 48,74 & 39,44 \\
QC + CMN & 39,96 & 46,55 & 9,80 & 13,61 & 59,63 & 50,36 & 40,79 \\
Discrete Reg. & 49,59 & 49,05 & 12,64 & 16,07 & 63,38 & 49,51 & 40,37 \\
TSVM & 24,71 & 50,08 & 17,77 & 25,20 & 67,50 & 49,15 & 31,21 \\
SGT & 22,76 & 18,64 & 8,92 & 25,36 & - & 49,59 & 29,02 \\
Cluster-Kerne1 & 48,28 & 42,05 & 18,73 & 19,41 & 67,32 & 48,31 & 42,72 \\
Data-Dep. Reg. & 41,25 & 45,89 & 12,49 & 17,96 & 63,65 & 50,21 & - \\
LDS & 28,85 & 50,63 & 15,63 & 17,57 & 61,90 & 49,27 & 27,15 \\
Laplacian RLS & 43,95 & 45,68 & 5,44 & 18,99 & 54,54 & 48,97 & 33,68 \\
CHM (normed) & 39,03 & 43,01 & 14,86 & 20,53 & - & 46,90 & - \\
Método Proposto & 43,14 & 43,94 & 11,75 & 17,75 & 58,65 & 47,67 & 34,53 \\
\hline
\end{tabular}

Tabela 4.8: Erros de teste (\%) com 100 pontos de dados rotulados.

\begin{tabular}{lrrrrrrr}
\hline & g241c & g241d & Digit1 & USPS & COIL & BCI & Text \\
\hline 1-NN & 43,93 & 42,45 & 3,89 & 5,81 & 17,35 & 48,67 & 30,11 \\
SVM & 23,11 & 24,64 & 5,53 & 9,75 & 22,93 & 34,31 & 26,45 \\
MVU + 1-NN & 43,01 & 38,20 & 2,83 & 6,50 & 28,71 & 47,89 & 32,83 \\
LEM + 1-NN & 40,28 & 37,49 & 6,12 & 7,64 & 23,27 & 44,83 & 30,77 \\
GC + CMN & 22,05 & 28,20 & 3,15 & 6,36 & 10,03 & 46,22 & 25,71 \\
Discrete Reg. & 43,65 & 41,65 & 2,77 & 4,68 & 9,61 & 47,67 & 24,00 \\
TSVM & 18,46 & 22,42 & 6,15 & 9,77 & 25,80 & 33,25 & 24,52 \\
SGT & 17,41 & 9,11 & 2,61 & 6,80 & - & 45,03 & 23,09 \\
Cluster-Kernel & 13,49 & 4,95 & 3,79 & 9,68 & 21,99 & 35,17 & 24,38 \\
Data-Dep. Reg. & 20,31 & 32,82 & 2,44 & 5,10 & 11,46 & 47,47 & - \\
LDS & 18,04 & 23,74 & 3,46 & 4,96 & 13,72 & 43,97 & 23,15 \\
Laplacian RLS & 24,36 & 26,46 & 2,92 & 4,68 & 11,92 & 31,36 & 23,57 \\
CHM (normed) & 24,82 & 25,67 & 3,79 & 7,65 & - & 36,03 & - \\
Modelo Proposto & 24,20 & 23,93 & 2,65 & 4,99 & 16,48 & 44,38 & 25,03 \\
\hline
\end{tabular}

Nas Tabelas 4.7 e 4.8, observamos que alguns métodos estão entre os melhores para algumas bases de dados, mas ao mesmo tempo, estão entre os 
piores para outras bases de dados. O método proposto é mais balanceado que todos os outros e está bem classificado especialmente nos casos que tem poucos dados rotulados. Isto é, novamente, uma característica interessante porque é normalmente difícil selecionar um método apropriado para um dado conjunto de dados na prática. Para comparar o desempenho médio de todos os algoritmos em todas as bases de dados avaliadas, construímos uma classificação dos métodos em cada base de dados, e pegamos a posição média de cada método. Estas classificações são apresentadas nas Tabelas 4.9 e 4.10 para 10 e 100 pontos de dados de treinamento rotulados, respectivamente. Podemos observar que o método proposto tem a melhor posição média no caso de 10 pontos de dados de treinamento rotulados.

Tabela 4.9: Classificação de métodos de aprendizado semi-supervisionado com 10 pontos de dados rotulados

\begin{tabular}{lrrrrrrrr}
\hline & g241c & g241d & Digit1 & USPS & COIL & BCI & Text & Média \\
\hline 1-NN & 12 & 11 & 7 & 3 & 6 & 7 & 6 & $\mathbf{7 , 4}$ \\
SVM & 11 & 10 & 14 & 10 & 12 & 12 & 12 & $\mathbf{1 1 , 6}$ \\
MVU + 1-NN & 10 & 6 & 8 & 12 & 5 & 3 & 11 & $\mathbf{7 , 9}$ \\
LEM + 1-NN & 9 & 4 & 13 & 9 & 9 & 5 & 7 & $\mathbf{8 , 0}$ \\
QC + CMN & 5 & 9 & 3 & 1 & 3 & 14 & 9 & $\mathbf{6 , 3}$ \\
Discrete Reg. & 14 & 12 & 6 & 2 & 7 & 10 & 8 & $\mathbf{8 , 4}$ \\
TSVM & 2 & 13 & 11 & 13 & 11 & 8 & 3 & $\mathbf{8 , 7}$ \\
SGT & 1 & 1 & 2 & 14 & - & 11 & 2 & $\mathbf{5 , 2}$ \\
Cluster-Kerne1 & 13 & 2 & 12 & 8 & 10 & 4 & 10 & $\mathbf{8 , 4}$ \\
Data-Dep. Reg. & 6 & 8 & 5 & 6 & 8 & 13 & - & $\mathbf{7 , 7}$ \\
LDS & 3 & 14 & 10 & 4 & 4 & 9 & 1 & $\mathbf{6 , 4}$ \\
Laplacian RLS & 8 & 7 & 1 & 7 & 1 & 6 & 4 & $\mathbf{4 , 9}$ \\
CHM (normed) & 4 & 3 & 9 & 11 & - & 1 & - & $\mathbf{5 , 6}$ \\
Modelo Proposto & 7 & 5 & 4 & 5 & 2 & 2 & 5 & $\mathbf{4 , 3}$ \\
\hline
\end{tabular}

Tabela 4.10: Classificação de métodos de aprendizado semi-supervisionado com 100 pontos de dados rotulados

\begin{tabular}{lrrrrrrrr}
\hline & g241c & g241d & Digit1 & USPS & COIL & BCI & Text & Média \\
\hline 1-NN & 14 & 14 & 11 & 6 & 7 & 14 & 10 & $\mathbf{1 0 , 9}$ \\
SVM & 7 & 6 & 12 & 13 & 9 & 3 & 9 & $\mathbf{8 , 4}$ \\
MVU + 1-NN & 12 & 12 & 5 & 8 & 12 & 13 & 12 & $\mathbf{1 0 , 6}$ \\
LEM + 1-NN & 11 & 11 & 13 & 10 & 10 & 8 & 11 & $\mathbf{1 0 , 6}$ \\
OC + CMN & 6 & 9 & 7 & 7 & 2 & 10 & 8 & $\mathbf{7 , 0}$ \\
Discrete Reg. & 13 & 13 & 4 & 1 & 1 & 12 & 4 & $\mathbf{6 , 9}$ \\
TSVM & 4 & 3 & 14 & 14 & 11 & 2 & 6 & $\mathbf{7 , 7}$ \\
SGT & 2 & 2 & 2 & 9 & - & 9 & 1 & $\mathbf{4 , 2}$ \\
Cluster-Kernel & 1 & 1 & 9 & 12 & 8 & 4 & 5 & $\mathbf{5 , 7}$ \\
Data-Dep. Reg. & 5 & 10 & 1 & 5 & 3 & 11 & - & $\mathbf{5 , 8}$ \\
LDS & 3 & 4 & 8 & 3 & 5 & 6 & 2 & $\mathbf{4 , 4}$ \\
Laplacian RLS & 9 & 8 & 6 & 1 & 4 & 1 & 3 & $\mathbf{4 , 6}$ \\
CHM (normed) & 10 & 7 & 9 & 11 & - & 5 & - & $\mathbf{8 , 4}$ \\
Método Proposto & 8 & 5 & 3 & 4 & 6 & 7 & 7 & $\mathbf{5 , 7}$ \\
\hline
\end{tabular}




\subsubsection{Saída Nebulosa e Detecção de Outliers}

Uma comunidade em uma rede é definida como um subgrafo cujos nós são densamente conectados internamente, mas esparsamente conectados com o restante da rede. Porém, na prática há muitos casos onde alguns nós na rede podem pertencer a mais de uma comunidade. Por exemplo, em uma rede social de amizades, indivíduos freqüentemente pertencem a várias comunidades: a comunidade de suas famílias, a comunidade de seus colegas de trabalho, a comunidade de seus colegas de classe, etc. Estes nós sobrepostos normalmente tem especial importância para conectar diferentes comunidades. Conseqüentemente, descobrir a estrutura sobreposta de redes se torna um tópico importante em mineração de dados (Zhang et al., 2007a; Palla et al., 2005; Zhang et al., 2007b). A estrutura de sobreposição caracteriza os níveis nos quais cada item de dado pertence a cada classe e, portanto, é chamada graus de crença da propagação de dados.

Em princípio, a maioria dos métodos de aprendizado semi-supervisionados baseado em grafos são de fato estimadores de funções, ou seja, eles estimam valores contínuos para os rótulos antes de fazer a classificação (Zhu, 2005), mas há pouco estudo para verificar se tais valores realmente correspondem a estrutura de sobreposição real, e este valores acabam sendo usados somente para fornecer os rótulos discretos. Por exemplo, o método apresentado na Seção 4.2.1 é capaz de fornecer rótulos contínuos, isto é apenas uma questão de pular o último passo do algoritmo, mas estes rótulos contínuos não correspondem a estrutura de sobreposição real. Com o objetivo de detectar a estrutura de sobreposição ou grau de crença da propagação de rótulos, introduzimos algumas modificações no modelo apresentado na Seção 4.2.1, tornando-o capaz de fornecer saída nebulosa (contínua), que corresponde aos níveis reais de pertinência de cada nó para cada classe. Em outras palavras, aqui incorporamos algumas características do modelo de aprendizado não-supervisionado apresentado na Seção 4.1.1 ao modelo de aprendizado semi-supervisionado apresentado na Seção 4.2.1, de forma que este último também possa detectar comunidades sobrepostas, mas mantendo toda a dinâmica peculiar inerente ao aprendizado semi-supervisionado.

À primeira vista, os níveis de domínio dos nós $\mathbf{v}_{\mathbf{i}}^{\omega}(\mathbf{t})$, introduzidos na Seção 4.2.1 (os quais chamaremos aqui de níveis de domínio instantâneos), parecem ser escolhas naturais para as saídas nebulosas (graduais) dos nós, pois indicam os níveis de domínio de cada time (classe) sobre cada nó quantificado em termos de valores contínuos em $[0,1]$. Porém, os níveis de domínio instantâneo são bastante voláteis em certas condições. Por exemplo, o time dominante de um nó não sobreposto após a última iteração normalmente é aquele que dominou o nó em todas ou na grande maioria das iterações, mas isto pode não 
acontecer para nós sobrepostos, nos quais o time dominante muda freqüentemente, e assim o time dominante após a última iteração pode não corresponder ao time que dominou o nó por mais tempo. Além disso, devido ao efeito da competição, o nível de domínio instantâneo do time dominante é bastante amplificado e não corresponde ao nível real de sobreposição.

Para evitar este problema, um novo vetor variável chamado níveis de domínio acumulados é introduzido. Ele representa a média temporal dos níveis de domínio para cada time e cada nó. Estes níveis de domínio acumulados iniciam em zero e aumentam toda vez que um nó é escolhido como alvo por uma partícula que escolheu a regra de movimento aleatória. A partícula irá aumentar seu nível de domínio acumulado, mas não irá mudar os níveis de outros times. Não há um limite superior e o crescimento é sempre proporcional à força da partícula. Note que os níveis de domínio acumulados não mudam quando a regra de movimento guloso é escolhida, caso contrário ela iria amplificar a vantagem da partícula dominante, o que não é desejável. A nova variável não tem qualquer efeito na dinâmica do sistema (que permanece a mesma já descrita na Seção 4.2.1) e é usada apenas para aproveitar as informações temporais do sistema para fornecer os rótulos nebulosos no final. Mais uma vez podemos usar a analogia de que o time campeão não será aquele que ganhou os últimos jogos, mas sim aquele que ganhou mais jogos durante o campeonato todo.

Os níveis de domínio acumulados são definidos como $\mathbf{v}_{\mathbf{i}}^{\lambda}$, que é um vetor $\mathbf{v}_{\mathbf{i}}^{\lambda}(\mathbf{t})=\left\{v_{i}^{\lambda_{1}}(t), v_{i}^{\lambda_{2}}(t), \ldots, v_{i}^{\lambda_{c}}(t)\right\}$ do mesmo tamanho de $L$, e $v_{i}^{\lambda_{\ell}}(t) \in\left[\begin{array}{ll}0 & \infty\end{array}\right]$ representa o nível de domínio acumulado do time $\ell$ sobre o nó $v_{i}$. Á cada iteração, para cada nó selecionado $v_{i}$ (com o movimento aleatório), o nível de domínio acumulado $v_{i}^{\lambda_{\ell}}(t)$ é atualizado da seguinte forma:

$$
v_{i}^{\lambda_{\ell}}(t+1)=v_{i}^{\lambda_{\ell}}(t)+\rho_{j}^{\omega}(t)
$$

onde $\ell$ é o rótulo de classe da partícula $\rho_{j}$. A Equação (4.25) mostra que a atualização dos níveis de domínio acumulado $v_{i}^{\lambda_{\ell}}(t+1)$ é proporcional à força da partícula atual $\rho_{j}^{\omega}(t)$. Esta é uma característica desejável porque a partícula provavelmente terá uma força maior quando estiver chegando de sua própria vizinhança, e terá uma força menor quando estiver chegando da vizinhança de outros times.

Após a última iteração, os graus de pertinência $f_{i}^{\ell} \in\left[\begin{array}{ll}0 & 1\end{array}\right]$ correspondentes a cada nó $v_{i}$ são calculados usando o nível de domínio acumulado, como segue:

$$
f_{i}^{\ell}=\frac{v_{i}^{\lambda_{\ell}}(\infty)}{\sum_{q=1}^{c} v_{i}^{\lambda_{q}}(\infty)}
$$

onde $f_{i}^{\ell}$ representa o nível final de pertinência do nó $v_{i}$ à comunidade $\ell$. 
Baseado nos graus de pertinência (saída nebulosa), formamos uma medida de sobreposição para ilustrar a aplicação do algoritmo. Conseqüentemente, o índice de sobreposição $o_{i}$ para um nó $v_{i}$ é definido como $o_{i}=\frac{f_{i}^{\ell * *}}{f_{i}^{\ell * *}}$, onde $\ell *=\arg \max _{\ell} f_{i}^{\ell} \mathrm{e} \ell * *=\arg \max _{\ell, \ell \neq \ell *} f_{i}^{\ell}$, ou seja, o maior e o segundo maior grau de pertinência do nó, respectivamente; e $o_{i} \in\left[\begin{array}{ll}0 & 1\end{array}\right]$, onde $o_{i}=0$ significa total confiança de que o nó pertence a uma única comunidade, enquanto $o_{i}=1$ significa que o nó está completamente indefinido sendo compartilhado entre duas ou mais comunidades.

Agora apresentamos alguns resultados de simulação para avaliar a eficácia destas modificações. Os grafos são construídos a partir das bases de dados utilizando a Equação (4.14), com o parâmetro $\sigma$ sendo selecionado empiricamente para cada problema, ou seja, um conjunto de simulações é executado variando $\sigma$ e o valor que levar ao melhor resultado é escolhido. Os parâmetros do algoritmo nesta versão modificada são menos sensíveis que na versão original, e conseqüentemente eles são ajustados empiricamente para $\Delta_{v}=0,1 \mathrm{e}$ $p_{\text {grd }}=0,5$ para todos os experimentos desta subseção.

As Figuras 4.11a, 4.11b, e 4.11c mostram os resultados fornecidos pelo método proposto com as modificações explicadas acima quando aplicado a três problemas com duas classes em forma de banana geradas usando a função gendatb do PRTools (Duin et al., 2007) com 1.000 elementos cada (500 por classe) e diferentes parâmetros de variância $s=\{0,6 ; 0,8 ; 1,0\}$. Para cada conjunto de dados, 50 elementos $(5 \%)$ foram selecionados aleatoriamente para formar o subconjunto rotulado. O tamanho dos nós no gráfico são proporcionais a seus respectivos índices de sobreposição. Observamos que há mais nós sobrepostos e que os níveis de sobreposição são maiores conforme as classes se tornam mais misturadas. Esta situação combina com os resultados obtidos através de inspeção visual direta.

A Figura 4.12a mostra um conjunto de dados com 4 classes com distribuição Gaussiana, gerado usando a função gendats do PRTools (Duin et al., 2007) com 1.000 elementos (250 por classe) e 20 deles são rotuladas (5 por classe), representados por quadrados vermelhos, triângulos azuis, losangos verdes e estrelas púrpuras. A versão modificada do algoritmo é aplicada para o conjunto de dados e os índices de sobreposição detectados são mostrados na Figura $4.12 \mathrm{~b}$. Observamos que os nós no interior de cada classe são pequenos e com tom azul escuro, ou seja, são claramente nós não-sobrepostos. Ao mesmo tempo, os nós nas bordas entre as classes têm tonalidades e tamanhos que representam seus diferentes níveis de sobreposição. Estes resultados, novamente, estão de acordo com nossa intuição.

Com relação à Figura 4.12a, observamos que há um triângulo azul no espaço da classe quadrado vermelho, que é claramente um outlier. Porém, ele 


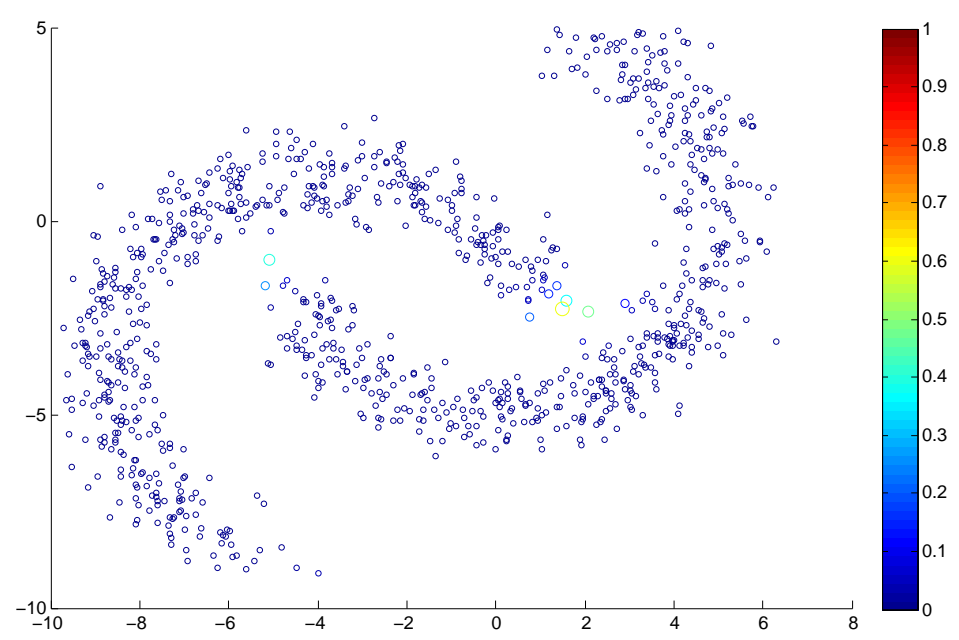

(a)

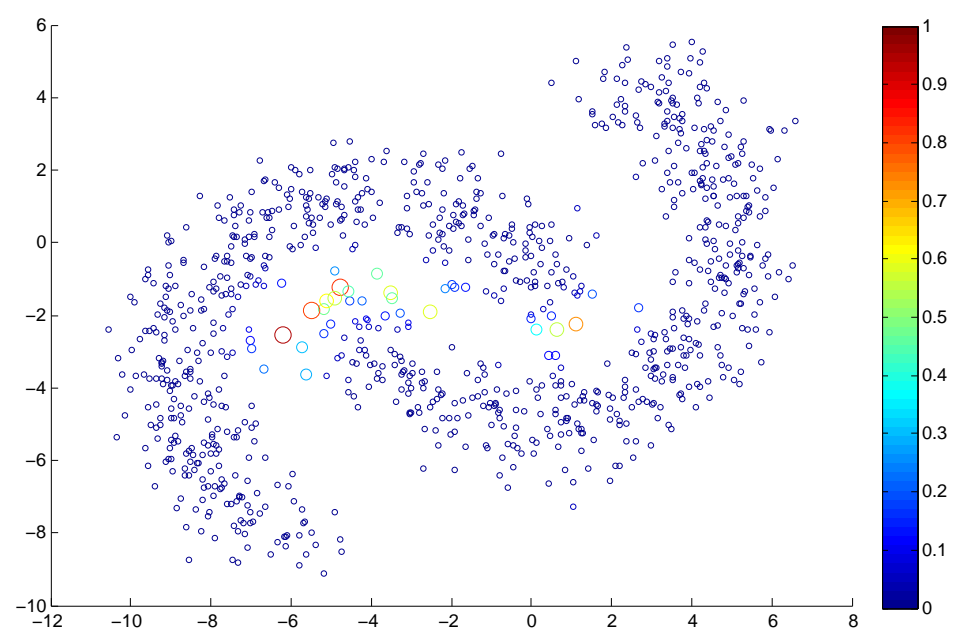

(b)

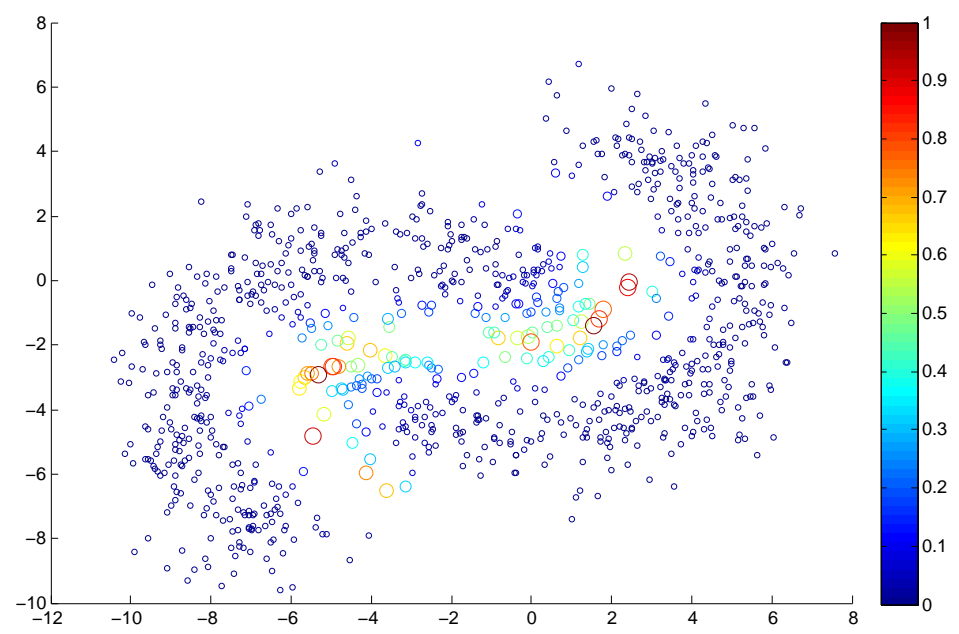

(c)

Figura 4.11: Classificação nebulosa de duas classes em forma de banana geradas com diferentes parâmetros: (a) $s=0,6$; (b) $s=0,8$; (c) $s=1.0$. Os tamanhos e as cores dos nós representam seus respectivos índices de sobreposição detectados pelo método proposto. 


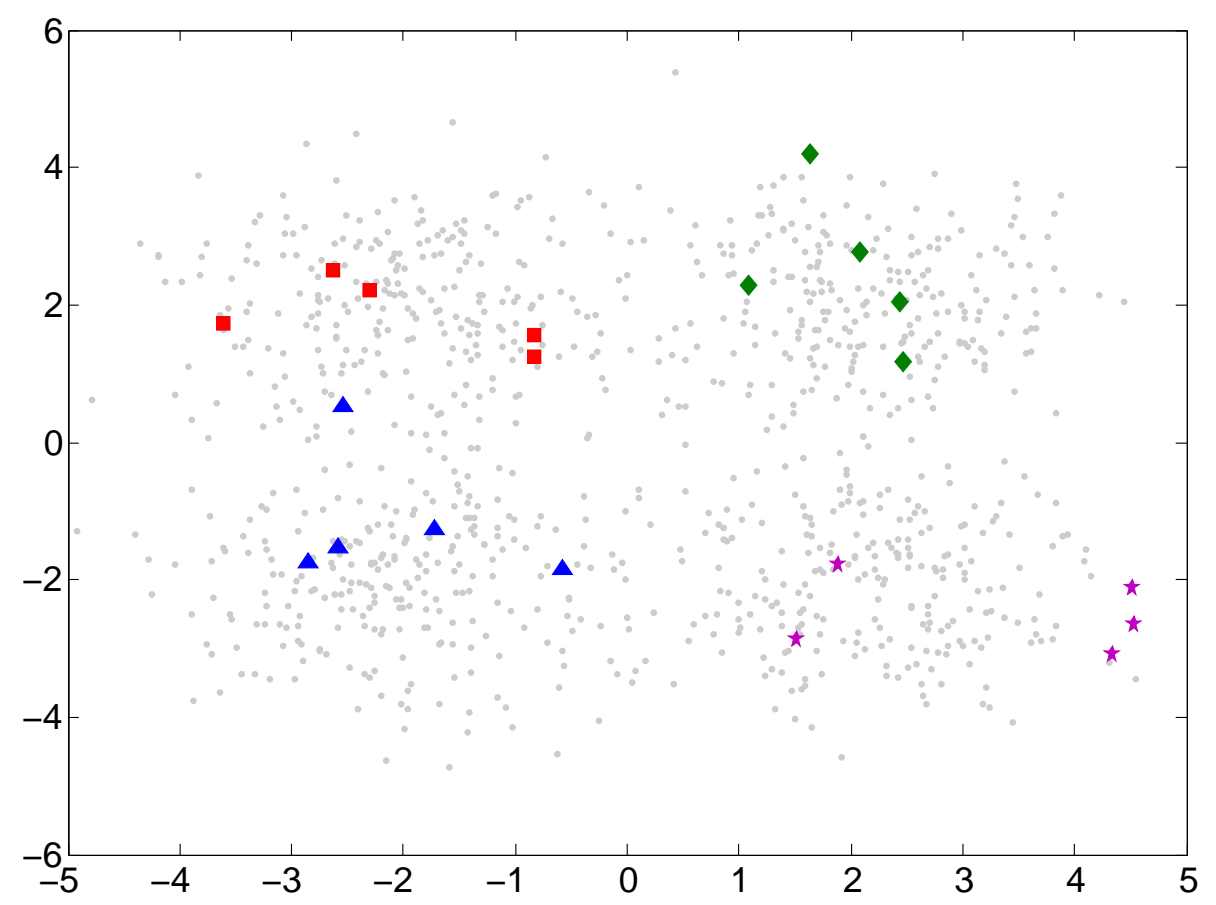

(a)

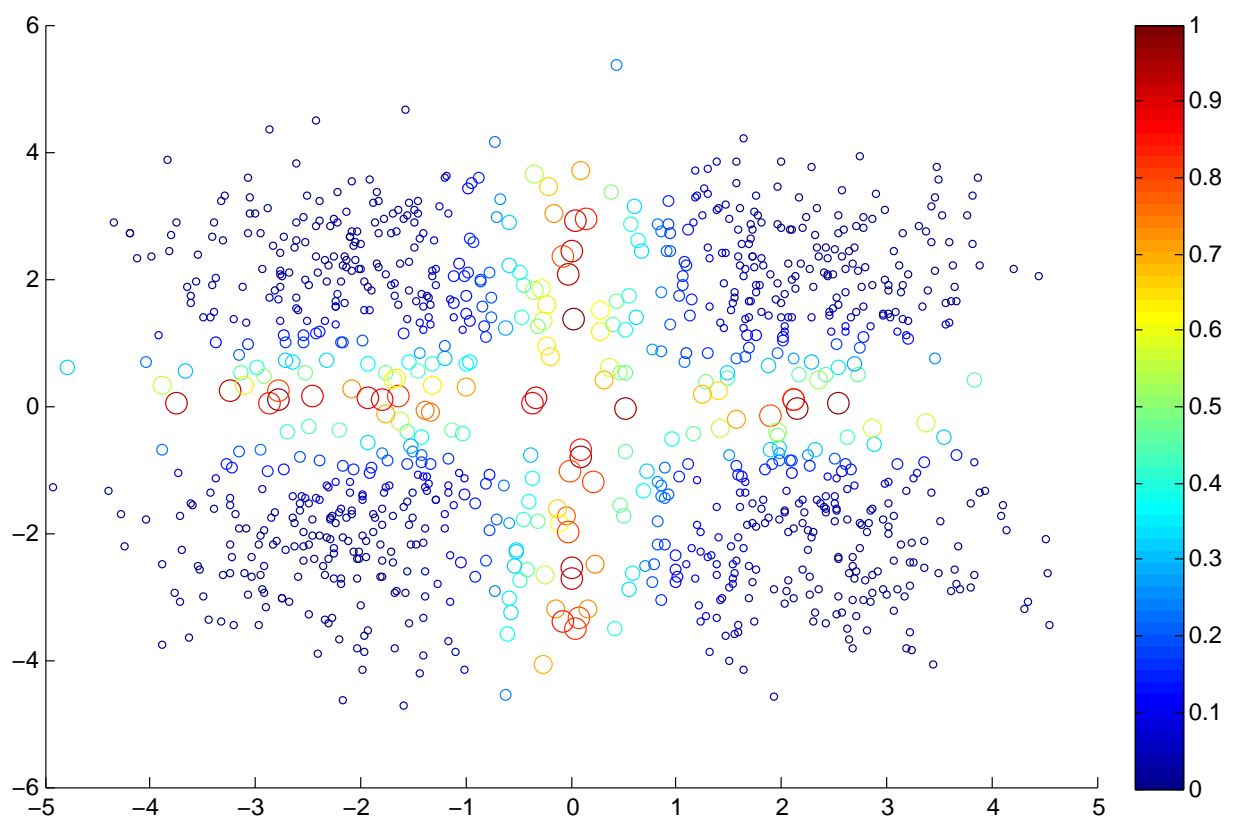

(b)

Figura 4.12: Classificação de classes com distribuição normal (distribuição Gaussiana): (a) base de dados artificial com 1.000 amostras divididas em quatro classes, 20 amostras são rotuladas, 5 de cada classe (quadrados vermelhos, triângulos azuis, losangos verdes, e estrelas púrpuras); (b) tamanhos e cores dos nós representam seus respectivos índices de sobreposição detectados pelo método proposto. 
não altera o índice de sobreposição dos nós em torno dele. Isto significa que uma partícula, cujo nó-casa é um outlier, tem dificuldade para defender sua vizinhança, pois ele está muito longe de seus companheiros de equipe e recebe pouca ou nenhuma ajuda deles. Uma partícula cujo nó-casa é um outlier pode eventualmente abandonar sua casa, se sua vizinhança for dominada por outro time. Neste caso, ela pode migrar para a vizinhança de um de seus colegas de equipe mais próximos. Apesar de um outlier poder eventualmente modificar um pouco os níveis de domínio instantâneos $\left(v_{i}^{\omega}(t)\right)$ de seus vizinhos, ele tem um efeito muito fraco nos níveis de domínio acumulados $\left(v_{i}^{\lambda}(t)\right)$ de sua vizinhança. Portanto, em base de dados onde outliers estão presentes, podemos obter resultados de classificação melhores derivando os rótulos absolutos dos rótulos nebulosos obtidos com os níveis de domínio acumulados, em vez dos níveis de domínio instantâneos usados nos experimentos de classificação anteriores. Neste caso, os rótulos dos itens não rotulados são definidos da seguinte forma:

$$
y_{i}=\arg \max _{\ell} f_{i}^{\ell}
$$

ou seja, o item receberá o rótulo da partícula que tiver o maior nível de domínio acumulado no respectivo nó.

Note que os níveis de domínio instantâneos são fixos para nós rotulados, mas os níveis de domínio acumulados não são. Portanto, através dos níveis de domínio acumulados, um nó rotulado pode ser reclassificado se for um outlier. Para demonstrar estas características, realizamos simulações nos dados artificiais apresentados pela Figura 4.13a, onde há 2.000 elementos distribuídos em duas classes em forma de banana (1.000 elementos por classe), 100 (5\%) deles são rotulados (círculos vermelhos e quadrados azuis), porém, 10 destes nós rotulados têm o rótulo errado, representando outliers. A Figura 4.13b mostra a classificação obtida pelo método apresentado na Seção 4.2.1, onde observamos que os nós com rótulo errado (outliers) e alguns vizinhos destes são classificados na classe errada. Por outro lado, a Figura 4.13c mostra a classificação pelo mesmo método com as modificações introduzidas nesta seção e os rótulos definidos pela Equação (4.27). Neste caso, observamos que os nós com rótulos errados não afetam a classificação de seus vizinhos e os próprios outliers são eventualmente reclassificados para suas respectivas classes corretas.

Finalmente, o algoritmo modificado é aplicado em uma base de dados do mundo real: a Rede do Clube de Caratê de Zachary (Zachary, 1977). A base de dados é apresentada ao algoritmo com apenas dois nós rotulados: 1 e 34, cada um representando uma classe diferente. Os resultados são mostrados na Figura 4.14, e o índice de sobreposição de cada nó é indicado por seus respectivos tamanhos e cores. Nossa inspeção visual indica que este também 


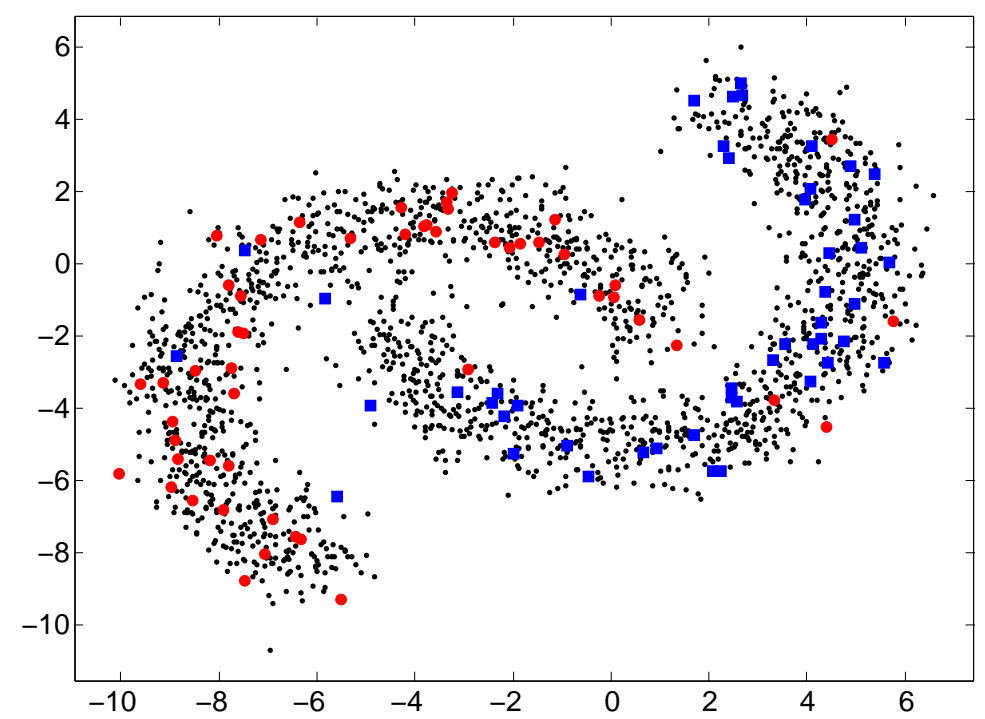

(a)

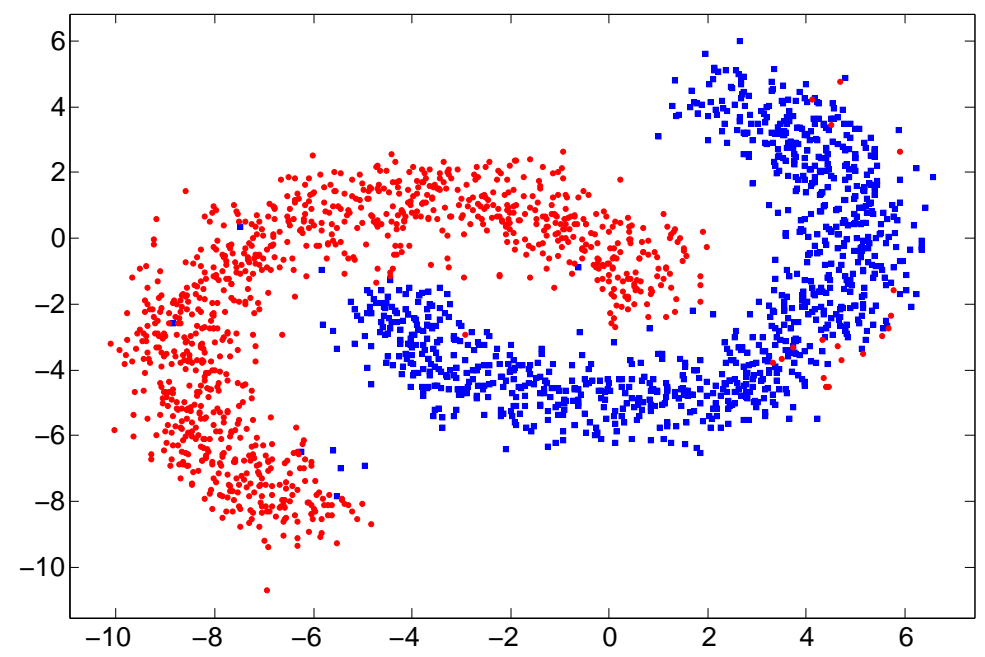

(b)

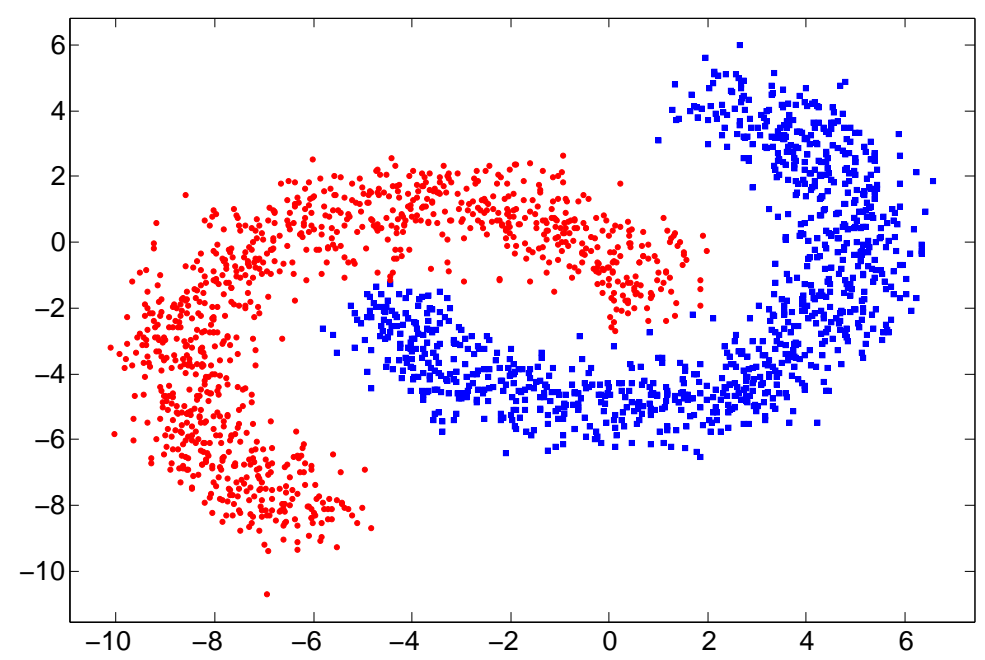

(c)

Figura 4.13: Comparativo entre o modelo padrão e o modificado: (a) conjunto de dados artificiais com alguns nós com rótulo errado; (b) classificação pelo método de partículas padrão; (c) classificação pelo modelo de partículas modificado. 


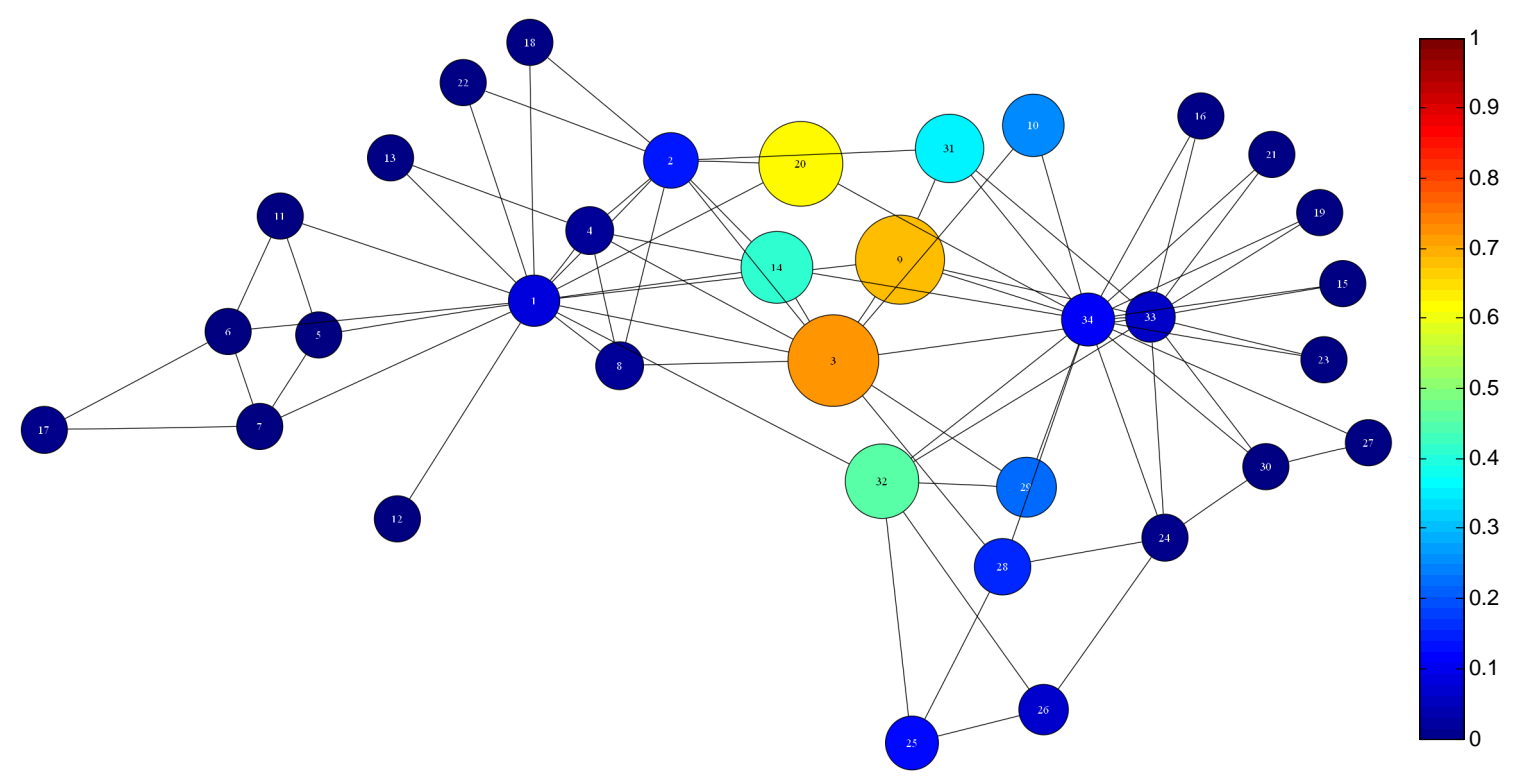

Figura 4.14: A Rede do Clube de Caratê de Zachary (Zachary, 1977). Tamanhos e cores dos nós representam seus respectivos índices de sobreposição detectados pelo método proposto.

é um bom resultado. Note que apesar dos dois nós rotulados exibirem algum grau de sobreposição, o algoritmo ainda produz um bom resultado, até mesmo detectando aqueles graus de sobreposição nos nós rotulados (note o tamanho um pouco maior e o tom azul um pouco mais claro). Isto também é uma característica desejável, pois não precisamos escolher nós não-sobrepostos para representar uma classe.

\subsubsection{Aplicação em Dados Biológicos}

Nesta subseção são mostrados os resultados da aplicação do método proposto em uma base de dados biológicos, especificamente a base de dados Yeast do UCI Machine Learning Repository (Asuncion \& Newman, 2007), a qual se refere a predição da localização celular de proteínas de levedura. Existem 10 diferentes posições (classes), que são ${ }^{3}$ : CYT (citosólica ou citoesquelética), NUC (nuclear), MIT (mitocondrial), ME3 (proteína de membrana, sem sinal Ntérmino), ME2 (proteína de membrana, sinal não-clivado), ME1 (proteína de membrana, sinal clivado), EXC (extra-celular), VAC (vacuolar), POX (peroxisomal) and ERL (lúmen do retículo endoplasmático). Esta base de dados possui 1484 elementos e 8 atributos. Os dados são bastante ruidosos e são um desafio até mesmo para métodos de classificação supervisionada que utilizam até $2 / 3$ dos dados para treinamento, obtendo classificações corretas para apenas

3 As siglas são derivadas das localizações celulares no original em inglês: CYT (cytosolic ou cytoskeletal), NUC (nuclear), MIT (mitochondrial), ME3 (membrane protein, no N-terminal signal), ME2 (membrane protein, uncleaved signal), ME1 (membrane protein, cleaved signal), EXC (extracellular), VAC (vacuolar), POX (peroxisomal) e ERL (endoplasmic reticulum lumen). 
cerca de $50 \%$ a $60 \%$ das amostras (Horton \& Nakai, 1997; Athitsos \& Sclaroff, 2004; Pavlov et al., 2003; Allwein et al., 2001).

Devido ao ruído alto nos dados, optamos por utilizar a versão modificada do Algoritmo 4.2, ou seja, incorporando as modificações propostas na Seção 4.2.4 e obtendo os rótulos com a Equação 4.27. Para comparação, aplicamos aos mesmos dados outros três métodos de aprendizado semi-supervisionado: o método de Consistência Local e Global ${ }^{4}$ (GLC) (Zhou et al., 2004), o método de Propagação de Rótulos ${ }^{5}$ (LP) (Zhu \& Ghahramani, 2002) e o método de Propagação de Rótulos Através de Vizinhanças Lineares ${ }^{6}$ (LNP) (Wang \& Zhang, 2006, 2008). Das 1484 amostras da base de dados, escolhemos aleatoriamente 100 delas para compor nosso subconjunto de treinamento, com a única restrição de que deve haver pelo menos uma amostra de cada classe nesse subconjunto. Tal procedimento foi repetido 34 vezes, de forma que foram obtidos 34 subconjuntos de treinamento distintos, e os quatro métodos foram aplicados a cada um dos subconjuntos. Os parâmetros do método proposto foram otimizados dentro da seguinte faixa de valores: $0 \leq p_{\text {grd }} \leq 1 ; 0<\Delta_{v} \leq 1$; e $1 \leq k \leq 100$. Nos métodos GLC e LP foi otimizado o parâmetro $0<\sigma \leq 100$ e no método LNP foi otimizado o parâmetro $1 \leq k \leq 100$. Nos métodos GLC e LNP o parâmetro $\alpha=0,99$ foi mantido fixo. As otimizações foram realizadas utilizando o algoritmo genético disponível no Global Optimization Toolbox do MATLAB, com seus parâmetros padrões. Como o método proposto é nãodeterminístico, para cada subconjunto o experimento é repetido 200 vezes, com os mesmos parâmetros otimizados, para obter a média. As taxas de classificação corretas obtidas por cada algoritmo são mostrados na Tabela 4.11, e o método proposto (MP) apresentou o melhor resultado para todos os subconjuntos, exceto o terceiro. Além disso, a taxa obtida pelo método proposto com apenas 100 amostras rotuladas é comparável à obtida por algoritmos de aprendizado supervisionado com muito mais dados de treinamento.

\footnotetext{
4 do inglês: Local and Global Consistency

5 do inglês: Label Propagation

6 do inglês: Label Propagation through Linear Neighborhoods
} 
Tabela 4.11: Taxa de classificação correta dos algoritmos de aprendizado semi-supervisionado aplicados a base de dados Yeast (Asuncion \& Newman, 2007).

\begin{tabular}{ccccc}
\hline Subconj. & GLC & LP & LNP & MP \\
\hline 1 & 0,5130 & 0,4957 & 0,4097 & $\mathbf{0 , 5 2 8 0}$ \\
2 & 0,5058 & 0,4884 & 0,3829 & $\mathbf{0 , 5 4 7 1}$ \\
3 & $\mathbf{0 , 5 4 1 2}$ & 0,5390 & 0,4003 & 0,5361 \\
4 & 0,4277 & 0,4422 & 0,3721 & $\mathbf{0 , 5 4 4 6}$ \\
5 & 0,4263 & 0,4364 & 0,4314 & $\mathbf{0 , 4 6 8 7}$ \\
6 & 0,5137 & 0,4827 & 0,4328 & $\mathbf{0 , 5 5 4 7}$ \\
7 & 0,4776 & 0,4436 & 0,3829 & $\mathbf{0 , 5 5 7 7}$ \\
8 & 0,5051 & 0,5000 & 0,3721 & $\mathbf{0 , 5 4 3 3}$ \\
9 & 0,5123 & 0,5419 & 0,4039 & $\mathbf{0 , 5 4 2 6}$ \\
10 & 0,3634 & 0,5116 & 0,3461 & $\mathbf{0 , 5 2 5 3}$ \\
11 & 0,4848 & 0,4545 & 0,3439 & $\mathbf{0 , 5 4 3 4}$ \\
12 & 0,4762 & 0,4552 & 0,3251 & $\mathbf{0 , 5 5 5 1}$ \\
13 & 0,4978 & 0,4632 & 0,3671 & $\mathbf{0 , 5 4 7 4}$ \\
14 & 0,4964 & 0,4790 & 0,4191 & $\mathbf{0 , 5 1 5 0}$ \\
15 & 0,5332 & 0,5014 & 0,3194 & $\mathbf{0 , 5 6 8 8}$ \\
16 & 0,5137 & 0,4682 & 0,3772 & $\mathbf{0 , 5 5 7 4}$ \\
17 & 0,4993 & 0,4971 & 0,3425 & $\mathbf{0 , 5 5 6 4}$ \\
18 & 0,5007 & 0,5072 & 0,4740 & $\mathbf{0 , 5 5 9 5}$ \\
19 & 0,5462 & 0,5426 & 0,3909 & $\mathbf{0 , 5 5 6 0}$ \\
20 & 0,5311 & 0,4899 & 0,3938 & $\mathbf{0 , 5 5 5 8}$ \\
21 & 0,4863 & 0,4993 & 0,4212 & $\mathbf{0 , 5 1 4 2}$ \\
22 & 0,5224 & 0,4855 & 0,3902 & $\mathbf{0 , 5 5 3 4}$ \\
23 & 0,4082 & 0,5202 & 0,3829 & $\mathbf{0 , 5 5 3 2}$ \\
24 & 0,4790 & 0,4704 & 0,3237 & $\mathbf{0 , 5 6 2 1}$ \\
25 & 0,5152 & 0,4978 & 0,4314 & $\mathbf{0 , 5 3 9 7}$ \\
26 & 0,5296 & 0,5181 & 0,4379 & $\mathbf{0 , 5 4 1 4}$ \\
27 & 0,3620 & 0,4978 & 0,3909 & $\mathbf{0 , 5 6 8 7}$ \\
28 & 0,4870 & 0,4884 & 0,3786 & $\mathbf{0 , 5 6 0 4}$ \\
29 & 0,4617 & 0,4653 & 0,3829 & $\mathbf{0 , 4 8 5 9}$ \\
30 & 0,5282 & $\mathbf{0 , 5 4 1 9}$ & 0,4039 & 0,5410 \\
31 & 0,5311 & 0,5072 & 0,3873 & $\mathbf{0 , 5 3 3 5}$ \\
32 & 0,3945 & 0,5195 & 0,4220 & $\mathbf{0 , 5 6 2 4}$ \\
33 & 0,5181 & 0,5007 & 0,3851 & $\mathbf{0 , 5 4 4 9}$ \\
34 & 0,5137 & 0,5058 & 0,3931 & $\mathbf{0 , 5 1 9 6}$ \\
\hline Média & $\mathbf{0 , 4 8 8 3}$ & $\mathbf{0 , 4 9 2 9}$ & $\mathbf{0 , 3 8 8 8}$ & $\mathbf{0 , 5 4 2 5}$ \\
\hline & & & &
\end{tabular}




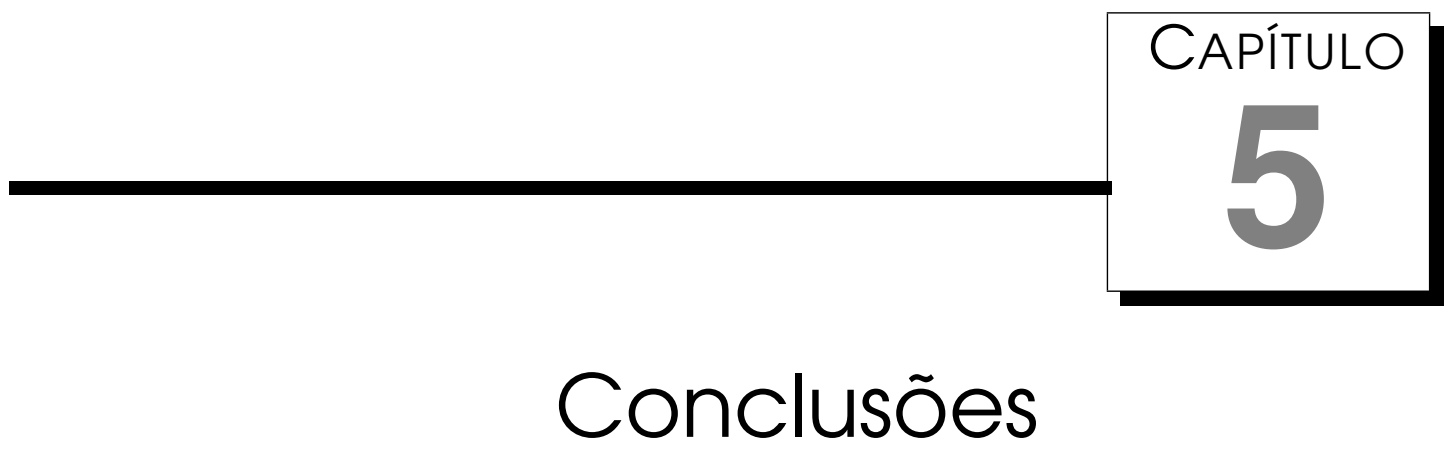

Neste trabalho, foram estudadas diversas formas de aprendizado de máquina, com foco nas categorias de aprendizado não supervisionado e semisupervisionado, com o objetivo de criar novas técnicas que pudessem ser aplicadas em redes complexas, e que pudessem contornar algumas limitações dos modelos existentes, como a detecção de classes ou grupos de formas irregulares, e a detecção de classes ou grupos sobrepostos. O Capítulo 2 mostra uma revisão sobre redes complexas, apresenta as principais técnicas de aprendizado não supervisionado e de aprendizado semi-supervisionado e faz uma pequena revisão sobre sistemas dinâmicos e sincronização.

No Capítulo 3 são apresentados dois modelos baseados em sistemas dinâmicos e sincronização por fase entre osciladores caóticos organizados em reticulado. Tais modelos foram desenvolvidos de forma incremental, e foram aplicados em tarefas de atenção visual, que é parte essencial de muitos sistemas de visão computacional. Iniciamos com o estudo do modelo dinâmico de agrupamento de dados proposto por Zhao et al. (2004), que utiliza sincronização completa entre osciladores acoplados. Com base em tal estudo foi construído um modelo de segmentação de imagens (Zhao \& Breve, 2008) utilizando sincronização completa entre osciladores Wilson-Cowan acoplados e dispostos em uma grade bi-dimensional, cada oscilador representando um pixel da imagem. Este modelo foi posteriormente estendido para realizar tarefas de atenção visual (Zhao et al., 2007; Quiles et al., 2007a), capaz de selecionar um de vários objetos de interesse em uma imagem de entrada, além de ser capaz de trocar o foco de um objeto para outro. Tal modelo se utiliza das propriedades do caos e da sincronização caótica para separar os objetos que compõe a cena de entrada, e também inclui um mecanismo de inibição res- 
ponsável por destacar o objeto mais saliente. Outra característica interessante deste modelo é a mudança de comportamento quando o objeto recebe o foco de atenção. Neste caso, o comportamento previamente caótico dá lugar a uma trajetória com fase fixa, que já foi observada em experimentos de reconhecimento de padrões feitos com coelhos (Skarda \& Freeman, 1987). Simulações computacionais foram realizadas para checar a viabilidade do mecanismo de seleção e mostraram que este é um mecanismo promissor para sistemas de atenção visual.

O próximo passo foi substituir a sincronização completa pela sincronização por fase, que é mais robusta e requer uma força de acoplamento menor. Para isso estudamos os osciladores de Rössler (Rössler, 1976) e suas condições de sincronização. Além disso, tal substituição é particularmente interessante porque vários modelos de atenção visual já foram propostos utilizando sincronização completa entre osciladores para representar objetos (Wang, 1999; Kazanovich \& Borisyuk, 2002; Quiles et al., 2007b), mas o fenômeno de sincronização observado em experimentos reais raramente representa uma sincronização completa, pois esta só é possivel entre subsistemas idênticos, o que não acontece na natureza. Por outro lado, a sincronização por fase pode ser observada entre subsistemas não idênticos, e acredita-se que ela possa ser o mecanismo chave para integração de neurônios no cérebro (Varela et al., 2001). Tal estudo resultou no modelo apresentado na Seção 3.2, que utiliza uma grade de osciladores Rössler acoplados, cada um representando um pixel da imagem. Os osciladores estão inicialmente em regime caótico, sendo que osciladores pertencendo ao mesmo objeto sincronizam por fase entre si, podendo manter amplitudes não correlacionadas, ao mesmo tempo em que osciladores de objetos diferentes diferem em fase. A atenção é caracterizada por uma mudança de comportamento nos osciladores correspondentes ao objeto selecionado, passando do regime caótico para um regime periódico, ao mesmo tempo em que a freqüência é aumentada. Este modelo tem como vantagem requerer uma força de acoplamento menor, sem risco de divergência para o infinito que ocorre quando uma força de acoplamento muito alta é usada. Por outro lado, na sincronização completa os diferentes objetos são identificados rapidamente devido as diferentes trajetórias caóticas, mas na sincronização por fase a amplitude não é levada em consideração, então é necessário mais tempo para detectar que os objetos se dessincronizaram em fase.

Com o objetivo de resolver este problema, além de introduzir outras melhorias para aperfeiçoar o método, foi desenvolvido o novo modelo (Breve et al., 2009c,d) que é apresentado na Seção 3.3, que é semelhante ao anterior, porém neste caso a segmentação ocorre em paralelo com o processo de atenção. Do ponto de vista biológico, este modelo é mais plausivel, pois apenas o ob- 
jeto que recebe atenção terá seus correspondentes osciladores sincronizados, enquanto que os demais objetos terão seus correspondentes osciladores dessincronizados. Além disso, o objeto considerado saliente é aquele que tem maior contraste de cores e intensidade com relação a outras partes da imagem, ao contrário dos modelos anteriores que utilizavam apenas a intensidade absoluta. Esta melhoria tem suporte direto de experimentos biológicos que mostram que o contraste entre atributos é mais importante que o valor absoluto dos mesmos quando tarefas de busca visual são realizadas em sistemas visuais biológicos (Wolfe \& Horowitz, 2004; Yantis, 2005). Este modelo foi desenvolvido em duas etapas, sendo que o modelo preliminar (Breve et al., 2009d) não incluía o mecanismo de mudança de foco, que foi implementado posteriormente (Breve et al., 2009c). Mais simulações foram realizadas com imagens artificiais e reais e bons resultados foram obtidos, tanto com o mecanismo de mudança de foco ativado, quanto com ele desativado. Como já citado, este modelo e seus antecessores são pioneiros na utilização de sincronização por fase entre osciladores caóticos acoplados para tarefas de atenção visual, aproveitando a característica de requerer uma menor força de acoplamento para obter a sincronização, tornando possivel a sincronização de uma maior quantidade de osciladores sem que o sistema diverja para o infinito. Destaca-se também a possibilidade de sincronizar osciladores não-idênticos, como acontece em sistemas biológicos. Estas características permitem lidar com imagens do mundo real relativamente complexas, como foi visto nas simulações apresentadas. Outra contribuição importante é a combinação do sistema de segmentação das imagens e do sistema de atenção visual em um único sistema, diferentemente do que ocorre em vários outros modelos de atenção visual onde as etapas são separadas.

Apesar da aplicação com sucesso dos modelos baseados em osciladores no domínio de atenção visual, utilizando acoplamento adaptativo em forma de reticulado, não foi possível estendê-lo para tratar problemas genéricos de classificação ou agrupamento em redes de formas gerais. As principais dificuldades encontradas estão relacionadas com a questão da sincronização, que tem maior probabilidade de ocorrer entre osciladores mais similares. Porém é difícil definir as características de um oscilador a priori, sem ter que utilizar hipóteses quanto a seu grupo ou classe. Criar osciladores Rössler com características iguais faz com que eles tenham comportamentos semelhantes e, mesmo tendo trajetórias caóticas diferentes por conta de uma inicialização aleatória, ficam automaticamente sincronizados por fase mesmo sem qualquer força de acoplamento. Criar osciladores com características aleatórias também não é viável, visto que isso introduziria um viés, criando uma similaridade que não existe na realidade entre alguns elementos. Outro problema 
enfrentado nos modelos baseados em osciladores é que os modelos criados são baseados em sistemas contínuos, e mesmo utilizando técnicas de resolução numérica eficientes, os modelos ainda são lentos para serem utilizados em redes muito grandes. Uma alternativa seria utilizar sistemas discretos, mas a sincronização nestes casos é mais complicada e difícil de controlar.

Durante o desenvolvimento deste trabalho, uma nova abordagem de detecção de comunidades foi proposta por integrantes do mesmo grupo de pesquisa (Quiles et al., 2008). Neste modelo, partículas caminham em uma rede competindo entre si pela posse dos vértices, e evitando a invasão de outras partículas nos vértices que já foram possuídos. Após um número de iterações é possível separar os grupos através da informação de posse de cada vértice. Tal abordagem pareceu bastante promissora, pois poderia ser utilizada em outros tipos de modelos que são o objetivo deste trabalho, como a detecção de comunidades sobrepostas, não apenas no âmbito do aprendizado não supervisionado, onde o modelo original foi proposto, como também no âmbito do aprendizado semi-supervisionado. Conseqüentemente, optou-se por fazer um estudo mais aprofundado dessa abordagem com o objetivo de criar novos modelos.

No Capítulo 4 são apresentados dois modelos baseados em movimentação de partículas, criados a partir de extensivos estudos da abordagem utilizada no modelo original de Guiles et al. (2008). Na Seção 4.1 apresentamos uma nova técnica de agrupamento de dados (Breve et al., 2009b) combinando caminhada determinística e aleatória e competição entre partículas, onde cada partícula corresponde a uma classe do problema. O algoritmo fornece como saída não apenas rótulos com valores absolutos, mas também valores nebulosos para cada nó da rede, que correspondem aos níveis de pertinência daquele nó com relação a cada comunidade da rede. Para tanto foram utilizados mecanismos que medem o potencial dos vértices de maneira independente para cada partícula, e foram utilizadas informações extraídas da dinâmica temporal do modelo para compor as saídas do algoritmo. Simulações computacionais foram realizadas em dados sintéticos e reais, e os resultados mostram que este modelo é um mecanismo bastante promissor para descobrir a estrutura sobreposta de comunidades em redes complexas.

Em seguida, o modelo anterior foi modificado para permitir sua utilização no âmbito do aprendizado semi-supervisionado (Breve et al., 2009a), onde apresentou bons resultados, comparáveis aos de métodos tradicionais, ao mesmo tempo em que apresentava um tempo de execução mais baixo. No segundo semestre de 2009, foi realizado um estágio de doutorado no exterior, junto ao Department of Electrical and Computer Engineering da University of Alberta, Edmonton, AB, Canadá, sob supervisão do Prof. Dr. Witold Pedrycz. Com a colaboração do Dr. Pedrycz, o modelo foi modificado incluindo 
não apenas competição entre partículas, mas também a cooperação. Além disso, o novo modelo incluiu a possibilidade de obter saídas contínuas, revelando a estrutura de sobreposição das classes. Na Seção 4.2 apresentamos este novo método de classificação, que utiliza cooperação e competição entre partículas de forma combinada (Breve et al., 2009e). Utilizamos um conceito de caminhada aleatório-gulosa de partículas, onde cada uma delas corresponde a um ponto de dado rotulado. Iniciando em um pequeno território que corresponde aos poucos nós rotulados, estas partículas expandem seu domínio caminhando na rede, colaborando com outras partículas da mesma classe, e competindo com partículas de outras classes para evitar que elas invadam seu território. Devido ao mecanismo de competição, há um efeito de dividir-e-conquistar embutido no método proposto. Desta forma, evita-se que partículas visitem uma quantidade considerável de nós que definitivamente pertencem a outros times de partículas. Em outras palavras, modelos de aprendizado semi-supervisionado baseado em grafos tradicionais espalham seus rótulos de uma maneira global, enquanto que o modelo proposto espalha seus rótulos de maneira local. Conseqüentemente, o método proposto tem uma complexidade de tempo menor que outros modelos baseados em grafos, nossa análise mostra que sua ordem de complexidade é no máximo $O\left(n^{2}\right)$, enquanto a maioria dos métodos baseados em grafos tem ordem de complexidade cúbica $\left(O\left(n^{3}\right)\right)$ (Zhu, 2005). Portanto, o método proposto pode ser usado para classificar bases de dados maiores, sendo mais adequado ao estudo de redes complexas. Simulações computacionais mostram que o método proposto é promisor para o aprendizado semi-supervisionado, resultando em boa taxa de classificação tanto para dados sintéticos quanto para dados do mundo real, especialmente em casos onde poucos dados estão disponiveis. Como citamos, assim como no modelo de agrupamento, o modelo semi-supervisionado também pode gerar uma saída nebulosa para cada nó na rede. A saída nebulosa corresponde ao nivel de pertinência de cada nó da rede com relação a cada classe. Uma medida de sobreposição é derivada dessa saída e pode ser considerada como um grau de confidência no rótulo fornecido. Este mecanismo também permite detectar outliers na base de dados. A saída nebulosa e a detecção de outliers realizadas por nosso algoritmo fornecem mecanismos para ajudar a impedir a propagação de erros durante o processo de aprendizado semi-supervisionado, evitando o risco da propagação de rótulos em um certo nível.

Podemos destacar os seguintes itens como principais conclusões deste projeto:

- A combinação de dinâmica e estrutura se mostrou uma abordagem bastante adequada para tratamento dos problemas computacionais aborda- 
dos nessa tese. Conseqüentemente, a continuidade deste estudo poderá trazer novas soluções para outros problemas computacionais e outros problemas relacionados com sistemas complexos;

- O uso da sincronização por fase - mais robusta - além de biologicamente plausível, pode oferecer uma boa contribuição em sistemas de análise de dados (padrões) baseados em sincronização de sistemas caóticos acoplados;

- A abordagem inédita de construção de um sistema que combina tarefas de segmentação e atenção visual em um único passo, tem importância teórica e prática, pois oferece um novo caminho no desenvolvimento de sistemas de visão computacional;

- O mecanismo de competição e cooperação entre partículas em redes complexas oferece um caminho alternativo para o desenvolvimento de redes neurais artificiais, que considera a estrutura dos dados de entrada;

- A abordagem de competição de partículas se mostrou bastante eficaz na detecção de nós sobrepostos, oferecendo novas possibilidades de tratamento de dados que apresentem tais estruturas;

- A estratégia de competição e cooperação entre partículas é diferente de todas as técnicas tradicionais de aprendizado semi-supervisionado, apresentando bom desempenho de classificação, baixa complexidade computacional, e possibilidade de detectar outliers e evitar a propagação de erros vinda dos mesmos, mostrando ser uma abordagem de aprendizado bastante promissora, e abrindo caminho para o desenvolvimento de outras técnicas inspiradas na natureza.

\subsection{Principais Contribuições}

Com base no desenvolvimento realizado e descrito acima, podemos destacar como principais contribuições deste projeto o desenvolvimento de:

- Novos modelos de atenção visual, utilizando pela primeira vez a sincronização por fase entre sistemas caóticos;

- Novos modelos de atenção visual que realizam a segmentação de um objeto ao mesmo tempo em que direcionam a ele o foco de atenção;

- Nova técnica de agrupamento de dados, com capacidade de detectar sobreposição entre grupos e fornecer graus de pertinência à cada grupo por cada elemento; 
- Nova técnica de aprendizado semi-supervisionado, com desempenho comparável ao de técnicas do estado da arte, além de complexidade computacional inferior a de muitos outros modelos baseados em grafos, e abordagem fundamentalmente diferente das demais;

- Nova técnica de aprendizado semi-supervisionado capaz de detectar sobreposição entre classes e minimizar a propagação de erros provenientes de outliers.

\subsection{Trabalhos Futuros}

Embora os modelos desenvolvidos apresentem características interessantes e bons resultados de simulação, alguns novos desenvolvimentos poderão ser efetuados em trabalhos futuros. Dentre as possibilidades podemos citar, para os modelos de atenção visual:

- Criar um mapa de saliência completo, utilizando outros atributos, como cores, saturação, orientação, dentre outros;

- Verificar a possibilidade de incluir algum mecanismo de viés para simular algum conhecimento a priori sobre a imagem de entrada, como o efeito de memória de algum objeto específico;

- Criar um framework de atenção visual que separa as tarefas de segmentação e atenção, de forma que algoritmos do estado da arte em segmentação possam ser usados em conjunto com os mecanismos de atenção visual;

- Modificar os modelos para considerarem o contraste de um objeto com sua vizinhança, detectando o objeto saliente em cenas mais heterogêneas, onde apesar de um objeto não ser muito diferente de todos os outros, ele ainda consegue o foco de atenção devido ao seu contraste com relação aos seus vizinhos mais próximos;

- Criar algum mecanismo que permita otimizar os parâmetros do modelo automaticamente de acordo com a imagem de entrada, sem necessidade de intervenção humana.

Para os modelos baseados em movimentação de partículas, os seguintes desenvolvimentos podem ser realizados em trabalhos futuros:

- Estudar outras formas de compor a rede a partir dos dados de entrada, incluindo outras medidas de distância e informações sobre a base de dados disponiveis a priori; 
- Verificar a possibilidade de utilização dos modelos para realizar agrupamentos de forma hierárquica;

- Estender o modelo de aprendizado não supervisionado para decidir automaticamente o número ideal de partículas (grupos) para cada base de dados de entrada;

- Estudar a possibilidade de introduzir modificações que permitam a convergência de todos os potenciais de vértices, possivelmente combinando algum sistema de subida da colina ${ }^{1}$ ou recozimento simulado ${ }^{2}$ no parâmetro que controla a proporção entre caminhada gulosa e aleatória.

- Estudar novas medidas que possam ser extraídas das informações temporais do algoritmo, da mesma forma que foi feito com a medida de sobreposição de um elemento; 


\section{Referências Bibliográficas}

Abney, S. (2004). Understanding the yarowsky algorithm. Computational linguistics, 30(3), 365-395.

Abney, S. (2008). Semisupervised Learning for Computational Linguistics. CRC Press.

Aggarwal, C. \& Yu, P. (2009). A survey of uncertain data algorithms and applications. IEEE Transactions on Knowledge and Data Engineering, 21(5), 609-623.

Agrawal, R., Gehrke, J., Gunopulos, D., \& Raghavan, P. (1998). Automatic subspace clustering of high dimensional data for data mining applications. SIGMOD Rec., 27(2), 94-105.

Agrawala, A. K. (1970). Learning with a probabilistic teacher. IEEE Transactions on Information Theory, 16, 373-379.

Albert, R. \& Barabasi, A.-L. (2002). Statistical mechanics of complex networks. Reviews of Modern Physics, 74, 47-97.

Allwein, E. L., Schapire, R. E., \& Singer, Y. (2001). Reducing multiclass to binary: a unifying approach for margin classifiers. Journal of Machine Learning Research, 1, 113-141.

Alpaydin, E. (2004). Introduction to machine learning. MIT Press.

Ankerst, M., Breunig, M. M., Kriegel, H.-P., \& Sander, J. (1999). Optics: ordering points to identify the clustering structure. In SIGMOD '99: Proceedings of the 1999 ACM SIGMOD international conference on Management of data (pp. 49-60). New York, NY, USA: ACM.

Asuncion, A. \& Newman, D. (2007). UCI machine learning repository. 
Athitsos, V. \& Sclaroff, S. (2004). Boosting nearest neighbor classifiers for multiclass recognition. Boston University Computer Science Tech. Report No, 2004-006. athitsos@cs.bu.edu.

Barabasi, A.-L. \& Albert, R. (1999). Emergence of scaling in random networks. Science, 286(5439), 509-512.

Belkin, M., Matveeva, I., \& Niyogi, P. (2004). Regularization and semisupervised learning on large graphs. In Conference on Learning Theory (pp. 624638).: Springer.

Belkin, M. \& Niyogi, P. (2003). Laplacian eigenmaps for dimensionality reduction and data representation. Neural Computation, 15(6), 1373-1396.

Belkin, M., P., N., \& Sindhwani, V. (2005). On manifold regularization. In Proceedings of the Tenth International Workshop on Artificial Intelligence and Statistics (AISTAT 2005) (pp. 17-24). New Jersey: Society for Artificial Intelligence and Statistics.

Bengio, Y., Delalleau, O., \& Roux, N. L. (2006). Semi-Supervised Learning, chapter Label Propagation and Quadratic Criterion, (pp. 193-216). Adaptive Computation and Machine Learning. The MIT Press: Cambridge, MA.

Bennett, M., Schatz, M. F., Rockwood, H., \& Wiesenfeld, K. (2002). Huygens's clocks. Proceedings: Mathematical, Physical and Engineering Sciences, 458(2019), 563-579.

Bishop, C. M. (2006). Pattern Recognition and Machine Learning. Springer.

Blum, A. \& Chawla, S. (2001). Learning from labeled and unlabeled data using graph mincuts. In Proceedings of the Eighteenth International Conference on Machine Learning (pp. 19-26). San Francisco: Morgan Kaufmann.

Blum, A. \& Mitchell, T. (1998). Combining labeled and unlabeled data with cotraining. In COLT: Proceedings of the Workshop on Computational Learning Theory (pp. 92-100).

Boccaletti, S., Ivanchenko, M., Latora, V., Pluchino, A., \& Rapisarda, A. (2007). Detection of complex networks modularity by dynamical clustering. Physical Review E, 75, 045102 (1-5).

Boccaletti, S., Latora, V., Moreno, Y., Chavez, M., \& Hwang, D.-U. (2006). Complex networks: Structure and dynamics. Physics Reports, 424(4-5), 175 $-308$.

Bornholdt, S. \& Schuster, H. (2006). Handbook of Graphs and Networks: From the Genome to the Internet. Wiley-VCH. 
Brandes, U., Gaertler, M., \& Wagner, D. (2003). Experiments on graph clustering algorithms. In G. D. Batista \& U. Zwick (Eds.), Lecture Notes in Computer Science, volume 2832 (pp. 568-579). Heidelberg, Germany: Springer-Verlag $\mathrm{GmbH}$.

Breve, F. A., Zhao, L., \& Quiles, M. G. (2009a). Particle competition in complex networks for semi-supervised classification. In J. Zhou (Ed.), Complex (1), volume 4 of Lecture Notes of the Institute for Computer Sciences, Social Informatics and Telecommunications Engineering (pp. 163-174).: Springer.

Breve, F. A., Zhao, L., \& Quiles, M. G. (2009b). Uncovering overlap community structure in complex networks using particle competition. In International Conference on Artificial Intelligence and Computational Intelligence (AICI'O9), volume 5855 (pp. 619-628).

Breve, F. A., Zhao, L., Quiles, M. G., \& Macau, E. E. N. (2009c). Chaotic phase synchronization and desynchronization in an oscillator network for object selection. Neural Networks, 22(5-6), 728-737.

Breve, F. A., Zhao, L., Quiles, M. G., \& Macau, E. E. N. (2009d). Chaotic phase synchronization for visual selection. IEEE - INNS - ENNS International Joint Conference on Neural Networks, (pp. 383-390).

Breve, F. A., Zhao, L., Quiles, M. G., Pedrycz, W., \& Liu, J. (2009e). Particle competition and cooperation in networks for semi-supervised learning. Artigo submetido para IEEE Transactions on Knowledge and Data Engineering.

Buia, C. \& Tiesinga, P. (2006). Attentional modulation of firing rate and synchrony in a model cortical network. Journal of Computational Neuroscience, 20, 247-264.

Burges, C. J. C. \& Platt, J. C. (2006). Semi-supervised Learning, chapter SemiSupervised Learning with Conditional Harmonic Mixing, (pp. 251-273). MIT Press: Cambridge, MA.

Campbell, S. \& Wang, D. (1996). Synchronization and desynchronization in a network of locally coupled Wilson-Cowan oscillators. IEEE Transactions on Neural Networks, 7(3), 541-554.

Campbell, S. R., Wang, D. L., \& Jayaprakash, C. (1999). Synchrony and desynchrony in integrate-and-fire oscillators. Neural Computation, 11, 1595-1619.

Carota, L., Indiveri, G., \& Dante, V. (2004). A softwarehardware selective attention system. Neurocomputing, 58-60, 647-653. 
Carrasco, J., Fain, D., Lang, K., \& Zhukov, L. (2003). Clustering of bipartite advertiser-keyword graph. In Proceedings of the Third IEEE International Conference on Data Mining, Workshop on Clustering Large Data Sets.

Chapelle, O., Chi, M., \& Zien, A. (2006a). A continuation method for semisupervised svms. In ICML '06: Proceedings of the 23rd international conference on Machine learning (pp. 185-192). New York, NY, USA: ACM.

Chapelle, O., Schölkopf, B., \& Zien, A., Eds. (2006b). Semi-Supervised Learning. Adaptive Computation and Machine Learning. Cambridge, MA: The MIT Press.

Chapelle, O., Weston, J., \& Schölkopf, B. (2003). Cluster kernels for semisupervised learning. In Advances in Neural Information Processing Systems, volume 15.

Chapelle, O. \& Zien, A. (2005). Semi-supervised classification by low density separation. In Tenth International Workshop on Artificial Intelligence and Statistics (pp. 57-64).

Cios, K. J., Pedrycz, W., Swiniarski, R. W., \& Kurgan, L. A. (2007). Data Mining: A Knowledge Discovery Approach. Springer.

Clauset, A. (2005). Finding local community structure in networks. Physical Review E, 72, 026132 (1-7).

Collobert, R., Sinz, F., Weston, J., \& Bottou, L. (2006). Trading convexity for scalability. In ICML '06: Proceedings of the 23rd international conference on Machine learning (pp. 201-208). New York, NY, USA: ACM.

Corduneanu, A. \& Jaakkola, T. (2006). Semi-supervised Learning, chapter Data-Dependent Regularization, (pp. 163-190). MIT Press: Cambridge, MA.

Cormen, T. H., Leirserson, C. E., Rivest, R. L., \& Stein, C. (2001). Introduction to Algorithms. MA,USA: MIT Press, 2 edition.

Danon, L., Díaz-Guilera, A., Duch, J., \& Arenas, A. (2005). Comparing community structure identification. Journal of Statistical Mechanics: Theory and Experiment, 9, P09008 (1-10).

Dara, R., Kremer, S., \& Stacey, D. (2002). Clustering unlabeled data with soms improves classification of labeled real-world data. In Proceedings of the World Congress on Computational Intelligence (WCCI) (pp. 2237-2242).

Deco, G. \& Rolls, E. T. (2005). Attention, short-term memory, and action selection: A unifying theory. Progress in Neurobiology, 76, 236-256. 
Delalleau, O., Bengio, Y., \& Roux, N. L. (2005). Efficient non-parametric function induction in semi-supervised learning. In Artificial Intelligence and Statistics (pp. 96-103).

Demiriz, A., Bennett, K. P., \& Embrechts, M. J. (1999). Semi-supervised clustering using genetic algorithms. In Proceedings of Artificial Neural Networks in Engineering (ANNIE-99 (pp. 809-814).: ASME Press.

Desimone, R. \& Duncan, J. (1995). Neural mechanisms of selective visual attention. Annual Review of Neuroscience, 18, 193-222.

Dorogovtsev, S. \& Mendes, F. (2003). Evolution of Networks: From Biological Nets to the Internet and $W W W$. Oxford University Press.

Duch, J. \& Arenas, A. (2006). Community detection in complex networks using extremal optimization. Physical Review E, 72, 027104.

Duda, R. O., Hart, P. E., \& Stork, D. G. (2000). Pattern Classification (2nd Edition). Wiley-Interscience.

Duin, R., Juszczak, P., Paclik, P., Pekalska, E., de Ridder, D., Tax, D., \& Verzakov, S. (2007). Prtools4.1, a matlab toolbox for pattern recognition.

Eckhorn, R., Bauer, R., Jordan, W., Brosch, M., Kruse, W., Munk, M., \& Reitboeck, H. J. (1988). Coherent oscillation: A mechanism of feature linking in the visual cortex? Biological Cybernetics, 60, 121-130.

Elias, P., Feinstein, A., \& Shannon, C. (1956). A note on the maximum flow through a network. IEEE Transactions on Information Theory, 2(4), 117-119.

Engel, A. K., König, P., Kreiter, A. K., \& Singer, W. (1991). Interhemispheric synchronization of oscillatory neuronal responses in cat visual cortex. Science, 252, 1177-1178.

Erdõs, P. \& Rényi, A. (1961). On the strength of connectedness of a random graph. Acta Mathematica Hungarica, 12(1), 261-267.

Ester, M., Kriegel, H.-P., Sander, J., \& Xu, X. (1996). A density-based algorithm for discovering clusters in large spatial databases with noise. In E. Simoudis, J. Han, \& U. Fayyad (Eds.), Second International Conference on Knowledge Discovery and Data Mining (pp. 226-231). Portland, Oregon: AAAI Press.

Everitt, B. S., Landau, S., \& Leese, M. (2001). Cluster Analysis. Oxford University Press, 4th edition edition. 
Flake, G. W., Lawrence, S., Giles, C. L., \& Coetzee, F. M. (2002). Selforganization and identification of web communities. Computer, 35(3), 66-71.

Flake, G. W., Tarjan, R. E., \& Tsioutsiouliklis, K. (2004). Graph clustering and minimum cut trees. Internet Mathematics, 1(4), 385-408.

Fortunato, S., Latora, V., \& Marchiori, M. (2004). A method to find community structures based on information centrality. Physical Review E, 70, 056104 (1-13).

Fralick, S. C. (1967). Learning to recognize patterns without a teacher. IEEE Transactions on Information Theory, 13, 57-64.

Freeman, L. C. (1977). A set of measures of centrality based upon betweenness. Sociometry, 40(1), 35-41.

Fries, P., Reynolds, J. H., Rorie, A. E., \& Desimone, R. (2001). Modulation of oscillatory neuronal synchronization by selective visual attention. Science, 291(5508), 1560 - 1563.

Fujino, A., Ueda, N., \& Saito, K. (2005). A hybrid generative/discriminative approach to semi-supervised classifier design. In AAAI-05, Proceedings of the Twentieth National Conference on Artificial Intelligence (pp. 764-769).

Fujisaka, H. \& Yamada, T. (1983). Stability Theory of Synchronized Motion in Coupled-Oscillator Systems. Progress of Theoretical Physics, 69, 32-47.

Fukunaga, K. (1990). Introduction to statistical pattern recognition (2nd ed.). San Diego, CA, USA: Academic Press Professional, Inc.

Garey, M. R., Johnson, D. S., \& Stockmeyer, L. (1974). Some simplified npcomplete problems. In STOC '74: Proceedings of the sixth annual ACM symposium on Theory of computing (pp. 47-63). New York, NY, USA: ACM.

Goldberg, A. V. \& Tarjan, R. E. (1986). A new approach to the maximum flow problem. In STOC '86: Proceedings of the eighteenth annual ACM symposium on Theory of computing (pp. 136-146). New York, NY, USA: ACM.

Gong, P., Nikolaev, A. R., \& van Leeuwen, C. (2003). Scale-invariant fluctuations of the dynamical synchronization in human brain electrical activity. Neuroscience Letter, 336, 33-36.

Grady, L. (2006). Random walks for image segmentation. IEEE Transactions on Pattern Analysis and Machine Intelligence, 28(11), 1768-1783. 
Grey, C. M., König, P., Engel, A. K., \& Singer, W. (1989). Oscillatory responses in cat visual cortex exhibit inter-columnar synchronization which reflects global stimulus properties. Nature, 338(6213), 334-337.

Haffari, G. \& Sarkar, A. (2007). Analysis of semi-supervised learning with the yarowsky algorithm. In 23rd Conference on Uncertainty in Artificial Intelligence (UAI).

Hansel, D. \& Sompolinsky, H. (1992). Synchronization and computation in a chaotic neural network. Physical Review Letters, 68(5), 718-721.

Hansen, P. \& Jaumard, B. (1997). Cluster analysis and mathematical programming. Mathematical Programming, 79(1-3), 191-215.

Hartuv, E. \& Shamir, R. (2000). A clustering algorithm based on graph connectivity. Inf. Process. Lett., 76(4-6), 175-181.

Hayes, S., Grebogi, C., Ott, E., \& Mark, A. (1994). Experimental control of chaos for communication. Physical Review Letters, 73(13), 1781-1784.

Hinneburg, A. \& Keim, D. A. (1998). An efficient approach to clustering in large multimedia databases with noise. In Knowledge Discovery and Data Mining (pp. 58-65).

Hinton, G. E. \& Sejnowski, T. J. (1999). Unsupervised Learning: Foundations of Neural Computation. MIT Press.

Horton, P. \& Nakai, K. (1997). Better prediction of protein cellular localization sites with the it $\mathrm{k}$ nearest neighbors classifier. In Proceedings of the 5th International Conference on Intelligent Systems for Molecular Biology (pp. 147-152).: AAAI Press.

Hramov, A. E. \& Koronovskii, A. A. (2005). Generalized synchronization: a modified system approach. Physical Review E, 71, 067201 (1-4).

Itti, L. \& Koch, C. (2001). Computational modelling of visual attention. Nature Reviews Neuroscience, 2, 194-203.

Itti, L., Koch, C., \& Niebur, E. (1998). A model of saliency-based visual attention for rapid scene analysis. IEEE Transactions on Pattern Analysis and Machine Intelligence, 20(11), 1254-1259.

Jain, A. K. \& Dubes, R. C. (1988). Algorithms for clustering data. Printice Hall.

Jain, A. K., Murty, M. N., \& Flynn, P. J. (1999). Data clustering: a review. ACM Computing Surveys, 31(3), 264-323. 
Jermakowicz, W. J. \& Casagrande, V. A. (2007). Neural networks a century after cajal. Brain Research Reviews, 55(2), 264-284.

Joachims, T. (2003). Transductive learning via spectral graph partitioning. In Proceedings of International Conference on Machine Learning (pp. 290-297).: AAAI Press.

Kaneko, K. (1994). Relevance of dynamic clustering to biological networks. In Proceedings of the Oji international seminar on Complex systems: from complex dynamical systems to sciences of artificial reality (pp. 55-73). New York, NY, USA: Elsevier North-Holland, Inc.

Kannan, R., Vempala, S., \& Vetta, A. (2000). On clusterings: Good, bad, and spectral. In Proceedings of the 41st Annual Symposium on the Foundation of Computer Science (pp. 367-380).: IEEE Computer Society.

Kaplan, D. \& Glass, L. (1995). Understanding Nonlinear Dynamics. Springer.

Kaufman, L. \& Rousseeuw, P. J. (1990). Finding groups in data: An introduction to cluster analysis. John Wiley and Sons.

Kazanovich, Y. \& Borisyuk, R. (2002). Object selection by an oscillatory neural network. Biosystems, 67, 103-111.

Kim, Y. J., Grabowecky, M., Paller, K. A., Muthu, K., \& Suzuki, S. (2007). Attention induces synchronization-based response gain in steady-state visual evoked potentials. Nature Neuroscience, 10(1), 117-125.

King, B. (1967). Step-wise clustering procedures. Journal of the American Statistical Association, 62(317), 86-101.

Latora, V. \& Marchiori, M. (2001). Efficient behavior of small-world networks. Physical Review Letters, 87(19), 198701 (1-4).

MacQueen, J. B. (1967). Some methods for classification and analysis of multivariate observations. In L. M. L. Cam \& J. Neyman (Eds.), Proceedings of the fifth Berkeley Symposium on Mathematical Statistics and Probability, volume 1 (pp. 281-297).: University of California Press.

Maila, M. \& Shi, J. (2001a). Learning segmentation with random walk. In Advances Neural Information Processing Systems, NIPS.

Maila, M. \& Shi, J. (2001b). A random walks view of spectral segmentation. In International Conference on AI and Statistics (AISTAT).

Mitchell, T. (1997). Machine Learning. McGraw Hill. 
Mitchell, T. M. (1999). The role of unlabeled data in supervised learning. In Proceedings of the Sixth International Colloquium on Cognitive Science.

Murthy, V. N. \& Fetz, E. E. (1992). Coherent 25- to 35-hz oscillations in the sensorimotor cortex of awake behaving monkeys. Proceedings of the National Academy of Sciences of the United States of America, 89(12), 5670-5674.

Natarajan, B. K. (1991). Machine learning: a theoretical approach. Morgan Kaufmann.

Newman, M. (2006). Modularity and community structure in networks. In Proceedings of the National Academy of Science of the United States of America, volume 103 (pp. 8577-8582).

Newman, M. E. J. (2003). The structure and function of complex networks. SIAM Review, 45, 167-256.

Newman, M. E. J. (2004). Fast algorithm for detecting community structure in networks. Physical Review E, 69(6), 066133 (1-5).

Newman, M. E. J. \& Girvan, M. (2004). Finding and evaluating community structure in networks. Physical Review E, 69, 026113 (1-16).

Niebur, E. \& Koch, C. (1994). A model for neuronal implementation of selective visual attention based on temporal correlation among neurons. Journal of Computational Neuroscience, 1, 141-158.

Nigam, K., Mccallum, A. K., Thrun, S., \& Mitchell, T. (2000). Text classification from labeled and unlabeled documents using em. In Machine Learning, volume 39 (pp. 103-134).

O’Craven, K. M., Downing, P. E., \& Kanwisher, N. (1999). fmri evidence for objects as the units of attentional selection. Nature, 401, 584-587.

Ott, E. (1994). Chaos in dynamical System. Cambridge University Press.

Palla, G., Derényi, I., Farkas, I., \& Vicsek, T. (2005). Uncovering the overlapping community structure of complex networks in nature and society. Nature, 435(7043), 814-818.

Pavlov, D., Popescul, A., Pennock, D. M., \& Ungar, L. H. (2003). Mixtures of conditional maximum entropy models. In International Conference on Machine Learning (pp. 584-591).

Pecora, L. M. \& Carroll, T. L. (1990). Synchronization in chaotic systems. Physical Review Letters, 64(8), 821-824. 
Pecora, L. M., Carroll, T. L., Johnson, G. A., Mar, D. J., \& Heagy, J. F. (1997). Fundamentals of synchronization in chaotic systems, concepts, and applications. Chaos: An Interdisciplinary Journal of Nonlinear Science, 7(4), 520543.

Pikovsky, A., Rosenblum, M., \& Kurths, J. (2001). Synchronization: A universal concept in nonlinear sciences. Cambridge University Press.

Press, W. H., Teukolsky, S. A., Vetterling, W. T., \& Flannery, B. P. (2002). Numerical recipes in $C$ : the art of scientific computing. Cambridge University Press, 2 edition.

Quiles, M., Breve, F., Zhao, L., \& Romero, R. (2007a). A visual selection mechanism based on network of chaotic wilson-cowan oscillators. In ISDA '07: Proceedings of the Seventh International Conference on Intelligent Systems Design and Applications (pp. 919-924). Washington, DC, USA: IEEE Computer Society.

Quiles, M. G., Zhao, L., Alonso, R. L., \& Romero, R. A. F. (2008). Particle competition for complex network community detection. Chaos, 18(3), 033107 $(1-10)$.

Quiles, M. G., Zhao, L., \& Romero, R. (2007b). A selection mechanism based on a pulse-coupled neural network. In The 20th International Joint Conference on Neural Networks (IJCNN) (pp. 1-6). Orlando-US.

Reichardt, J. \& Bornholdt, S. (2004). Detecting fuzzy community structures in complex networks with a potts model. Physical Review Letters, 93(21), $218701(1-4)$.

Richard, A. M., Lee, H., \& Vecera, S. P. (2008). Efficient visual search without top-down or bottom-up guidance. Journal of Experimental Psychology: $\mathrm{Hu}$ man Perception and Performance, 34(4), 842-853.

Riloff, E., Wiebe, J., \& Wilson, T. (2003). Learning subjective nouns using extraction pattern bootstrapping. In Proceedings of the seventh conference on Natural language learning at HLT-NAACL 2003 (pp. 25-32). Morristown, NJ, USA: Association for Computational Linguistics.

Roelfsema, P. R., Lamme, V. A. F., \& Spekreijse, H. (1998). Object-based attention in the primary visual cortex of the macaque monkey. Nature, 395, 376-381.

Rosenblum, M. G., Pikovsky, A. S., \& Kurths, J. (1996). Phase synchronization of chaotic oscillators. Physical Review Letters, 76(11), 1804-1807. 
Rosenblum, M. G., Pikovsky, A. S., \& Kurths, J. (1997). From phase to lag synchronization in coupled chaotic oscillators. Physical Review Letters, 78(22), 4193-4196.

Rössler, O. E. (1976). An equation for continuous chaos. Physics Letters A, 57(5), 397-398.

Schaeffer, S. E. (2007). Graph clustering. Computer Science Review, 1(1), 27-64.

Scudder, H. J. (1965). Probability of error of some adaptive pattern-recognition machines. IEEE Transactions on Information Theory, 11, 363-371.

Shi, J. \& Malik, J. (2000). Normalized cuts and image segmentation. IEEE Transactions on Pattern Analysis and Machine Intelligence, 22(8), 888-905.

Shic, F. \& Scassellati, B. (2007). A behavioral analysis of computational models of visual attention. International Journal of Computer Vision, 73(2), 159177.

Sindhwani, V. \& Keerthi, S. S. (2006). Large scale semi-supervised linear svms. In SIGIR '06: Proceedings of the 29th annual international ACM SIGIR conference on Research and development in information retrieval (pp. 477484). New York, NY, USA: ACM.

Sindhwani, V., Keerthi, S. S., \& Chapelle, O. (2006). Deterministic annealing for semi-supervised kernel machines. In ICML '06: Proceedings of the 23rd international conference on Machine learning (pp. 841-848). New York, NY, USA: ACM.

Sindhwani, V., Niyogi, P., \& Belkin, M. (2005). Beyond the point cloud: from transductive to semi-supervised learning. In ICML '05: Proceedings of the 22nd international conference on Machine learning (pp. 824-831). New York, NY, USA: ACM.

Skarda, C. A. \& Freeman, W. J. (1987). How brain make chaos in order to make sense of the world. Behavioral and Brain Sciences, 10, 161-195.

Sneath, P. H. A. \& Sokal, R. R. (1973). Numerical Taxonomy. London, UK: Freeman.

Sun, J., Boyd, S., Xiao, L., \& Diaconis, P. (2006). The fastest mixing markov process on a graph and a connection to a maximum variance unfolding problem. SIAM Review, 48(4), 681-699. 
Szummer, M. \& Jaakkola, T. (2002). Partially labeled classification with markov random walks. In Advances in Neural Information Processing Systems, volume 14 .

Terman, D. \& Wang, D. L. (1995). Global competition and local cooperation in a network of neural oscillators. Physica D, 81(1-2), 148-176.

Tsotsos, J. K. (1992). On the relative complexity of active vs. passive visual search. International Journal of Computer Vision, 7, 127-141.

Tsotsos, J. K., Culhane, S. M., Wai, W. Y. K., Lai, Y., Davis, N., \& Nuflo, F. (1995). Modeling visual attention via selective tuning. Artificial Intelligence, 78, 507-545.

Uchida, A., McAllister, R., Meucci, R., \& Roy, R. (2003). Generalized synchronization of chaos in identical systems with hidden degrees of freedom. Physical Review Letters, 91(17), 174101 (1-4).

van Dongen, S. (2000). Graph clustering by flow simulation. PhD thesis, University of Utrecht.

Vapnik, V. N. (1995). The nature of statistical learning theory. New York, NY, USA: Springer-Verlag New York, Inc.

Vapnik, V. N. (2008). Statistical Learning Theory. New York: WileyInterscience.

Varela, F., Lachaux, J.-P., Rodriguez, E., \& Martinerie, J. (2001). The brainweb: Phase synchronization and large-scale integration. Nature Reviews Neuroscience, 2, 229-239.

von der Malsburg, C. (1981). The Correlation Theory of Brain Function. Internal Report 81-2, Max Planck Institute for Biophysical Chemistry.

von der Malsburg, C. \& Schneider, W. (1986). A neural cocktail-party processor. Biological Cybernetics, 54, 29-40.

Voss, H. U. (2000). Anticipating chaotic synchronization. Physical Review E, 61(5), 5115-5119.

Walther, D., Rutishauser, U., Cock, C., \& Perona, P. (2005). Selective visual attention enables learning and recognition of multiples objects in cluttered scenes. Computer Vision and Image Understanding, 100, 41-63.

Wang, D. \& Terman, D. (1997). Image segmentation based on oscillatory correlation. Neural Computation, 9(4), 805-836. 
Wang, D.-L. (1995). Emergent synchrony in locally coupled neural oscillators. IEEE Transactions on Neural Networks, 6(4), 941-948.

Wang, D. L. (1999). Object selection based on oscillatory correlation. Neural Networks, 12, 579-592.

Wang, D. L. (2005). The time dimension of scene analysis. IEEE Transactions on Neural Networks, 16(6), 1401-1426.

Wang, D. L., Kristjansson, A., \& Nakayama, K. (2005). Efficient visual search without top-down or bottom-up guidance. Perception \& Psychophysics, 67(2), 239-253.

Wang, F. \& Zhang, C. (2006). Label propagation through linear neighborhoods. In ICML '06: Proceedings of the 23rd International Conference on Machine Learning (pp. 985-992). New York, NY, USA: ACM.

Wang, F. \& Zhang, C. (2008). Label propagation through linear neighborhoods. IEEE Transactions on Knowledge and Data Engineering, 20(1), 55-67.

Watts, D. J. \& Strogatz, S. H. (1998). Collective dynamics of "small-world" networks. Nature, 393, 440-442.

Weinberger, K. Q. \& Saul, L. K. (2004). Unsupervised learning of image manifolds by semidefinite programming. In Proceedings of the IEEE Conference on Computer Vision and Pattern Recognition, volume 2 (pp. 988-995). Washington D.C.

Witten, I. H. \& Frank, E. (2005). Data Mining: Practical Machine Learning Tools and Techniques. Morgan Kaufmann, 2 edition.

Wolfe, J. M. \& Horowitz, T. S. (2004). What attributes guide the deployment of visual attention and how do they do it? Nature Reviews Neuroscience, 5(6), 495-501.

Wolff, R., Bhaduri, K., \& Kargupta, H. (2009). A generic local algorithm for mining data streams in large distributed systems. IEEE Transactions on Knowledge and Data Engineering, 21(4), 465-478.

Xu, Z., Jin, R., Zhu, J., King, I., \& Lyu, M. (2008). Efficient convex relaxation for transductive support vector machine. Advances in neural information processing systems, 20, 1641-1648.

Yantis, S. (2005). How visual salience wins the battle for awareness. Nature Neuroscience, 8(8), 975-977. 
Yarowsky, D. (1995). Unsupervised word sense disambiguation rivaling supervised methods. In Proceedings of the 33rd annual meeting on Association for Computational Linguistics (pp. 189-196). Morristown, NJ, USA: Association for Computational Linguistics.

Yip, A. M., Ding, C., \& Chan, T. F. (2006). Dynamic cluster formation using level set methods. IEEE Transactions on Pattern Analysis and Machine Intelligence, 28(6), 877-889.

Zachary, W. W. (1977). An information flow model for conflict and fission in small groups. Journal of Anthropological Research, 33, 452-473.

Zhang, S., Wang, R.-S., \& Zhang, X.-S. (2007a). Identification of overlapping community structure in complex networks using fuzzy c-means clustering. Physica A Statistical Mechanics and its Applications, 374, 483-490.

Zhang, S., Wang, R.-S., \& Zhang, X.-S. (2007b). Uncovering fuzzy community structure in complex networks. Physical Review E (Statistical, Nonlinear, and Soft Matter Physics), 76(4), 046103 (1-7).

Zhao, L. \& Breve, F. A. (2008). Chaotic synchronization in 2 d lattice for scene segmentation. Neurocomputing, 71(13-15), 2761-2771.

Zhao, L., Breve, F. A., Quiles, M. G., \& Romero, R. A. (2007). Visual selection and shifting mechanisms based on a network of chaotic wilson-cowan oscillators. In ICNC 2007: Third International Conference on Natural Computation, volume 5 (pp. 754-762).

Zhao, L., Damiance, A. P. G., \& de Carvalho, A. C. P. L. F. (2005). A selforganized network for data clustering. In L. Wang, K. Chen, \& Y.-S. Ong (Eds.), ICNC (1), volume 3610 of Lecture Notes in Computer Science (pp. 1189-1198).: Springer.

Zhao, L., de Carvalho, A., \& Li, Z. (2004). Pixel clustering by adaptive moving and chaotic synchronization. IEEE Transactions on Neural Networks, 15(5), 1176-1185.

Zhao, L. \& Macau, E. E. N. (2001). A network of dynamically coupled chaotic maps for scene segmentation. IEEE Transactions on Neural Networks, 12(6), $1375-1385$.

Zhao, L., Macau, E. E. N., \& Omar, N. (2000). Scene segmentation of the chaotic oscillator network. International Journal of Bifurcation and Chaos, 10(7), 1697-1708. 
Zhou, D., Bousquet, O., Lal, T. N., Weston, J., \& Schölkopf, B. (2004). Learning with local and global consistency. In Advances in Neural Information Processing Systems, volume 16 (pp. 321-328).: MIT Press.

Zhou, D. \& Schölkopf, B. (2006). Semi-supervised Learning, chapter Discrete Regularization, (pp. 237-250). MIT Press: Cambridge, MA.

Zhou, H. (2003a). Distance, dissimilarity index, and network community structure. Physical Review E, 67(6), 061901 (1-10).

Zhou, H. (2003b). Network landscape from a brownian particle's perspective. Physical Review E, 67(4), 041908 (1-5).

Zhou, Z.-H. \& Li, M. (2005). Tri-training: exploiting unlabeled data using three classifiers. IEEE Transactions on Knowledge and Data Engineering, 17(11), $1529-1541$.

Zhou, Z.-H. \& Li, M. (2007). Semisupervised regression with cotraining-style algorithms. IEEE Transactions on Knowledge and Data Engineering, 19(11), 1479-1493.

Zhu, X. (2005). Semi-Supervised Learning Literature Survey. Technical Report 1530, Computer Sciences, University of Wisconsin-Madison.

Zhu, X. \& Ghahramani, Z. (2002). Learning from Labeled and Unlabeled Data with Label Propagation. Technical Report CMU-CALD-02-107, Carnegie Mellon University, Pittsburgh.

Zhu, X., Ghahramani, Z., \& Lafferty, J. (2003). Semi-supervised learning using gaussian fields and harmonic functions. In Proceedings of the Twentieth International Conference on Machine Learning (pp. 912-919). 